\title{
Modelling induced bank filtration effects on freshwater ecosystems to ensure sustainable drinking water production
}

Mikael Gillefalk (1) https://orcid.org/0000-0002-7642-776X, Wolf M. Mooij (1) https://orcid.org/0000-0001-5586-8200, Sven Teurlincx (1) https://orcid.org/0000-0001-6740-6521, Annette B. G. Janssen (1) https://orcid.org/0000-0001-50007161, Jan H. Janse, Manqi Chang, Jan Köhler, Sabine Hilt $\mathbb{1}$ https://orcid.org/0000-0002-0585-2822

DOI

10.1016/i.watres.2019.03.048

Original publication date

26 March 2019 (Available online)

\section{Document version}

Accepted manuscript

\section{Published in}

Water Research

\section{Citation}

Gillefalk M, Mooij WM, Teurlincx S, Janssen ABG, Janse JH, Chang M, et al. Modelling induced bank filtration effects on freshwater ecosystems to ensure sustainable drinking water production. Water Research. 2019;157:19-29. 
2 Modelling induced bank filtration effects on freshwater ecosystems to ensure sustainable

3 drinking water production

4

5

6

7 Mikael Gillefalk ${ }^{\mathrm{a}, b^{*}}$, Wolf M. Mooij ${ }^{\mathrm{c}}$, Sven Teurlincx ${ }^{\mathrm{c}}$, Annette B.G. Janssen ${ }^{\mathrm{c}, \mathrm{d}}$, Jan H. Janse ${ }^{\mathrm{c}, \mathrm{e}}$, Manqi

8 Chang $^{\mathrm{c}}$, Jan Köhler ${ }^{\mathrm{a}}$, Sabine Hilt ${ }^{\mathrm{a}}$

9

10

${ }^{a}$ Leibniz Institute of Freshwater Ecology and Inland Fisheries (IGB), Müggelseedamm 301, 12587

11

Berlin, Germany

12

${ }^{\mathrm{b}}$ Technical University Berlin, Germany

13

${ }^{c}$ Netherlands Institute of Ecology (NIOO)

14

${ }^{\mathrm{d}}$ Water Systems and Global Change Group, Wageningen University \& Research, the Netherlands

${ }^{\mathrm{e}}$ PBL Netherlands Environmental Assessment Agency

16

17

18

*corresponding author: mikaelgillefalk@gmail.com (M. Gillefalk)

19 
Induced bank filtration (IBF) is a water abstraction technology using different natural infiltration systems for groundwater recharge, such as river banks and lake shores. It is a cost-effective pretreatment method for drinking water production used in many regions worldwide, predominantly in urban areas. Until now, research concerning IBF has almost exclusively focussed on the purification efficiency and infiltration capacity. Consequently, knowledge about the effects on source water bodies is lacking. Yet, IBF interrupts groundwater seepage and affects processes in the sediment potentially resulting in adverse effects on lake or river water quality. Securing sufficient source water quality, however, is important for a sustainable drinking water production by IBF.

In this study, we analysed the effects of five predicted mechanisms of IBF on shallow lake ecosystems using the dynamic model PCLake: declining $\mathrm{CO}_{2}$ and nutrient availability, as well as increasing summer water temperatures, sedimentation rates and oxygen penetration into sediments. Shallow lake ecosystems are abundant worldwide and characterised by the occurrence of alternative stable states with either clear water and macrophyte dominance or turbid, phytoplankton-dominated conditions.

Our results show that IBF in most scenarios increased phytoplankton abundance and thus had adverse effects on shallow lake water quality. Threshold levels for critical nutrient loading inducing regime shifts from clear to turbid conditions were up to $80 \%$ lower with IBF indicating a decreased resilience to eutrophication. The effects were strongest when IBF interrupted the seepage of $\mathrm{CO}_{2}$ rich groundwater resulting in lower macrophyte growth. IBF could also enhance water quality, but only when interrupting the seepage of groundwater with high nutrient concentrations. Higher summer water temperatures increased the share of cyanobacteria in the phytoplankton community and thus the risk of toxin production. In relative terms, the effects of changing sedimentation rates and oxygen penetration were small. Lake depth and size influenced the effect of IBF on critical nutrient loads, which was strongest in shallower and smaller lakes. Our model results stress the need of a more comprehensive ecosystem perspective including an assessment of IBF effects on threshold levels for regime shifts to prevent high phytoplankton abundance in the source water body and secure a sustainable drinking 


\section{$48 \quad$ Keywords}

49 surface water-groundwater interaction, regime shift, shallow lakes, macrophytes, phytoplankton, $50 \quad$ PCLake 


\section{Introduction}

Since more than a century, induced bank filtration (IBF), or bank filtration (BF), has served as a costeffective and reliable drinking water production technique (Ray et al., 2003). Infiltration is induced by installing production wells close to rivers or lakes and pump large quantities of water resulting in a lowering of the hydraulic head at the wells below the surface water level (Fig. 1). Contaminants are filtered and attenuated while surface water flows through sediment and porous soils. So far, IBF has mostly been used throughout Europe (Sprenger et al., 2017), but the technique is increasingly applied on other continents as well (Ray et al., 2008, Gillefalk et al., 2018). IBF is put to use where groundwater resources are scarce but surface water quality is insufficient for direct use for drinking water production (Hiscock and Grischek, 2002). Apart from IBF, which is clearly planned and fully intentional, there is also unintentional BF, affecting surface waters in the same way as IBF (Acreman et al., 2000).

Existing studies on IBF focus on the purification capacity and the production quantity (Gillefalk et al. 2018). They usually investigate whether concentrations of unwanted compounds are sufficiently reduced during bank passage and how much water is purified. However, IBF interrupts groundwater seepage into surface waters due to a lowering of the groundwater table far below water levels of surface waters (Fig. 1). In Berlin (Germany), about $60 \%$ of the drinking water comes from IBF (Hiscock and Grischek, 2002) which has resulted in a drawdown of groundwater levels by up to $5 \mathrm{~m}$ around three major lakes used for IBF (Schröter, 2015, Fig. 2A-C). A recent conceptual study indicates that cutting off groundwater seepage can significantly alter the water quality of the source water body due to several physical, chemical and biological processes (Gillefalk et al., 2018). In addition, surface water is infiltrated through sediments which might affect several processes in this compartment (Gillefalk et al., 2018). In Lake Müggelsee, a doubling of groundwater abstraction rates (data provided by Berliner Wasserbetriebe) by IBF in the 1970s was paralleled by a significant decrease in surface water quality, indicated by a decreased Secchi depth (data from Leibniz-Institute for Freshwater Ecology and Inland Fisheries' long-term monitoring, Fig. 2D). Groundwater abstraction rates were reduced in the 1990s and lake water quality recovered. A link between these 
processes, however, could not be made as studies on the effect of IBF on the quality of the source water body are completely lacking. This is surprising given the fact that the source water quality is of high importance for securing high drinking water quality and quantity.

Factors of major concern in source water quality are high phytoplankton abundance which can deteriorate infiltration effectiveness (Grischek and Bartak, 2016) and impair taste and odour (Hargesheimer and Watson, 1996). A high share of toxic cyanobacteria can break through to groundwater wells and increase the risk of toxin contamination in drinking water (Pazouki et al., 2016) and will lead to the need for chlorination, use of activated carbon or a combination of both (Zamyadi et al., 2012). Surface waters with a particular risk of high phytoplankton abundances and a high share of cyanobacteria are shallow lakes, the most abundant lake type in the world (Cael et al., 2016). They provide near optimum conditions for phytoplankton primary production due to regular mixing of the water column and phosphorus (P) release from sediments (Søndergaard et al., 2003). Abundant submerged vegetation stabilizes clear-water conditions and hinders phytoplankton, including cyanobacteria, blooms through nutrient uptake, provision of refuge for phytoplankton grazers, reduced sediment resuspension, increased sediment trapping and excretion of allelopathic substances (Scheffer et al., 1993). However, increasing nutrient loading above a critical threshold results in macrophyte losses and triggers a shift to the turbid state with phytoplankton dominance (Scheffer et al., 1993). Apart from declining source water quality for drinking water production, these regime shifts also lead to losses in biodiversity and other important ecosystem functions (Hilt et al., 2017). Lowland rivers with low flowing velocities and delta regions can respond to nutrient loading in a similar way with high phytoplankton abundances after macrophyte losses (Hilt et al., 2011).

In this study, we tested the hypothesis that IBF can significantly alter the water quality of source shallow lakes in terms of phytoplankton abundance and share of cyanobacteria. To test our hypothesis, we adapted an existing shallow lake ecosystem model and tested different scenarios combining several combinations of potential effects of IBF on groundwater seepage. Specifically, we expect that an IBFinduced reduction of groundwater seepage will 1) reduce macrophyte growth due to lower $\mathrm{CO}_{2}$ availability leading to higher probability of shifts to a turbid state, 2) decrease nutrient loading via 
groundwater leading to a lower probability of shifts to a turbid state and 3) increase summer water temperatures leading to a higher share of cyanobacteria in the phytoplankton community (Fig. 3). We also expect that IBF will 4) increase particle sedimentation rates and 5) increase oxygen penetration depth into the sediment (Fig. 3). These mechanisms affect P release from sediments in opposite ways and thus promote either macrophyte or phytoplankton dominance (Fig. 3). Finally, we tested whether lake size and depth significantly modify IBF effects on source water quality. Both size and depth have been shown to potentially affect shallow lake resilience to disturbance (Janssen et al., 2014). Overall, knowledge on IBF effects is needed to lower the risk of unwanted regime shifts in source water bodies (Scheffer et al., 2009) and to aid the selection process for future IBF sites to secure an optimal and sustainable application of this drinking water production technique.

\section{Material and methods}

\subsection{Ecosystem model PCLake}

We used the dynamic ecosystem model PCLake to simulate the effect of IBF on shallow water systems. The investigated scenarios simulations were variations on the PCLake default settings, describing a theoretical shallow temperate lake in a European climate. It was chosen because of its sediment component with groundwater exchange (Fig. A.1) and because of its very short computational times which allowed testing a multitude of parameter combinations.

PCLake was developed in the 1990s to simulate the impact of eutrophication of shallow lakes (Janse, 2005). It has been calibrated and validated using data from more than 40 lakes in several countries in northern continental Europe, mainly lakes in the Netherlands (Aldenberg et al., 1995; Janse, 2005; Janse et al., 2010). Since the 1990s, the model has also been used to estimate impacts of various potential stressors, for example, climate change (Mooij et al., 2007, 2009), and input of terrestrial particulate organic matter (Lischke et al., 2014).

PCLake simulates different functional groups including fish (plankti-/benthivorous fish and predatory fish), zooplankton, zoobenthos, submerged plants and phytoplankton (Fig. A.1). Phytoplankton is 
131 divided into the subgroups green algae, diatoms and cyanobacteria with different traits such as the

132 response to temperature and nutrient affinity, and respective typical seasonal successions expected in

133 lake ecosystems (Table A.1). The subgroups' abundance is measured either as dry-weight, P weight or

$134 \mathrm{~N}$ weight, with a variable stoichiometry adjusted by nutrient concentration in the water column.

135 Phytoplankton is found either in the water column or settled on the sediment surface and can be remobilized by the wind. Together with detritus, phytoplankton in the water column increases

137 turbidity and lowers Secchi depth. The water body is completely mixed and the water column rests

138 upon a sediment layer (default thickness $0.1 \mathrm{~m}$ ). Exchange takes place with underlying groundwater (P 139 and $\mathrm{N}$, more on this later), overlaying atmosphere (e.g. $\mathrm{O}_{2}$ ) as well as inflow and outflow of surface

140 water and nutrients. Nutrients are distributed throughout the model (water column and sediment)

141 through uptake, predation, grazing, egestion, mortality fluxes, mineralization, denitrification, feeding, settling, resuspension and sorption. Technically these fluxes are calculated using coupled differential

143 equations, one for each state-variable. Apart from the state-variables there are also 410 parameters; a

144 few of them were changed from their default settings during the runs (Table 1, Appendix B). An R 145 script was used to run the DATM generated C++ code of PCLake (Database Approach To Modelling, 146 Mooij et al., 2014). A detailed description of changes made follows below. For a full description of the 147 model and its default parameter settings see Janse (2005).

148 PCLake is often used to show effects of changing nutrient loading on phytoplankton abundance 149 expressed as phytoplankton chlorophyll $a(\operatorname{chl} a)$. Researchers, and lake managers alike, want to know 150 at what nutrient load a lake will shift either from a clear-water state to a turbid or vice versa. To 151 illustrate this, bifurcation plots show hysteresis and critical nutrient loads, which describe the nutrient 152 load at which the system shifts from one state to the other (Fig. 4A; illustrated by the sudden shift in 153 the response variable shown on the y-axis). The further to the left in the graph such shift is found a) 154 the less resilient a lake is towards increasing nutrient loading (shift from clear to turbid state), or b) the more lowered must the nutrient load be for a recovery to take place (shift from turbid to clear state). 
PCLake contains both phosphorus $(\mathrm{P})$ and nitrogen $(\mathrm{N})$ as essential nutrients for organismal growth. In PCLake, the load of $\mathrm{P}$ and $\mathrm{N}$ via surface water are coupled and, in our setup, the ratio is $\mathrm{N}: \mathrm{P}=7$. In continuation, when mentioning nutrients, this should be understood as $\mathrm{P}$ and $\mathrm{N}$.

In PCLake, the water temperature and light intensity is based on the long-term average for a temperate climate and is modelled as an average sine curve (Fig. A.2). The light intensity declines with increasing water depth following the Lambert-Beer law. The adaptations we made to simulate the impact of groundwater seepage are described below.

\subsection{Adaptations to PCLake}

We assessed potential impacts of IBF on lake water quality (Gillefalk et al., 2018) by first defining two major pathways of IBF: 1) interruption of groundwater seepage and 2) infiltration of lake water and particles into sediments. As a consequence, changes are expected in a) supply of $\mathrm{CO}_{2}$ to submerged plants (macrophytes) affecting their growth rate, b) nutrient loading, c) lake water temperature, d) particle settling velocity and e) oxygen penetration depth (Fig. 3). To simulate these effects, we adapted PCLake (all equations as well as state and parameter values in Appendix B) in the following way:

\subsection{1 $\mathrm{CO}_{2}$ loading by groundwater seepage and its effects on plant growth}

Effects of $\mathrm{CO}_{2}$ infiltration on plant growth were added to the model through the two parameters $\mathrm{cCO} 2 \mathrm{~W}\left(\mathrm{CO}_{2}\right.$ concentration in inflowing surface water $)$ and cCO2Ground $\left(\mathrm{CO}_{2}\right.$ concentration in groundwater). When there is groundwater seepage $(\mathrm{cQInf}<0)$ the two concentrations determine, together with the amount of surface water inflow and amount of seepage, the concentration of $\mathrm{CO}_{2}$ in the total inflowing water (uCO2W) as follows:

If $c$ QInf $\geq 0$ (no groundwater seepage), then:

$$
u C O 2 W=c \operatorname{co} 2 W
$$

$$
\text { If } \mathrm{cQInf}<0 \text { (groundwater seepage), then: }
$$




$$
u C O 2 W=\frac{c Q I n * c C O 2 W+|c Q I n f| * c C O 2 G r o u n d}{(c Q I n+|c Q I n f|)}
$$

179 Where: $\mathrm{cQIn}=$ surface water inflow (default: $20 \mathrm{~mm} / \mathrm{d}$ ), $\mathrm{cCO} 2 \mathrm{~W}=\mathrm{CO}_{2}$ concentration in inflowing 180 surface water $\left(150 \mathrm{mmol} / \mathrm{m}^{3}\right), \mathrm{cQInf}=$ infiltration/seepage rate $($ in $\mathrm{mm} / \mathrm{d}$, varies between runs $)$,

$181 \mathrm{cCO} 2 \mathrm{Ground}=\mathrm{CO}_{2}$ concentration in groundwater (in $\mathrm{mmol} / \mathrm{m}^{3}$, varies between runs). For references 182 see Table 2. The $\mathrm{CO}_{2}$ in the total inflowing water (via surface water and groundwater) is assumed to

The maximum macrophyte growth rate was changed from being a constant parameter to being dependent on $\mathrm{CO}_{2}$ concentration in the lake water $(\mathrm{uCO} 2 \mathrm{~W})$ as follows (Fig. A.3A):

If $\mathrm{uCO} 2 \mathrm{~W} \leq \mathrm{cCO} 2 \mathrm{~W}$, then

$$
\text { uMuMaxVeg }=\text { cMuMaxVeg }
$$

If $\mathrm{uCO} 2 \mathrm{~W}>\mathrm{cCO} 2 \mathrm{~W}$, then:

$$
\text { uMuMaxVeg }=\text { cMuMaxVeg } * \frac{(0.0013044 * u C O 2 W+0.94940714)}{c M u M a x N o r m}
$$

$$
\text { If } \mathrm{uCO} 2 \mathrm{~W}>600 \text {, then: }
$$

$$
\text { uMuMaxVeg }=\text { cMuMaxVeg } * \text { cMultiMuMaxVeg }
$$

Where cMuMaxVeg = default maximum growth rate at $20^{\circ} \mathrm{C}($ default: $0.2 \mathrm{~g} / \mathrm{g}$ shoot/d), uCO2W= calculated $\mathrm{CO}_{2}$ concentration in lake water (in $\mathrm{mmol} / \mathrm{m}^{3}$, varies between runs), $\mathrm{cMuMaxNorm}=\mathrm{a}$ constant to normalize maximum growth rate at certain $\mathrm{CO}_{2}$ level in the inflowing surface water (1.145). The value of cCO2Norm corresponds to the $\mathrm{CO}_{2}$ concentration in the inflowing surface water $\left(150 \mathrm{mmol} / \mathrm{m}^{3}\right)$ so that it follows the macrophyte growth rate in accordance with the results found by Madsen and Sand-Jensen (1994). The coefficients 0.0013044 and 0.94940714 are derived from a linear regression using the data from Madsen and Sand-Jensen (1994). cMultiMuMaxVeg= multiplication term equal to the one where $\mathrm{uCO} 2 \mathrm{~W}=600$, when $\mathrm{uCO} 2 \mathrm{~W}>600 \mathrm{mmol} / \mathrm{m}^{3}$, the macrophyte growth rate cannot benefit from increasing $\mathrm{CO}_{2}$ concentrations (Madsen and Sand-Jensen (1994), therefore the maximum macrophyte growth rate (uMuMaxVeg) is $0.314 \mathrm{~g} / \mathrm{g}$ shoot/d. In our 
scenarios, the resulting $\mathrm{CO}_{2}$ concentration in the lake water from inflowing surface water and groundwater ranged from 150 to $600 \mathrm{mmol} / \mathrm{m}^{3}$, depending on the parameter values of the run. For further discussion see section 4.1.3.

\subsubsection{Nutrient loading from groundwater seepage}

Simulations of changes in nutrient loading by groundwater were possible without adaptations in the equations. For parameter values used and references see Table 2.

\subsubsection{Temperature changes from groundwater seepage}

A water temperature parameter was introduced to account for the effect of groundwater. This addition allowed groundwater seepage to affect lake water temperature. When there was groundwater seepage, the introduced parameter for annual lake water temperature variation (uTmVar) was calculated according to (Fig. A.3B):

If $\mathrm{cQInf} \geq 0$ (no groundwater seepage), then:

$$
\text { uTmVar }=c T M V a r
$$

$$
\text { If cQInf }<0 \text { (groundwater seepage), then: }
$$

$$
\begin{gathered}
\text { uTmVar }=\left(\frac{c Q I n *(c T m A v e+c T m V a r)+|c Q I n f| * c T m G r o u n d}{2 *(c Q I n+|c Q I n f|)}-c T m V a r\right) \\
+\left(c T m V a r-\frac{c Q I n *(c T m A v e-c T m V a r)+|c Q I n f| * c T m G r o u n d}{2 *(c Q I n+|c Q I n f|)}\right)
\end{gathered}
$$

Where: $c$ QIn = surface water inflow (default: $20 \mathrm{~mm} / \mathrm{d}), \mathrm{cTmVar}=$ annual lake water temperature variation (default: $\left.\pm 10^{\circ} \mathrm{C}\right), \mathrm{cTmAve}=$ annual lake water temperature $\left(\right.$ default: $\left.12^{\circ} \mathrm{C}\right), \mathrm{cQInf}=$ infiltration/seepage rate (in $\mathrm{mm} / \mathrm{d}$, varies between runs), cTmGround $=$ groundwater temperature $(10$ ${ }^{\circ} \mathrm{C}$, Northern continental Europe, Berlin Senate 2016). The surface water inflow is assumed to have the same temperature as the lake if there is no groundwater seepage. For actual parameter values used and references for them see Table 2. In our scenarios, the lake water temperature variation was the smallest when groundwater seepage was $10 \mathrm{~mm} / \mathrm{d}(\mathrm{cQInf}=-10): 6.67^{\circ} \mathrm{C}$. When groundwater seepage 
was $5 \mathrm{~mm} / \mathrm{d}(\mathrm{cQInf}=-5): 8^{\circ} \mathrm{C}$. When groundwater seepage was zero or when lake water infiltrated into the groundwater $(\mathrm{cQInf} \geq 0)$ the lake water temperature variation took its default value: $10^{\circ} \mathrm{C}$.

\subsubsection{Changing sedimentation rate by seepage}

225

226

227

228

We coupled lake water infiltration to the settling velocity of inorganic matter, detritus, cyanobacteria, green algae and diatoms so that if infiltration was equal to for example $5 \mathrm{~mm} / \mathrm{d}$, the settling velocity was increased by $5 \mathrm{~mm} / \mathrm{d}$ (Fig. A.3C).

\subsubsection{Changing sediment oxygen penetration by seepage}

Lake water infiltration was coupled to the sediment oxidization depth. We assumed that extra oxygen would be brought into the sediment with IBF, so we set infiltration equal to added oxygen depth (Fig. A.3D). We assumed that the added oxygen via infiltration is consumed within a day and divided the added oxygen depth via IBF by the unit conversion constant $\operatorname{coxyCons}=1 / \mathrm{d}$.

\subsection{Tested parameter combinations and definition of a model run}

Each model configuration was run for 100 years in total (Fig. A.4). First an initialization period of 50 years was run where the infiltration/seepage rate was kept constant at the respective rate for each of all configurations. For the last 50 years the model run is divided into two parts: 1) infiltration/seepage rate was kept constant and 2) infiltration/seepage rate was changed to a lower seepage rate or a higher infiltration rate (simulating IBF), thereby enabling a comparison between a lake without and with IBF. Summer average values of target parameters (summer average phytoplankton chl $a$, cyanobacteria, diatoms, macrophytes, Secchi depth, sediment oxygen penetration depth, maximum P adsorption) were used to compare scenarios, and the summer period was defined as 1 April - 30 September following Janse et al. (2010). The nutrient loading via surface water was varied between 0.1-10 mg $\mathrm{P} / \mathrm{m}^{2} / \mathrm{d}$ and nitrogen $(\mathrm{N})$ was coupled to $\mathrm{P}$ so that $\mathrm{N}$ concentration equalled seven times that of the $\mathrm{P}$ concentration. Similarly, groundwater nutrients concentrations in PCLake are by default set so that the value of phosphate (cPO4Ground) is equal to that of nitrate (cNO3Ground), which in turn is equal to a tenth of the ammonium concentration (cNH4Ground). These default proportions between $\mathrm{N}$ and $\mathrm{P}$ 
concentrations in the groundwater are similar to findings by Lewandowski et al. (2015). Of the ranges of groundwater-borne $\mathrm{N}$ and $\mathrm{P}$ loads to lakes they reported, the bulk of values fall within $0.8-16.5 \mathrm{mg} /$ $\mathrm{N} / \mathrm{m}^{2} /$ year and $0.03-1.1 \mathrm{mg} \mathrm{P} / \mathrm{m}^{2} /$ year. When running scenarios where $\mathrm{CQInf} \geq 0$ the groundwater nutrient and $\mathrm{CO}_{2}$ concentrations were not varied since they would not have any effect, thereby saving computational time. The model runs were performed as follows:

a) First, we tested all parameter combinations of groundwater $\mathrm{CO}_{2}$ and nutrient concentrations focussing on how they impact summer average phytoplankton chl $a$, cyanobacteria, diatoms and macrophytes at different nutrient loads and groundwater flow conditions (Table 3). We also tested how the isolated effect of seasonal temperature variation influenced the same parameters at different nutrient loads by running PCLake in its default mode (without the adaptations explained in 2.2) and setting the cTmVar parameter to $6.67,8$ and $10^{\circ} \mathrm{C}$, values that correspond to groundwater seepage rates 10,5 and $\geq 0 \mathrm{~mm} / \mathrm{d}$. The lake depth and fetch were kept constant at their respective default values ( $2 \mathrm{~m}$ and $1000 \mathrm{~m})$.

b) Second, we again tested the same parameter combinations as in a) (except for the isolated temperature runs) but focussing on the impact on sedimentation and sediment characteristics: sediment oxygen penetration depth and maximum $\mathrm{P}$ adsorption. The lake depth and fetch length were kept constant at their respective default values ( $2 \mathrm{~m}$ and $1000 \mathrm{~m})$.

c) Finally, we tested the effects of lake size (expressed as fetch length in PCLake) and depth on IBF effects on phytoplankton chl $a$ concentrations. The effect was investigated using an average parameter combination as follows: $\mathrm{cQInf}=-5 \mathrm{~mm} / \mathrm{d}$ (seepage) and $5 \mathrm{~mm} / \mathrm{d}$ (IBF), cPO4Ground $=0.02 \mathrm{mg} \mathrm{P} / \mathrm{L}, \mathrm{cNH} 4$ Ground $=0.2 \mathrm{mg} \mathrm{N} / \mathrm{L}, \mathrm{cNO} 3$ Ground $=0.02 \mathrm{mg} \mathrm{N} / \mathrm{L}$ and $\mathrm{cCO} 2$ Ground $=900 \mathrm{mmol} / \mathrm{m} 3$. Two lake sizes were compared: $1000 \mathrm{~m}$ (default) and $100 \mathrm{~m}$ fetch length. Two lake depths were compared: $2 \mathrm{~m}$ (default) and $1.5 \mathrm{~m}$.

\section{Results}

Induced bank filtration (IBF) reduced the critical nutrient loads (expressed as P loads in all figures) at which regime shifts took place in shallow lakes in the majority of the investigated scenarios (Figs. 4, 5 
and 6). This decrease in critical nutrient load was found both when the system was initially in a clear state and shifted to a turbid state (Fig. 6 left) and vice versa (Fig. 6 right). In addition, the difference between the critical nutrient load for shifting from clear conditions and shifting from turbid conditions was smaller for lakes with IBF compared to lakes with groundwater seepage (Fig. 6). This result points to a reduction in the range of nutrient loading, where the system could either be clear or turbid depending on initial conditions.

\subsection{Effects of interrupted groundwater seepage: $\mathrm{CO}_{2} /$ nutrient concentrations and temperature variation}

Effects of groundwater flow conditions in the initial state were important for the effect of IBF: lakes that infiltrated into the groundwater in the initial state were affected to a much lesser extent compared to groundwater-fed lakes (data not shown). The effect of IBF on critical nutrient loads was influenced by the concentration of nutrients and $\mathrm{CO}_{2}$ in the seeping groundwater. A low concentration of nutrients and a high concentration of $\mathrm{CO}_{2}$ in the initial condition resulted in a stronger effect of IBF (Fig. 6, Fig. A.5). Critical nutrient loads representing a switch from a clear to a turbid state were found to be up to four times higher when groundwater seeped into the lake compared to when applying IBF. The lower the nutrient concentration and the higher the $\mathrm{CO}_{2}$ concentration in the groundwater seeping into the lake, the stronger the effect of reversing the groundwater flow was (Fig. A.5). In some specific cases, IBF was found to increase critical nutrient loads (Fig. 7: low $\mathrm{CO}_{2}$, high P, Fig. A.5). This scenario occurred when the initial groundwater seeping into the lake contained high nutrient concentrations combined with low to middle high $\mathrm{CO}_{2}$ concentrations. However, in most scenario combinations of groundwater $\mathrm{CO}_{2}$ and nutrient concentrations, critical nutrient loads declined when applying IBF (Fig. A.6).

The model runs where temperature variation was decoupled from groundwater flow and instead independently changed showed small effects on critical nutrient loads (Fig. A.7A). However, they showed an increase in cyanobacteria abundance with increasing temperature variation (Fig. A.7B, corresponding to IBF scenarios). 
Comparing the impact of the three parameters that are affected by the change from groundwater seepage to IBF, we found that the largest impact was due to the change in $\mathrm{CO}_{2}$, then nutrients and lastly temperature variation, when looking at critical nutrient loads and changes in phytoplankton and vegetation abundance (Figs. A.7C, A.8A and A.8B). The change from a vegetation dominated state to a phytoplankton dominated state is facilitated by a change in turbidity (Fig. A.9).

\subsection{Effects of increased sedimentation rate and sediment oxygen penetration}

The combined effect of increased sedimentation rate and sediment oxygen penetration via IBF led to a net increase of sediment oxygen penetration depth in the IBF scenarios (Fig. A.10). The depth of sediment oxidization increased with increasing infiltration rates and decreased with increasing groundwater $\mathrm{CO}_{2}$ and nutrient concentration. Under infiltrating conditions the increase was very similar to the increase of infiltration. The deeper oxygen penetration in the sediment increased maximum P binding capacity in the sediment (Fig. A.11).

\subsection{Influence of lake depth and size}

The effect of IBF on critical nutrient loads was greater for a simulated lake with smaller depth compared to a lake with larger depth; the shift of the critical nutrient loads was larger for the shallower lake (Fig. 8). Similarly, the fetch length made the relative effect of IBF smaller, i.e. applying IBF to a large lake changed the critical nutrient loads to a smaller extent than in the case of a smaller lake Fig. 8).

\section{Discussion}

Our model results clearly show that IBF has adverse effects on source water quality in most of the tested scenarios. The effects originated from IBF interrupting groundwater seepage, once the seepage was gone an increase of IBF withdrawal rate did not further strengthen the effects on source water 
quality. IBF negatively affects the threshold nutrient loading required for the freshwater shallow lake ecosystem to persist in a clear water state, the preferred state for water purification. Moreover, it increases the resilience of the turbid state, making it harder to shift to a clear state when IBF is applied. This persistence of the turbid state is unwanted due to the lower ecological water quality including lower biodiversity (Hilt et al., 2011) as well as increased risks of clogging of the sediment bed and presence of toxic cyanobacteria. The latter are not only directly disadvantageous for the ecosystem services of the water body, but can also impair IBF (Grischek and Bartak, 2016;

Hargesheimer and Watson, 1996; Pazouki et al., 2016). These adverse effects were shown in our model results for temperate shallow lakes using parameter values that are well within plausible ranges that are found in the literature (Table 2). Consequently, it is conceivable that IBF leads to a decreased resilience of shallow lakes and slow-flowing lowland rivers to increasing nutrient loads which are expected in many areas worldwide due to urbanisation and climate warming. Effects of IBF were decreasing with increasing size and depth of the source lake. Securing a sustainable drinking water production by reliable and cost-effective IBF thus requires an extension of the assessment of IBF effects from the current focus on drinking water quality and quantity to source water bodies in the planning phase.

Several mechanisms in the model are together responsible for the effect of IBF on source water quality, mainly the interruption of groundwater seepage, increased particle sedimentation rate and increased oxygen penetration depth (Fig. 3), all of which are discussed in more detail below.

\subsection{Consequences of interrupting groundwater seepage by IBF}

Our model results indicate that water quality of lakes fed by groundwater declines when applying IBF, while lakes that are infiltrating in their natural condition will hardly be affected by IBF. In reality, lakes often are both infiltrating as well as gaining water through seepage, but the net-effect is that most lakes receive a net flux of water from groundwater sources (Rosenberry et al., 2015). The size of both seepage and IBF rates in our scenarios -5 and $10 \mathrm{~mm} / \mathrm{d}$ in both cases - are well within documented ranges; seepage values range from 0.05 to $190 \mathrm{~mm} / \mathrm{d}$ (Rosenberry et al., 2015) and the abstraction rate in Lake Müggelsee is $22 \mathrm{~mm} / \mathrm{d}$ (Zippel and Hannappel, 2008). 
Interrupting groundwater seepage by IBF has consequences for $\mathrm{CO}_{2}$ availability for macrophytes, nutrient loading and seasonal water temperature variation in source water bodies (Fig. 3, for a detailed review, see Gillefalk et al., 2018) which together can lead to opposing effects.

\subsubsection{Consequences of interrupting groundwater nutrient loading}

IBF could improve the water quality of source water bodies and increase their critical nutrient loads in case groundwater influx comprises a major share of the nutrient budget and as long as the $\mathrm{CO}_{2}$ supply via groundwater is low. Under such conditions, IBF would interrupt the groundwater-born nutrient load and result in a recovery and shift back to clear conditions (Figs. 6 and A.5). A major contribution of groundwater seepage to nutrient loading has been shown for several lakes (Lewandowski et al., 2015). IBF could thus be part of a management strategy to combat this excessive nutrient loading. However, the critical nutrient load for switching back to the turbid state in those cases lies marginally higher which means that the clear state will remain sensitive to increased surface water nutrient loads.

\subsubsection{Consequences for seasonal temperature variation}

Interrupting groundwater influx by IBF results in an increased amplitude of the seasonal temperature variations in the source water bodies in temperate regions, as groundwater temperature is higher than surface water temperature in winter, and vice versa in summer (e.g. Cieśliński et al., 2016). In general, most biological processes are temperature-dependent and changing water temperature will thus have consequences for aquatic organisms and their interactions. In our IBF scenarios, lake water was $3.3^{\circ} \mathrm{C}$ cooler in winter and $3.3{ }^{\circ} \mathrm{C}$ warmer in summer compared to initial states where lakes had groundwater seepage equal to $10 \mathrm{~mm} / \mathrm{d}$. When groundwater seepage was $5 \mathrm{~mm} / \mathrm{d}$, the difference was $2{ }^{\circ} \mathrm{C}$ cooler and warmer, respectively. These differences in temperature are similar to those found by Liu et al. (2016). Lower temperatures in winter can lead to changes in ice coverage with potential consequences for water quality aspects such as the timing of the spring phytoplankton bloom (Adrian et al., 2006). In PCLake though, a potential ice cover was not considered. In PCLake, all organism growth rates as well as mineralization of organic matter are temperature-dependent processes. Higher temperatures and higher $\mathrm{P}$ availability in summer have been shown to facilitate phytoplankton more than macrophytes. Especially cyanobacteria will profit due to their high $\mathrm{P}$ affinity and steeper temperature 
function as compared to other phytoplankton groups (Mooij et al., 2007). As a consequence, warmer lakes have a lower critical nutrient loading and a higher risk of cyanobacterial dominance (e.g. Mooij

381

382

383

et al., 2007; Kosten et al., 2012). Cooler winter water temperatures in IBF-affected lakes could counterbalance this effect as temperate shallow lake ecosystems have been found to be most sensitive to temperature changes in winter and early spring (Mooij et al., 2007). Our model results, however, indicate that the net effects of IBF reinforce rather than dampen the effects of climate warming on shallow temperate lakes and slow-flowing lowland rivers, especially in cases where IBF would interrupt significant $\mathrm{CO}_{2}$ inflow via groundwater. In our artificial scenarios, where temperature variation was changed, while keeping groundwater inflow $=0$, the temperature had a much smaller impact on chl $a$ concentration compared to groundwater nutrients and $\mathrm{CO}_{2}$ concentrations (compare Fig. A.7A to Fig. 7 and Fig. A.7C to Figs. A.8A and A.8B). There was a small effect that lowered critical nutrient loads when temperature variation was higher, which represents scenarios with IBF (Fig. A.6A). A higher temperature variation, leading to higher summer temperatures did lead to higher cyanobacteria concentrations in the water (Fig. A.7B), both by lowering the critical nutrient loads and by increasing the cyanobacteria concentration in turbid states. But the latter is not visible when looking at scenarios produced using all parameters, because then the model showed that cyanobacteria are outcompeted by diatoms (Figs. A.8A and A.8B).

\subsubsection{Consequences for groundwater $\mathrm{CO}_{2}$ loading}

In our scenarios, IBF-driven changes in $\mathrm{CO}_{2}$ availability thus have stronger effects than those in water temperature. Interrupting groundwater influx by IBF can lower $\mathrm{CO}_{2}$ concentrations in lake water since groundwater in general shows higher concentrations of $\mathrm{CO}_{2}$ (Sand-Jensen and Borum, 1991; SandJensen and Staehr, 2012). The majority of boreal lakes are $\mathrm{CO}_{2}$-sustained by groundwater (Weyhenmeyer et al., 2015) and in tropical and temperate lakes $\mathrm{CO}_{2}$ supersaturation is dependent on groundwater $\mathrm{CO}_{2}$ coming from weathering of minerals rather than on internal production (Marcé et al., 2015). Lowered $\mathrm{CO}_{2}$ concentrations negatively affect macrophyte growth since some species fully depend on $\mathrm{CO}_{2}$ (Maberly, 1985; Maberly and Madsen, 1998) and others, which are able to use $\mathrm{HCO}_{3}{ }^{-}$ in addition, still grow faster in $\mathrm{CO}_{2}$-rich environments (Madsen and Sand-Jensen, 1994; Vadstrup and 
Madsen, 1995; Olesen and Madsen, 2000), partly due to the higher metabolic cost of using $\mathrm{HCO}_{3}{ }^{-}$ (Jones, 2005). Elevation of atmospheric $\mathrm{CO}_{2}$ under eutrophic conditions may increase the growth rate of macrophytes using $\mathrm{CO}_{2}$ and $\mathrm{HCO}_{3}{ }^{-}$by $100 \%$ and of macrophytes restricted to $\mathrm{CO}_{2}$ assimilation by $200 \%$ (Schippers et al., 2004). The lack of groundwater-borne $\mathrm{CO}_{2}$ due to IBF can be particularly relevant for macrophyte growth in summer since $\mathrm{CO}_{2}$ concentrations in lakes reach their minimum in July (Weyhenmeyer et al., 2012). The effect might, therefore, be overestimated as increasing macrophyte biomass should decrease $\mathrm{CO}_{2}$ concentrations. But the resulting $\mathrm{CO}_{2}$ concentrations were similar to those measured close to where groundwater seeps out into a river (Maberly et al., 2015). Also, since macrophytes grow where groundwater enters, those areas can be assumed to have higher $\mathrm{CO}_{2}$ concentrations than average lake water. Overall, the growth rate of macrophytes is a very sensitive parameter in PCLake and any decline favours phytoplankton abundance.

\subsection{Consequences of increased sedimentation rate and sediment oxygen penetration}

We assumed that IBF can increase particle sedimentation rates equal to the infiltration rates. In our model results, this increase in particle sedimentation rate did not increase oxygen consumption sufficiently to consume all the added oxygen through infiltration into sediments. The resulting net increase in the sediment oxidation depth led to more $\mathrm{P}$ being bound in the sediment and less $\mathrm{P}$ available for phytoplankton. But the effect is small; an increase of infiltration rate from 5 to $10 \mathrm{~mm} / \mathrm{d}$ did not change the critical nutrient loads at all (Fig. A.5). An increase in sediment oxidation depth can have consequences for redox conditions affecting the removal of e.g. pharmaceutically active compounds during IBF (Wiese et al., 2011).

In deeper lakes, cold water from the bottom could, in theory, be withdrawn, potentially decrease the stratification stability and net sedimentation. But in general, sediments in deeper part of lakes are covered with fine particles and organic material, drastically reducing the permeability and infiltration rates. That is why infiltration at lake IBF sites only takes place in the littoral zone (Hoffmann and Gunkel, 2011) 
433

434

435

436

437

438

439

440

441

442

443

444

445

446

447

\subsection{Effect size depends on lake depth and size}

Most lakes in the world are small $\left(<0.01 \mathrm{~km}^{2}\right)($ Verpoorter et al., 2014) and shallow $(<2.6 \mathrm{~m})($ Cael et al., 2016). Small and shallow lakes are in general more sensitive to changes than large or deep ones; accordingly, our simulations indicate that IBF effects on phytoplankton abundance are stronger when source water bodies are smaller and shallower. The macrophytes in a small system benefited more from the groundwater $\mathrm{CO}_{2}$ inflow, after the interruption of seepage by IBF those systems reacted stronger. IBF effects can thus be minimized if larger and deeper water bodies are chosen for drinking water production. In addition, unintentional BF may also affect the water quality, especially in small aquatic ecosystems in the vicinity of source water bodies. This may impair their ecosystem functions and services such as provision of habitats for a diverse aquatic flora and fauna as well as carbon and nutrient retention (Hilt et al., 2017). Considering these effects in future planning will allow for a more comprehensive approach aiming at sustainable drinking water production with minimized negative effects on the water quality in both, target and neighbouring water bodies.

\section{Conclusions}

- Our results show that the major impact of IBF on shallow lakes is a result of interrupting groundwater seepage into the lake. In most scenarios this led to an increasing risk of a clearwater lake shifting to a turbid state and strengthening the persistence of the turbid state (lower critical nutrient loads), thus increasing the risk of the occurrence of potentially toxic cyanobacteria blooms. This effect was stronger in smaller and shallower lakes.

- As the valuable technique of IBF is spread over the world, choosing the most suitable sites to ensure sustainable drinking water production gains in importance. Modelling is a valuable tool to use for this purpose. Model simulations can help to avoid consequences that emerge from ecological and technological perspectives. 
- Our model results are based on model input with realistic values for seepage rates, IBF rates, groundwater $\mathrm{CO}_{2}$ and nutrient concentrations. Assumptions for our model input regarding effects on lake water temperature by changing groundwater regimes, effects of $\mathrm{CO}_{2}$ on macrophyte growth and effects of groundwater-borne nutrient loading are well founded in existing literature. Based on well-embedded model input, this study could provide an explicit and flexible way to see the effects of IBF in different conditions.

- Further research on IBF effects on source water bodies is needed by expanding the scope to rivers and deeper lakes and by field investigations. Future management should aim at ensuring the sustainable use of IBF for drinking water supply by considering potential ecological impacts on all types of source water bodies.

\section{Acknowledgements}

The authors would like to thank the members of the DFG (German Research Foundation) Research Training Group "Urban Water Interfaces”.

We thank the many staff and students of the Leibniz-Institute of Freshwater Ecology and Inland Fisheries who run the long-term Müggelsee sampling and analysis, especially Rita Adrian, Tobias Goldhammer, Hans-Jürgen Exner, Jörg Gelbrecht, Thomas Hintze, Reinhard Hölzel, Antje Lüder, Ursula Newen, Kathrin Preuß, Thomas Rossoll, Jürgen Schreiber, Bernd Schütze and Barbara Stein.

We also want to thank the Berlin Senate Department for the Environment, Transport and Climate Protection, especially Antje Köhler, Alexander Limberg, Benjamin Creutzfeldt and Daniel Brüggemann, for providing data and discussions and the Berlin Wasserbetriebe, especially Dörte Siebenthaler, for her invaluable help during data collection.

Funding: This work was supported by the German Research Foundation [DFG research training group “Urban water interfaces”, grant no. GRK 2032/1]. 
MG and SH conceived the concept, wrote the manuscript and produced figures and tables. MG performed the modelling work. All authors contributed with important feedback during all stages of the modelling work and participated in choosing what results were relevant to include in final draft of the manuscript. JJ, ST and AJ provided technical help and hands-on solutions for the modelling work. JK was responsible for handling Müggelsee long-term data. All authors provided feedback on manuscript, including figures and tables. All authors have approved the final article.

\section{References}

Acreman, M.C., Adams, B., Birchall, P., Connorton, B., 2000. Does groundwater abstraction cause degradation of rivers and wetlands? Water Environ. J. 14, 200-206. https://doi.org/10.1111/j.1747-6593.2000.tb00250.x

Adrian, R., Wilhelm, S., Gerten, D., 2006. Life-history traits of lake plankton species may govern their phenological response to climate warming. Glob. Change Biol. 12, 652-661. https://doi.org/10.1111/j.1365-2486.2006.01125.x

Aldenberg, T., Janse, J.H., Kramer, P.R.G., 1995. Fitting the dynamic model PCLake to a multi-lake survey through Bayesian Statistics. Ecol. Modell. 78, 83-99. https://doi.org/10.1016/03043800(94)00119-3

Berlin Senate, 2016. Environmental Atlas. Berlin Senate Department of Urban Development and Housing.

Borges, A.V., Darchambeau, F., Lambert, T., Bouillon, S., Morana, C., Brouyère, S., Hakoun, V., Jurado, A., Tseng, H.-C., Descy, J.-P., Roland, F.A.E., 2018. Effects of agricultural land use on fluvial carbon dioxide, methane and nitrous oxide concentrations in a large European river, the Meuse (Belgium). Sci. Total Environ. 610-611, 342-355. https://doi.org/10.1016/j.scitotenv.2017.08.047

Cael B.B., Heathcote A.J., Seekell D.A., 2016. The volume and mean depth of Earth's lakes. Geophys. Res. Lett. 44, 209-218. https://doi.org/10.1002/2016GL071378

Campeau, A., del Giorgio, P.A., 2014. Patterns in $\mathrm{CH}_{4}$ and $\mathrm{CO}_{2}$ concentrations across boreal rivers: Major drivers and implications for fluvial greenhouse emissions under climate change scenarios. Glob. Change Biol. 20, 1075-1088. https://doi.org/10.1111/gcb.12479 
Cieśliński, R., Piekarz, J., Zieliński, M., 2016. Groundwater supply of lakes: the case of Lake Raduńskie Górne (northern Poland, Kashubian Lake District). Hydrolog. Sci. J. 61, 2427-2434. https://doi.org/10.1080/02626667.2015.1112903

Gillefalk, M., Massmann, G., Nützmann, G., Hilt, S., 2018. Potential impacts of induced bank filtration on surface water quality: a conceptual framework for future research. Water 10, 1240. https://doi.org/10.3390/w10091240

Grischek, T., Bartak, R., 2016. Riverbed clogging and sustainability of riverbank filtration. Water 8, 604. https://doi.org/10.3390/w8120604

Hargesheimer, E., Watson, S., 1996. Drinking water treatment options for taste and odor control. Water Res. 30, 1423-1430. https://doi.org/10.1016/0043-1354(96)00027-9

Hilt, S., Köhler, J., Kozerski, H.-P., van Nes, E.H., Scheffer, M., 2011. Abrupt regime shifts in space and time along rivers and connected lake systems. Oikos 120, 766-775. https://doi.org/10.1111/j.1600-0706.2010.18553.x

Hilt, S., Brothers, S., Jeppesen, E., Veraart, A.J., Kosten, S., 2017. Translating regime shifts in shallow lakes into changes in ecosystem functions and services. BioScience 67, 928-936. https://doi.org/10.1093/biosci/bix106

Hiscock, K.M., Grischek, T., 2002. Attenuation of groundwater pollution by bank filtration. J. Hydrol. 266, 139-144. https://doi.org/10.1016/S0022-1694(02)00158-0

Hoffmann, A., Gunkel, G., 2011. Bank filtration in the sandy littoral zone of Lake Tegel (Berlin): Structure and dynamics of the biological active filter zone and clogging processes. Limnologica 41, 10-19. https://doi.org/10.1016/j.limno.2009.12.003

Janse, J.H., 2005. Model studies on the eutrophication of shallow lakes and ditches. Doctoral thesis Wageningen University. ISBN 90-8504-214-3

Janse, J.H., Scheffer, M., Lijklema, L., Van Liere, L., Sloot, J.S., Mooij, W.M., 2010. Estimating the critical phosphorus loading of shallow lakes with the ecosystem model PCLake: Sensitivity, calibration and uncertainty. Ecol. Model. 221, 654-665. https://doi.org/10.1016/j.ecolmodel.2009.07.023

Janssen A.B.G., Teurlincx S., An S., Janse J.H., Paerl H.W., Mooij W.M., 2014. Alternative stable states in large shallow lakes? J. Great Lakes R. 40, 813-826. https://doi.org/10.1016/j.jglr.2014.09.019

Jones, J.I., 2005. The metabolic cost of bicarbonate use in the submerged plant Elodea nuttallii. Aquat. Bot. 83, 71-81. https://doi.org/10.1016/j.aquabot.2005.05.002

Kempe, S., Pettine, M., Cauwet., G., 1991. Biogeochemistry of Europe rivers (Chapter 8). In: Degens, E. T., Kempe S., Richey, J.E. (Eds.), SCOPE 42 - Biogeochemistry of major world rivers. John Wiley \& Sons., pp. 169-211.

Kosten, S., Huszar, V.L.M., Becares, E., Costa, L.S., van Donk, E., Hansson, L.-A., Jeppesenk, E., Kruk, C., Lacerot, G., Mazzeo, N., De Meester, L., Moss, B., Lurling, M., Noges, T., Romo, S., Scheffer, M., 2012. Warmer climates boost cyanobacterial dominance in shallow lakes. Glob. Change Biol. 18, 118-126. https://doi.org/10.1111/j.1365-2486.2011.02488.x 
Kunkel, R., Voigt, H.-J., Wendland, F., Hannappel, S., 2004. The natural groundwater quality in Germany (original language: German). Publications of the Jülich Forschungszentrum, Environment, Volume 47.

Lauerwald, R., Laruelle, G.G., Hartmann, J., Ciais, P., Regnier, P.A.G., 2015. Spatial patterns in $\mathrm{CO}_{2}$ evasion from the global river network. Global Biogeochem. Cy. 29, 534-554. https://doi.org/10.1002/2014GB004941

Lewandowski, J., Meinikmann, K., Nützmann, G., Rosenberry, D.O., 2015. Groundwater - the disregarded component in lake water and nutrient budgets. Part 2: effects of groundwater on nutrients. Hydrol. Process. 29, 2922-2955. https://doi.org/10.1002/hyp.10384

Lischke, B., Hilt, S., Janse, J.H., Kuiper, J.J., Mehner, T., Mooij, W.M., Gaedke, U., 2014. Enhanced Input of Terrestrial Particulate Organic Matter Reduces the Resilience of the Clear-Water State of Shallow Lakes: A Model Study. Ecosystems 17, 616-626. https://doi.org/10.1007/s10021014-9747-7

Liu, C., Liu, J., Wang, X.-S., Zheng, C., 2016. Analysis of groundwater-lake interaction by distributed temperature sensing in Badain Jaran Desert, Northwest China. Hydrol. Process. 30, 1330-1341. doi:10.1002/hyp.10705

Maberly, S.C., 1985. Photosynthesis by Fontinalis antipyretica. II. New Phytol. 100, 141-155. https://doi.org/10.1111/j.1469-8137.1985.tb02766.x

Maberly, S.C., Madsen, T.V., 1998. Affinity for $\mathrm{CO}_{2}$ in relation to the ability of freshwater macrophytes to use $\mathrm{HCO}_{3}{ }^{-}$. Funct. Ecol. 12, 99-106. https://doi.org/10.1046/j.13652435.1998.00172.x

Maberly, S.C., Berthelot, S.A., Stott, A.W., Gontero, B., 2015. Adaptation by macrophytes to inorganic carbon down a river with naturally variable concentrations of CO2. J. Plant Physiol. 172, 120-127. https://doi.org/10.1016/j.jplph.2014.07.025

Macpherson, G.L., 2009. $\mathrm{CO}_{2}$ distribution in groundwater and the impact of groundwater extraction on the global C cycle. Chem. Geol. 264, 328-336. https://doi.org/10.1016/j.chemgeo.2009.03.018

Madsen, T.V., Sand-Jensen, K., 1994. The interactive effects of light and inorganic carbon on aquatic plant growth. Plant Cell Environ. 17, 955-962. https://doi.org/10.1111/j.13653040.1994.tb00324.x

Marcé, R., Obrador, B., Morgui, J.-A., Lluis Riera, J., Lopez, P., Armengol, J., 2015. Carbonate weathering as a driver of $\mathrm{CO} 2$ supersaturation in lakes. Nat. Geosci. 8, 107-111. https://doi.org/10.1038/NGEO2341

Mooij, W.M., Janse, J.H., De Senerpont Domis, L.N., Hülsmann, S., Ibelings, B.W., 2007. Predicting the effect of climate change on temperate shallow lakes with the ecosystem model PCLake. Hydrobiologia 584, 443-454. https://doi.org/10.1007/s10750-007-0600-2

Mooij, W.M., De Senerpont Domis, L.N., Janse, J.H., 2009. Linking species- and ecosystem-level impacts of climate change in lakes with a complex and a minimal model. Ecol. Model. 220, 3011-3020. https://doi.org/10.1016/j.ecolmodel.2009.02.003

Mooij, W.M., Brederveld, R.J., de Klein, J.J.M., DeAngelis, D.L., Downing, A.S., Faber, M., Gerla, D.J., Hipsey, M.R., ’t Hoen, J., Janse, J.H., Janssen, A.B.G., Jeuken, M., Kooi, B.W., Lischke, 
B., Petzoldt, T., Postma, L., Schep, S.A., Scholten, H., Teurlincx, S., Thiange, C., Trolle, D., van Dam, A.A., van Gerven, L.P.A., van Nes, E.H., Kuiper, J.J., 2014. Serving many at once: How a database approach can create unity in dynamical ecosystem modelling. Environ. Modell. Softw. 61, 266-273. https://doi.org/10.1016/j.envsoft.2014.04.004

Olesen, B., Madsen, T.V., 2000. Growth and physiological acclimation to temperature and inorganic carbon availability by two submerged aquatic macrophyte species, Callitriche cophocarpa and Elodea canadensis. Funct. Ecol. 14, 252-260. https://doi.org/10.1046/j.1365-2435.2000.00412.x

Pazouki, P., Prévost, M., McQuaid, N., Barbeau, B., de Boutray, M.-L., Zamyadi, A., Dorner, S., 2016. Breakthrough of cyanobacteria in bank filtration. Water Res. 102, 170-179. https://doi.org/10.1016/j.watres.2016.06.037

Ray, C., 2008. Worldwide potential of riverbank filtration. Clean Technol. Environ. Policy 10, 223225. https://doi.org/10.1007/s10098-008-0164-5

Ray, C., Schubert, J., Linsky, R.B., Melin, G., 2003. Introduction. Riverbank filtration - improving source-water quality. Ed. Ray, C., Melin, G., Linsky, R.B. Kluwer Academic Publishers; Dordrecht; Boston, London, 1-15.

Rosenberry, D.O., Lewandowski, J., Meinikmann, K., Nützmann, G., 2015. Groundwater - the disregarded component in lake water and nutrient budgets. Part 1: effects of groundwater on hydrology. Hydrol. Process. 29, 2895-2921. https://doi.org/10.1002/hyp.10403

Sand-Jensen, K., Borum, J., 1991. Interactions among phytoplankton, periphyton, and macrophytes in temperate fresh-waters and estuaries. Aquat. Bot. 41, 137-175. https://doi.org/10.1016/03043770(91)90042-4

Sand-Jensen, K., Staehr, P.A., 2012. $\mathrm{CO}_{2}$ dynamics along Danish lowland streams: water-air gradients, piston velocities and evasion rates. Biogeochemistry 111, 615-628. https://doi.org/10.1007/s10533-011-9696-6

Scheffer, M., Hosper, S., Meijer, M., Moss, B., Jeppesen, E., 1993. alternative equilibria in shallow lakes. Trends Ecol. Evol. 8, 275-279. https://doi.org/10.1016/0169-5347(93)90254-M

Scheffer, M., Bascompte, J., Brock, W.A., Brovkin, V., Carpenter, S.R., Dakos, V., Held, H., van Nes, E.H., Rietkerk, M., Sugihara, G., 2009. Early-warning signals for critical transitions. Nature 461, 53-59. https://doi.org/10.1038/nature08227

Schippers, P., Vermaat, J.E., de Klein, J., Mooij, W.M., 2004. The Effect of Atmospheric Carbon Dioxide Elevation on Plant Growth in Freshwater Ecosystems. Ecosystems 7, 63-74. https://doi.org/10.1007/s10021-003-0195-z

Schröter, W., 2015. Groundwater levels of the main aquifer and Panke Valley aquifer. Berlin Senate Department for Urban Development and the Environment. URL http://www.stadtentwicklung.berlin.de/umwelt/umweltatlas/kq212.htm (accessed 5.15.18).

Søndergaard, M., Jensen, J.P., Jeppesen, E., 2003. Role of sediment and internal loading of phosphorus in shallow lakes. Hydrobiologia 506-509, 135-145. https://doi.org/10.1023/B:HYDR.0000008611.12704.dd

Sprenger, C., Hartog, N., Hernández, M., Vilanova, E., Grützmacher, G., Scheibler, F., Hannappel, S., 2017. Inventory of managed aquifer recharge sites in Europe: historical development, current 

situation and perspectives. Hydrogeol. J. 25, 1909-1922. https://doi.org/10.1007/s10040-017$1554-8$

Vadstrup, M., Madsen, T.V., 1995. Growth limitation of submerged aquatic macrophytes by inorganic carbon. Freshwater Biology 34, 411-419. https://doi.org/10.1111/j.1365-2427.1995.tb00899.x

Verpoorter, C., Kutser, T., Seekell, D.A., Tranvik, L.J., 2014. A global inventory of lakes based on high-resolution satellite imagery. Geophys. Res. Lett. 41, 2014 GL060641. https://doi.org/10.1002/2014GL060641

Vesper, D.J., Edenborn, H.M., 2012. Determination of free $\mathrm{CO}_{2}$ in emergent groundwaters using a commercial beverage carbonation meter. J. Hydrol. 438-439, 148-155. https://doi.org/10.1016/j.jhydrol.2012.03.015

Weyhenmeyer, G.A., Kortelainen, P., Sobek, S., Mueller, R., Rantakari, M., 2012. Carbon dioxide in boreal surface waters: a comparison of lakes and streams. Ecosystems 15, 1295-1307. https://doi.org/10.1007/s10021-012-9585-4

Weyhenmeyer, G.A., Kosten, S., Wallin, M.B., Tranvik, L.J., Jeppesen, E., Roland, F., 2015. Significant fraction of $\mathrm{CO}_{2}$ emissions from boreal lakes derived from hydrologic inorganic carbon inputs. Nat. Geosci. 8, 933-U62. https://doi.org/10.1038/NGEO2582

Wiese, B., Massmann, G., Jekel, M., Heberer, T., Dünnbier, U., Orlikowski, D., Grützmacher, G., 2011. Removal kinetics of organic compounds and sum parameters under field conditions for managed aquifer recharge. Water Res. 45, 4939-4950.

Zamyadi, A., Ho, L., Newcombe, G., Bustamante, H., Prévost, M., 2012. Fate of toxic cyanobacterial cells and disinfection by-products formation after chlorination. Water Res. 46, 1524-1535. https://doi.org/10.1016/j.watres.2011.06.029

Zippel, M., Hannappel, S., 2008. Evaluation of the groundwater yield of Berlin water works using regional numerical groundwater flow models (original language: German). Grundwasser 13, 195-207. https://doi.org/10.1007/s00767-008-0079-4 
658 Table 1. Main parameter values for this study (default values of PCLake, Aldenberg et al., 1995;

659 Janse, 2005).

660

\begin{tabular}{lll}
\hline Parameter & Abbreviation & Value \\
\hline Marsh zone & - & Marsh zone not used \\
Inflow of surface water & cQIn & $20 \mathrm{~mm} / \mathrm{d}$ \\
Average water temperature & cTMAve & $12{ }^{\circ} \mathrm{C}$ \\
Sediment depth & cDepthS & $0.1 \mathrm{~m}$ \\
Sediment dry matter & fDtotS0 & $0.3 \mathrm{~g} \mathrm{solid} / \mathrm{g}$ sediment \\
Sediment organic fraction & fDOrgS0 & $0.1 \mathrm{~g} / \mathrm{g}$ \\
Clay in inorganic matter & fLutum & $0.1 \mathrm{~g} \mathrm{lutum} / \mathrm{g} \mathrm{DW}$ \\
Iron in inorganic matter & fFeDIM & $0.01 \mathrm{~g} \mathrm{Fe} / \mathrm{g} \mathrm{DW}$ \\
Aluminium in inorganic matter & fAlDIM & $0.01 \mathrm{~g} \mathrm{Al} / \mathrm{g} \mathrm{DW}$ \\
\hline
\end{tabular}

661

662

663 
Table 2. Literature values for key parameters used. Where relevant, the values are given as extremes 665 and as averages along with the values used in the modelled scenarios.

\begin{tabular}{|c|c|c|c|}
\hline Parameter & $\begin{array}{l}\text { Range, extreme } \\
\text { (typical values) }\end{array}$ & Reference & In model \\
\hline Groundwater $\mathrm{CO}_{2}$ & $\begin{array}{l}18-7200 \mathrm{mmol} / \mathrm{m}^{3} \\
\left(630-1260 \mathrm{mmol} / \mathrm{m}^{3}\right)\end{array}$ & $\begin{array}{l}\text { Vesper and Edenborn, } \\
\text { 2012; Macpherson, } 2009\end{array}$ & $\begin{array}{l}180,360,600,900,1200 \\
1500 \mathrm{mmol} / \mathrm{m}^{3}\end{array}$ \\
\hline River $\mathrm{CO}_{2}$ & $\begin{array}{l}54-360 \mathrm{mmol} / \mathrm{m}^{3} \\
\left(90-180 \mathrm{mmol} / \mathrm{m}^{3}\right)\end{array}$ & $\begin{array}{l}\text { Kempe et al., 1991; } \\
\text { Campeau and Del Giorgio, } \\
\text { 2014; Borges et al., 2018; } \\
\text { Lauerwald et al., } 2015\end{array}$ & $150 \mathrm{mmol} / \mathrm{m}^{3}$ \\
\hline $\begin{array}{l}\mathrm{CO}_{2}=> \\
\text { macrophyte } \\
\text { growth }\end{array}$ & $\begin{array}{l}57-74 \% \text { increased growth } \\
\text { depending on baseline }\end{array}$ & $\begin{array}{l}\text { Madsen and Sand-Jensen, } \\
1994\end{array}$ & $\begin{array}{l}\text { Calculated based on } \mathrm{GW} \\
\text { concentration. Max. } 51 \% \\
\text { with assumed river } \mathrm{CO}_{2}= \\
150 \mathrm{mmol} / \mathrm{m}^{3}\end{array}$ \\
\hline $\begin{array}{l}\text { Groundwater } \\
\text { nutrient } \\
\text { concentration }\end{array}$ & $\begin{array}{l}0.001-0.5 \mathrm{mg} \mathrm{P} / \mathrm{L} \text {, } \\
\text { sewage plumes reaching } 5 \\
\mathrm{mg} \mathrm{P} / \mathrm{L} \\
(0.01-0.04 \mathrm{mg} \mathrm{P} / \mathrm{L}) \\
0.15-9 \mathrm{mg} \mathrm{N} / \mathrm{L} \\
(0.5-5 \mathrm{mg} \mathrm{N} / \mathrm{L}) \\
\mathrm{N} \text { is sum of } \mathrm{NO}_{3} \text { and } \mathrm{NH}_{4}\end{array}$ & $\begin{array}{l}\text { Lewandowski et al., 2015; } \\
\text { Kunkel et al., } 2004\end{array}$ & $\begin{array}{l}0.005,0.02,0.06,0.1,0.3, \\
0.8 \mathrm{mg} \mathrm{P} / \mathrm{L} \\
0.055,0.22,0.66,1.1,3.3, \\
8.8 \mathrm{mg} \mathrm{N} / \mathrm{L} \text { (coupled to } \mathrm{P} \text { ) }\end{array}$ \\
\hline $\begin{array}{l}\text { Groundwater } \\
\text { seepage }\end{array}$ & $\begin{array}{l}0.05-190 \mathrm{~mm} / \mathrm{d} \text { (median } \\
\text { of measured values) }\end{array}$ & Rosenberry et al., 2015 & $\begin{array}{l}-10,-5,0 \mathrm{~mm} / \mathrm{d}(\mathrm{cQInf}<0 \\
=\text { seepage })\end{array}$ \\
\hline $\begin{array}{l}\text { Induced bank } \\
\text { filtration }\end{array}$ & $22 \mathrm{~mm} / \mathrm{d}$ & $\begin{array}{l}\text { Zippel and Hannappel, } \\
2008\end{array}$ & $\begin{array}{l}0,5,10 \mathrm{~mm} / \mathrm{d}(\mathrm{cQInf}>0= \\
\text { infiltration) }\end{array}$ \\
\hline $\begin{array}{l}\text { Nutrient loading } \\
\text { (via surface } \\
\text { water) }\end{array}$ & - & - & $\begin{array}{l}0.1-10 \mathrm{mg} \mathrm{P} / \mathrm{m}^{2} / \mathrm{d} \\
\left(0.7-70 \mathrm{mg} \mathrm{N} / \mathrm{m}^{2} / \mathrm{d}\right)\end{array}$ \\
\hline
\end{tabular}


667 Table 3. All modelled parameter combinations. cQInfPre = infiltration during initialization period of 668 simulated 50 years $($ negative values $=$ seepage into lake, positive values $=$ infiltration into

669 groundwater), $\mathrm{GW}=$ groundwater, $\mathrm{P}=$ phosphorus $(\mathrm{N}$ in groundwater is coupled and takes the value 670 of $\mathrm{P} * 11)$, cQInfPost $=$ infiltration during last simulated 50 years, results were taken from the last of 671 these 50 years.

\begin{tabular}{|c|c|c|c|c|c|}
\hline $\begin{array}{l}\text { cQInfPre } \\
(\mathrm{mm} / \mathrm{d})\end{array}$ & -10 & -5 & 0 & 5 & 10 \\
\hline Initial state & Clear, Turbid & Clear, Turbid & Clear, Turbid & Clear, Turbid & Clear, Turbid \\
\hline $\begin{array}{l}\mathrm{CO} 2 \text { in } \mathrm{GW} \\
\left(\mathrm{mmol} / \mathrm{m}^{3}\right)\end{array}$ & $\begin{array}{l}0.005,0.02,0.06 \\
0.1,0.3,0.8\end{array}$ & $\begin{array}{l}0.005,0.02,0.06, \\
0.1,0.3,0.8\end{array}$ & - & - & - \\
\hline $\begin{array}{l}P \text { in } G W \\
(N \text { is coupled }) \\
(\mathbf{m g} P / L)\end{array}$ & $\begin{array}{l}180,360,600 \\
900,1200,1500\end{array}$ & $\begin{array}{l}180,360,600 \\
900,1200,1500\end{array}$ & - & - & - \\
\hline $\begin{array}{l}\text { cQInfPost } \\
(\mathrm{mm} / \mathrm{d})\end{array}$ & $-10,-5,0,5,10$ & $-5,0,5,10$ & $0,5,10$ & 5,10 & 10 \\
\hline Combinations & 330 & 288 & 6 & 4 & 2 \\
\hline
\end{tabular}

672

673 
674 Figure 1. Groundwater level (dotted line) and seepage (blue arrow) into a surface water body without

675 bank filtration (A). A production well installed to induce bank filtration resulting in a lower

676 groundwater level and interrupted groundwater seepage into the surface water body (B).

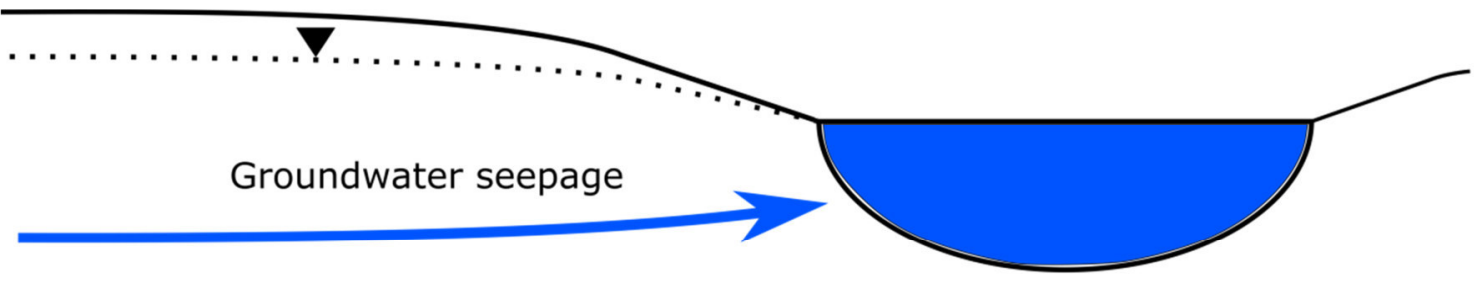

A

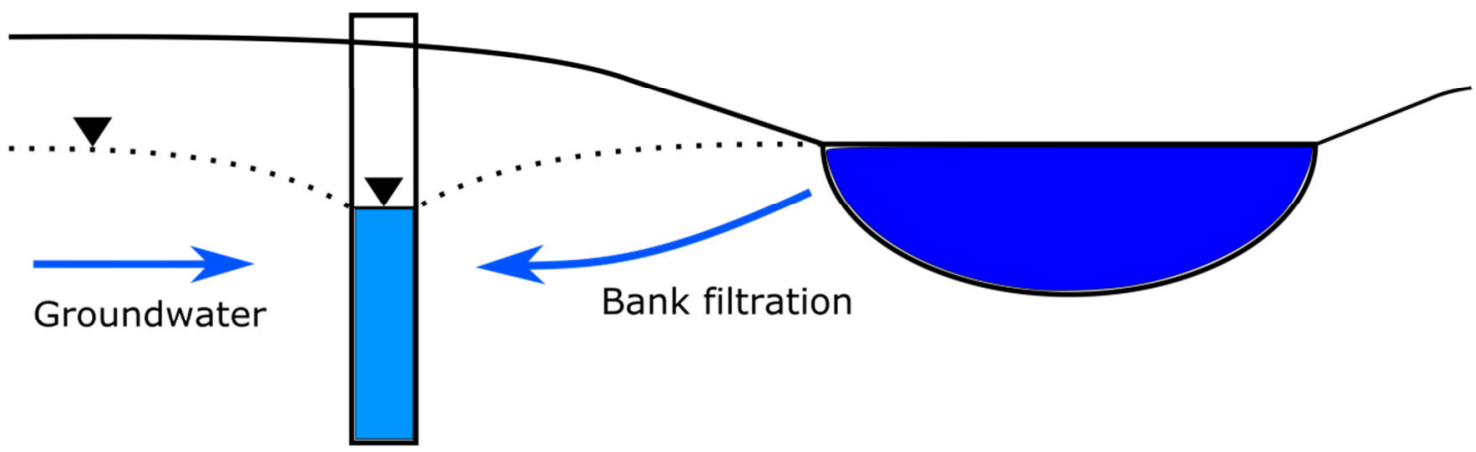

677

B 
678 Figure 2. Lake surface elevation and groundwater $(\mathrm{GW})$ level drawdown (grey area and purple GW

679 isolines) around Lake Wannsee (A), Lake Tegel (B) and Lake Müggelsee (C) in Berlin (Germany)

680 close to series of groundwater abstraction wells (red lines) installed for drinking water production by

681 induced bank filtration. Groundwater abstraction rates and Secchi depth in Lake Müggelsee between

6821960 and 2014 (D, data on GW abstraction rates from Berliner Wasserbetriebe).

683
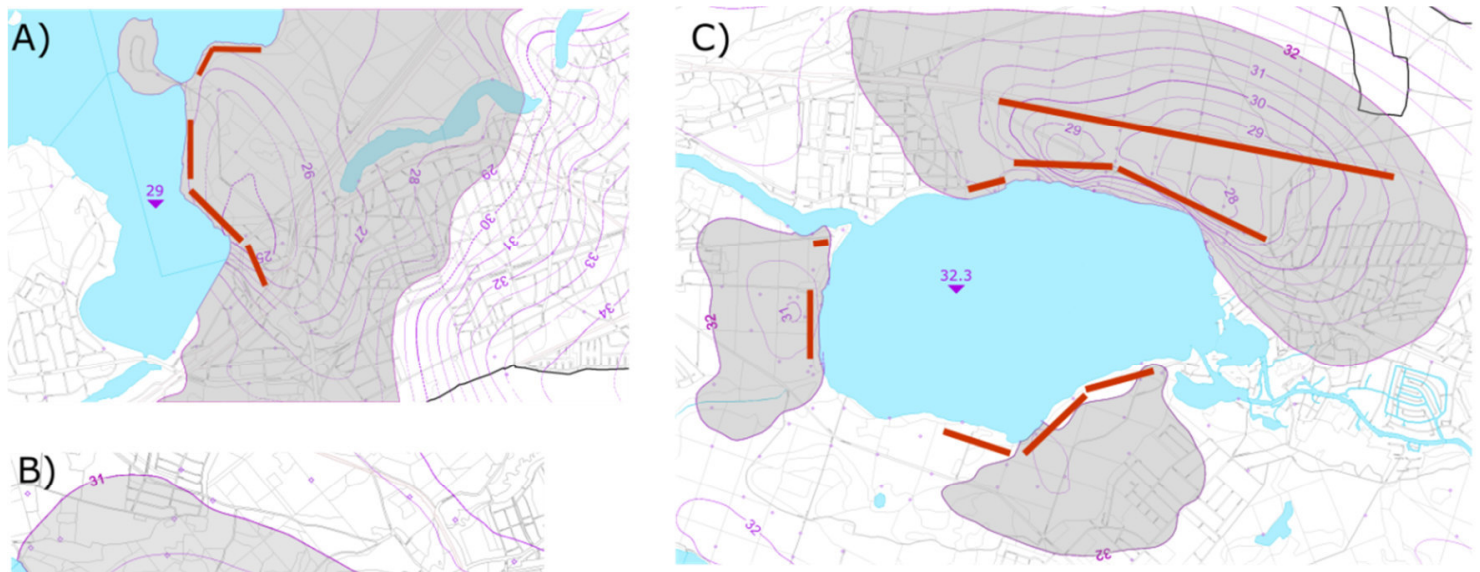

B)
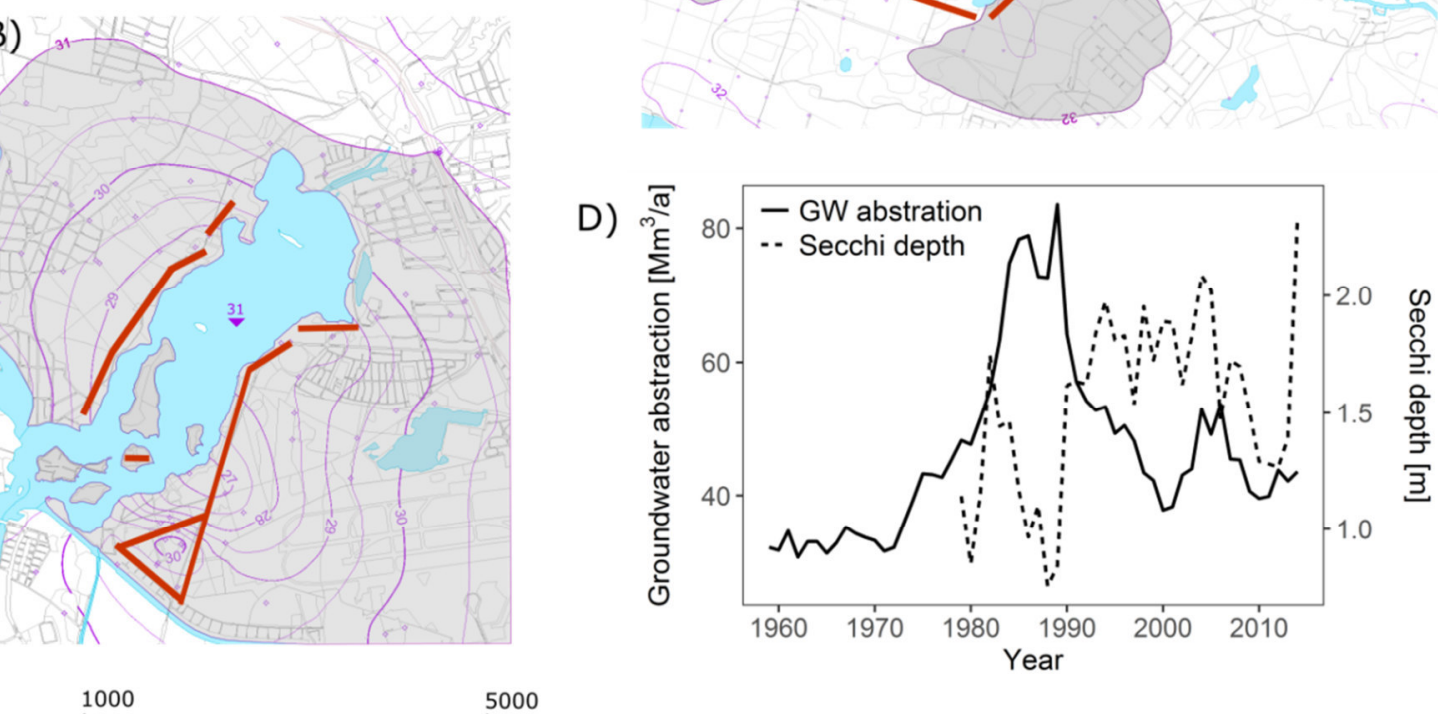

\section{Well gallery}


Figure 3. Expected effects of induced bank filtration on shallow lake ecosystems via interrupted

687 seepage input of groundwater $\mathrm{CO}_{2}$ (1), nutrients (2) and increased summer water temperature (WT, 3),

688 as well as increased sedimentation rate (4) and increased sediment oxygen penetration depth (5) due to

689 induced infiltration (+/- indicate increase/reduction, multiplication of signs reveals final effect).

690

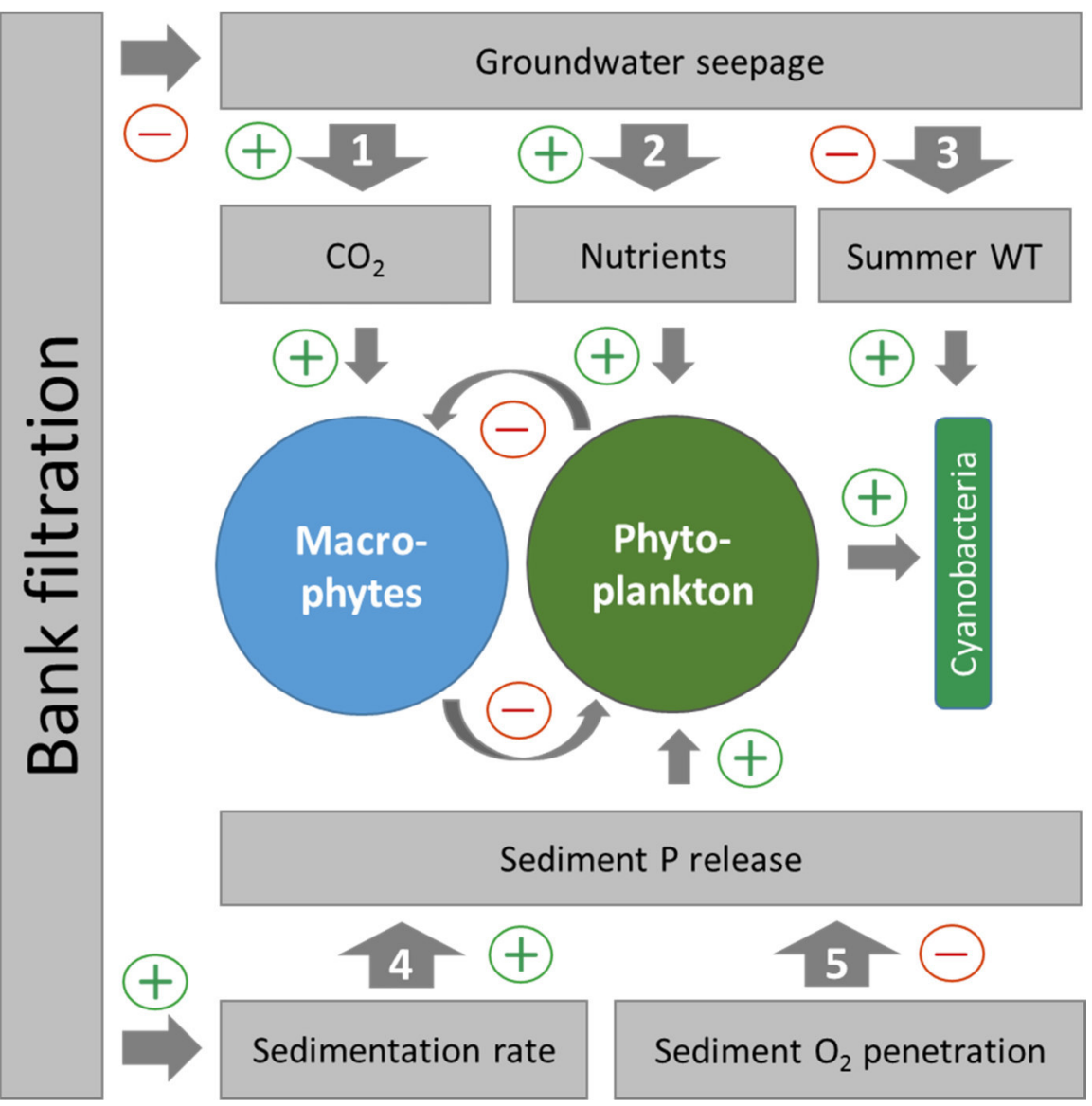


Figure 4. Summer average chlorophyll $a$ (total (panel A) and cyanobacteria (panel B)) concentrations

693

694

695

696

697

698

699

700 depending on nutrient loading (here displayed as phosphorus $(\mathrm{P})$ ) in a standard shallow lake with groundwater seepage (GW seepage) or induced bank filtration using average parameter values: cQInf $(\mathrm{GW}$ seepage $)=-5 \mathrm{~mm} / \mathrm{d}, \mathrm{cQInf}($ bank filtration $)=5 \mathrm{~mm} / \mathrm{d}$, cPO4Ground (groundwater $\mathrm{PO}_{4}$ concentration) $=0.02 \mathrm{mg} \mathrm{P} / \mathrm{L}, \mathrm{cNH} 4 \mathrm{Ground}\left(\right.$ groundwater $\mathrm{NH}_{4}$ concentration) $=0.2 \mathrm{mg} \mathrm{N} / \mathrm{L}$, $\mathrm{cNO} 3$ Ground (groundwater $\mathrm{NO}_{3}$ concentration) $=0.02 \mathrm{mg} \mathrm{N} / \mathrm{L}$ and $\mathrm{cCO} 2 \mathrm{Ground}$ (groundwater $\mathrm{CO}_{2}$ concentration $)=900 \mathrm{mmol} / \mathrm{m}^{3}$. Shaded areas indicate zones of hysteresis, small black arrows indicate the direction of the hysteresis, and grey arrows indicate the impact of induced bank filtration on critical nutrient loads.

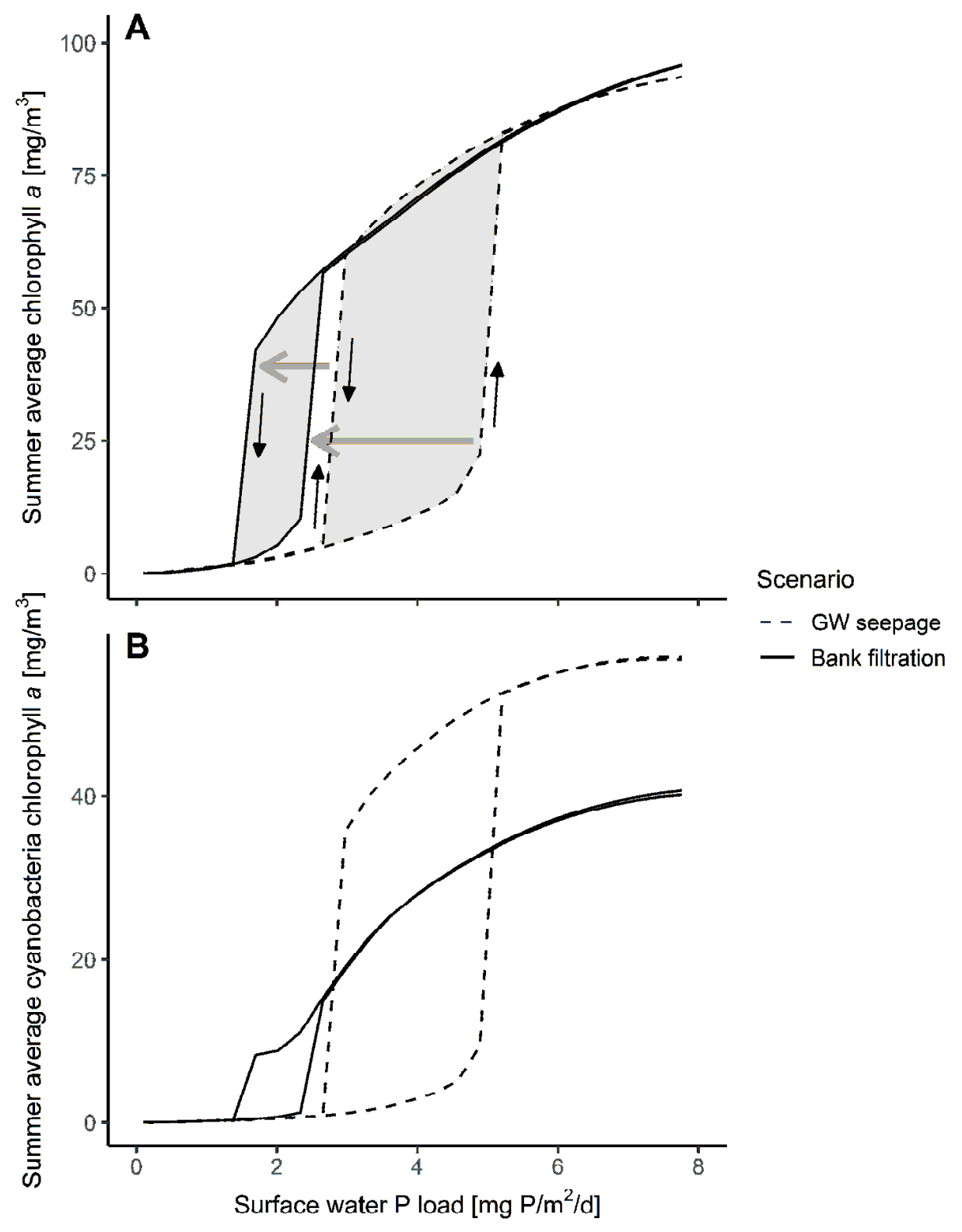


Figure 5. Chlorophyll $a$ concentrations in the last year of a 50 year model run in a standard temperate shallow lake starting with clear-water conditions with groundwater seepage (GW seepage) or induced bank filtration using average parameter values: $\mathrm{cQInf}(\mathrm{GW}$ seepage $)=-5 \mathrm{~mm} / \mathrm{d}$, cQInf (bank

705 filtration $)=5 \mathrm{~mm} / \mathrm{d}, \mathrm{cPO} 4$ Ground $\left(\right.$ groundwater $\mathrm{PO}_{4}$ concentration $)=0.02 \mathrm{mg} \mathrm{P} / \mathrm{L}, \mathrm{cNH} 4 \mathrm{Ground}$ (groundwater $\mathrm{NH}_{4}$ concentration) $=0.2 \mathrm{mg} \mathrm{N} / \mathrm{L}, \mathrm{cNO} 3$ Ground (groundwater $\mathrm{NO}_{3}$ concentration) $=$ $0.02 \mathrm{mg} \mathrm{N} / \mathrm{L}$ and cCO2Ground (groundwater $\mathrm{CO}_{2}$ concentration) $=900 \mathrm{mmol} / \mathrm{m}^{3}$. Nutrient loading via surface water: cPLoad $(\mathrm{P}$ load $)=3 \mathrm{mg} \mathrm{P} / \mathrm{m}^{2} / \mathrm{d}$, cNLoad $(\mathrm{N}$ Load $)=30 \mathrm{mg} \mathrm{N} / \mathrm{m}^{2} / \mathrm{d}$.

709

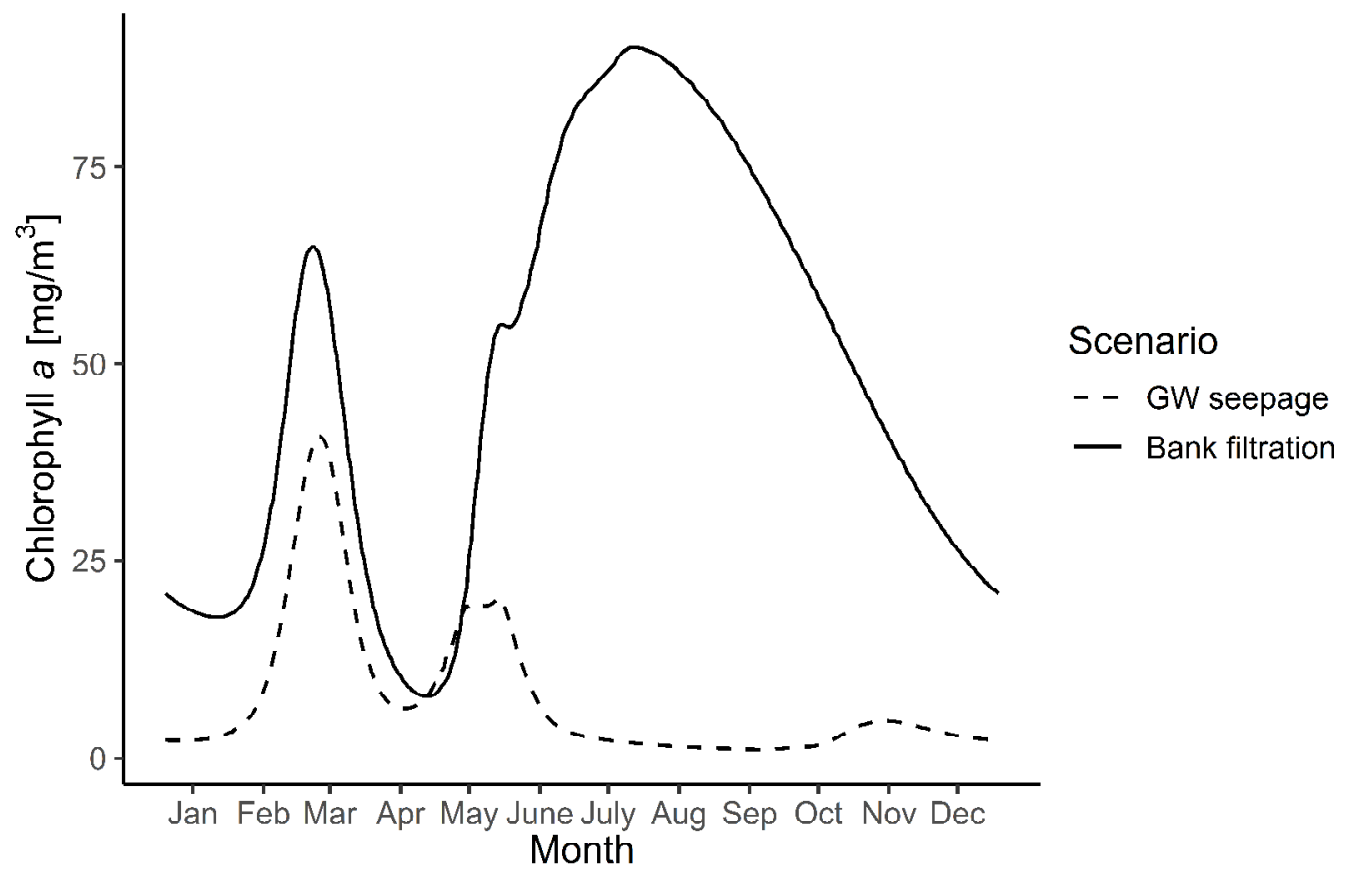


711 Figure 6. Critical phosphorus (P) loading in shallow model lake ecosystems initially in a clear-water

712 (left) and turbid (right) state running for 50 years with groundwater seepage (groundwater flow $=-10$ )

713 and a subsequent 50 years with groundwater seepage (groundwater flow $=-10,-5 \mathrm{~mm} / \mathrm{d}$ ), neither

714 seepage nor infiltration (groundwater flow $=0 \mathrm{~mm} / \mathrm{d}$ ) or induced bank filtration (groundwater flow 5 ,

$71510 \mathrm{~mm} / \mathrm{d}$, grey background). The spread in critical P loads is due to differences in groundwater $\mathrm{CO}_{2}$

716 and nutrient concentrations (details on different scenarios shown in Fig. A.5).

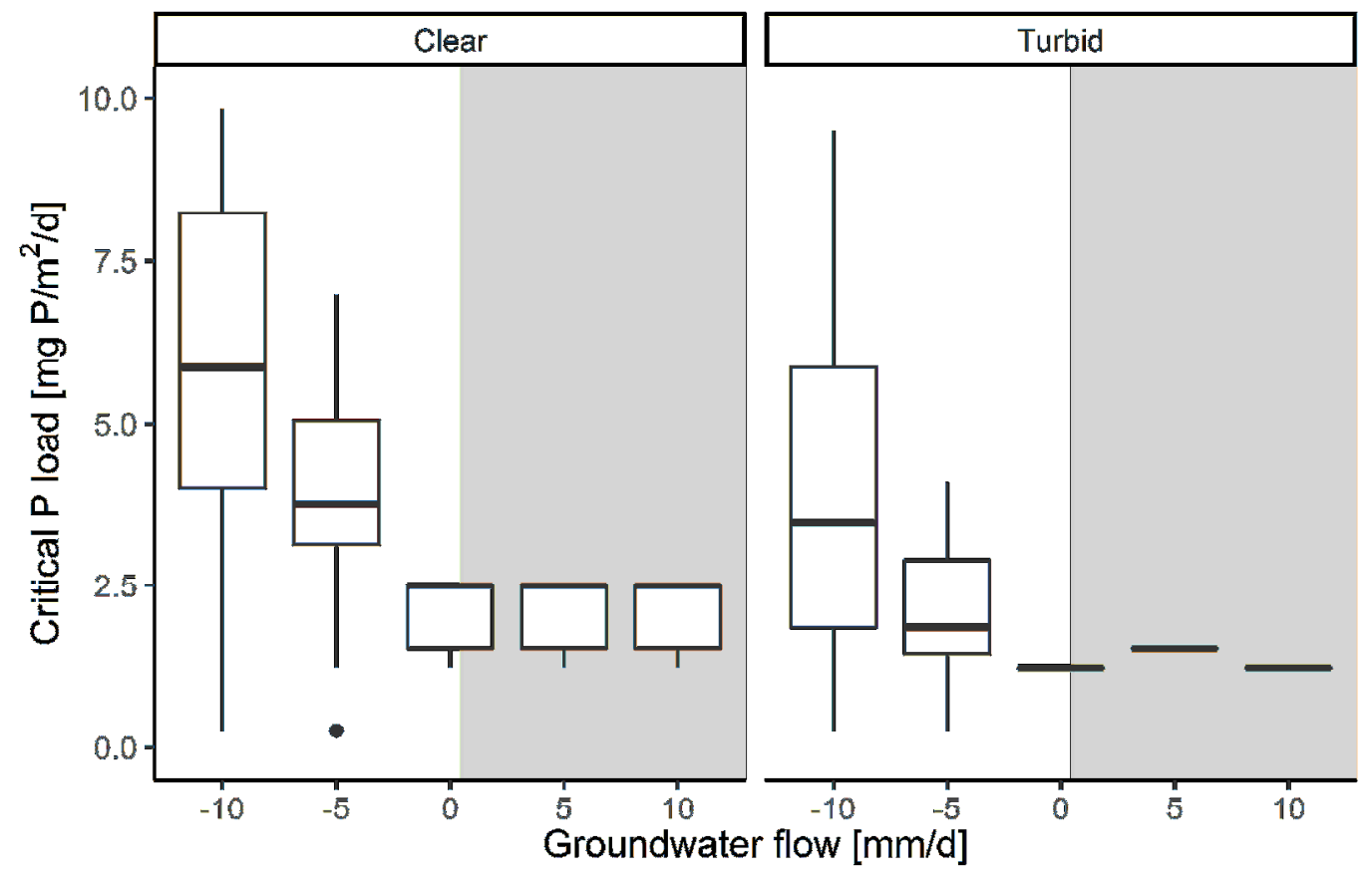


718 Figure 7. Chlorophyll $a$ concentrations in a model shallow lake depending on phosphorus (P; low: $7190.005 \mathrm{mg} / \mathrm{L}$, high: $0.8 \mathrm{mg} / \mathrm{L}$ ) and $\mathrm{CO}_{2}$ (low: $180 \mathrm{mmol} / \mathrm{m}^{3}$, high: $1500 \mathrm{mmol} / \mathrm{m}^{3}$ ) concentrations in the 720 groundwater in scenarios with groundwater seepage (cQInf $=-5 \mathrm{~mm} / \mathrm{d}$ ) and induced bank filtration $721(\mathrm{cQInf}=5 \mathrm{~mm} / \mathrm{d})$ after a run-in period of 50 years with groundwater seepage $(\mathrm{cQInf}=-5 \mathrm{~mm} / \mathrm{d})$.

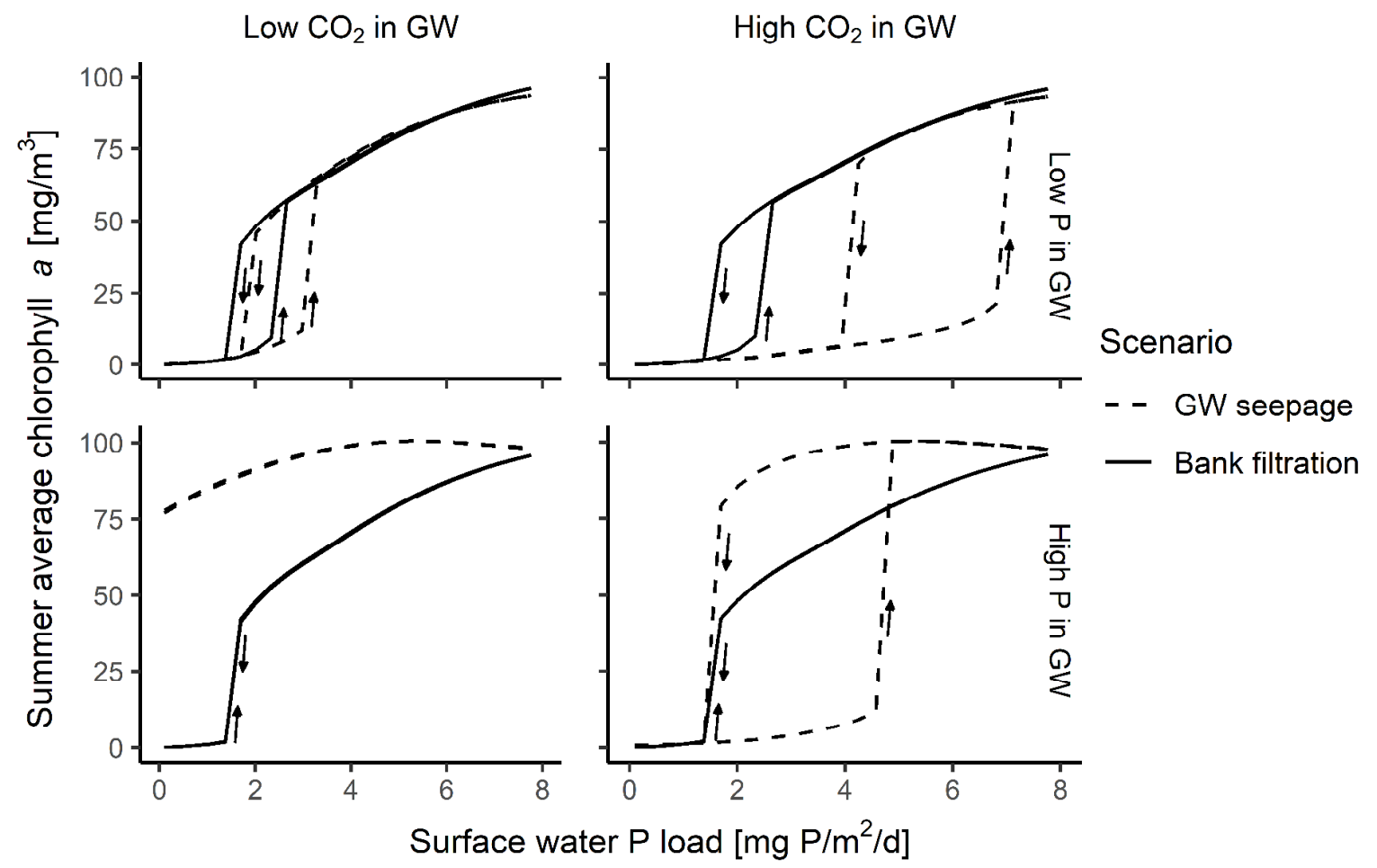


Figure 8. Chlorophyll $a$ concentrations in a modelled shallow lake depending on fetch (low: $100 \mathrm{~m}$,

725

726

727

728

729

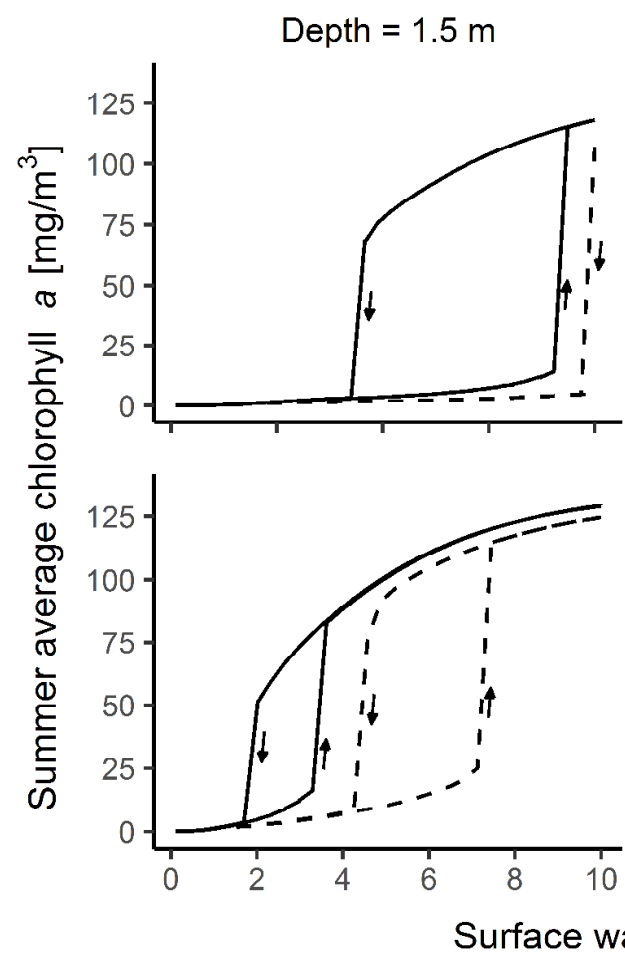
$\mathrm{N} / \mathrm{L}, \mathrm{cNO} 3$ Ground $=0.02 \mathrm{mg} \mathrm{N} / \mathrm{L}$.
Depth $=2.0 \mathrm{~m}$
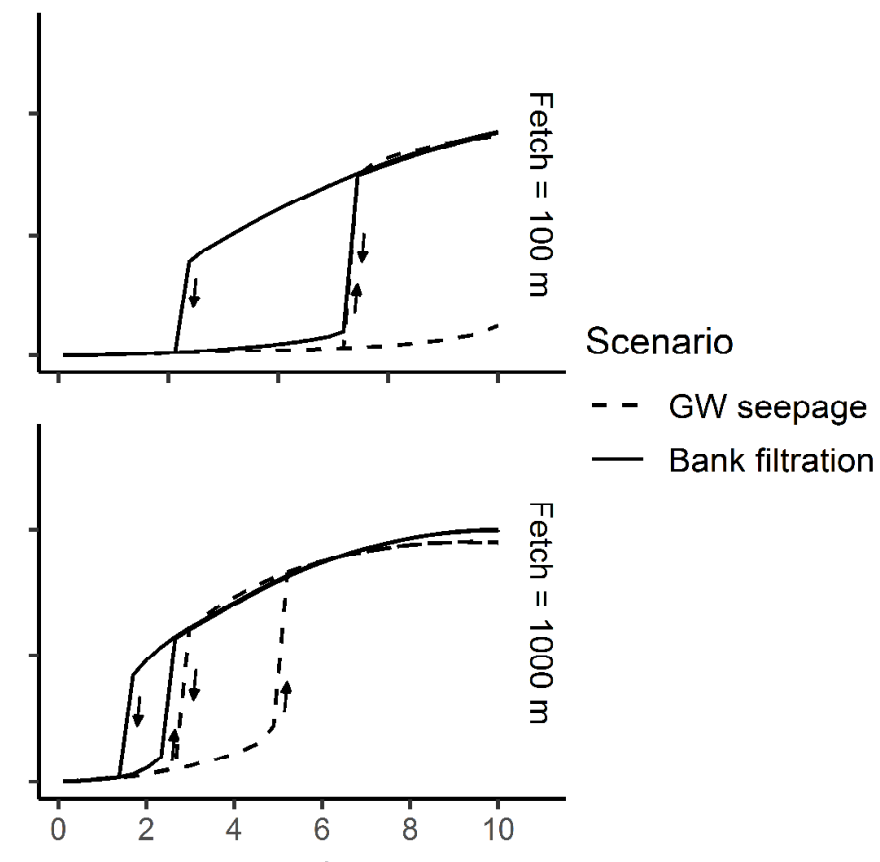

\begin{tabular}{l}
70 \\
0 \\
0 \\
3 \\
11 \\
$\overrightarrow{8}$ \\
8 \\
3 \\
\hline
\end{tabular} high, $1000 \mathrm{~m}$ ) and water depth (low: $1.5 \mathrm{~m}$, high: $2 \mathrm{~m}$ ) in scenarios with natural groundwater inflow and induced bank filtration on shallow lake ecosystems. Scenarios with GW seepage (cQInf $=-5$ $\mathrm{mm} / \mathrm{d})$, Bank filtration $(\mathrm{cQInf}=5 \mathrm{~mm} / \mathrm{d}), \mathrm{CO}_{2}$ concentration in groundwater $=\mathrm{cCO} 2 \mathrm{Ground}=900$ $\mathrm{mmol} / \mathrm{m}^{3}, \mathrm{PO}_{4}$ concentration in groundwater $=\mathrm{cPO} 4$ Ground $=0.02 \mathrm{mg} / \mathrm{L}, \mathrm{cNH} 4 \mathrm{Ground}=0.2 \mathrm{mg}$ Surface water $\mathrm{P}$ load $\left[\mathrm{mg} \mathrm{P} / \mathrm{m}^{2} / \mathrm{d}\right]$ 
Table A.1. Characteristics of the three phytoplankton subgroups in PCLake.

\begin{tabular}{ll}
\hline Systematic group & Characteristics \\
\hline Green algae & $\begin{array}{l}\text { High growth rate. High loss rate through settling and zooplankton grazing. } \\
\text { Not inhibited by high light intensities. }\end{array}$ \\
Diatoms & $\begin{array}{l}\text { High growth rate. High loss rate through settling and zooplankton grazing. } \\
\text { May be limited by silica. Low temperature optimum. }\end{array}$ \\
Cyanobacteria & $\begin{array}{l}\text { High light affinity. High phosphorus uptake rate. Strong sensitivity to } \\
\text { temperature. Low maximum growth rate. }\end{array}$ \\
\hline
\end{tabular}


Figure A.1. PCLake model structure (adapted from Janse, 2005). Adaptations made in connection to groundwater flow and by adding $\mathrm{CO}_{2}$, highlighted in red.

\section{PCLake Model Structure}

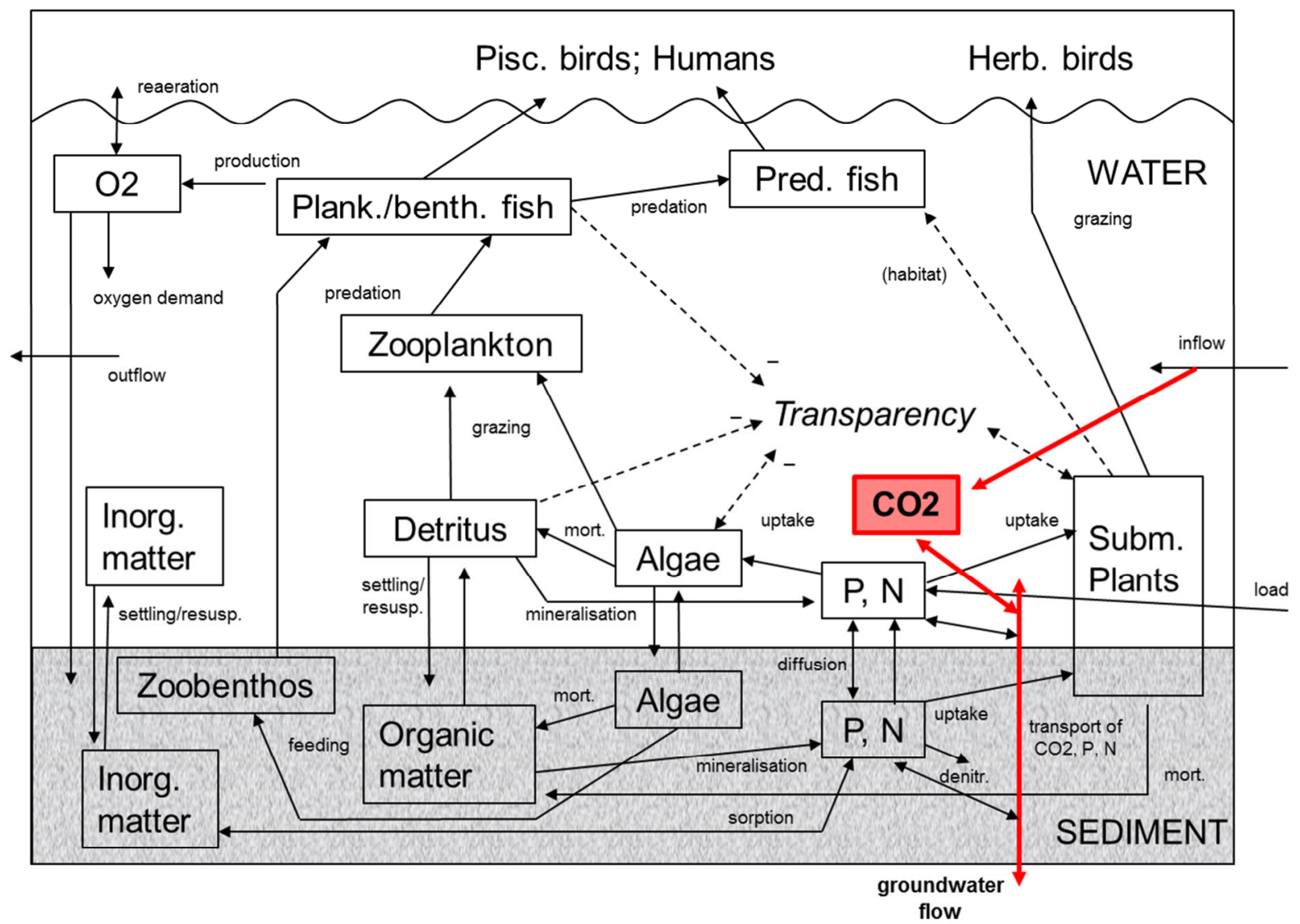


Figure A.2. Seasonal lake temperature variation. The "GW seepage" scenario represents a lake where groundwater seepage increases the temperature in winter and decreases it in summer compared to the "Bank filtration" scenario, where no groundwater seepage takes place.

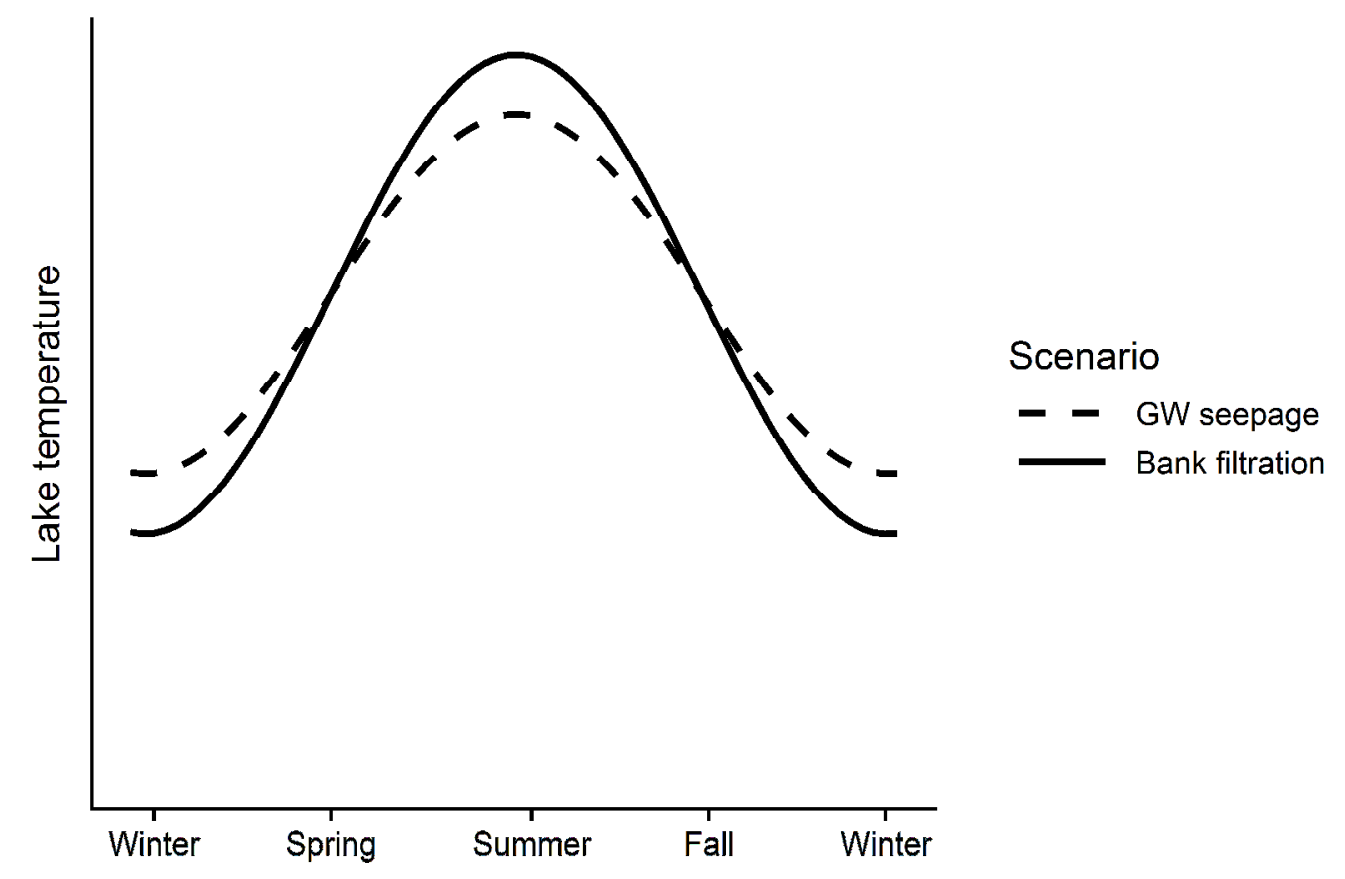


Figure A.3. Relationship between $\mathrm{CO}_{2}$ concentration in the lake water and the maximum growth rate of macrophytes (B), between infiltration/seepage and lake temperature variation (A), between infiltration/seepage and added settling velocity $(\mathrm{C})$ and between infiltration/seepage and increased oxygen penetration depth (D).

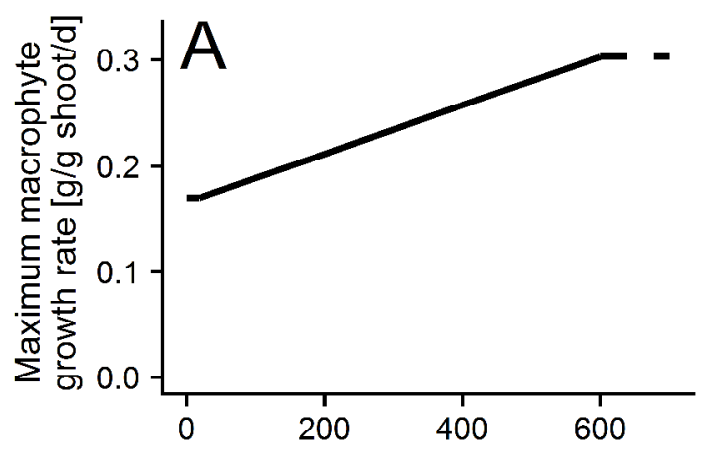

$\mathrm{CO}_{2}$ concentration in water $\left[\mathrm{mmol} / \mathrm{m}^{3}\right]$

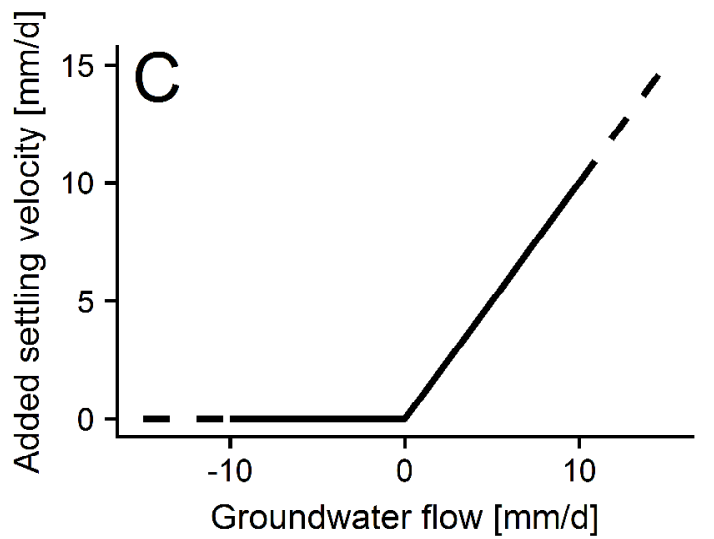

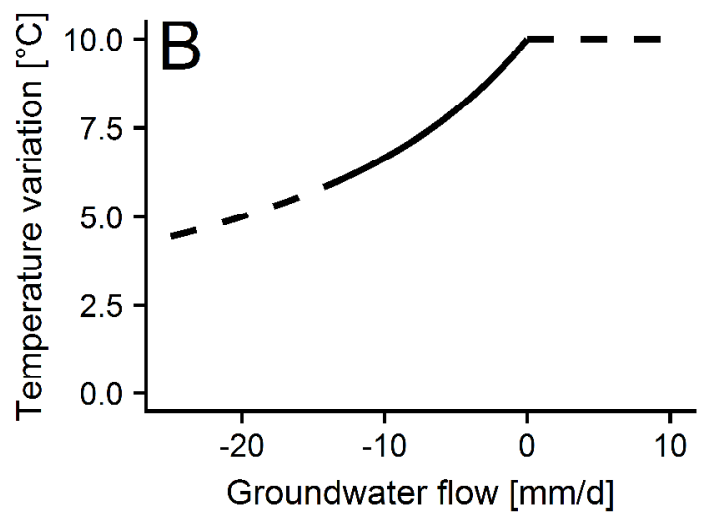

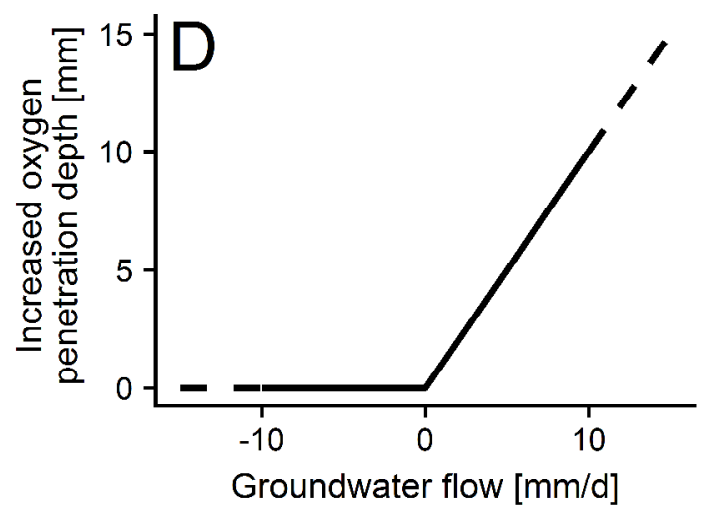


Figure A.4. A typical model scenario consists of two parts. The first part is an initialization period of 50 years where a stable state is reached. The second part consists of two versions: one where all the settings from the first part are kept constant, and a second where induced bank filtration is simulated by changing the groundwater flow term. In the end an output variable (typically summer average chlorophyll $a$ ) is used to examine the difference between groundwater seepage and induced bank filtration.

Initialisation: 50 years

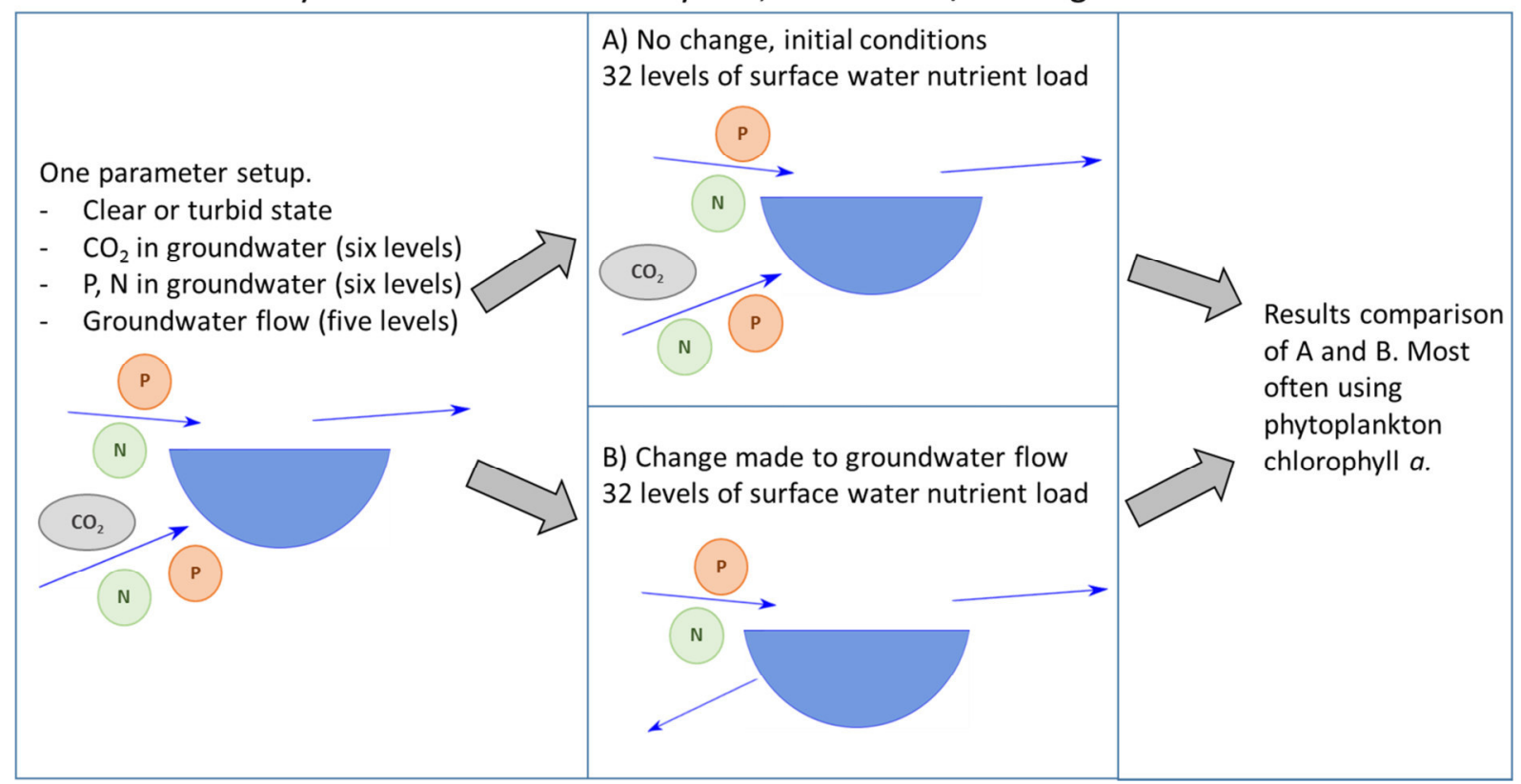


Figure A.5. Critical nutrient loading (here shown as phosphorus $(\mathrm{P})$ values) in shallow model lake ecosystems initially in a clear-water (left) and turbid (right) state running for 50 years with groundwater seepage (groundwater flow $=-10$ ) and a subsequent 50 years with groundwater seepage (groundwater flow $=-10,-5 \mathrm{~mm} / \mathrm{d}$ ), neither seepage nor infiltration (groundwater flow $=0 \mathrm{~mm} / \mathrm{d}$ ) or induced bank filtration (groundwater flow $=5,10 \mathrm{~mm} / \mathrm{d}$, grey background). The symbols and colours indicate different combinations of $\mathrm{CO}_{2}$ and $\mathrm{P}$ concentrations in groundwater (box plots in Fig. 6).

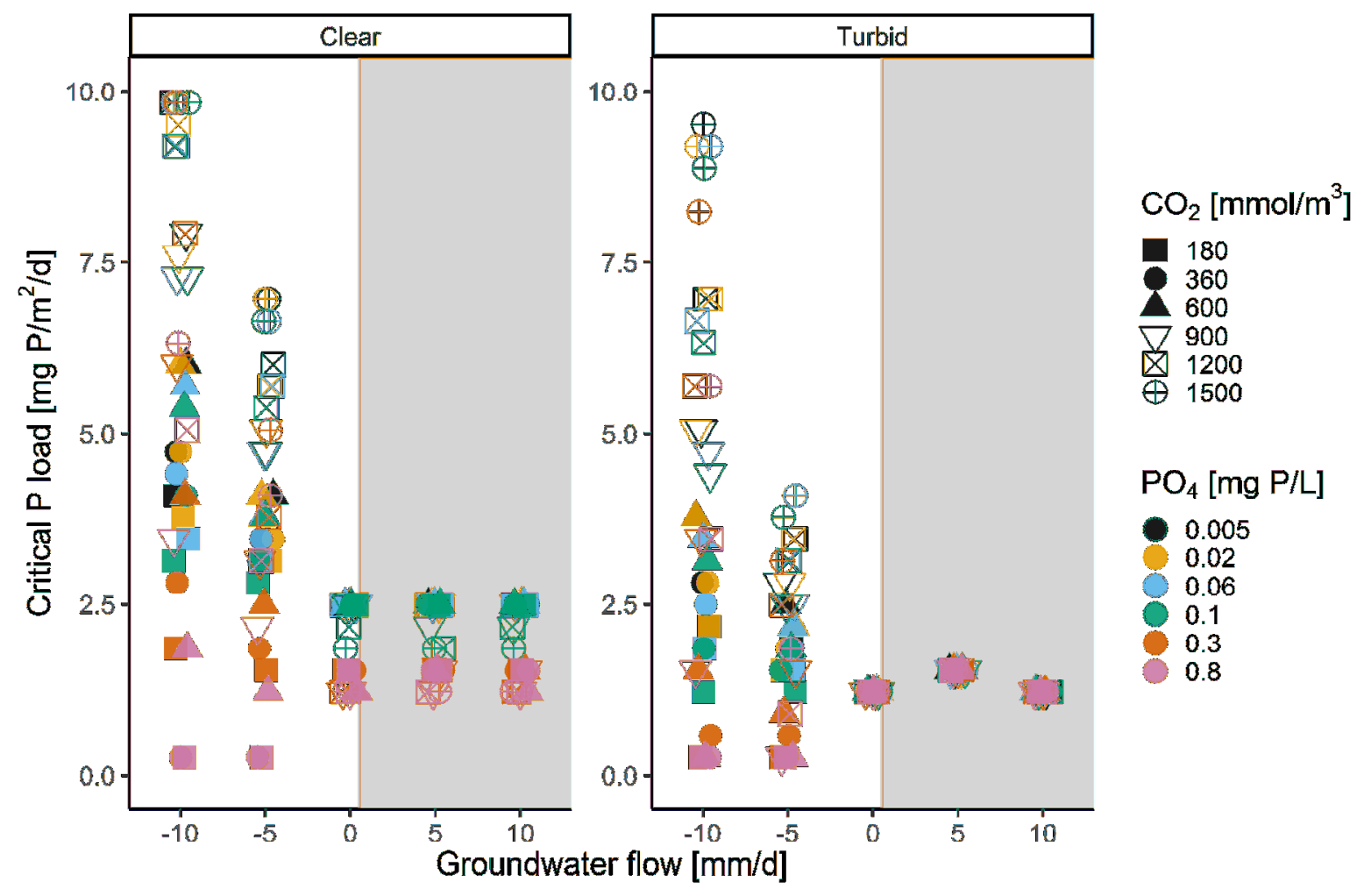


Figure A.6. Effects of induced bank filtration (IBF) on critical nutrient loads from clear to turbid state (A) and from turbid to clear state (B). IBF lowers critical nutrient loads (green), difference between groundwater seepage and IBF is small (grey) and IBF increases critical nutrient loads (blue). IBF scenario: $\mathrm{cQInf}=5 \mathrm{~mm} / \mathrm{d}$, groundwater seepage: $\mathrm{cQInf}=-5 \mathrm{~mm} / \mathrm{d}$.
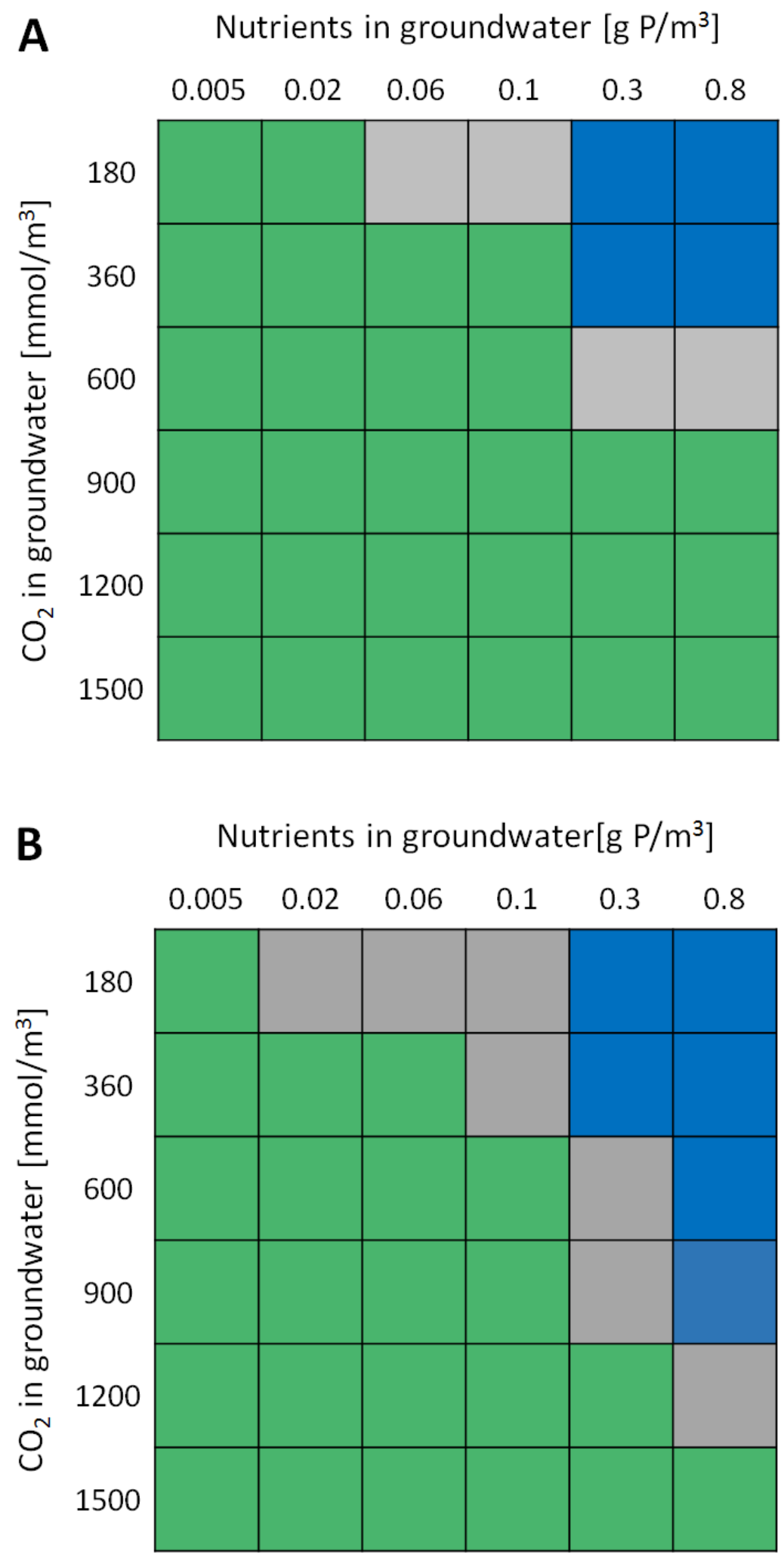
Figure A.7. Effects of changes in temperature variation (TempVar). A higher temperature variation lowers critical nutrient loads (A), increases cyanobacteria chlorophyll $a(\mathrm{~B})$ and promotes phytoplankton dominance over macrophyte vegetation at lower nutrient loads (C).

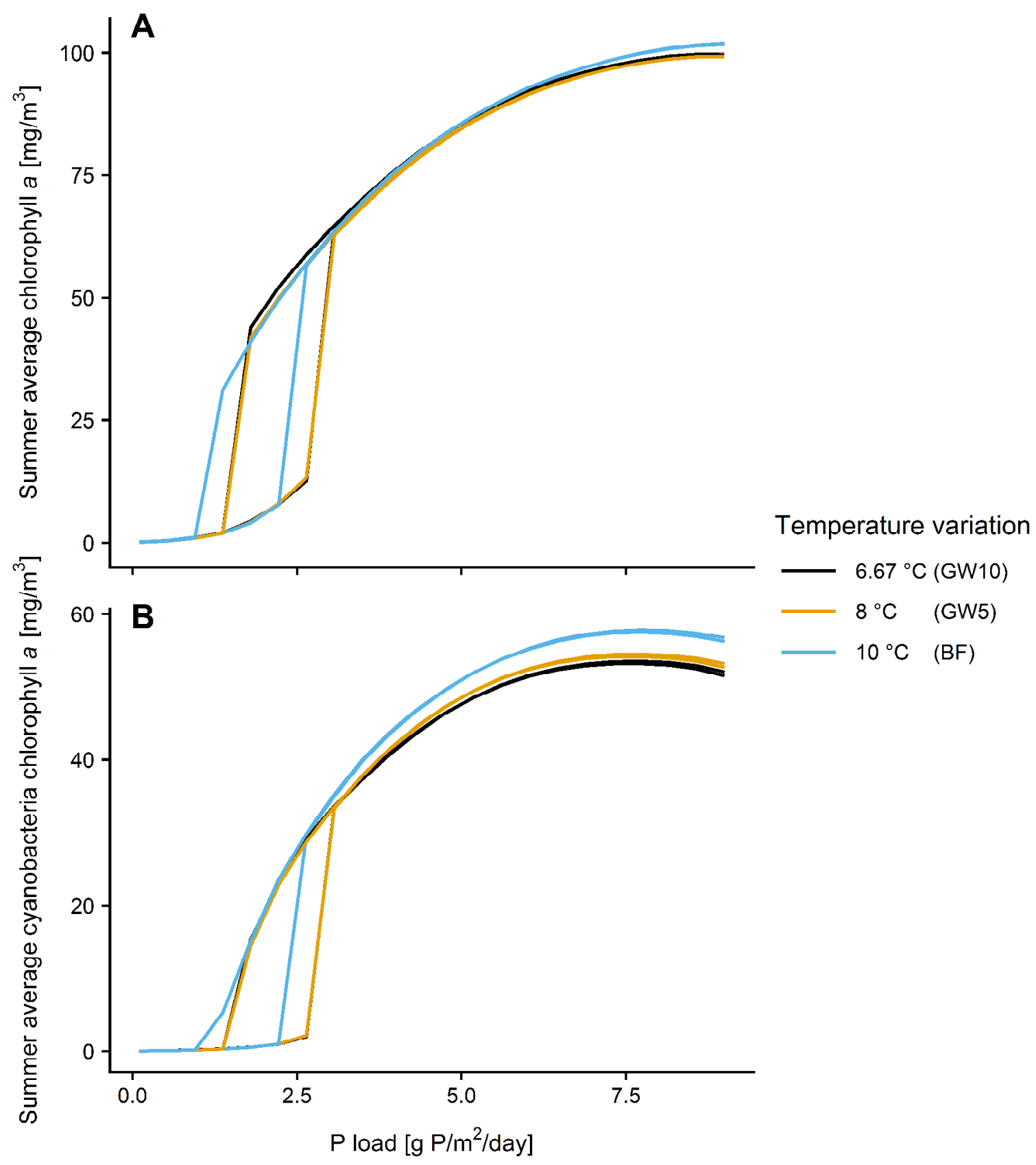




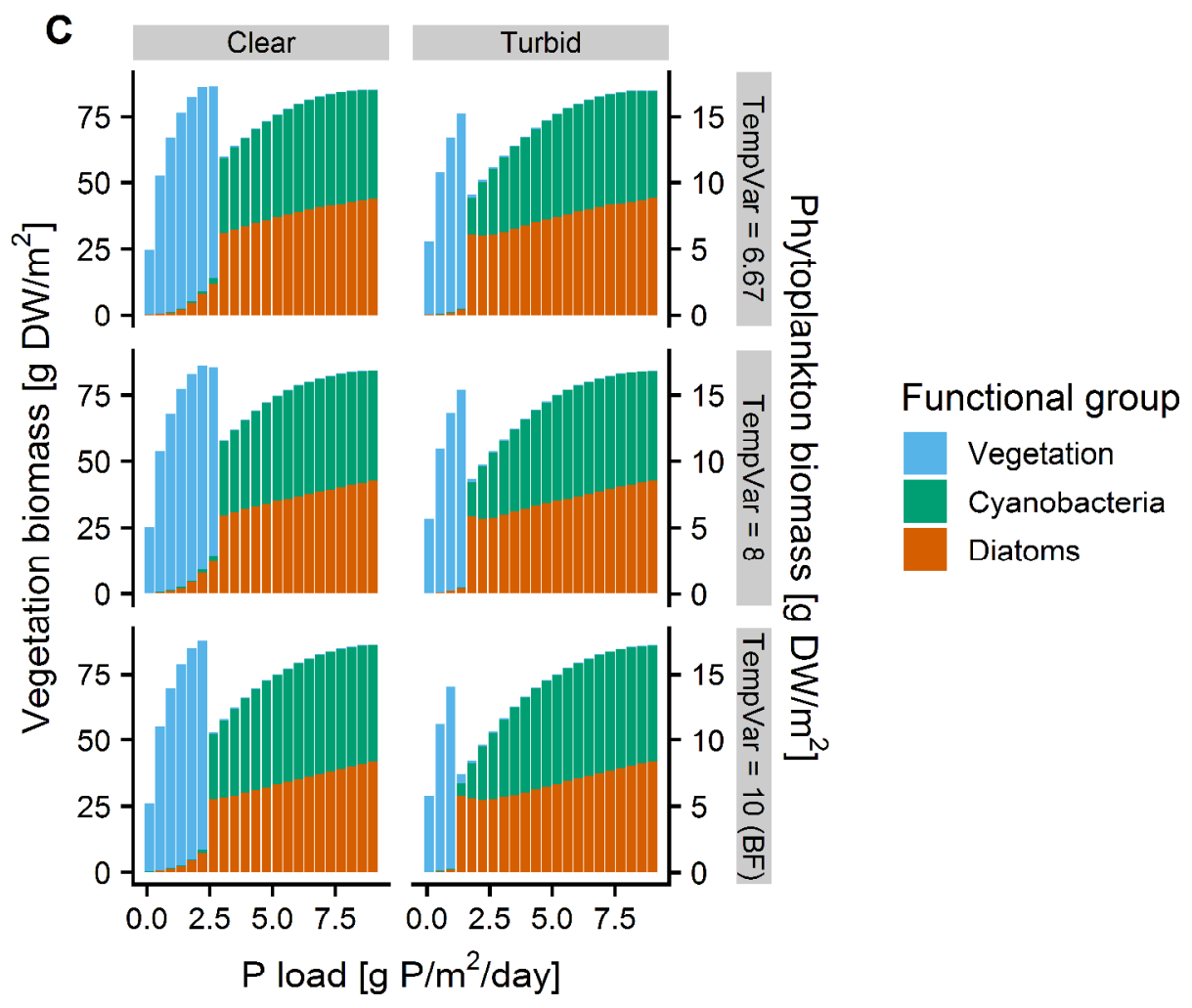


Figure A.8. Effects of changes in groundwater $\mathrm{CO}_{2}(\mathrm{~A})$ and nutrient (B) concentration on phytoplankton community and macrophyte vegetation.

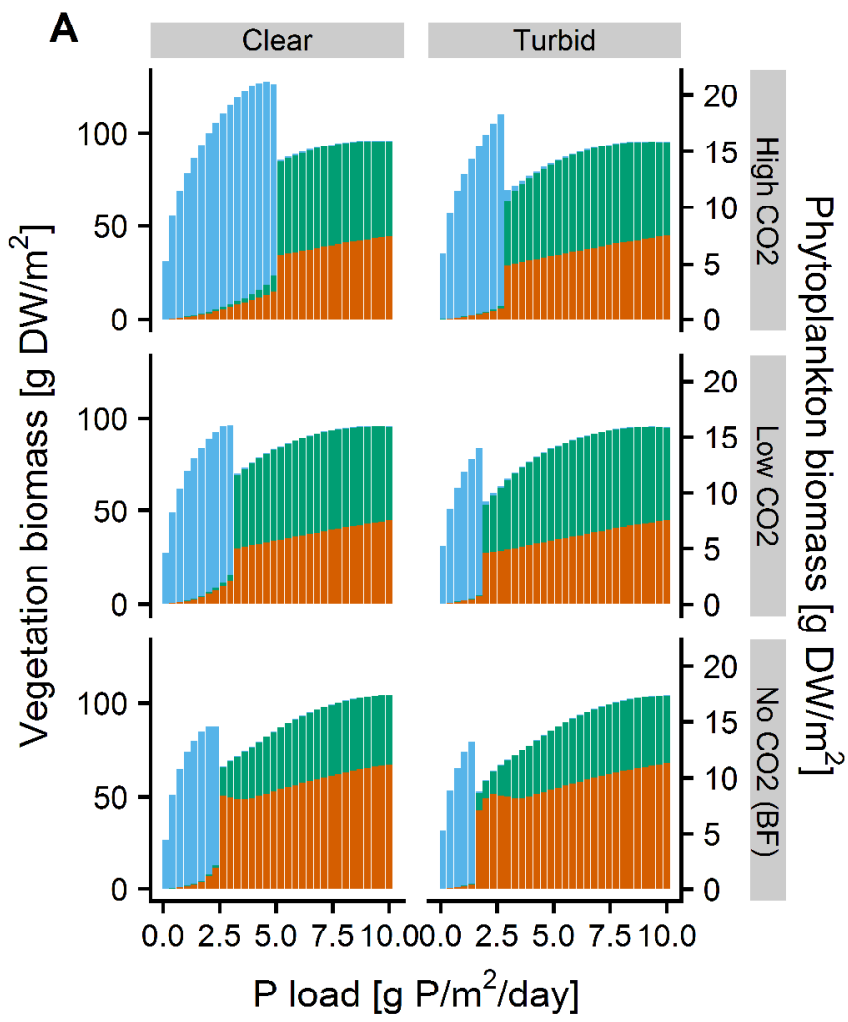

Functional group
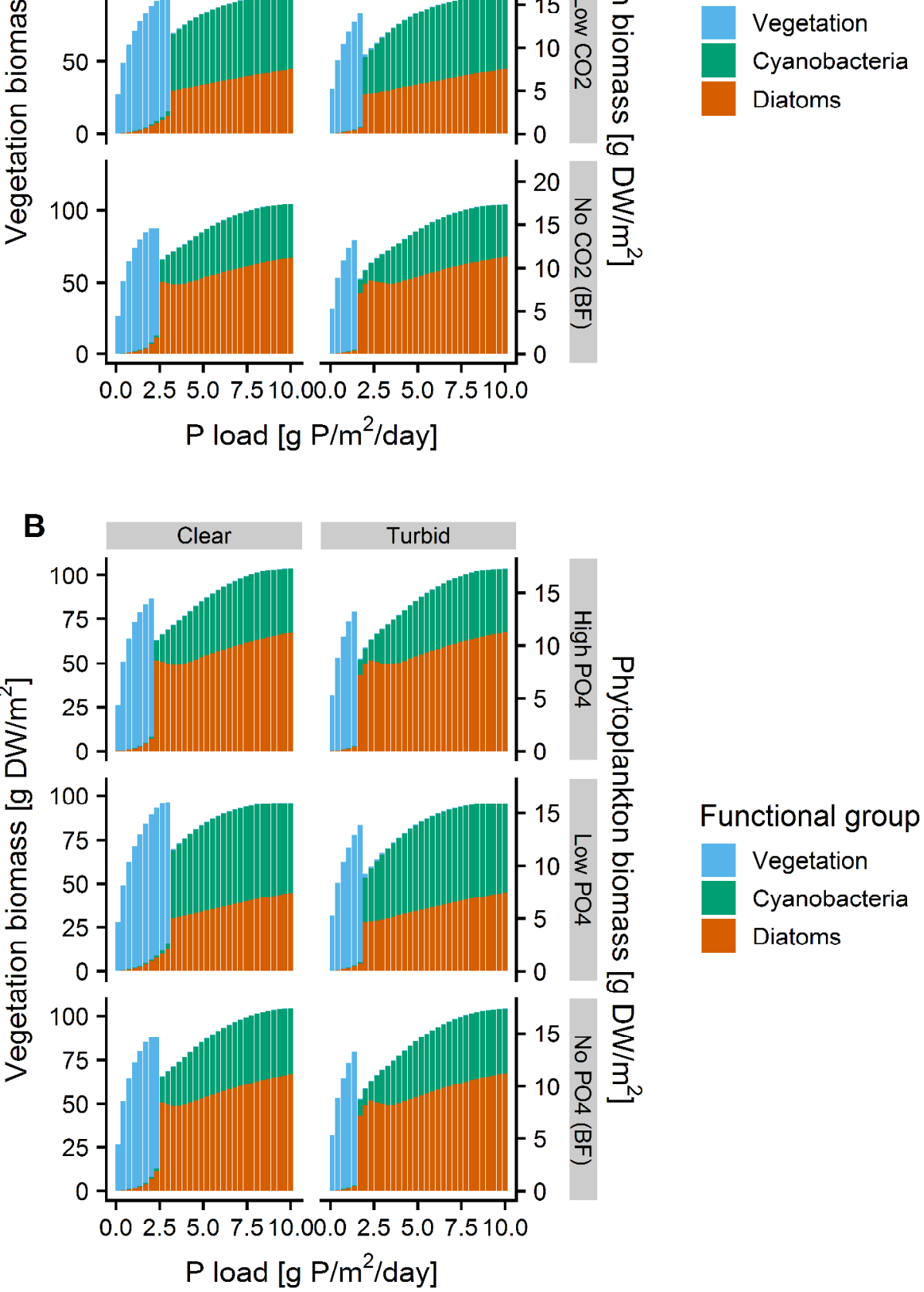

Functional group

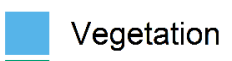

Cyanobacteria

Diatoms 
Figure A.9. Phytoplankton increases turbidity, lowers Secchi depth and shades macrophyte vegetation.

The biomass of phytoplankton has been multiplied by five to better illustrate the shift between states.

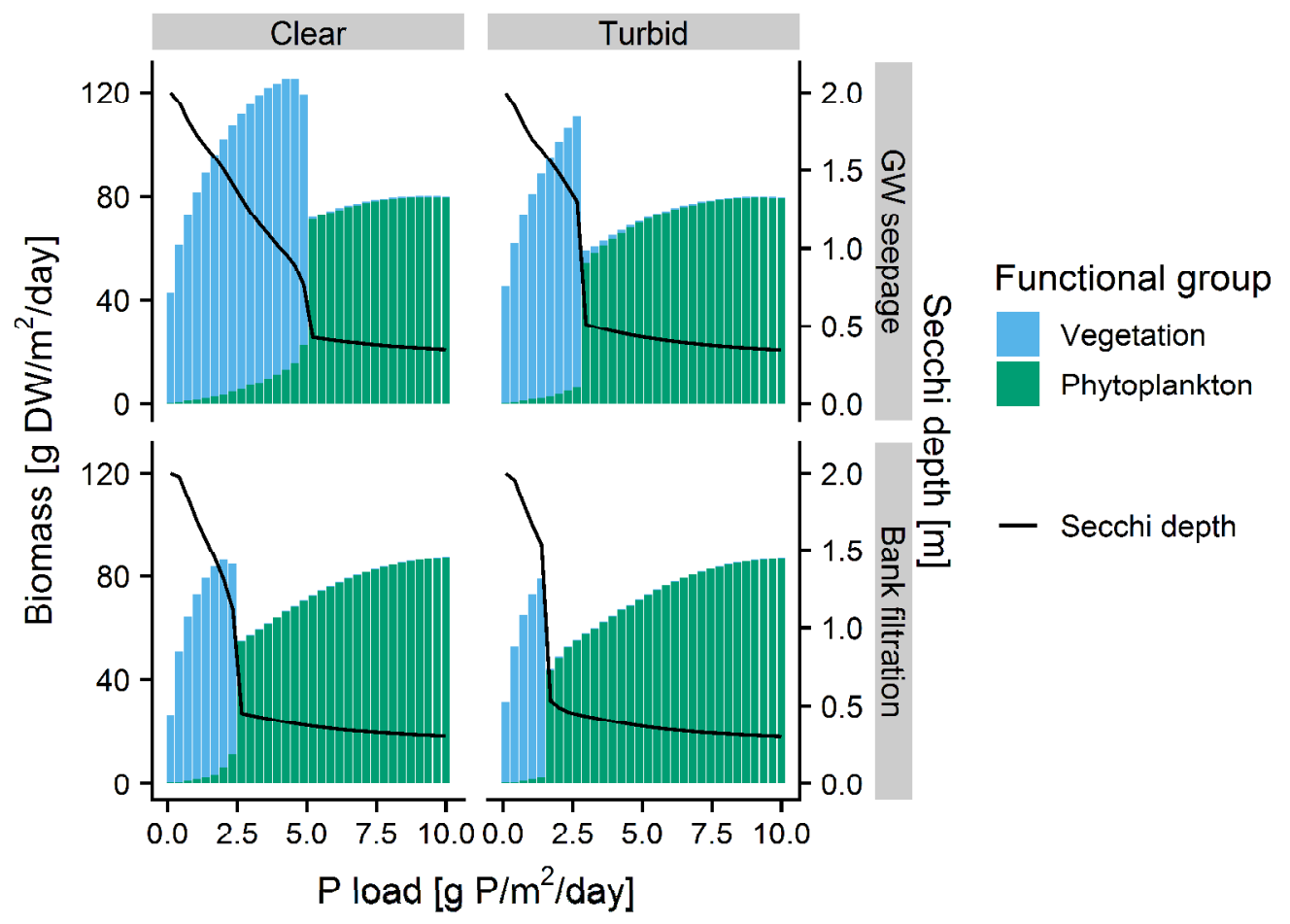


Figure A.10. Sediment oxygen penetration depth under initially clear-water (left) and turbid (right) conditions in a model shallow lake running for 50 years with groundwater seepage (groundwater flow $=-10)$ and a subsequent 50 years with groundwater seepage $(-10,-5 \mathrm{~mm} / \mathrm{d})$, neither seepage nor infiltration (groundwater flow $=0 \mathrm{~mm} / \mathrm{d}$ ) or induced bank filtration $(5,10 \mathrm{~mm} / \mathrm{d}$, grey background). Different dots indicate different combinations of $\mathrm{CO}_{2}$ and $\mathrm{P}$ concentrations in groundwater.

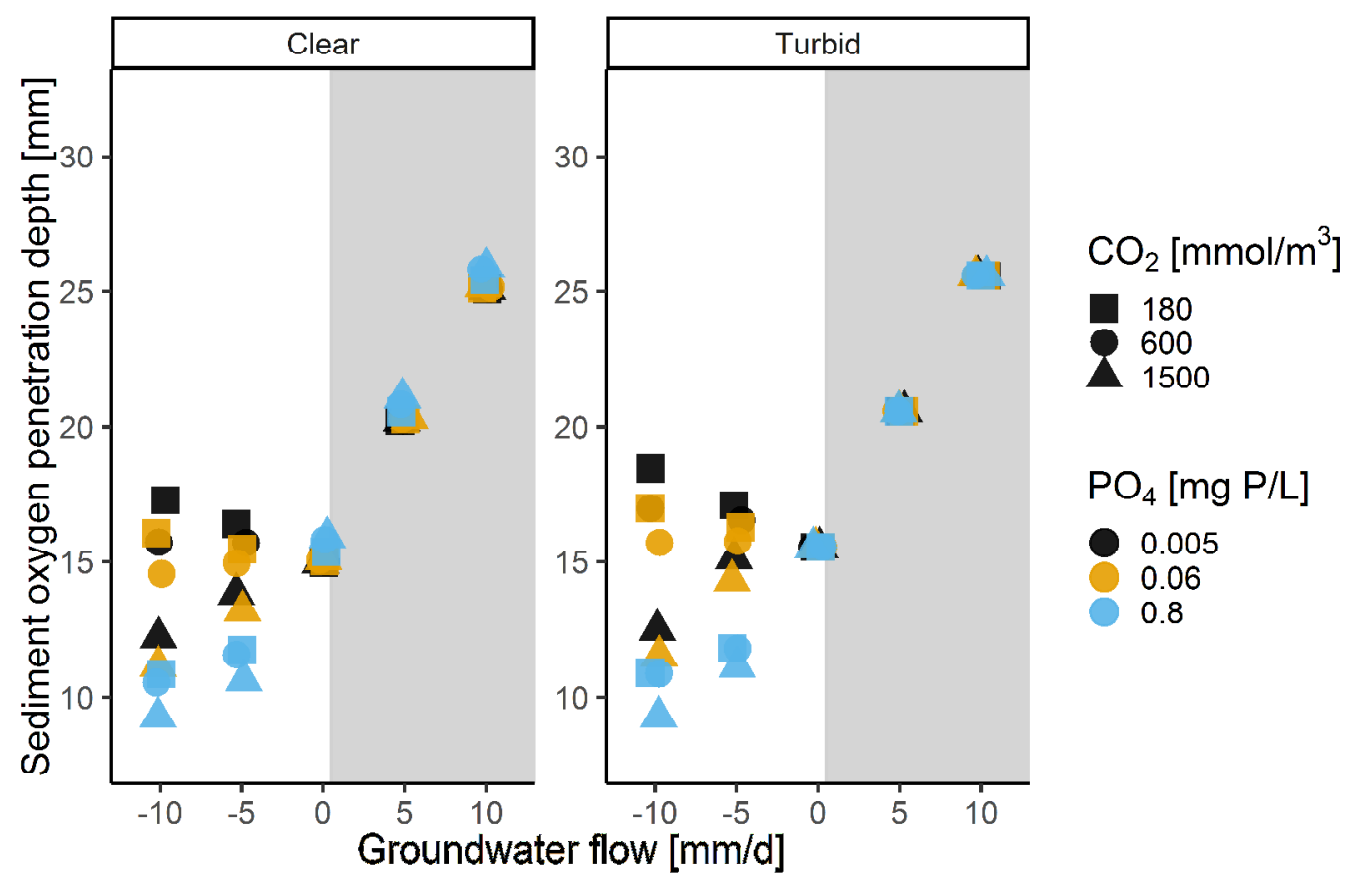


Figure A.11. Correlation between oxygen penetration depth and maximum adsorbed phosphorus (P) to inorganic matter (IM) in sediment in groundwater (GW) seepage and two bank filtration scenarios and with varying surface water nutrient load.

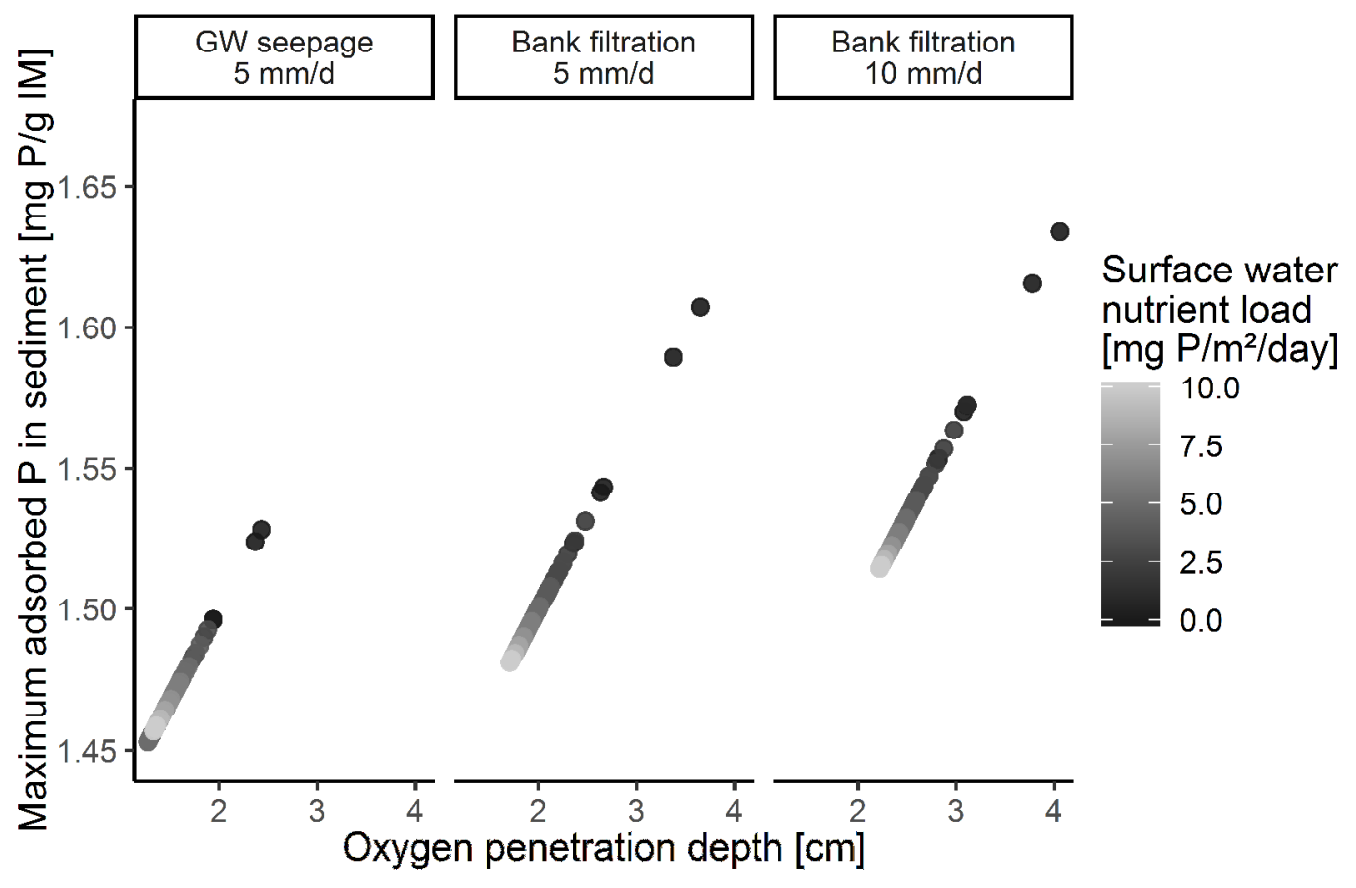


Appendix B: PCLake state values, parameter values and equations

Some of the values were varied between runs, they have been named "var". Those values can be found in the manuscript

<states>

name

sDepthW_

sNH4W

SNO3W

SPO4W

_sPAIMW_

_sSiO2W_

_sO2W_

_sDDetW_

_SNDetW_

_sPDetW

_sSiDetW

_sDIMW_

_sDDiatW_

_sNDiatW_

_sPDiatW_

_sDGrenW

sNGrenW_

_sPGrenW_

_sDBlueW_

_sNBlueW_

_sPBlueW_

_sDZoo

-SNZOO_

_sPZoo_

_sDFiAd_

_sDFiJv_

_sNFiAd_

_sNFiJv_

sPFiAd_

_sPFiJv_

_sDPisc_

_SNH4S_

_sNO3S_

_sPO4S_

_SPAIMS

_sDDets

sNDetS

_sPDetS_

_sSiDetS_

_sDHums

_sNHums_

_sPHums

_SDIMS

_sDDiats_

_sNDiats_

_sPDiats_

_sDGrens_

_sNGrens_

_sPGrens_

_sDBlues_

sNBlues

_sPBlues_

_sDVeg_

_sNVeg_

_sPVeg_

sDBent

_sNBent_

_sPBent_

_sDepthWM

_sNH4WM

_sNO3WM

sPO4WM unit

$\mathrm{m}$

$\mathrm{gN} / \mathrm{m} 3$

$\mathrm{gN} / \mathrm{m} 3$

$\mathrm{gP} / \mathrm{m} 3$

$\mathrm{gP} / \mathrm{m} 3$

$\mathrm{gSi} / \mathrm{m} 3$

gO2/m3

$\mathrm{gDW} / \mathrm{m} 3$

$\mathrm{gN} / \mathrm{m} 3$

$\mathrm{gP} / \mathrm{m} 3$

$\mathrm{gSi} / \mathrm{m} 3$

$\mathrm{gDIM} / \mathrm{m} 3$

$\mathrm{gDW} / \mathrm{m} 3$

$\mathrm{gN} / \mathrm{m} 3$

$\mathrm{gP} / \mathrm{m} 3$

$\mathrm{gDW} / \mathrm{m} 3$

$\mathrm{gN} / \mathrm{m} 3$

$\mathrm{gP} / \mathrm{m} 3$

$\mathrm{gDW} / \mathrm{m} 3$

$\mathrm{gN} / \mathrm{m} 3$

$\mathrm{gP} / \mathrm{m} 3$

$\mathrm{gDW} / \mathrm{m} 3$

$\mathrm{gN} / \mathrm{m} 3$

$\mathrm{gP} / \mathrm{m} 3$

$\mathrm{gDW} / \mathrm{m} 2$

$\mathrm{gDW} / \mathrm{m} 2$

$\mathrm{gN} / \mathrm{m} 2$

$\mathrm{gN} / \mathrm{m} 2$

$\mathrm{gP} / \mathrm{m} 2$

$\mathrm{gP} / \mathrm{m} 2$

$\mathrm{gDW} / \mathrm{m} 2$

$\mathrm{gN} / \mathrm{m} 2$

$\mathrm{gN} / \mathrm{m} 2$

$\mathrm{gP} / \mathrm{m} 2$

$\mathrm{gP} / \mathrm{m} 2$

$\mathrm{gDW} / \mathrm{m} 2$

$\mathrm{gN} / \mathrm{m} 2$

$\mathrm{gP} / \mathrm{m} 2$

$\mathrm{gSi} / \mathrm{m} 2$

$\mathrm{gDW} / \mathrm{m} 2$

$\mathrm{gN} / \mathrm{m} 2$

$\mathrm{gP} / \mathrm{m} 2$

gDIM/m2

$\mathrm{gDW} / \mathrm{m} 2$

$\mathrm{gN} / \mathrm{m} 2$

$\mathrm{gP} / \mathrm{m} 2$

$\mathrm{gDW} / \mathrm{m} 2$

$\mathrm{gN} / \mathrm{m} 2$

$\mathrm{gP} / \mathrm{m} 2$

$\mathrm{gDW} / \mathrm{m} 2$

$\mathrm{gN} / \mathrm{m} 2$

$\mathrm{gP} / \mathrm{m} 2$

$\mathrm{gDW} / \mathrm{m} 2$

$\mathrm{gN} / \mathrm{m} 2$

$\mathrm{gP} / \mathrm{m} 2$

$\mathrm{gDW} / \mathrm{m} 2$

$\mathrm{gN} / \mathrm{m} 2$

$\mathrm{gP} / \mathrm{m} 2$

$\mathrm{m}$

$\mathrm{gN} / \mathrm{m} 3$

$\mathrm{gN} / \mathrm{m} 3$

$\mathrm{gP} / \mathrm{m} 3$ turbid state valı clear state valuı description

Depth_of_lake_water

0,100000001 0,0781417 N_in_NH4_in_lake_water

0,100000001 0,139291 N_in_NO3_in_lake_water

0,0668054 P_in_PO4_in_lake_water

0,000238167 P_adsorbed_onto_IM_in_lake_water

3,72024 Dissolved_Si_in_lake_water

12,9174 Oxygen_in_lake_water

3,16455 Detritus_DW_in_lake_water

0,050000001 0,0596219 Detritus_N_in_lake_water

$0,005 \quad 0,00878401$ Detritus_P_in_lake_water

0,147208 Detritus_Si_in_lake_water

3,84865 Inorganic_matter_in_lake_water

0,414496 Diatoms_DW_in_lake_water

0,0175416 Diatoms_N_in_lake_water

0,00183624 Diatoms_P_in_lake_water

0,0113223 Green_algae_DW_in_lake_water

0,050000001 0,000875793 Green_algae_N_in_lake_water

0,005 0,000127791 Green_algae_P_in_lake_water

0,0280964 Blue-greens_DW_in_lake_water

0,300000004 0,00356158 Blue-greens_N_in_lake_water

$0,0299999990,000663414$ Blue-greens_P_in_lake_water

0,199642 Zooplankton_DW_in_lake_water

0,00989778 Zooplankton_N_in_lake_water

0,00137144 Zooplankton_P_in_lake_water

2,88693 Adult_fish_DW_in_lake_water

0,353491 Young_fish_DW_in_lake_water

0,295867 Adult_fish_N_in_lake_water

0,0358126 Young_fish_N_in_lake_water

0,0565285 Adult_fish_P_in_lake_water

0,00740722 Young_fish_P_in_lake_water

0,0755329 Predatory_fish_DW_in_lake_water

0,0378029 N_in_NH4_in_lake_sediment_pore_water

0,0255708 N_in_NO3_in_lake_sediment_pore_water 0,0199575 P_in_PO4_in_lake_sediment_pore_water

2,02023 P_adsorbed_onto_IM_in_lake_sediment

474,522 Detritus_DW_in_lake_sediment

6,05322 Detritus_N_in_lake_sediment

0,997002 Detritus_P_in_lake_sediment

14,4451 Detritus_Si_in_lake_sediment

3719,32 Humus_DW_in_lake_sediment

166,104 Humus_N_in_lake_sediment

16,9661 Humus_P_in_lake_sediment

31706,9 Inorganic_matter_in_lake_sediment

0,204502 Diatoms_DW_on_lake_sediment

0,00914177 Diatoms_N_on_lake_sediment

0,000933588 Diatoms_P_on_lake_sediment

0,00308052 Green_algae_DW_on_lake_sediment

$0,0010,000245786$ Green_algae_N_on_lake_sediment

1E-05 3,54802E-05 Green_algae_P_on_lake_sediment

0,001 0,00148975 Blue-greens_DW_on_lake_sediment

0,0001 0,000188868 Blue-greens_N_on_lake_sediment

1E-05 3,52081E-05 Blue-greens_P_on_lake_sediment

21,2055 Vegetation_DW_in_lake_water

0,740716 Vegetation_N_in_lake_water

0,074054 Vegetation_P_in_lake_water

2,4032 Zoobenthos_DW_in_lake_sediment

0,108189 Zoobenthos_N_in_lake_sediment

0,0178026 Zoobenthos_P_in_lake_sediment 0,5 Depth_of_marsh_water

0,1 N_in_NH4_in_marsh_water

0,1 N_in_NO3_in_marsh_water

0,01 P_in_PO4_in_marsh_water 


\begin{tabular}{|c|c|c|}
\hline _SPAIMWM_ & $\mathrm{gP} / \mathrm{m} 3$ & 0 \\
\hline _sSiO2WM_ & $\mathrm{gSi} / \mathrm{m} 3$ & 3 \\
\hline _sO2WM_ & $\mathrm{gO} 2 / \mathrm{m} 3$ & 10 \\
\hline _sDDetWM_ & $\mathrm{gDW} / \mathrm{m} 3$ & 2 \\
\hline _sNDetWM_ & $\mathrm{gN} / \mathrm{m} 3$ & 0,050000001 \\
\hline _sPDetWM_ & $\mathrm{gP} / \mathrm{m} 3$ & 0,005 \\
\hline _sSiDetWM_ & $\mathrm{gSi} / \mathrm{m} 3$ & 0,02 \\
\hline _sDIMWM_ & $\mathrm{gDIM} / \mathrm{m} 3$ & 5 \\
\hline _sDDiatWM_ & $\mathrm{gDW} / \mathrm{m} 3$ & 0,5 \\
\hline _sNDiatWM_ & $\mathrm{gN} / \mathrm{m} 3$ & 0,050000001 \\
\hline _sPDiatWM_ & $\mathrm{gP} / \mathrm{m} 3$ & 0,005 \\
\hline _sDGrenWM_ & $\mathrm{gDW} / \mathrm{m} 3$ & 0,5 \\
\hline _sNGrenWM_ & $\mathrm{gN} / \mathrm{m} 3$ & 0,050000001 \\
\hline _sPGrenWM_ & $\mathrm{gP} / \mathrm{m} 3$ & 0,005 \\
\hline _sDBlueWM_ & $\mathrm{gDW} / \mathrm{m} 3$ & 3 \\
\hline _sNBlueWM_ & $\mathrm{gN} / \mathrm{m} 3$ & 0,300000004 \\
\hline _sPBlueWM_ & $\mathrm{gP} / \mathrm{m} 3$ & 0,029999999 \\
\hline _sDZooM_ & $\mathrm{gDW} / \mathrm{m} 3$ & 0,050000001 \\
\hline _sNZooM_ & $\mathrm{gN} / \mathrm{m} 3$ & 0,0035 \\
\hline _sPZooM_ & $\mathrm{gP} / \mathrm{m} 3$ & 0,0005 \\
\hline _sNH4SM_ & $\mathrm{gN} / \mathrm{m} 2$ & 1 \\
\hline _sNO3SM_ & $\mathrm{gN} / \mathrm{m} 2$ & 0,01 \\
\hline _SPO4SM_ & $\mathrm{gP} / \mathrm{m} 2$ & 0,181702837 \\
\hline _SPAIMSM_ & $\mathrm{gP} / \mathrm{m} 2$ & 17,98859821 \\
\hline _sDDetSM_ & $\mathrm{gDW} / \mathrm{m} 2$ & 181,7030072 \\
\hline _sNDetSM_ & $\mathrm{gN} / \mathrm{m} 2$ & 4,542575248 \\
\hline _sPDetSM_ & $\mathrm{gP} / \mathrm{m} 2$ & 0,454257508 \\
\hline _sSiDetSM_ & $\mathrm{gSi} / \mathrm{m} 2$ & 1,817030032 \\
\hline _sDHumSM_ & $\mathrm{gDW} / \mathrm{m} 2$ & 3452,357083 \\
\hline _sNHumSM_ & $\mathrm{gN} / \mathrm{m} 2$ & 172,6178567 \\
\hline _sPHumSM_ & $\mathrm{gP} / \mathrm{m} 2$ & 17,26178503 \\
\hline _SDIMSM_ & $\mathrm{gDIM} / \mathrm{m} 2$ & 32706,54027 \\
\hline _sDRootPhra_ & $\mathrm{gDW} / \mathrm{m} 2$ & 5000 \\
\hline _sDShootPhra_ & $\mathrm{gDW} / \mathrm{m} 2$ & 1000 \\
\hline _sNRootPhra_ & $\mathrm{gN} / \mathrm{m} 2$ & 99,99999776 \\
\hline _sNShootPhra_ & $\mathrm{gN} / \mathrm{m} 2$ & 19,99999955 \\
\hline _sPRootPhra_ & $\mathrm{gP} / \mathrm{m} 2$ & 10,00000048 \\
\hline _sPShootPhra_ & $\mathrm{gP} / \mathrm{m} 2$ & 2,000000095 \\
\hline _sDExtTotT__ & $\mathrm{gDW} / \mathrm{m} 2$ & 36367,21336 \\
\hline _sNExtTotT_ & $\mathrm{gN} / \mathrm{m} 2$ & 178,830732 \\
\hline _sPExtTotT_ & $\mathrm{gP} / \mathrm{m} 2$ & 36,06459358 \\
\hline _sSiExtTotT_ & $\mathrm{gSi} / \mathrm{m} 2$ & 8,007180153 \\
\hline
\end{tabular}

0 P_adsorbed_onto_IM_in_marsh_water

3 Dissolved_Si_in_marsh_water

10 Oxygen_in_marsh_water

2 Detritus_DW_in_marsh_water

0,05 Detritus_N_in_marsh_water

0,005 Detritus_P_in_marsh_water

0,02 Detritus_Si_in_marsh_water

3,84865 Inorganic_matter_in_marsh_water

0,5 Diatoms_DW_in_marsh_water

0,05 Diatoms_N_in_marsh_water

0,005 Diatoms_P_in_marsh_water

0,5 Green_algae_DW_in_marsh_water

0,05 Green_algae_N_in_marsh_water

0,005 Green_algae_P_in_marsh_water

3 Blue-greens_DW_in_marsh_water

0,3 Blue-greens_N_in_marsh_water

0,03 Blue-greens_P_in_marsh_water

0,05 Zooplankton_DW_in_marsh_water

0,0035 Zooplankton_N_in_marsh_water

0,0005 Zooplankton_P_in_marsh_water

$1 \mathrm{~N}$ _in_NH4_in_marsh_sediment_pore_water

0,01 N_in_NO3_in_marsh_sediment_pore_water

0,181703 P_in_PO4_in_marsh_sediment_pore_water

17,9886 P_adsorbed_onto_IM_in_marsh_sediment

181,703 Detritus_DW_in_marsh_sediment

4,54258 Detritus_N_in_marsh_sediment

0,454258 Detritus_P_in_marsh_sediment

1,81703 Detritus_Si_in_marsh_sediment

3452,36 Humus_DW_in_marsh_sediment

172,618 Humus_N_in_marsh_sediment

17,2618 Humus_Pin_marsh_sediment

32706,5 Inorganic_matter_in_marsh_sediment

5000 Root_biomass_DW_in_marsh_sediment

1000 Shoot_biomass_DW_in_marsh_water

100 Root_biomass_N_in_marsh_sediment

20 Shoot_biomass_N_in_marsh_water

10 Root_biomass_P_in_marsh_sediment

2 Shoot_biomass_P_in_marsh_water

44412,5 Total_amount_of_DW_moved_into_or_out_from_the_syster

233,735 Total_amount_of_N_moved_into_or_out_from_the_syster

29,9042 Total_amount_of_P_moved_into_or_out_from_the_syster

23,0079 Total_amount_of_Si_moved_into_or_out_from_the_syster

$<$ parameters>

name

unit

value

description

_InitCalc_

ConstDepth

InclTran

_InclPhyts__

_InclBed

IncIWeb_

_InclMarsh_

InclSeason

_ReadTemp_

_ReadLOut_

_ReadVWind

_ReadQIn_

_ReadQOut_

ReadQEv

_ReadPLoad

_ReadNLoad_

ReadNutFrac

_ReadPLoadPhyt

ReadDLoadDet_

_ReadDLoadIM_

_UseSeasonLoad

UsePulseLoad_

$-$

$-$

$-$

\footnotetext{
1 If_T_skip_calculation_of_initial_values_used_in_case_of_REINIT_commanc

1 If_T_water_depth_kept_constant_by_daily_dredging

1 transport_processes

1 Include_phytoplankton_module

1 Include_vegetation_module

1 Include_food_web_module

0 Include_marsh_zone

1 Include_season

0 If_TRUE_use_measured_time-series_of_water_temperature_otherwise_sinus

0 If_TRUE_use_measured_time-series_of_light_otherwise_sinus

0 If_TRUE_use_measured_time-series_of_wind_otherwise_constant

0 If_TRUE_use_measured_time-series_of_inflow_otherwise_constant

0 If_TRUE_use_measured_time-series_of_inflow_otherwise_constant

0 If_TRUE_use_measured_time-series_of_evaporation_otherwise_constant

0 If_TRUE_use_measured_time-series_of_P_loading_otherwise_constant

0 If_TRUE_use_measured_time-series_of_N_loading_otherwise_constant

0 If_TRUE_use_measured_time-series_of_loading_with_diff_nutrient_fraction:

0 If_TRUE_use_measured_time-series_of_P_loading_algal_input_otherwise_constant

0 If_TRUE_use_measured_time-series_of_DDet_loading_otherwise_constan

0 If_TRUE_use_measured_time-series_of_DIM_loading_otherwise_constan

0 If_TRUE_use_different_inflow_and_loading_for_summer_and_winter_period:

0 If_TRUE_use_a_pulse-wise_nutrient_loading
} 


\begin{tabular}{|c|c|c|}
\hline _mTemp_ & $\mathrm{oC}$ & 0 measured_time-series_of_water_temperature \\
\hline _mLOut_ & $\mathrm{W} / \mathrm{m} 2$ & 0 measured_time-series_of_light \\
\hline _mVWind_ & $\mathrm{m} / \mathrm{s}$ & 0 measured_time-series_of_wind \\
\hline mQIn_ & $\mathrm{mm} /$ day & 0 use_measured_time-series_of_inflow \\
\hline _mQOut_ & $\mathrm{mm} /$ day & 0 use_measured_time-series_of_outflow \\
\hline _mQEv_ & $\mathrm{mm} /$ day & 0 use_measured_time-series_of_evaporatior \\
\hline _mPLoad__ & $\mathrm{gP} / \mathrm{m} 2 /$ day & 0 use_measured_time-series_of_P_loading \\
\hline _mPLoadPO4_ & $\mathrm{gP} / \mathrm{m} 2 /$ day & 0 use_measured_time-series_of_PO4_loading \\
\hline _mPLoadOrg_ & $\mathrm{gP} / \mathrm{m} 2 /$ day & 0 use_measured_time-series_of_loading_P_bound_to_org_matteı \\
\hline _mPLoadPhytTot_ & $\mathrm{gP} / \mathrm{m} 2 /$ day & 0 use_measured_time-series_of_P_loading_algal_input \\
\hline _mNLoad__ & $\mathrm{gN} / \mathrm{m} 2 /$ day & 0 use_measured_time-series_of_N_loading \\
\hline _mNLoadNH4_ & $\mathrm{gN} / \mathrm{m} 2 /$ day & 0 use_measured_time-series_of_NH4_loading \\
\hline _mNLoadNO3_ & $\mathrm{gN} / \mathrm{m} 2 /$ day & 0 use_measured_time-series_of_NO3_loading \\
\hline mNLoadOrg_ & $\mathrm{gN} / \mathrm{m} 2 /$ day & 0 use_measured_time-series_of_loading_N_bound_to_org_matte \\
\hline _mDLoadDet_ & $\mathrm{gDW} / \mathrm{m} 2 / \mathrm{day}$ & 0 use_measured_time-series_of_Detritus_loading \\
\hline _mDLoadIM_ & $\mathrm{gDW} / \mathrm{m} 2 /$ day & 0 use_measured_time-series_of_loading_of_DW_of_inorg_matteI \\
\hline _BeginTime_ & day & 0 begintime \\
\hline EndTime_ & day & 365 (=1_year) \\
\hline _YearZero_ & - & 0 Note_also_Day_no_1_=_1_Jan_of_this_year \\
\hline _cFetch_- & $\mathrm{m}$ & wind_fetch \\
\hline _fMarsh_ & m2_marsh/m2_lak & 0 relative_marsh_area \\
\hline _flutum_ & - & 0,1 lutum_content_of_inorg_matter \\
\hline _fFeDIM_ & gFe/gDW & 0,01 Fe_content_of_inorg_matter \\
\hline _fAIDIM_- & gAl/gDW & 0,01 Al_content_of_inorg_matter \\
\hline cTmAve_ & $\mathrm{oC}$ & 12 average_water_temperature \\
\hline _cTmGround_ & $\mathrm{oC}$ & 10 groundwater_temperature \\
\hline _cTmVar_ & $\mathrm{oC}$ & 10 annual_water_temperature_variation \\
\hline _cTimeLag_ & day & 40 time_lag_for_temperature \\
\hline _cVWind__ & $\mathrm{m} / \mathrm{s}$ & 5 average_wind_speed \\
\hline _cTmVarInfMin_ & $\mathrm{oC}$ & 5 annual_water_temperature_variation_minimum_used_for_infiltration \\
\hline CQInfTmL_ & $\mathrm{mm} /$ day & -20 lower_boundary_for_infiltration_affecting_temperature_variation \\
\hline cQInfTmU_- & $\mathrm{mm} /$ day & 0 upper_boundary_for_infiltration_affecting_temperature_variation \\
\hline _cQInfCO2U_ & $\mathrm{mm} / \mathrm{day}$ & 0 upper_boundary_for_infiltration_affecting_CO2 \\
\hline cQInf__ & $\mathrm{mm} /$ day & infiltration_rate \\
\hline _cPBackLoad_ & $\mathrm{gP} / \mathrm{m} 2 / \mathrm{d}$ & 0 Background_P_loading \\
\hline _cNBackLoad_ & $\mathrm{gP} / \mathrm{m} 2 / \mathrm{d}$ & 0 Background_N_loading \\
\hline _cLDayAve_ & $\mathrm{J} / \mathrm{m} 2 /$ day & 10000000 annual_average_radiation \\
\hline cLDayVar_ & $\mathrm{J} / \mathrm{m} 2 /$ day & 8000000 annual_variation_in_radiation \\
\hline _cfDayAve_ & - & 0,5 average_day_length \\
\hline _cfDayVar_ & - & 0,2 annual_variation_in_day_length \\
\hline fRefl_ & - & 0,2 the_fraction_photosynthetically_active_radiation_reflected_at_the_surfact \\
\hline _cExtWat__ & $\mathrm{m}-1$ & 0,5 background_extinction \\
\hline _cDredInterval_ & y & 9999000 dredging_interval \\
\hline cDredStart__ & y & 9999000 first_dredging_year_(should_be_n_times_cDredinterval_' \\
\hline _cDepthRef_ & $\mathrm{m}$ & 1,00E-28 reference_water_depth_for_dredging \\
\hline _cLengDred_ & day & 10 length_of_dredging_period \\
\hline _fEffDred_ & - & 0,95 dredging_efficiency_ $(<10)$ \\
\hline _fEffDredBent_ & - & 0,5 dredging_efficiency_for_zoobenthos_(<10) \\
\hline fPAR_ & - & 0,48 fraction_photosynthetically_active_radiation_(PAR' \\
\hline cExtSpDet_ & $\mathrm{m} 2 / \mathrm{gDW}$ & 0,15 specific_extinction_detritus \\
\hline cExtSpIM_ & $\mathrm{m} 2 / \mathrm{gDW}$ & 0,05 specific_extinction_inert_matter \\
\hline _fDTotSO_ & g_solid/g_sedimer & 0,3 initial_dry-weight_fraction_in_sediment \\
\hline _fDOrgSO_- & $\mathrm{g} / \mathrm{g}$ & 0,1 initial_organic_fraction_of_sediment_DW \\
\hline fDDetSo_ & $g / g$ & 0,05 initial_detritus_fraction_of_sediment_organic_matteı \\
\hline _fSedPhyt0_ & $\mathrm{g} / \mathrm{g}$ & 0,01 Fraction_diatoms_DW_on_lake_sediment \\
\hline${ }_{-}^{-} \mathrm{fPInorgSO}$ & $\mathrm{gP} / \mathrm{gDW}$ & 0,0005 initial_inorg_P_fraction_in_sed \\
\hline _fPAdsSO_ & - & 0,99 initial_adsorbed_fraction_of_inorg_P_in_sed \\
\hline _cPDDet0_ & gP/gDW_Detritus & 0,0025 initial_P_fraction_in_detritus \\
\hline CNDDet0_- & gN/gDW_Detritus & 0,025 initial_N_fraction_in_detritus \\
\hline cSiDDet0_ & gSi/gDW_Detritus & 0,01 initial_Si_fraction_in_detritus_Tentative \\
\hline _cPDHum0_ & gP/gDW_Detritus & 0,005 initial_P_fraction_in_humus \\
\hline _cNDHum0_ & gN/gDW_Detritus & 0,05 initial_N_fraction_in_humus \\
\hline _cPDPhyt0_ & $\mathrm{gP} / \mathrm{gDW}$ & 0,01 initial_P_fraction_in_algae \\
\hline _cNDPhyt0_ & gN/gDW & 0,1 initial_N_fraction_in_algae \\
\hline _CPDDiato_ & $\mathrm{gP} / \mathrm{gDW}$ & 0,01 initial_P_fraction_in_diatoms \\
\hline cNDDiat0_ & gN/gDW & 0,1 initial_N_fraction_in_diatoms \\
\hline _cPDGrenō & gP/gDW & 0,01 initial_P_fraction_in_green_algae \\
\hline
\end{tabular}




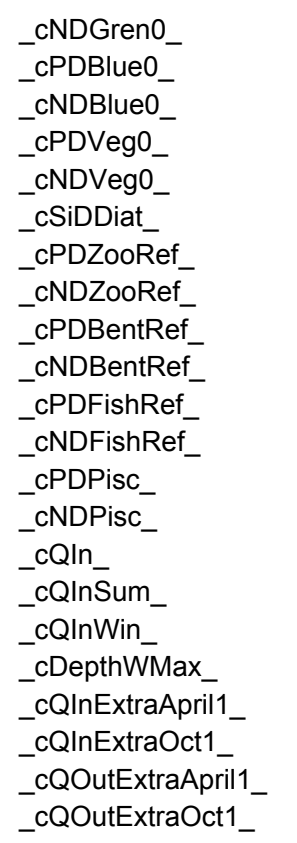

_cQEvAve_

_CQEvVar_

_cPLoad_

cPLoadS̄um

_cPLoadWin_

fPO4In

_fPhytlnWin_

fPhytlnSum_

fDiatPhytln_

_fGrenPhytln_

_fBluePhytln_

_cNLoad_

_cNLoadSum _

cNLoadWin

_CNPLoadMeas_

_cNPPhytln_

CNPDetIn_

_fNH4Dissin_

_cNDPhytln_

cNDDetIn

_CDIMIn_

_CO2In

_cSiO2In

_cSiDDetIn_

cDZooln

_CDayApril1_

_cDayOct1_

cLengChange _

_cNLoadS_

_fNH4LoadS_

_cDErosTot

_fSedErosIM_

_fDOrgSoil_

_CPDSoilOM_

_CNDSoilOM_

_cPO4Ground_

cNH4Ground

_cNO3Ground_

_cCO2Ground_

cCO2MuMaxU

_CCO2W_

_cCO2Norm

_CBMuMaxVeg_

_cMMuMaxVeg_

_cDepthS
gN/gDW

gP/gDW

gN/gDW

gP/gDW

gN/gDW

$\mathrm{mgSi} / \mathrm{mgDW}$

$\mathrm{mgP} / \mathrm{mgDW}$

$\mathrm{mgN} / \mathrm{mgDW}$

$\mathrm{mgP} / \mathrm{mgDW}$

$\mathrm{mgN} / \mathrm{mgDW}$

$\mathrm{mgP} / \mathrm{mgDW}$

$\mathrm{mgN} / \mathrm{mgDW}$

$\mathrm{mgP} / \mathrm{mgDW}$

$\mathrm{mgN} / \mathrm{mgDW}$

$\mathrm{mm} /$ day

$\mathrm{mm} /$ day

$\mathrm{mm} /$ day

$\mathrm{m}$

$\mathrm{mm} /$ day

$\mathrm{mm} /$ day

$\mathrm{mm} /$ day

$\mathrm{mm} /$ day

$\mathrm{mm} /$ day

$\mathrm{mm} /$ day

$\mathrm{gP} / \mathrm{m} 2 /$ day

$\mathrm{gP} / \mathrm{m} 2 /$ day

$\mathrm{gP} / \mathrm{m} 2 /$ day

-

-

-

-

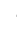

$\mathrm{gN} / \mathrm{m} 2 /$ day

$\mathrm{gN} / \mathrm{m} 2 /$ day

$\mathrm{gN} / \mathrm{m} 2 /$ day

$\mathrm{gN} / \mathrm{gP}$

gP/gDW

gP/gDW

-

gN/gDW

gN/gDW

$\mathrm{mgDW} / \mathrm{I}$

$\mathrm{mgO} / \mathrm{l}$

$\mathrm{mgSi} / \mathrm{l}$

gSi/gDW

$\mathrm{mgDW} / \mathrm{I}$

day

day

day

gN/m2/day

-

g/m2/day

$-$

gP/gDW

$\mathrm{gN} / \mathrm{gDW}$

$\mathrm{mgP} / \mathrm{l}$

$\mathrm{mgN} / \mathrm{l}$

$\mathrm{mgN} / \mathrm{l}$

$\mathrm{mmol} / \mathrm{m} 3$

$\mathrm{mmol} / \mathrm{m} 3$

$\mathrm{mmol} / \mathrm{m} 3$

-

$-$

m
0,1 initial_N_fraction_in_green_algae

0,01 initial_P_fraction_in_blue-green_algae

0,1 initial_N_fraction_in_blue-green_algae

0,002 initial_P_fraction_in_veg

0,02 initial_N_fraction_in_veg

0,15 Si/DW_ratio_of_daitoms

0,01 reference_P/C-ratio_herb_zooplankton

0,07 reference_N/C-ratio_herb_zooplankton

0,01 reference_P/C_ratio_of_zoobenthos

0,07 reference_N/C_ratio_of_zoobenthos

0,022 reference_P/C_ratio_of_Fish

0,1 reference_N/C_ratio_of_Fish

0,022 reference_P/C_ratio_of_Pi_sc

0,1 reference_N/C_ratio_of_Pi_sc

20 standard_water_inflow_if_not_measured

20 summer_water_inflow_if_not_measured

20 winter_water_inflow_if_not_measured

5 maximum_water_depth

0 extra_inflow_at_start_of_summer

0 extra_inflow_at_start_of_winter

0 extra_outflow_at_start_of_summer

0 extra_outflow_at_start_of_winter

1,5 standard_average_evaporation

1,3 standard_variation_in_evaporation standard_P_loading_if_not_measured

var

0,005 summer_P_loading_if_not_measured

0,005 winter_P_loading_if_not_measured

0,5 fraction_PO4_in_input_(if_PO4_input_not_measured)

0,02 minimum_algal_fraction_in_organic_P_input

0,1 maximum_algal_fraction_in_organic_P_input

0,33 diatoms_fraction_of_algal_input

0,34 greens_fraction_of_algal_input

0,33 blue-greens_fraction_of_algal_input standard_N_loading

0,05 summer_N_loading

0,05 winter_N_loading

7 N/P_loading_if_P_is_measured_and_N_not

7 N/P_ratio_of_algal_input

7 N/P_ratio_of_detrital_input

0,5 NH4_fraction_of_dissolved_N_load_(if_NH4_not_measured'

$0,07 \mathrm{~N} /$ day_ratio_of_algal_input

0,07 N/P_ratio_of_detrital_input

5 IM_conc_in_inflow

5 02_conc_in_inflow

3 SiO2_conc_in_inflow

0,05 Si_content_of_sediment_detritus

0,1 zoopl_conc_in_inflowing_water

91 April_1

273 October_1

10 length_of_season_change

$0 \mathrm{~N}$ _fertilizer_to_sediment

0,5 NH4_fraction_of_N_fertilizer_to_sediment

0,1 Erosion_input_(tentative)

0,95 instantly_sedimentating_fraction_of_IM

0,1 fraction_soil_organic_matter

0,001 P/day_ratio_of_soil_organic_matter

0,01 N/day_ratio_of_soil_organic_matter

PO4_cone_in_groundwater

$\mathrm{NH} 4$ cone_in_groundwater

NO3_cone_in_groundwater

CO2_conc_in_groundwater

600 Upper_boundary_for_CO2_conc_in_water_that_affects_MuMaxVeg_

150 CO2_conc_in_surface_water

1,145 Constant_to_normalize_max_growth_rate_at_certain_CO2_level

0,0013044 Constant_b_before_x_in_linear_equation_to_set_uMuMaxVeg_multiplier 0,94940714 Constant_m_in_linear_equation_to_set_uMuMaxVeg_multiplier

0,1 sediment_depth 


\begin{tabular}{|c|c|}
\hline _cCPerDW_ & gC/gDW \\
\hline _cRholM_ & g/m3_solid \\
\hline _cRhoOM_ & $\mathrm{g} / \mathrm{m} 3$ \\
\hline _cTmRef_ & $\mathrm{oC}$ \\
\hline _cAerRoot_ & - \\
\hline _cAerLin_ & s/day \\
\hline _cAerSquare_ & - \\
\hline cThetaAer_ & $1 / \mathrm{e}^{\wedge} \mathrm{oC}$ \\
\hline _cVSetIM_ & $\mathrm{m} /$ day \\
\hline _cVSetDet_ & $\mathrm{m} /$ day \\
\hline _cThetaSet_ & $1 / \mathrm{e}^{\wedge} \mathrm{oC}$ \\
\hline _cSuspMin_ & - \\
\hline _cSuspMax_ & - \\
\hline _cSuspSlope_ & - \\
\hline _hDepthSusp_ & - \\
\hline _cFetchRef_ & $\mathrm{m}$ \\
\hline _flutumRef_ & - \\
\hline cSuspRef_ & - \\
\hline _kVegResus_ & $\mathrm{m} 2 / \mathrm{gDW}$ \\
\hline _kTurbFish_ & g/g_fish/day \\
\hline _kResusPhytMax_ & day-1 \\
\hline _cResusPhytExp_ & (gDW/m2/day)-1 \\
\hline _cThetaMinW__ & - \\
\hline kDMinDetW_ & day-1 \\
\hline hO2BOD_ & $\mathrm{mgO} / \mathrm{l}$ \\
\hline _O2PerNO3_ & - \\
\hline _cThetaMins__ & - \\
\hline _kDMinDetS_ & day-1 \\
\hline _RefrDetS_ & - \\
\hline hNO3Denit__ & $\mathrm{mgN} / \mathrm{l}$ \\
\hline NO3PerC_ & - \\
\hline _kDMinHum_ & day-1 \\
\hline _kNitrW__ & day-1 \\
\hline _kNitrS_ & day-1 \\
\hline cThetaNitr_ & $1 / \mathrm{eoC}$ \\
\hline OO2PerNH4_ & - \\
\hline hO2Nitr_ & $\mathrm{mgO} / \mathrm{l}$ \\
\hline _kPDifPO4_ & $\mathrm{m} 2 /$ day \\
\hline _kNDifNO3_ & m2/day \\
\hline _kNDifNH4_ & m2/day \\
\hline kO2Dif__ & $\mathrm{m} 2 /$ day \\
\hline _cThetaDif_ & $1 / \mathrm{eoC}$ \\
\hline _fDepthDifS_ & - \\
\hline _cTurbDifNut_ & - \\
\hline _cTurbDifO2_ & - \\
\hline _kPSorp_ & day-1 \\
\hline _cRelPAdsD_ & gP/gDW \\
\hline cRelPAdsFe_ & $\mathrm{gP} / \mathrm{gFe}$ \\
\hline CRelPAdsAl__ & $\mathrm{gP} / \mathrm{gAl}$ \\
\hline _cKPAdsOx_ & $\mathrm{m} 3 / \mathrm{gP}$ \\
\hline _fRedMax_ & - \\
\hline _coPO4Max_ & $\mathrm{mgP} / \mathrm{l}$ \\
\hline -kPChemPO4_ & day-1 \\
\hline _cDayManVeg1_ & day \\
\hline _cDayManVeg2_- & day \\
\hline fManVeg_ & - \\
\hline _cLengMan_ & day \\
\hline _cYearStartBirds_ & $y$ \\
\hline _cDayStartBirds_ & day \\
\hline _cDayEndBirds_ & day \\
\hline _cBirdsPerha_- & $\mathrm{n} / \mathrm{ha}$ \\
\hline _cDGrazPerBird_ & gDW/coot/day \\
\hline _hDVegBird_ & $\mathrm{gDW} / \mathrm{m} 2$ \\
\hline fDAssBird & - \\
\hline _fDissEgesBird_ & - \\
\hline _fDissMortVeg_ & - \\
\hline _CLengAllo_ & day \\
\hline
\end{tabular}

0,4 C_content_of_organic_matter

2500000 density_of_sediment_IM

1400000 density_of_sediment_detritus

20 reference_temperature

0,727 coefficient_for_VWind ${ }^{\wedge} 05$

$-0,371$ coefficient_for_VWind_(is_negative)

0,0376 coefficient_for_VWind ${ }^{\wedge} 2$

1,024 Temperature_coeff_for_reaeration_(Downing_\&_Truesdale_1955)

1 max_sedimentation_velocity_of_inert_org_matter_(10)

0,25 max_sedimentation_velocity_of_detritus

1,01 temp_parameter_of_sedimentation

6,1 minimum_value_of_logistic_empirical_suspended_matter_function

25,2 maximum_value_of_logistic_empirical_suspended_matter_function

2,1 slope_of_logistic_empirical_suspended_matter_function

2 half_sat_value_of_depth_in_logistic_empirical_suspended_matter_function

1000 reference_fetch

0,2 reference_lutum_fraction_(of_sandy_clay_soils)

0,5 reference_supsended_matter_function

0,01 rel_resuspension_reduction_per_g_vegetation

1 relative_resuspension_by_adult_fish_browsing

0,25 max_phytopl_resuspension

-0,379 exp_par_for_phytopl_resuspension

1,07 expon_temp_constant_of_mineralization_in_water

0,01 decomposition_constant_of_detritus

1 half-sat_oxygen_conc_for_BOD

1,5 mol_O2_formed_per_mol_NO3-_ammonified

1,07 expon_temp_constant_of_sediment_mineralization

0,002 decomposition constant of sediment detritus

0,15 refractory_fraction_of_sed_detritus

2 quadratic_half-sat_NO3_conc_for_denitrification

0,8 mol_NO3_denitrified_per_mol_C_mineralised

0,00001 maximum_decomposition_constant_of_humic_material_(1D-5)

0,1 nitrification_rate_constant_in_water

1 nitrification_rate_constant_in_sediment

1,08 temperature_coefficient_of_nitrification

2 mol_O2_used_per_mol_NH4+_nitrified

2 half-sat_O2_conc_for_nitrification_in_water

0,000072 mol_PO4_diffusion_constant

0,000086 mol_NO3_diffusion_constant

0,000112 mol_NH4_diffusion_constant

0,000026 mol_O2_diffusion_constant

1,02 Temperature coefficient for diffusion

0,5 nutrient_diffusion_distance_as_fraction_of_sediment_depth

5 bioturbation_factor_for_diffusion

5 bioturbation_factor_for_diffusion

0,05 P_sorption_rate_constant_not_too_high_->_model_speed

0,00003 max_P_adsorption_per_g_DW

0,065 max_P_adsorption_per_g_Fe

0,134 max_P_adsorption_per_g_Al

0,6 P_adsorption_affinity_at_oxidized_conditions

0,9 max_reduction_factor_of_P_adsorption_affinity

1 max_SRP_conc_in_pore_water

0,03 chem PO4 loss rate

-9999000 first_mowing_day_(default_non-existent)

-9999000 second_mowing_day_(Note_259_=_16_Sep)

0 Fraction_removed_by_management_for_submerged_plants

10 length_of_mowing_period

0 first_year_of_birds_presence

46 yearly_first_day_of_birds_presence

288 yearly_last_day_of_birds_presence

0 number_of_birds_per_ha_vegetated_lake_(Default_=_0)

45 daily_grazing_of_birds

5 half-sat_vegetation_biomassfor_birds_grazing

0,5 birds_assim_efficiency

0,25 fraction_dissolved_nutrient_of_coot_egestion

0,25 fraction_dissolved_nutrients_from_died_plants

15 duration_of_allocation_and_reallocation_phase 
_cLengMort

UseEmpUpt_

_fSedUptVegMax

fSedUptVegCoef

fSedUptVegExp_

fRootVegSum

_RootVegWin_

fFloatVeg_

fEmergVeg_

fDepth1Veg

fDepth2Veg_

_CDLayerVeg_

_CovSpVeg_

kMigrVeg_

_cDVegln_

cTmlnitVeg_

cDCarrVeg_

_cMuMaxVeg_

cMultiMuMaxVegU_

_cQ10ProdVeg_

_hLRefVeg_

cExtSpVeg_

_kDRespVeg_

_cQ10RespVeg_

kMortVegSum

fWinVeg_

_cDayWinVeg_

fDetWMortVeg_

_cPrefVegBird

_cVPUptMaxVeg_

cAffPUptVeg

CPDVegMin

_CPDVegMax

_cVNUptMaxVeg_

_cAffNUptVeg_

_cNDVegMin

CNDVegMax

_PACoefMin

cPACoefMax

hPACoef

cSecchiPlus_

cEuph

_cCovSpPhyt_

cTmOptLoss_

cSigTmLoss

_fDissMortPhyt_

fDissLoss

cMuMaxDiat

_cTmOptDiat_

cSigTmDiat

cExtSpDiat_

_UseSteeleDiat

cLOptRefDiat_

_hLRefDiat

_cChDDiatMin_

cChDDiatMax

_kDRespDiat_

kLossDiat_

kMortDiatW

_kMortDiatS_

cVSetDiat_

_cVPUptMaxDiat_

_cAffPUptDiat

cPDDiatMin

CPDDiatMax

_cVNUptMaxDiat_

_CAffNUptDiat_ day

g_root_/g_veg

g_root_lg_veg

g_floating_/g_sh

g_floating_/_g_sh

$\mathrm{gDW} / \mathrm{m} 2$

\%_cover/gDW/m2

day-1

$\mathrm{gDW} / \mathrm{m} 2$

oC

$\mathrm{gDW} / \mathrm{m} 2$

g/g_shoot/day

W/m2_PAR

$\mathrm{m} 2 / \mathrm{gDW}$

day-1

day-1

-

day

-

$\mathrm{mgP} / \mathrm{mgDW} /$ day

I/mgDW/day

$\mathrm{mgP} / \mathrm{mg}$

$\mathrm{mgP} / \mathrm{mgDW}$

$\mathrm{mgN} / \mathrm{mgDW} /$ day

I/mgDW/day

$\mathrm{mgN} / \mathrm{mgDW}$

$\mathrm{mgN} / \mathrm{mgDW}$

$\mathrm{g} / \mathrm{m} 2$

$\mathrm{m}$

$\% / g D W / m 2$

oC

$\mathrm{oC}$

day-1

oC

$\mathrm{OC}$

$\mathrm{m} 2 / \mathrm{gDW}$

$\mathrm{W} / \mathrm{m} 2$

$\mathrm{W} / \mathrm{m} 2$

$\mathrm{mgChl} / \mathrm{mgDW}$

$\mathrm{mgChl} / \mathrm{mgDW}$

day-1

day-1

day-1

$\mathrm{m} /$ day

$\mathrm{mgP} / \mathrm{mgDW} / \mathrm{day}$

I/mgDW/day

$\mathrm{mgP} / \mathrm{mgDW}$

$\mathrm{mgP} / \mathrm{mgDW}$

$\mathrm{mgN} / \mathrm{mgDW} /$ day

I/mgDW/day
15 duration_of_autumn_mortality_period

0 false_=_do_not_use_this_empirical_relation

0,998 maximum_sediment_fraction_of_nutrient_uptake

2,66 sigm_regr_coeff_for_sediment_fraction_of_nutrient_uptake

-0,83 exponent_in_sigm_regr_for_sediment_fraction_of_nutrient_uptake

0,1 root_fraction_outside_growing_season

0,6 root_fraction_outside_growing_season

0 floating_fraction_of_shoot

0 emergent_fraction_of_shoot

0 max_upper_depth_of_submerged_veget_layer_as_fraction_of_water_depth

1 max_lower_depth_of_submerged_veget_layer_as_fraction_of_water_depth

0 biomass_of_a_single_layer_floating_leaves

0,5 specific_cover

0,001 vegetation_migration_rate

1 external_vegetation_density

9 temperature_for_initial_growth

400 max_vegetation_standing_crop

0,2 maximum_growth_rate_of_vegetation_at_20oC

1,51 upper_boundary_MuMaxVeg_multiplier

1,2 temperature_quotient_of_production

17 half-sat_light_at_20_oC

0,01 specific_extinction

0,02 dark_respiration_rate_of_vegetation

2 temperature_quotient_of_respiration

0,005 vegetation_mortality_rate_in_Spring_and_Summer_(low)

0,3 fraction_surviving_in_winter

259 end_of_growing_season_=_16_Sep

0,1 fraction_of_shoot_mortality_becoming_water_detritus

1 edibility_for_birds

0,01 maximum_P_uptake_capacity_of_vegetation

0,2 initial_P_uptake_affinity_vegetation

0,0008 minimum_P/day_ratio_vegetation

0,0035 maximum_P/day_ratio_vegetation

0,1 maximum_N_uptake_capacity_of_vegetation

0,2 initial_N_uptake_affinity_vegetation

0,01 minimum_N/day_ratio_vegetation

0,035 maximum_N/day_ratio_vegetation

1,5 minimum_Poole-Atkins_coefficient

2,5 maximum_Poole-Atkins_coefficient

3 decrease_constant_for_PA_coeff_with_DOMW

0 maximum_Secchi_depth_above_water_depth

1,7 conversion_constant_Secchi_depth_->_euphotic_depth

2 specific_coverage_Tentative

25 optimum_temp_for_grazing

13 temperature_constant_of_grazing(sigma_in_Gaussian_curve)

0,2 soluble_nutrient_fraction_of_died_Algae

0,25 dissolved_nutrient_fraction_of_grazing_loss

2 maximum_growth_rate_Diatoms

18 optimum_temp_diatoms

20 temperature_constant_diatoms(sigma_in_Gaussian_curve)

0,25 specific_extinction_Diatoms

1 Flag_1_=_use_Steele_function0_=_use_Lehman_function

54 optimum_PAR_for_Diatoms_at_20_oC(Steele_function)

1000 half-sat_PAR_at_20_oC(Lehmann_function)_Fake_value

0,004 min_chlorophyll/C_ratio_Diatoms

0,012 max_chlorophyll/C_ratio_Diatoms

0,1 maintenance_respiration_constant_diatoms $\left(=\_005\right.$ _*_MuMax $)$

0,25 grazing_loss_rate_for_Diatoms

0,01 mortality_constant_of_Diatoms_in_water

0,05 mortality_constant_of_sed_Diatoms

0,5 sedimentation_velocity_Diatoms

0,01 maximum_P_uptake_capacity_of_Diatoms

0,2 initial_P_uptake_affinity_Diatoms

0,0005 minimum_P/day_ratio_Diatoms

0,005 max_P/day_ratio_Diatoms

0,07 maximum_N_uptake_capacity_of_Diatoms

0,2 initial $N$ uptake affinity Diatoms 
_NDDiatMin_ _cNDDiatMax_ hSiAssDiat_

_cMuMaxGren_

_cTmOptGren_

_cSigTmGren_

_cExtSpGren_

_UseSteeleGren_

_hLRefGren_

_cLOptRefGren_

_cChDGrenMin

_cChDGrenMax_

_kDRespGren_

kLossGren

_kMortGrenW_

_kMortGrens_

_cVSetGren_

_cVPUptMaxGren_

_cAffPUptGren

_CPDGrenMin_

_CPDGrenMax

_cVNUptMaxGren_

_cAffNUptGren_

_cNDGrenMin_

_cNDGrenMax_

_hSiAssGren_

_cMuMaxBlue_

cTmOptBlue

_cSigTmBlue_

cExtSpBlue

_UseSteeleBlue_

_cLOptRefBlue_

hLRefBlue

cChDBlueMin_

_cChDBlueMax

_cCyDBlueMin_

_cCyDBlueMax-

_kDRespBlue

kLossBlue

kMortBlueW

_kMortBlues_

_cVSetBlue_

_cVPUptMaxBlue

_cAffPUptBlue_

_CPDBlueMin_

_cPDBlueMax_

_cVNUptMaxBlue_

_cAffNUptBlue

_cNDBlueMin_

_cNDBlueMax_

_hSiAssBlue_

_cDBentIn

_kMigrBent_

_kMigrFish_

_cDFiJvln_

_CDFiAdln_

_kHarvFishWin

_kHarvFishSum_

_cDPiscln_

kMigrPisc

_kHarvPiscWin_

_kHarvPiscSum_

_cFiltMax_

_hFilt_

_cDCarrZoo_

_cPrefDiat_

_cPrefGren_
$\mathrm{mgN} / \mathrm{mgDW}$

$\mathrm{mgN} / \mathrm{mgDW}$

$\mathrm{mgSi} / \mathrm{l}$

day-1

oC

oC

m2/gDW

$\mathrm{W} / \mathrm{m} 2$

$\mathrm{W} / \mathrm{m} 2$

$\mathrm{mgCh} / \mathrm{mgDW}$

$\mathrm{mgChl} / \mathrm{mgDW}$

day-1

day-1

day-1

$\mathrm{m} /$ day

$\mathrm{mgP} / \mathrm{mgDW} /$ day

I/mgDW/day

$\mathrm{mgP} / \mathrm{mgDW}$

$\mathrm{mgP} / \mathrm{mgDW}$

$\mathrm{mgN} / \mathrm{mgDW} /$ day

I/mgDW/day

$\mathrm{mgN} / \mathrm{mgDW}$

$\mathrm{mgN} / \mathrm{mgDW}$

$\mathrm{mgSi} / \mathrm{l}$

day-1

oC

oC

m2/gDW

$\mathrm{W} / \mathrm{m} 2$

$\mathrm{W} / \mathrm{m} 2$

$\mathrm{mgChl} / \mathrm{mgDW}$

$\mathrm{mgChl} / \mathrm{mgDW}$

$\mathrm{mgChl} / \mathrm{mgDW}$

$\mathrm{mgChl} / \mathrm{mgDW}$

day-1

day-1

day-1

$\mathrm{m} /$ day

$\mathrm{mgP} / \mathrm{mgDW} /$ day

I/mgDW/day

$\mathrm{mgP} / \mathrm{mgDW}$

$\mathrm{mgP} / \mathrm{mgDW}$

$\mathrm{mgN} / \mathrm{mgDW} /$ day

I/mgDW/day

$\mathrm{mgN} / \mathrm{mgDW}$

$\mathrm{mgN} / \mathrm{mgDW}$

$\mathrm{mgSi} / \mathrm{l}$

$\mathrm{gDW} / \mathrm{m} 2$

day-1

day-1

$\mathrm{gDW} / \mathrm{m} 2$

$\mathrm{gDW} / \mathrm{m} 2$

day-1

day-1

$\mathrm{gDW} / \mathrm{m} 2$

day-1

day-1

day-1

Itr/mgDW/day

$\mathrm{mgDW} / \mathrm{l}$

$\mathrm{mg} / \mathrm{l}$
0,01 minimum_N/day_ratio_Diatoms

0,05 max_N/day_ratio_Diatoms

0,09 half_sat_Si_for_diatoms

1,5 maximum_growth_rate_greens

25 optimum_temp_of_greens

15 temperature_constant_greens(sigma_in_Gaussian_curve)

0,25 specific_extinction_greens

0 Flag_1_=_use_Steele_function0_=_use_Lehman_function

17 half-sat_PAR_for_green_algae_at_20_oC(Lehmann_function)

1000 optimum_PAR_at_20_oC(Steele_function)_Fake_value

0,01 min_chlorophyll/C_ratio_greens

0,02 max_chlorophyll/C_ratio_greens

0,075 maintenance_respiration_constant_greens(=_005_*_MuMax)

0,25 grazing_loss_rate_for_greens

0,01 mortality_constant_of_Diatoms_in_water

0,05 mortality_constant_greens

0,2 sedimentation_velocity_of_greens

0,01 maximum_P_uptake_capacity_of_greens

0,2 initial_P_uptake_affinity_greens

0,0015 minimum_P/day_ratio_greens

0,015 max_P/day_ratio_greens

0,07 maximum_N_uptake_capacity_of_greens

0,2 initial_N_uptake_affinity_greens

0,02 minimum_N/day_ratio_greens

0,1 max_N/day_ratio_greens

0 half-sat_Si_conc_for_growth_of_green_algae_=_0

0,6 maximum_growth_rate_Bluegreens

25 optimum_temp_blue-greens

12 temperature_constant_blue-greens(sigma_in_Gaussian_curve)

0,35 specific_extinction_Bluegreens

1 Flag_1_=_use_Steele_function0_=_use_Lehman_function

13,6 optimum_PAR_for_blue-greens_at_20_oC(Steele_function)

1000 half-sat_PAR_at_20_oC(Lehmann_function)_Fake_value

0,005 min_chlorophyll/C_ratio_Bluegreens

0,015 max_chlorophyll/C_ratio_Bluegreens

0,004 min_c-phycocyanin/C_ratio_Bluegreens

0,06 max_c-phycocyanin/C_ratio_Bluegreens

0,03 maintenance_respiration_constant_blue-greens(=_005_*

0,03 grazing_loss_rate_for_Blue-greens

0,01 mortality_constant_of_blue-greens_in_water

0,2 mortality_constant_Bluegreens

0,06 sedimentation_velocity_Blue-greens

0,04 maximum_P_uptake_capacity_of_Bluegreens

0,8 initial_P_uptake_affinity_Bluegreens

0,0025 minimum_P/day_ratio_Bluegreens

0,025 max_P/day_ratio_blue-greens

0,07 maximum_N_uptake_capacity_of_Bluegreens

0,2 initial_N_uptake_affinity_Bluegreens

0,03 minimum_N/day_ratio_Bluegreens

0,15 max_N/DW_ratio_blue-greens

0 half-sat_Si_conc_for_growth_of_blue-greens_=_0

0,01 external_zoobenthos_density

0,001 zoobenthos_migration_rate

0,001 fish_migration_rate

0,005 external_fish_density

0,005 external_fish_density

0 fish_harvesting_fraction_in_winter

0 fish_harvesting_fraction_in_summer

0,001 external_Pi_sc_density

0,001_Pi_sc_migration_rate

0 _Pi_sc_harvesting_fraction_in_winter

0 _Pi_sc_harvesting_fraction_in_summer

4,5 maximum_filtering_rate(when_DOMW $=0$ )

1 half-sat_food_conc_for_filtering

25 carrying_capacity_of_zooplankton

0,75 selection_factor_for_Diatoms

0,75 selection_factor_for_Greens 
_cPrefBlue_

CPrefDet

fDAssZoo

_fDissEgesZ̄oo_

kDRespZoo_

kMortZoo

_fDissMortZoo_

cTmOptZoo_

cSigTmZoo_

_CDCarrBent_

kDAssBent_

hDFoodBent

fDAssBent_

fDissEgesBent

kDRespBent_

_kMortBent_

fDissMortBent

_CTmOptBent_

_cSigTmBent_

fDBone_

fPBone

cDCarrFish

fDissEgesFish

fDissMortFish

_cTmOptFish_

cSigTmFish_

_CDayReprFish_

fReprFish

_AgeFish_

cRelVegFish_

kDAssFiJv

hDZooFiJv

fDAssFiJv

kDRespFiJv

kMortFiJv_

kDAssFiAd

hDBentFiĀ

fDAssFiAd

kDRespFiAd

kMortFiAd

cDCarrPiscMax

cDCarrPiscMin

_cDCarrPiscBare

CDPhraMinPisc_

_cCovVegMin

_CRelPhraPisc_

_cRelVegPisc_

kDAssPisc

hDVegPisc

hDFishPisc

fDAssPisc

fDissEgesPisc

kDRespPisc

kMortPisc

fDissMortPisc

cTmOptPisc

_cSigTmPisc_

cDepthSM

kExchMax $\bar{M}$

hfMarsh

fDTotSM0

fDOrgSMO

fDDetSMO

fPInorgSM0

CPDPhra0

cNDPhra0

cDensStemPhra
$-$

day-1

day- 1

-

oC

oC

gDW/m2

day-1

$\mathrm{g} / \mathrm{m} 2$

day-1

day-1

oC

$\mathrm{OC}$

$\mathrm{gDW} / \mathrm{m} 2$

oC

oC

day-1

$\mathrm{g} / \mathrm{m} 2$

day-1

day-1

day-1

$\mathrm{g} / \mathrm{m} 2$

day-1

day-1

$\mathrm{gDW} / \mathrm{m} 2$

$\mathrm{gDW} / \mathrm{m} 2$

$\mathrm{gDW} / \mathrm{m} 2$

$\mathrm{gDW} / \mathrm{m} 2$

$\%$

$\mathrm{gDW} / \mathrm{m} 2 / \%$

$\mathrm{gDW} / \mathrm{m} 2 / \%$

day-1

$\mathrm{g} / \mathrm{m} 2$

$\mathrm{g} / \mathrm{m} 2$

-

day-1

day-1

-

oC

oC

m3/m3_marshwat

g_solid/g_sedimer

g_AFDWIg_solid

$g / g$

gP/gDW

gP/gDW

$\mathrm{gN} / \mathrm{gDW}$

$\mathrm{m}-2$
0,125 selection_factor_for_Bluegreens_Cal

0,25 selection_factor_for_detritus

$0,35 \mathrm{DW}$-assimilation_efficiency_of_herb_zooplankton

0,25 soluble_nutrient_fraction_of_by_herbzoopl_egested_food

0,15 maintenance_respiration_constant_herbzooplankton

0,04 mortality_constant_herbzooplankton

0,1 soluble_nutrient_fraction_of_died_zooplankton

25 optimum_temp_zooplankton

13 temperature_constant_zooplankton(sigma_in_Gaussian_curve)

10 carrying_capacity_of_zoobenthos

0,1 maximum_assimilation_rate

200 half-saturating_food_for_zoobenthos

0,3 C_ass_efficiency_of_zoobenthos

0,25 soluble_nutrient_fraction_of_by_zoobenthos_egested_food

0,005 maint_respiration_constant_of_zoobenthos

0,005 mortality_constant_of_zoobenthos

0,1 soluble_P_fraction_of_died_zoobenthos_P

25 optimum_temp_of_zoobenthos

16 temperature_constant_of_zoobenthos(sigma_in_Gaussian_curve)

0,35 fraction_of_fish_C_fixed_in_bones_and_scales

0,5 fraction_of_fish_P_fixed_in_bones_and_scales

15 carrying_capacity_of_fish(=_100_gFW/m2Grimm_1983)

0,25 soluble_nutrient_fraction_of_by_fish_egested_food

0,1 soluble_nutrient_fraction_of_died_fish(excl_bones_and_scales

25 optimum_temp_of_fish

10 temperature_constant_of_fish(sigma_in_Gaussian_curve)

120 reproduction_date_of_fish_=_1_May

0,02 yearly_reproduction_fraction_of_adult_fish

0,5 yearly_ageing_fraction_of_young_fish

0,009 decrease_of_fish_feeding_per_\%_vegetation_cover(max_001)

0,12 maximum_assimilation_rate_of_young_fish

1,25 half-saturating_zooplankton_biomass_for_young_fish_predation

0,4 C_assimilation_efficiency_of_young_fish

0,01 maintenance_respiration_constant_of_young_fish

0,00137 specific_mortality_of_young_fish $(=01$ 01_y-1)

0,06 maximum_assimilation_rate_of_adult_fish

2,5 half-saturating_zoobenthos_biomass_for_adult_fish_predation

0,4 C_assimilation_efficiency_of_adult_fish

0,004 maintenance_respiration_constant_of_adult_fish

0,00027 specific_mortality_of_adult_fish $\left(=\_01 \_y-1\right)$

1,2 maximum_carrying_capacity_of_Pi_sc $(=75$ _kg $/ \mathrm{ha})$

0,1 minimum_carrying_capacity_of_Pi_sc $\left(=6 \_\mathrm{kg} / \mathrm{ha}\right)$

0,1 carrying_capacity_of_Pi_sc_for_lake_without_marsh_zone

50 min_reed_biomass_for_Pi_sc

40 min_submveg_coverage_for_Pi_sc

0,075 rel_Pi_sc_density_per_\%_reed_if_submveg_absent

0,03 extra_rel_Pi_sc_density_per_\%_reed_if_aCovVeg_>_cCovVegMin

0,025 maximum_assimilation_rate

5 half-sat_vegetation_biomass_for_Pi_sc_growth

1 half-saturating_DFish_for_Pi_sc_predation

0,4 C_ass_efficiency_of_Pi_sc

0,25 soluble_P_fraction_of_by_fish_egested_food

0,005 maint_respiration_constant_of_Pi_sc

0,00027 specific_mortality_of_Pi_sc_ $==01$ _ $y-1$

0,1 soluble_nutrient_fraction_of_died_Pi_sc(excl_bones_and_scales

25 optimum_temp_of_Pi_sc

10 temperature_constant_of_Pi_sc(sigma_in_Gaussian_curve)

0,1 sediment_depth

1 maximum_dispersive_marsh_water_exchange_coefficient

0,1 rel_marsh_area_where_exchange_is_50\%

0,3 initial_dry-weight_fraction_in_sediment

0,1 initial_organic_fraction_of_sed

0,05 initial_detritus_fraction_of_sediment_organic_matter

0,0005 initial_inorg_P_fraction_in_sed

0,002 initial_P/day_ratio_of_reed

0,02 initial_N/day_ratio_of_reed

61,5 density_stem(+/-_139) 


\begin{tabular}{|c|c|}
\hline _cTmInitPhra_ & $\mathrm{OC}$ \\
\hline _fDAllPhra_ & - \\
\hline _kDAllPhra_ & $1 /$ day \\
\hline cDStemPhra_ & $\mathrm{g} / \mathrm{m}$ \\
\hline _cQ10ProdPhra_ & - \\
\hline cMuPhraMax & $1 /$ day \\
\hline _cDShootPhraMax_ & $\mathrm{gDW} / \mathrm{m} 2$ \\
\hline _cCovSpPhra_ & \%_cover_per_gD/ \\
\hline _cPDPhraMin_ & - \\
\hline _cPDPhraMax_ & - \\
\hline _cNDPhraMin_ & - \\
\hline _cNDPhraMax_ & - \\
\hline _cAffNUptPhra_ & I/mgDW/DWay \\
\hline _cAffPUptPhra_ & I/mgDW/DWay \\
\hline _cVNUptPhraMax_ & $\mathrm{mgN} / \mathrm{mgD} / \mathrm{day}$ \\
\hline cVPUptPhraMax_ & mgP/mgD/day \\
\hline kDRespPhra_ & 1/day \\
\hline _cQ10RespPhra_ & $1 / \mathrm{e}^{\wedge} \mathrm{oC}$ \\
\hline fDayWin_ & - \\
\hline _fDRealPhra_ & - \\
\hline _kDRealPhra_ & 1/day \\
\hline kDMortShootPhra_ & 1/day \\
\hline _kDMortRootPhra_ & $1 /$ day \\
\hline _cDayWinPhra_ & day \\
\hline _cDayManPhra_ & day \\
\hline _ManPhra_ & - \\
\hline _kDManShootPhra_ & $1 /$ day \\
\hline cOxyCons_ & $1 /$ day \\
\hline _DaysPerYear_ & $d / y$ \\
\hline _TenDays_ & d \\
\hline _HoursPerDay_ & $h / d$ \\
\hline _SecsPerDay_ & $s / d$ \\
\hline _mmPerm_ & $\mathrm{mm} / \mathrm{m}$ \\
\hline _m2Perha_ & $\mathrm{m} 2 / \mathrm{ha}$ \\
\hline _mgPerg_ & $\mathrm{mg} / \mathrm{g}$ \\
\hline _gPerkg_ & $\mathrm{g} / \mathrm{kg}$ \\
\hline _gPerton_ & g/ton \\
\hline _PerCent_ & $\%$ \\
\hline _NearZero_ & - \\
\hline _molO2molC_ & $\mathrm{gO} 2 / \mathrm{gC}$ \\
\hline _molO2molN_ & $\mathrm{gO} 2 / \mathrm{gN}$ \\
\hline _molNmolC_ & $\mathrm{gN} / \mathrm{gC}$ \\
\hline _cRhoWat_ & $\mathrm{g} / \mathrm{m} 3$ \\
\hline $\mathrm{Pi}_{-}$ & - \\
\hline
\end{tabular}

8 tempstart_initial_growth

0,3 allocation_fraction

0,05 allocation_rate

6 average_stem_weight

2 temp_quotient_of_production

0,03 maximum_growth_rate_reed

3500 max_shoot_biomass_of_reed

0,1 specific_coverage

0,0008 minPhra_P/day_-ratio

0,003 maxPhra_P/day_-ratio

0,008 minPhra_N/day_-ratio

0,03 maxPhra_N/day_ratio

0,0002 N_uptake_affinity_reed

0,0002 P_uptake_affinity_reed

0,1 max_uptake_rate_N_001

0,01 max_uptake_rate_P_0001

0,001 respiration_rate_of_reed

2,5 temp_quotient_of_respiration

0,52 Start_autumn

0,85 reallocated_fraction_day

0,05 reallocation_rate_day

0 mortality_rate_shoots

0,000391 mortality_rate_roots

259 begin_autumn(16_sept)

255 time_of_management

0 fraction_biomass_loss_by_management

1 rate_of_management

1 infiltrated_oxygen_consumed_in_one_day

365 DaysPerYear

10 TenDays

24 HoursPerDay

86400 SecsPerDay

$1000 \mathrm{mmPerm}$

10000 m2Perha

1000 mgPerg

1000 gPerkg

1000000 gPerton

0,01 PerCent

1,00E-28 very_small_number_used_to_avoid_dividing_by_zero_

2,6667 ratio_of_molweights

2,2857 ratio_of_molweights

1,1667 ratio_of_molweights

1000000 density_of_water

3,141592654 Pi_(approx_314159)

$<$ dynamics $>$

name

sTime

-TimeYears

_Day_

Years_

_uTmVar_

uTm

_uVWind_

_ufDay_

_uLDay_

_uLOut_

_uLPARSurf_

_aExtPhyt_

_aExtDet_

aExtIM

_aExtCoefOpen

_uQInSeason_

uQEvSinus_

_UQEv

_uQInExtra

_uQOutExtra

\begin{tabular}{|c|c|}
\hline unit & description \\
\hline d & _sTime_=_tir time \\
\hline y & _TimeYears_Time_in_years \\
\hline & _Day_=_sTir Time_(daynumber)_within_the_year_(0-365) \\
\hline & _Years_=_YıTime_in_calendar_years \\
\hline $\mathrm{oC}$ & _uTmVar_=_Temperature_variation \\
\hline $\mathrm{oC}$ & _uTm_ $={ }_{-} \mathrm{IF}_{-}^{-}$Forcing_function_temperature \\
\hline $\mathrm{m} / \mathrm{s}$ & _uVWind_=_Forcing_function_wind_speed \\
\hline $\mathrm{h} / 24 \mathrm{~h}$ & _ufDay_=_IF day_length \\
\hline otal_J/m2/d & _uLDay_=_If total_daily_radiation \\
\hline tal_J/m2/s_ & V_uLOut_=_IF average_light_intensity_during_daytime \\
\hline $\mathrm{m} 2 / \mathrm{s} \_\mathrm{PAR}$ & I_uLPARSurf_average_PAR_at_zero_depth \\
\hline $\mathrm{m}-1$ & _aExtPhyt_= contribution_of_algae_to_extinction \\
\hline$m-1$ & _aExtDet_=_detrital_contribution_to_extinction \\
\hline$n-1$ & aExtIM_=_contribution_of_inert_matter_to_extinction \\
\hline & _aExtCoefOpє extinction_coefficient_without_vegetation \\
\hline & _uQInSeason_seasonal_inflow \\
\hline $\mathrm{m} / \mathrm{d}$ & _uQEvSinus_sinusoid_evaporation \\
\hline $\mathrm{m} / \mathrm{d}$ & _uQEv_=_IF evaporation \\
\hline $\mathrm{m} / \mathrm{d}$ & _uQInExtra_= extra_inflow_(for_periodic_water_level_regulation \\
\hline & _uQOutExtra_extra_outflow_(for_periodic_water_level_regulation \\
\hline
\end{tabular}




\begin{tabular}{|c|c|c|}
\hline _uQln_ & $\mathrm{mm} / \mathrm{d}$ & _uQIn_=_IF_inflow \\
\hline _uQOut_ & $\mathrm{mm} / \mathrm{d}$ & _uQOut_=_If outflow \\
\hline _uQDil_ & $\mathrm{mm} / \mathrm{d}$ & _uQDil_=_uC inflow_minus_evaporation \\
\hline _ukDil__ & $d-1$ & _ukDil_=_uQdilution_rate_of_substances \\
\hline _ukDilWat_ & $d-1$ & _ukDilWat_= dilution_rate_of_water \\
\hline _ukOut__ & $d-1$ & _ukOut_=_u( outflow_rate \\
\hline _uTauWat_ & d & _uTauWat_= water_residence_time \\
\hline _uTauSubst__ & d & _uTauSubst_residence_time_of_substances \\
\hline _vTranDepthW_ & $\mathrm{m} / \mathrm{d}$ & _vTranDepthV change_in_water_depth \\
\hline _akExchM_ & m3/m3_marsh_we & _akExchM_ = marsh_water_exchange_coefficient \\
\hline _afVolMarsh_ & m3_marsh/m3_lar. & _afVolMarsh_relative_marsh_volume \\
\hline _akExchL_ & $\mathrm{m} 3 / \mathrm{m} 3$ _lake_wate & _akExchL_ = lake_water_exchange_coefficient \\
\hline $\mathrm{uCO} 2 \mathrm{~W}$ & $\mathrm{mmol} / \mathrm{m} 3$ & $\mathrm{uCO} 2 \mathrm{~W}=\mathrm{CO} 2$ in lake water \\
\hline _uMultiMuMaxVeg_ & - & _uMultiMuMas MuMaxVeg_multiplier \\
\hline _uMuMaxVeg_ & g/g_shoot/day & _uMuMaxVeg.maximum_growth_rate_of_vegetation_at_20oC \\
\hline _oDPhytW_ & $\mathrm{g} / \mathrm{m} 3$ & _oDPhytW_= total_DW_phytoplankton_in_lake_water \\
\hline _oPPhytW_ & $\mathrm{g} / \mathrm{m} 3$ & _oPPhytW_= total_P_phytoplankton_in_lake_water \\
\hline oNPhytW_ & $\mathrm{g} / \mathrm{m} 3$ & oNPhytW_ = total_N_phytoplankton_in_lake_water \\
\hline _aDPhyts_ & $\mathrm{g} / \mathrm{m} 2$ & _aDPhytS_= total_DW_phytoplankton_on_lake_sediment \\
\hline _aPPhyts_- & $\mathrm{g} / \mathrm{m} 2$ & _aPPhytS_= total_P_phytoplankton_on_lake_sediment \\
\hline _aNPhyts_- & $\mathrm{g} / \mathrm{m} 2$ & _aNPhyts_= total_N_phytoplankton_on_lake_sediment \\
\hline _oDOMW_ & $\mathrm{gDW} / \mathrm{m} 3$ & _oDOMW_ $=$ organic_seston \\
\hline oDSestW_ & $\mathrm{mgDW} / \mathrm{l}$ & oDSestW_ $=$ total_seston \\
\hline oPOMW_ & $\mathrm{gP} / \mathrm{m} 3$ & OPOMW_= organic_P_in_water \\
\hline _oPSestW_ & $\mathrm{gP} / \mathrm{m} 3$ & _oPSestW_ $=$ total_seston_P_(incl_adsorbed \\
\hline _oPInorgW & $\mathrm{gP} / \mathrm{m} 3$ & _oPInorgW_- = inorganic_P_in_water \\
\hline _oPTotW_ & $\mathrm{gP} / \mathrm{m} 3$ & _oPTotW_=_total_P_in_water_(excl_animals_AND_vegetation) \\
\hline oNDissW_ & $\mathrm{gN} / \mathrm{m} 3$ & _oNDissW_= SRN_in_water \\
\hline _oNOMW_ & $\mathrm{gN} / \mathrm{m} 3$ & _oNOMW_ = _orgseston_N \\
\hline oNSestW & $\mathrm{gN} / \mathrm{m} 3$ & oNSest $\mathrm{W}=$ total seston $\mathrm{N}$ \\
\hline _oNkjW_ & $\mathrm{gN} / \mathrm{m} 3$ & _oNkjW_=_o kjeldahl_N_in_water \\
\hline oNTotW_ & $\mathrm{gN} / \mathrm{m} 3$ & _oNTotW_= _total_N_in_water_(without_animals_AND_vegetation) \\
\hline bPorS_ & m3_water_m-3_st_ & _bPorS_ $=(1$. porosity \\
\hline _bPorCorS_ & - & _bPorCorS_= sediment_porosity_corrected_for_tortuosity \\
\hline aDTotS_ & $\mathrm{g} / \mathrm{m} 2$ & _aDTotS_ = : total_sediment_(excl_biota) \\
\hline _aRhoTots_ & g_solid_m-3_sediı & _aRhoTotS_=(apparent)_bulk_density_of_sediment \\
\hline _aRhoSolidS_ & $\mathrm{g} / \mathrm{m}-3$ _solid & _aRhoSolidS_average_solid_density \\
\hline _afDTotS_ & g_solid_g-1_sedin & _afDTotS_= 1 sediment_dry-weight_fraction \\
\hline _afDOrgs_ & - & _afDOrgS_= | total_organic_fraction_of_sediment_DW \\
\hline _afDetS_ & - & _afDetS_=_sdetrital_fraction_of_sediment_organic_DW \\
\hline _afDetTotS_ & - & _afDetTotS_= detrital_fraction_of_total_sediment_DW \\
\hline _aPInorgS_ & $\mathrm{gP} / \mathrm{m} 2$ & _aPInorgS_ = inorganic_P_in_sediment \\
\hline _aPTotAvails_ & $\mathrm{gP} / \mathrm{m} 2$ & _aPTotAvailS_total_P_in_sediment_(excl_humus_animals_AND_vegetation) \\
\hline aPTots_ & $\mathrm{gP} / \mathrm{m} 2$ & aPTotS_ $=$ _itotal_P_in_sediment_(excl_animals_AND_vegetation) \\
\hline _afPInorgS_ & $\mathrm{gP} / \mathrm{gD}$ & _afPInorgS_ = fraction_inorganic_P_in_sediment \\
\hline _afPTotS_ & $\mathrm{gP} / \mathrm{gD}$ & _afPTotS_=_total_P_fraction_in_sediment \\
\hline _afPO4S_- & - & _afPO4S_=_fraction_dissolved_P_in_sediment \\
\hline oPO4S_ & $\mathrm{gP} / \mathrm{m} 3$ & _oPO4S_=_conc_dissolved_P_in_interstitial_water \\
\hline${ }_{-}$aNDissS_ & $\mathrm{gN} / \mathrm{m} 2$ & _aNDissS_ $=$. total_dissolved_N_ _in_pore_water \\
\hline _aNkjAvails__ & $\mathrm{gN} / \mathrm{m} 2$ & _aNkjAvailS_ kjeldahl_N_in_sediment_excl_humus \\
\hline _aNkjS_ & $\mathrm{gN} / \mathrm{m} 2$ & _aNkjS_ = _al kjeldahl_N_in_sediment \\
\hline _aNTotAvails_ & $\mathrm{gN} / \mathrm{m} 2$ & _aNTotAvailS_total_N_in_sediment_excl_humus \\
\hline aNTotS & $\mathrm{gN} / \mathrm{m} 2$ & aNTotS_ $=$ total_N_in_sediment \\
\hline _afNInorgS_ & $\mathrm{gN} / \mathrm{gD}$ & _afNInorgS_=fraction_inorganic_N_in_sediment \\
\hline _afNTots_ & $\mathrm{gN} / \mathrm{gD}$ & _afNTotS_=_total_N_fraction_in_sediment \\
\hline -ONO3S_- & $\mathrm{gN} / \mathrm{m} 3$ & _oNO3S_=_conc_dissolved_N-NO3_in_interstitial_water \\
\hline oNH4S_ & $\mathrm{gN} / \mathrm{m} 3$ & _oNH4S_= _conc_dissolved_N-NH4_in_interstitial_water \\
\hline _oNDissS_ & $\mathrm{mgN} / \mathrm{l}$ & _oNDissS_ $=$. Dissolved_N_conc_in_sediment_needed_for_calc_of_veg_uptake_rate \\
\hline _rPDIMW_ & $\mathrm{gP} / \mathrm{gD}$ & _rPDIMW_=_P/D_ratio_of_water_DIM \\
\hline rPDIMS_ & $\mathrm{gP} / \mathrm{gD}$ & _rPDIMS_=_P/D_ratio_of_sediment_DIM \\
\hline rPDDetW_ & $\mathrm{gP} / \mathrm{gD}$ & _rPDDetW_ $=$ P/D_ratio_of_water_detritus \\
\hline rNDDetW_ & $\mathrm{gN} / \mathrm{gD}$ & _rNDDetW_ $=$ N/D_ratio_of_water_detritus \\
\hline _rSiDDetW_ & gSi/gD & _rSiDDetW_=Si/D_ratio_of_water_detritus \\
\hline _rPDHums_ & $\mathrm{gP} / \mathrm{gDW}$ & _rPDHumS_=P_content_of_sediment_OM \\
\hline _rNDHums_- & $\mathrm{gN} / \mathrm{gDW}$ & _rNDHumS_= N_content_of_sediment_OM \\
\hline rPDDetS_- & $\mathrm{gP} / \mathrm{gDW}$ & _rPDDetS_= P_content_of_sediment_detritus \\
\hline _rNDDetS_- & gN/gDW & _rNDDetS_= N_content_of_sediment_detritus \\
\hline
\end{tabular}




\begin{tabular}{|c|c|c|}
\hline _rSiDDetS_ & gSi/gDW & _rSiDDetS_= Si_content_of_sediment_detritus \\
\hline _oDPhytWM_ & gSi/gDW & _oDPhytWM_total_DW_phytoplankton_in_marsh_water \\
\hline _oPPhytWM_- & gSi/gDW & _oPPhytWM_total_P_phytoplankton_in_marsh_water \\
\hline oNPhytWM_- & gSi/gDW & _oNPhytWM_total_N_phytoplankton_in_marsh_water \\
\hline _oSiDiatWM_ & gSi/gDW & _oSiDiatWM_total_Si_diatoms_in_marsh_water \\
\hline oDOMWM_ & $\mathrm{mgD} / \mathrm{l}$ & _oDOMWM_: organic_seston \\
\hline _oDSestWM_ & $\mathrm{mgDW} / \mathrm{l}$ & _oDSestWM_total_seston \\
\hline _oPOMWM_ & $\mathrm{mgP} / \mathrm{l}$ & _oPOMWM_=organic_P_in_water \\
\hline _oPSestWM_ & $\mathrm{mgP} / \mathrm{l}$ & _oPSestWM_total_seston_P(incl_adsorbed \\
\hline _oPInorgWM_- & $\mathrm{mgP} / \mathrm{l}$ & _oPInorgWM_inorganic_P_in_water \\
\hline _oPTotWM_ & $\mathrm{mgP} / \mathrm{l}$ & _oPTotWM_ = total_P_in_water \\
\hline _oNDissWM_ & $\mathrm{mgN} / \mathrm{l}$ & _oNDissWM_SRN_in_water \\
\hline oNOMWM & $\mathrm{mgN} / \mathrm{l}$ & oNOMWM = orgseston $\mathrm{N}$ \\
\hline _oNSestWM_ & $\mathrm{mgN} / \mathrm{l}$ & _oNSestWM_total_seston_N \\
\hline oNkjWM_ & $\mathrm{mgN} / \mathrm{l}$ & _oNkjWM_= _kjeldahl_N_in_water \\
\hline oNTotWM_ & $\mathrm{mgN} / \mathrm{l}$ & _oNTotWM_ $=$ total_N_in_water \\
\hline _bPorSM_ & m3_water_m-3_st & ${ }_{\text {bPorSM_}}=($ porosity \\
\hline _bPorCorSM_ & 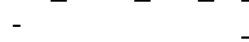 & _bPorCorSM_sediment_porosity_corrected_for_tortuosity \\
\hline _aDTotSM_ & $\mathrm{g} / \mathrm{m} 2$ & _aDTotSM_= total_sediment(excl_biota) \\
\hline aRhoTotSM_ & g_solid_m-3_sedil & _aRhoTotSM_(apparent)_bulk_density_of_sediment \\
\hline _aRhoSolidSM_. & g_m-3_solid & _aRhoSolidSn average_solid_density \\
\hline _afDTotSM_ & g_solid_g-1_sedin & _afDTotSM_ = sediment_dry-weight_fraction \\
\hline afDOrgSM_ & - & _afDOrgSM_: total_organic_fraction_of_sediment_DW \\
\hline _afDetSM_- & - & _afDetSM_ = detrital_fraction_of_sediment_organic_DW \\
\hline _afDetTotSM_ & - & _afDetTotSM_detrital_fraction_of_total_sediment_DW \\
\hline _aPInorgSM_- & $\mathrm{gP} / \mathrm{m} 2$ & _aPInorgSM_inorganic_P_in_sediment \\
\hline _aPTotAvailSM_ & $\mathrm{gP} / \mathrm{m} 2$ & _aPTotAvailSI total_P_in_sediment(excl_humusanimals_AND_vegetation) \\
\hline aPTotSM_ & $\mathrm{gP} / \mathrm{m} 2$ & _aPTotSM_ $=$ total_P_in_sediment(excl_animals_AND_vegetation $)$ \\
\hline _afPInorgSM_ & $\mathrm{gP} / \mathrm{gD}$ & _afPInorgSM_fraction_inorganic_P_in_sediment \\
\hline afPTotSM & $\mathrm{gP} / \mathrm{gD}$ & afPTotSM = total $P$ fraction in sediment \\
\hline _afPO4SM_- & - & _afPO4SM_= fraction_dissolved_P_in_sediment \\
\hline _oPO4SM_- & $\mathrm{gP} / \mathrm{m} 3$ & _oPO4SM_= conc_dissolved_P_in_interstitial_water \\
\hline _aNDissSM_ & $\mathrm{gN} / \mathrm{m} 2$ & _aNDissSM_ $\overline{-}_{\text {_total_dissolved_N_in_pore_water }}$ \\
\hline _aNkjAvailSM_ & $\mathrm{gN} / \mathrm{m} 2$ & _aNkjAvailSM kjeldahl_N_in_sedimentexcl_humus \\
\hline _aNkjSM_ & $\mathrm{gN} / \mathrm{m} 2$ & _aNkjSM_ = kjeldahl_N_in_sediment \\
\hline aNTotAvailSM & $\mathrm{gN} / \mathrm{m} 2$ & aNTotAvailSI total $\mathrm{N}$ in sedimentexcl humus \\
\hline _aNTotSM_ & $\mathrm{gN} / \mathrm{m} 2$ & _aNTotSM_ = total_N_in_sediment \\
\hline _afNInorgSM_ & $\mathrm{gN} / \mathrm{gD}$ & _afNInorgSM_fraction_inorganic_N_in_sediment \\
\hline _afNTotSM_- & $\mathrm{gN} / \mathrm{gD}$ & _afNTotSM_= total_N_fraction_in_sediment \\
\hline _oNO3SM_ & $\mathrm{gN} / \mathrm{m} 3$ & _oNO3SM_= conc_dissolved_N-NO3_in_interstitial_marsh_water \\
\hline _oNH4SM_- & $\mathrm{gN} / \mathrm{m} 3$ & _oNH4SM_= conc_dissolved_N-NH4_in_interstitial_marsh_water \\
\hline oNDissSM & $\mathrm{mgN} / \mathrm{l}$ & oNDissSM : Dissolved $\mathrm{N}$ conc in marsh sediment \\
\hline rPDIMWM_- & $\mathrm{gP} / \mathrm{gD}$ & _rPDIMWM_=P/D_ratio_of_DIM_in_marsh_water \\
\hline rPDIMSM_ & $\mathrm{gP} / \mathrm{gD}$ & _rPDIMSM_=P/D_ratio_of_DIM_marsh_sediment \\
\hline rPDDetWM_ & $\mathrm{gP} / \mathrm{gD}$ & _rPDDetWM_P/D_ratio_of_marsh_water_detritus \\
\hline _rNDDetWM_ & $\mathrm{gN} / \mathrm{gD}$ & _rNDDetWM_N/D_ratio_of_marsh_water_detritus \\
\hline rSiDDetWM_- & $\mathrm{gSi} / \mathrm{gD}$ & _rSiDDetWM_Si/D_ratio_of_marsh_water_detritus \\
\hline rPDHumSM & gP/gDW & rPDHumSM $\mathrm{P}$ content of marsh sediment OM \\
\hline _rNDHumSM_- & gN/gDW & _rNDHumSM_N_content_of_marsh_sediment_OM \\
\hline _rPDDetSM_- & $\mathrm{gP} / \mathrm{gDW}$ & _rPDDetSM_:P_content_of_marsh_sediment_detritus \\
\hline rNDDetSM_ & $\mathrm{gN} / \mathrm{gDW}$ & _rNDDetSM_N_content_of_marsh_sediment_detritus \\
\hline _rSiDDetSM_ & gSi/gDW & _rSiDDetSM_Si_content_of_marsh_sediment_detritus \\
\hline _aDTotM_ & $\mathrm{gD} / \mathrm{m} 2$ & _aDTotM_ =_total_D_in_marsh \\
\hline aPTotM_ & $\mathrm{gP} / \mathrm{m} 2$ & _aPTotM_ $=$ _total_P_in_marsh \\
\hline _aNTotM_- & $\mathrm{gN} / \mathrm{m} 2$ & _aNTotM_e $=$ _total_N_in_marsh \\
\hline _aSiTotM_- & $\mathrm{gSi} / \mathrm{m} 2$ & _aSiTotM_ = total_Si_in_marsh \\
\hline _iPPulse_ & - & _iPPulse_ $=1-$ \\
\hline _uPLoadSeason_ & $\mathrm{gP} / \mathrm{m} 2 / \mathrm{dag}$ & _uPLoadSeas seasonal_P_load \\
\hline _uPLoad__ & $\mathrm{gP} / \mathrm{m} 2 / \mathrm{dag}$ & _uPLoad_=_P_load -- \\
\hline _uPLoadPO4_ & $\mathrm{gP} / \mathrm{m} 2 / \mathrm{dag}$ & _uPLoadPO4_P_load_PO4 \\
\hline _uPLoadOrg_- & $\mathrm{gP} / \mathrm{m} 2 / \mathrm{dag}$ & _uPLoadOrg_P_load_bound_to_org_matter \\
\hline _uPLoadPhytTot_ & $\mathrm{gP} / \mathrm{m} 2 / \mathrm{d}$ & _uPLoadPhyt 7 (total)_algal_P_input \\
\hline _uPLoadDet_ & $\mathrm{gP} / \mathrm{m} 2 / \mathrm{d}$ & _uPLoadDet_detrital_P_input \\
\hline _uPLoadAIM_- & $\mathrm{gP} / \mathrm{m} 2 / \mathrm{d}$ & _uPLoadAIM_Adsorbed_P_loading_(=0) \\
\hline _iNPulse_ & - & iNPulse $=1$ \\
\hline uNLoadSeason & $\mathrm{gP} / \mathrm{m} 2 / \mathrm{d}$ & uNLoadSeas seasonal $\mathrm{N}$ load \\
\hline uNLoadPhytTot_- & $\mathrm{gN} / \mathrm{m} 2 / \mathrm{d}$ & _uNLoadPhyt (total)_algal_N_input \\
\hline
\end{tabular}




\begin{tabular}{|c|c|c|}
\hline _uNLoad_ & $\mathrm{gN} / \mathrm{m} 2 / \mathrm{d}$ & _uNLoad_=_N_load \\
\hline _uNLoadDet_ & $\mathrm{gN} / \mathrm{m} 2 / \mathrm{d}$ & _uNLoadDet_N_load_detritus \\
\hline _uNLoadOrg_- & $\mathrm{gN} / \mathrm{m} 2 / \mathrm{d}$ & _uNLoadOrg_loading_N_bound_to_org_matter \\
\hline uNLoadDiss_ & $\mathrm{gN} / \mathrm{m} 2 / \mathrm{d}$ & _uNLoadDiss_N_loading_dissolved_(sum_of_NO2_and_NH4) \\
\hline _uNLoadNH4_ & $\mathrm{gN} / \mathrm{m} 2 / \mathrm{d}$ & _uNLoadNH4_NH4_loading \\
\hline _uNLoadNO3_ & $\mathrm{gN} / \mathrm{m} 2 / \mathrm{d}$ & _uNLoadNO3_NO3_loading \\
\hline _uNTotln_ & $\mathrm{mgN} / \mathrm{l}$ & _uNTotln_ = _external_N_conc \\
\hline _uDLoadDet_ & $\mathrm{gDW} / \mathrm{m} 2 / \mathrm{d}$ & _uDLoadDet_detrital_DW_loading \\
\hline _uDLoadPhytTot_ & $\mathrm{gDW} / \mathrm{m} 2 / \mathrm{d}$ & _uDLoadPhyt" (total)_algal_DW_input \\
\hline uDLoadIM & $\mathrm{gDW} / \mathrm{m} 2 / \mathrm{d}$ & uDLoadIM = loading_of DW_of inorg matter \\
\hline _uDLoad_ & $\mathrm{gD} / \mathrm{m} 2 / \mathrm{d}$ & _uDLoad_=_total_DW_input \\
\hline _uPTotln_ & $\mathrm{gP} / \mathrm{m} 3==\mathrm{mgP} / \mathrm{l}$ & _uPTotln_=_external_P_concentration \\
\hline uDLoadDiat & $\mathrm{gD} / \mathrm{m} 2 / \mathrm{d}$ & uDLoadDiat Diat input \\
\hline _uPLoadDiat_- & $\mathrm{gP} / \mathrm{m} 2 / \mathrm{d}$ & _uPLoadDiat_Diat_input \\
\hline _uNLoadDiat__ & $\mathrm{gN} / \mathrm{m} 2 / \mathrm{d}$ & _uNLoadDiat_Diat_input \\
\hline _uDLoadGren_ & $\mathrm{gD} / \mathrm{m} 2 / \mathrm{d}$ & _uDLoadGren Gren_input \\
\hline _uPLoadGren_ & $\mathrm{gP} / \mathrm{m} 2 / \mathrm{d}$ & _uPLoadGren Gren_input \\
\hline _uNLoadGren_ & $\mathrm{gN} / \mathrm{m} 2 / \mathrm{d}$ & _uNLoadGren Gren_input \\
\hline _uDLoadBlue_ & $\mathrm{gD} / \mathrm{m} 2 / \mathrm{d}$ & _uDLoadBlue_Blue_input \\
\hline _uPLoadBlue_ & $\mathrm{gP} / \mathrm{m} 2 / \mathrm{d}$ & _uPLoadBlue_Blue_input \\
\hline _uNLoadBlue_ & $\mathrm{gN} / \mathrm{m} 2 / \mathrm{d}$ & _uNLoadBlue_Blue_input \\
\hline _wDDillM_ & $\mathrm{gD} / \mathrm{m} 3 / \mathrm{d}$ & _wDDillM_=_dilution_of_DW_IM \\
\hline _wDDilDet_ & $\mathrm{gD} / \mathrm{m} 3 / \mathrm{d}$ & _wDDilDet_= dilllution_of_detritus \\
\hline _wPDilPO4_ & $\mathrm{gP} / \mathrm{m} 3 / \mathrm{d}$ & _wPDilPO4_= dilution_of_SRP \\
\hline _wPDilDet_ & $\mathrm{gP} / \mathrm{m} 3 / \mathrm{d}$ & _wPDilDet_= dilution_of_detritus \\
\hline _wPDilAIM_- & $\mathrm{gP} / \mathrm{m} 3 / \mathrm{d}$ & _wPDilAIM_- = dilution_of_IM-ads_P \\
\hline _wNDilNH4_- & $\mathrm{gN} / \mathrm{m} 3 / \mathrm{d}$ & _wNDilNH4_=dilution_of_ammonium \\
\hline _wNDilNO3_ & $\mathrm{gN} / \mathrm{m} 3 / \mathrm{d}$ & _wNDilNO3_=dilution_of_nitrate \\
\hline _wNDilDet_ & $\mathrm{gN} / \mathrm{m} 3 / \mathrm{d}$ & _wNDilDet_= dilution_of_detritus \\
\hline _wO2Inflow_ & $\mathrm{gO} 2 / \mathrm{m} 3 / \mathrm{d}$ & _wO2Inflow_= oxygen_inflow \\
\hline _wO2Outfl_- & $\mathrm{gO} 2 / \mathrm{m} 3 / \mathrm{d}$ & _wO2Outfl_= oxygen_outflow \\
\hline _wDDilDiat_ & $\mathrm{g} / \mathrm{m} 3 / \mathrm{d}$ & _wDDilDiat_=dilution_of_Diat \\
\hline _wPDilDiat_ & $\mathrm{gP} / \mathrm{m} 3 / \mathrm{d}$ & _wPDilDiat_= dilution_of_Diat \\
\hline _wNDilDiat_ & $\mathrm{gN} / \mathrm{m} 3 / \mathrm{d}$ & _wNDilDiat_= dilution_of_Diat \\
\hline _wDDilGren_ & $\mathrm{g} / \mathrm{m} 3 / \mathrm{d}$ & _wDDilGren_dilution_of_Gren \\
\hline _wPDilGren_ & $\mathrm{gP} / \mathrm{m} 3 / \mathrm{d}$ & _wPDilGren_: dilution_of_Gren \\
\hline _wNDilGren_ & $\mathrm{gN} / \mathrm{m} 3 / \mathrm{d}$ & _wNDilGren_dilution_of_Gren \\
\hline _wDDilBlue_ & $\mathrm{g} / \mathrm{m} 3 / \mathrm{d}$ & _wDDilBlue_= dilution_of_Blue \\
\hline _wPDilBlue_ & $\mathrm{gP} / \mathrm{m} 3 / \mathrm{d}$ & _wPDilBlue_= dilution_of_Blue \\
\hline _wNDilBlue_ & $\mathrm{gN} / \mathrm{m} 3 / \mathrm{d}$ & _wNDilBlue_= dilution_of_Blue \\
\hline _wDDilPhyt_ & $\mathrm{gD} / \mathrm{m} 3 / \mathrm{d}$ & _wDDilPhyt_ = total_algal_dilution \\
\hline _wPDilPhyt_ & $\mathrm{gP} / \mathrm{m} 3 / \mathrm{d}$ & _wPDilPhyt_= total_algal_dilution \\
\hline _wNDilPhyt_ & $\mathrm{gN} / \mathrm{m} 3 / \mathrm{d}$ & _wNDilPhyt_=total_algal_dilution \\
\hline _wDOutflTot_ & $\mathrm{gD} / \mathrm{m} 3 / \mathrm{d}$ & _wDOutflTot_Outflow_of_DW \\
\hline _wPOutflTot_ & $\mathrm{gP} / \mathrm{m} 3 / \mathrm{d}$ & _wPOutflTot_Outflow_of_P \\
\hline _wNOutflTot_ & $\mathrm{gN} / \mathrm{m} 3 / \mathrm{d}$ & _wNOutflTot_Outflow_of_N \\
\hline _wDTranDiat_ & $\mathrm{gN} / \mathrm{m} 3 / \mathrm{d}$ & _wDTranDiat_transport_flux_of_D_in_Diat \\
\hline _wPTranDiat_ & $\mathrm{gN} / \mathrm{m} 3 / \mathrm{d}$ & _wPTranDiat_transport_flux_of_P_in_Diat \\
\hline _wNTranDiat_ & $\mathrm{gN} / \mathrm{m} 3 / \mathrm{d}$ & _wNTranDiat_transport_flux_of_N_in_Diat \\
\hline _wDTranGren_ & $\mathrm{gN} / \mathrm{m} 3 / \mathrm{d}$ & _wDTranGren transport_flux_of_D_in_Gren \\
\hline _wPTranGren_ & $\mathrm{gN} / \mathrm{m} 3 / \mathrm{d}$ & _wPTranGren transport_flux_of_P_in_Gren \\
\hline _wNTranGren_ & $\mathrm{gN} / \mathrm{m} 3 / \mathrm{d}$ & _wNTranGren transport_flux_of_N_in_Gren \\
\hline _wDTranBlue_- & $\mathrm{gN} / \mathrm{m} 3 / \mathrm{d}$ & _wDTranBlue_transport_flux_of_D_in_Blue \\
\hline _wPTranBlue & $\mathrm{gN} / \mathrm{m} 3 / \mathrm{d}$ & _wPTranBlue transport_flux_of_P_in_Blue \\
\hline _wNTranBlue_ & $\mathrm{gN} / \mathrm{m} 3 / \mathrm{d}$ & _wNTranBlue_transport_flux_of_N_in_Blue \\
\hline _wDTranPhyt_ & $\mathrm{gD} / \mathrm{m} 3 / \mathrm{d}$ & _wDTranPhyt_total_transport_flux_of_D_in_Phyt \\
\hline _wPTranPhyt__ & $\mathrm{gP} / \mathrm{m} 3 / \mathrm{d}$ & _wPTranPhyt_total_transport_flux_of_P_in_Phyt \\
\hline _wNTranPhyt_ & $\mathrm{gN} / \mathrm{m} 3 / \mathrm{d}$ & _wNTranPhyt_total_transport_flux_of_N_in_Phyt \\
\hline _uSiLoadSiO2_- & $\mathrm{gSi} / \mathrm{m} 2 / \mathrm{d}$ & _uSiLoadSiOż total_transport_flux_of_Si_in_SiO2 \\
\hline _uSiLoadDet_- & $\mathrm{gSi} / \mathrm{m} 2 / \mathrm{d}$ & _uSiLoadDet_total_transport_flux_of_Si_in_Det \\
\hline _uSiLoadDiat_ & $\mathrm{gSi} / \mathrm{m} 2 / \mathrm{d}$ & _uSiLoadDiat_total_transport_flux_of_Si_in_Diat \\
\hline _uSiLoad__ & $\mathrm{gSi} / \mathrm{m} 2 / \mathrm{d}$ & _uSiLoad_=_Silica_loading \\
\hline _wSiDilSiO2_ & $\mathrm{gSi} / \mathrm{m} 3 / \mathrm{d}$ & _wSiDilSiO2_Dilution_of_Si_in_SiO2 \\
\hline wSiDilDet_ & $\mathrm{gSi} / \mathrm{m} 3 / \mathrm{d}$ & _wSiDilDet_= Dilution_of_Si_in_detritus \\
\hline _wSiDilDiat_ & $\mathrm{gSi} / \mathrm{m} 3 / \mathrm{d}$ & _wSiDilDiat_= Dilution_of_Si_in_diatoms \\
\hline _wSiOutflTot_ & $\mathrm{gSi} / \mathrm{m} 3 / \mathrm{d}$ & _wSiOutflTot_total_Si_surface_outflow \\
\hline wSiTranSiO2 & $\mathrm{gSi} / \mathrm{m} 3 / \mathrm{d}$ & wSiTranSiOz transport flux of $\mathrm{Si}$ in $\mathrm{SIO} 2$ \\
\hline
\end{tabular}


_wSiTranDetW_ _tSiTranTotT_ wDTranZoo _wPTranZoo_ wNTranZoo wDTranIMW _wDTranDetW_ wO2TranW wPTranPO4W _wPTranAIMW _wPTranDetW_ _wNTranNH4W _wNTranNO3W_ _wNTranDetW_ _wDDilTot_ _wPDilTot _wNDilTot_ _wSiDilTot tDTranTotT_ tPTranTotT _tNTranTotT_ _wDExchIMM _wPExchPO4M_ _wPExchAIMM_ WNExchNH4M wNExchNO3M _wSiExchSiO2M_ wO2ExchM _wDExchDetM _wPExchDetM_ _wNExchDetM_ _wSiExchDetM_ _wDExchDiatM_ wPExchDiatM _wNExchDiatM_ wSiExchDiatM wDExchGrenM _wPExchGrenM_ wNExchGrenM_ _wDExchBlueM_ _wPExchBlueM_ wNExchBlueM _wDExchZooM_ _wPExchZooM_ _wNExchZooM_ _wDExchIM_ WPExchPO4 -WPExchAIM _wNExchNH4 wNExchNO3 _wSiExchSiO2 _wO2Exch_ wDExchDet wPExchDet _wNExchDet_ _wSiExchDet _wDExchDiat_ wPExchDiat _wNExchDiat_ wSiExchDiat wDExchGren_ -wPExchGren _wNExchGren_ wDExchBlue wPExchBlue wNExchBlue_ _wDExchZoo_
_wSiTranDetV transport_flux_of_Si_in_detritus

_tSiTranTotT_total_Si_transport_flux

_wDTranZoo_net_migration_flux_of_D_in_Zoo

_wPTranZoo_net_migration_flux_of_P_in_ZOO

_wNTranZoo_net_migration_flux_of_N_in_Zoo

_wDTranIMW_transport_flux_DW_in_IM

_wDTranDeth transport_flux_DW_in_detritus

_wO2TranW_transport_flux_O2

_wPTranPO4I transport_flux_of_P_in_PO4

_WPTranAIMV transport_flux_of_P_in_AIM

_WPTranDeth transport_flux_of_P_in_detritus

_wNTranNH4I transport_flux_of_N_in_NH4

_wNTranNO3! transport_flux_of_N_in_NO3

_wNTranDeth transport_flux_of_N_in_detritus

_wDDilTot_= Total_DW_dilution_fluxes

_wPDilTot_ = Total_P_dilution_fluxes

_wNDilTot_ $=$ Total_N_dilution_fluxes

_wSiDilTot_= Total_SI_dilution_fluxes

_tDTranTotT_total_transport_fluxes_of_DW_for_mass_balance_equations

_tPTranTotT_total_transport_fluxes_of_P_for_mass_balance_equations

_tNTranTotT_total_transport_fluxes_of_N_for_mass_balance_equations

_wDExchIMM exchange_flux_of_DW_in_IMM_between_marsh_and_lake_water _wPExchPO4lexchange_flux_of_P_in_PO4M_between_marsh_and_lake_water _WPExchAIMN exchange_flux_of_P_in_AIMM_between_marsh_and_lake_water _wNExchNH4 exchange_flux_of_N_in_NH4M_between_marsh_and_lake_water _wNExchNO3 exchange_flux_of_N_in_NO3M_between_marsh_and_lake_water _wSiExchSiO: exchange_flux_of_Si_in_hSiO2M_between_marsh_and_lake_water _wO2ExchM_exchange_flux_of_O2_in_hM_between_marsh_and_lake_water _wDExchDetN exchange_flux_of_DW_in_DetM_between_marsh_and_lake_water _wPExchDetN exchange_flux_of_P_in_DetM_between_marsh_and_lake_water _wNExchDeth exchange_flux_of_N_in_DetM_between_marsh_and_lake_water _wSiExchDetl exchange_flux_of_Si_in_hDetM_between_marsh_and_lake_water _wDExchDiatl exchange_flux_of_DW_in_DiatM_between_marsh_and_lake_water _wPExchDiat exchange_flux_of_P_in_DiatM_between_marsh_and_lake_water _wNExchDiat? exchange_flux_of_N_in_DiatM_between_marsh_and_lake_water _wSiExchDiatl exchange_flux_of_Si_in_DiatM_between_marsh_and_lake_water _wDExchGrer exchange_flux_of_DW_in_GrenM_between_marsh_and_lake_water _wPExchGren exchange_flux_of_P_in_GrenM_between_marsh_and_lake_water _wNExchGrer exchange_flux_of_N_in_GrenM_between_marsh_and_lake_water _wDExchBlue exchange_flux_of_DW_in_BlueM_between_marsh_and_lake_water _wPExchBluel exchange_flux_of_P_in_BlueM_between_marsh_and_lake_water _wNExchBlue exchange_flux_of_N_in_BlueM_between_marsh_and_lake_water _wDExchZool exchange_flux_of_DW_in_ZooM_between_marsh_and_lake_water _wPExchZooN exchange_flux_of_P_in_ZooM_between_marsh_and_lake_water _wNExchZool exchange_flux_of_N_in_ZooM_between_marsh_and_lake_water _WDExchIM_: exchange_flux_of_DW_in_IM_between_marsh_and_lake_water _WPExchPO4_exchange_flux_of_P_in_PO4_between_marsh_and_lake_water _WPExchAIM_exchange_flux_of_P_in_AIM_between_marsh_and_lake_water _wNExchNH4 exchange_flux_of_N_in_NH4_between_marsh_and_lake_water _wNExchNO3 exchange_flux_of_N_in_NO3_between_marsh_and_lake_water _wSiExchSiO، exchange_flux_of_Si_in_SiO2_between_marsh_and_lake_water _wO2Exch_= exchange_flux_of_O2_in_O2_between_marsh_and_lake_water _wDExchDet_exchange_flux_of_DW_in_Det_between_marsh_and_lake_water _wPExchDet_exchange_flux_of_P_in_Det_between_marsh_and_lake_water _wNExchDet_exchange_flux_of_N_in_Det_between_marsh_and_lake_water _wSiExchDet_exchange_flux_of_Si_in_Det_between_marsh_and_lake_water _wDExchDiat_exchange_flux_of_DW_in_Diat_between_marsh_and_lake_water _wPExchDiat_exchange_flux_of_P_in_Diat_between_marsh_and_lake_water _wNExchDiat_exchange_flux_of_N_in_Diat_between_marsh_and_lake_water _wSiExchDiat exchange_flux_of_Si_in_Diat_between_marsh_and_lake_water _wDExchGrer exchange_flux_of_DW_in_Gren_between_marsh_and_lake_water _wPExchGren exchange_flux_of_P_in_Gren_between_marsh_and_lake_water _wNExchGrer exchange_flux_of_N_in_Gren_between_marsh_and_lake_water _wDExchBlue exchange_flux_of_DW_in_Blue_between_marsh_and_lake_water _wPExchBlue exchange_flux_of_P_in_Blue_between_marsh_and_lake_water _wNExchBlue exchange_flux_of_N_in_Blue_between_marsh_and_lake_water _wDExchZoo_exchange_flux_of_DW_in_Zoo_between_marsh_and_lake_water 


\begin{tabular}{|c|c|c|}
\hline _wPExchZoo_ & $\mathrm{gP} / \mathrm{m} 3 / \mathrm{d}$ & _wPExchZoo_exchange_flux_of_P_in_Zoo_between_marsh_and_lake_water \\
\hline wNExchZoo_- & $\mathrm{gN} / \mathrm{m} 3 / \mathrm{d}$ & _wNExchZoo_exchange_flux_of_N_in_Zoo_between_marsh_and_lake_water \\
\hline tPInfPO4W_- & $\mathrm{gP} / \mathrm{m} 2 / \mathrm{d}$ & _tPInfPO4W_infiltr_of_SRP \\
\hline tNInfNH4W_ & $\mathrm{gN} / \mathrm{m} 2 / \mathrm{d}$ & _tNInfNH4W_infiltr_of_ammonium \\
\hline _tNInfNO3W_ & $\mathrm{gN} / \mathrm{m} 2 / \mathrm{d}$ & _tNInfNO3W_infiltr_of_nitrate \\
\hline _tPInfPO4S_ & $\mathrm{gP} / \mathrm{m} 2 / \mathrm{d}$ & _tPInfPO4S_: infiltration_of_interst_PO4 \\
\hline - $\mathrm{NInfNH} 4 \mathrm{~S}_{-}^{-}$ & $\mathrm{gN} / \mathrm{m} 2 / \mathrm{d}$ & _tNInfNH4S_: infiltration_of_interst_NH4 \\
\hline _tNInfNO3S_ & $\mathrm{gN} / \mathrm{m} 2 / \mathrm{d}$ & _tNInfNO3S_infiltration_of_interst_NO3 \\
\hline _tNH4LoadS__ & $\mathrm{gN} / \mathrm{m} 2 / \mathrm{d}$ & _tNH4LoadS_NH4_load_to_sediment_from_artificial_fertilizer \\
\hline tNO3LoadS_ & $\mathrm{gN} / \mathrm{m} 2 / \mathrm{d}$ & _tNO3LoadS_NO3_load_to_sediment_from_artificial_fertilizer \\
\hline _uDErosIM_ & $\mathrm{gD} / \mathrm{m} 2 / \mathrm{d}$ & _uDErosIM_ = IM_input_from_banks \\
\hline uDErosIMS_ & $\mathrm{gD} / \mathrm{m} 2 / \mathrm{d}$ & _uDErosIMS_IM_input_to_sediment_from_banks \\
\hline uDErosIMW_ & $\mathrm{gD} / \mathrm{m} 2 / \mathrm{d}$ & _uDErosIMW_IM_input_to_water_column_from_banks \\
\hline uDErosOM_ & $\mathrm{gD} / \mathrm{m} 2 / \mathrm{d}$ & _uDErosOM_organic_matter_input_from_banks \\
\hline _uPErosOM_- & $\mathrm{gP} / \mathrm{m} 2 / \mathrm{d}$ & _uPErosOM_organic_P_input_from_banks \\
\hline _uNErosOM_ & $\mathrm{gN} / \mathrm{m} 2 / \mathrm{d}$ & _uNErosOM_organic_N_input_from_banks \\
\hline _uO2Sat_ & $\mathrm{gO} 2 / \mathrm{m} 3$ & _uO2Sat_=1.oxygen_saturation_concentration \\
\hline kAer_ & $\mathrm{m} / \mathrm{d}$ & _kAer_=_cAtreaeration_coefficient \\
\hline _uFunTmAer_ & - & _uFunTmĀer_temperature_function_of_reaeration \\
\hline _aFunLemnAer_ & - & _aFunLemnAє duckweed_function_of_reaeration \\
\hline to2Aer_ & $\mathrm{gO} 2 / \mathrm{m} 2 / \mathrm{d}$ & _tO2Aer_= $k$ reaeration_flux_of_O-O2_into_the_water \\
\hline _uFunTmFish_ & - & _uFunTmFish temp_function_of_fish \\
\hline _tDTurbFish_ & $\mathrm{g} / \mathrm{m} 2 / \mathrm{d}$ & _tDTurbFish_bioturbation_by_fish \\
\hline _tDTurbFishIM_ & $\mathrm{g} / \mathrm{m} 2 / \mathrm{d}$ & _tDTurbFishIM IM_bioturbation_by_fish \\
\hline _aFunVegResus_ & - & _aFunVegRes vegetation_dependence_of_resuspension \\
\hline _aFunDimSusp_ & - & _aFunDimSus Empirical_suspended_matter_function_(logistic_fit_to_data) \\
\hline tDResusTauDead_ & $\mathrm{gD} / \mathrm{m} 2 / \mathrm{d}$ & _tDResusTaul resuspension_due_to_shear_stress \\
\hline tDResusBareDead_ & $\mathrm{gD} / \mathrm{m} 2 / \mathrm{d}$ & _tDResusBareresuspension_due_to_shear_stress_AND_fish \\
\hline _tDResusDead_ & $\mathrm{gD} / \mathrm{m} 2 / \mathrm{d}$ & _tDResusDea resuspension_corrected_for_vegetation_effect \\
\hline tDResusIM_ & $\mathrm{gD} / \mathrm{m} 2 / \mathrm{d}$ & _tDResusIM_IM_resuspension \\
\hline tDResusDet_ & $\mathrm{gD} / \mathrm{m} 2 / \mathrm{d}$ & _tDResusDet_detrital_resuspension \\
\hline _akResusPhytRef_ & d-1 & _akResusPhyl phytoplankton_resuspension_rate_constant \\
\hline tDResusPhytTot_ & $\mathrm{gD} / \mathrm{m} 2 / \mathrm{d}$ & _tDResusPhyl phytoplankton_resuspension \\
\hline _tPResusDet_ & $\mathrm{gP} / \mathrm{m} 2 / \mathrm{d}$ & _tPResusDet_resuspension_flux_of_detrital_P \\
\hline _tPResusPO4_ & $\mathrm{gP} / \mathrm{m} 2 / \mathrm{d}$ & _tPResusPO4 resuspension_flux_of_dissolved_P \\
\hline _tPResusAIM_ & $\mathrm{gP} / \mathrm{m} 2 / \mathrm{d}$ & _tPResusAIM_resuspension_flux_of_P_adsorbed_onto_inert_matter \\
\hline tNResusNO3_ & $\mathrm{gN} / \mathrm{m} 2 / \mathrm{d}$ & _tNResusNOミ resuspension_flux_of_nitrate \\
\hline - & $\mathrm{gN} / \mathrm{m} 2 / \mathrm{d}$ & _tNResusNH4 resuspension_flux_of_ammonium \\
\hline _tNResusDet_- & $\mathrm{gN} / \mathrm{m} 2 / \mathrm{d}$ & _tNResusDet_resuspension_flux_of_detrital_N \\
\hline tSiResusDet_ & $\mathrm{gSi} / \mathrm{m} 2 / \mathrm{d}$ & _tSiResusDet_resuspension_flux_of_detrial_SI \\
\hline _aFunTauSetOM_ & - & _aFunTauSet(correction_factor_for_IM_settling_rate_(<=_1) \\
\hline _aFunTauSetIM_ & - & _aFunTauSetl correction_factor_for_OM_settling_rate_(<=-1) \\
\hline _uFunTmSet_ & - & _uFunTmSet_temperature_correction_of_sedimentation \\
\hline _uCorVSetIM_- & $\mathrm{m} / \mathrm{d}$ & _uCorVSetIM_corrected_sedimentation_velocity_of_IM \\
\hline tDSetIM_ & $\mathrm{gDW} / \mathrm{m} 2 / \mathrm{d}$ & _tDSetIM_ =_sedimentation_flux_of_inert_matter \\
\hline _tPSetAIM_ & $\mathrm{gP} / \mathrm{m} 2 / \mathrm{d}$ & _tPSetAIM_= sedimentation_flux_of_P_adsorbed_onto_inert_org_matter \\
\hline uCorVSetDet_ & $\mathrm{m} / \mathrm{d}$ & _uCorVSetDet corrected_sedimentation_velocity_of_detritus \\
\hline _tDSetDet__ & $\mathrm{gDW} / \mathrm{m} 2 / \mathrm{d}$ & _tDSetDet_= sedimentation_flux_of_detritus \\
\hline _tPSetDet_ & $\mathrm{gP} / \mathrm{m} 2 / \mathrm{d}$ & _tPSetDet_= sedimentation_flux_of_detrital_P \\
\hline tNSetDet_ & $\mathrm{gN} / \mathrm{m} 2 / \mathrm{d}$ & _tNSetDet_= sedimentation_flux_of_detrital_N \\
\hline _SiSetDet_ & $\mathrm{gSi} / \mathrm{m} 2 / \mathrm{d}$ & _tSiSetDet_= sedimentation_flux_of_detrital_Si \\
\hline _kPMinDetW_ & $d-1$ & _kPMinDetW_P_mineralisation_constant_in_water \\
\hline kNMinDetW_ & $d-1$ & _kNMinDetW_N_mineralisation_constant_in_water \\
\hline kSiMinDetW_ & $d-1$ & _kSiMinDetW_Si_mineralisation_constant_in_water \\
\hline _uFunTmMinW_ & - & _uFunTmMinVtemp_function_of_mineralization_in_water \\
\hline _wDMinDetW_- & $\mathrm{g} / \mathrm{m} 3 / \mathrm{d}$ & _wDMinDetW_decomposition \\
\hline _wPMinDetW_ & $\mathrm{gP} / \mathrm{m} 3 / \mathrm{d}$ & _wPMinDetW_mineralization \\
\hline _wNMinDetW_ & $\mathrm{gN} / \mathrm{m} 3 / \mathrm{d}$ & _wNMinDetW_mineralization \\
\hline _wSiMinDetW_- & $\mathrm{gSi} / \mathrm{m} 3 / \mathrm{d}$ & _wSiMinDetW mineralization \\
\hline _aCorO2BOD_ & - & _aCorO2BOD correction_of_O2_demand_in_water_at_low_oxygen_conc \\
\hline wO2MinDetW_ & $\mathrm{gO} 2 / \mathrm{m} 3 / \mathrm{d}$ & _wO2MinDetV O2_flux_due_to_mineralization_of_detritus \\
\hline _wDDenitW_ & $\mathrm{gDW} / \mathrm{m} 2 / \mathrm{d}$ & _wDDenitW_: mineralisation_flux_by_denitrification \\
\hline _wNDenitW_ & $\mathrm{gN} / \mathrm{m} 2 / \mathrm{d}$ & _wNDenitW_: Denitrification_flux \\
\hline _uFunTmNitr_ & - & _uFunTmNitr_Temperature_dependence_for_nitrification \\
\hline aCorO2NitrW_ & - & _aCorO2Nitrh̄ oxygen_consumption_during_nitrification \\
\hline wNNitrW_ & $\mathrm{mgN} / \mathrm{l} / \mathrm{d}$ & _wNNitrW_= nitrification_flux \\
\hline _wO2NitrW_ & $\mathrm{gO} 2 / \mathrm{m} 3 / \mathrm{d}$ & _wO2NitrW $\overline{-}_{-}=\mathrm{O} 2$ flux_due_to_nitrification \\
\hline
\end{tabular}


_kPMinDetS

_kNMinDetS_

kSiMinDets

_uFunTmMins_

tDMinDetS

tPMinDetS

tNMinDetS

_tSiMinDetS_

_uFunTmDif_

akO2DifCor

_tSOD_

_aDepthOxySed_

_afOxySed_

_tDMinOxyDetS_

_tO2MinDetS_

_tDDenitS_

tNDenits

tNNitrS

_tO2NitrS

tDMinHums

_tPMinHums

tNMinHums

_aDepthDif_

_tPDifPO4_

- $\mathrm{NDDifNO}{ }_{-}^{-}$

_tNDifNH4_

_tO2Dif_

tPDifGroundPO4_

_tNDifGroundNO3_

_tNDifGroundNH4

_aPAdsMaxW_

_aKPAdsW_

_aPIsoAdsW_

_aPEqIMW_

_wPSorpIMW_

_aPAdsMaxs_

_aKPAdsS

_aPIsoAdsS_

aPEqIMS

tPSorpIMS

_tPChemPO4

_wDAbiolMW_

_wDAbioDetW_

tDAbiolMS

tDAbioDetS

_tDAbioHums_

tDAbioTotT_

wO2AbioW

_wPAbioDetW_

_wPAbioPO4W_

_wPAbioAIMW

_tPAbioDetS

tPAbioHum $\bar{S}$

tPAbioPO4S

_tPAbioAIMS_

_tPAbioTotT_

_WNAbioNH4W

_WNAbioNO3W

wNAbioDetW

_tNAbioNH4S

_tNAbioNO3S_

_tNAbioDetS_

_tNAbioHumS_

tNAbioTotT

_wSiAbioSiO2W_

_wSiAbioDetW_

_tSiAbioDetS_
$\mathrm{gDW} / \mathrm{m} 2 / \mathrm{d}$

$\mathrm{gP} / \mathrm{m} 2 / \mathrm{d}$

$\mathrm{gN} / \mathrm{m} 2 / \mathrm{d}$

$\mathrm{gN} / \mathrm{m} 2 / \mathrm{d}$

$\mathrm{m} 2 / \mathrm{d}$

$\mathrm{gO} 2 / \mathrm{m} 3 / \mathrm{d}$

$\mathrm{m}$

$-$

$\mathrm{gDW} / \mathrm{m} 2 / \mathrm{d}$

$\mathrm{gO} 2 / \mathrm{m} 2 / \mathrm{d}$

$\mathrm{gD} / \mathrm{m} / \mathrm{d}$

$\mathrm{gN} / \mathrm{m} 2 / \mathrm{d}$

$\mathrm{gN} / \mathrm{m} 2 / \mathrm{d}$

$\mathrm{gO} 2 / \mathrm{m} 2 / \mathrm{d}$

$\mathrm{gDW} / \mathrm{m} 2 / \mathrm{d}$

$\mathrm{gP} / \mathrm{m} 2 / \mathrm{d}$

$\mathrm{gN} / \mathrm{m} 2 / \mathrm{d}$

$\mathrm{m}$

$\mathrm{gP} / \mathrm{m} 2 / \mathrm{d}$

$\mathrm{gP} / \mathrm{m} 2 / \mathrm{d}$

$\mathrm{gP} / \mathrm{m} 2 / \mathrm{d}$

$\mathrm{gO} 2 / \mathrm{m} 2 / \mathrm{d}$

$\mathrm{gP} / \mathrm{m} 2 / \mathrm{d}$

$\mathrm{gN} / \mathrm{m} 2 / \mathrm{d}$

$\mathrm{gN} / \mathrm{m} 2 / \mathrm{d}$

$\mathrm{gP} / \mathrm{gD}$

$\mathrm{m} 3 / \mathrm{gP}$

$\mathrm{gP} / \mathrm{gD}$

$\mathrm{gP} / \mathrm{m} 3$

$\mathrm{gP} / \mathrm{m} 3 / \mathrm{d}$

$\mathrm{gP} / \mathrm{gD}$

$\mathrm{m} 3 / \mathrm{gP}$

$\mathrm{gP} / \mathrm{gD}$

$\mathrm{gP} / \mathrm{m} 2$

$\mathrm{gP} / \mathrm{m} 2 / \mathrm{d}$

$\mathrm{gP} / \mathrm{m} 2 / \mathrm{d}$

$\mathrm{gDW} / \mathrm{m} 3 / \mathrm{d}$

$\mathrm{gDW} / \mathrm{m} 3 / \mathrm{d}$

$\mathrm{gDW} / \mathrm{m} 2 / \mathrm{d}$

$\mathrm{gDW} / \mathrm{m} 2 / \mathrm{d}$

$\mathrm{gDW} / \mathrm{m} 2 / \mathrm{d}$

$\mathrm{gDW} / \mathrm{m} 2 / \mathrm{d}$

$\mathrm{gO} 2 / \mathrm{m} 3 / \mathrm{d}$

$\mathrm{gP} / \mathrm{m} 3 / \mathrm{d}$

$\mathrm{gP} / \mathrm{m} 3 / \mathrm{d}$

$\mathrm{gP} / \mathrm{m} 3 / \mathrm{d}$

$\mathrm{gP} / \mathrm{m} 2 / \mathrm{d}$

$\mathrm{gP} / \mathrm{m} 2 / \mathrm{d}$

$\mathrm{gP} / \mathrm{m} 2 / \mathrm{d}$

$\mathrm{gP} / \mathrm{m} 2 / \mathrm{d}$

$\mathrm{gP} / \mathrm{m} 2 / \mathrm{d}$

$\mathrm{gN} / \mathrm{m} 3 / \mathrm{d}$

$\mathrm{gN} / \mathrm{m} 3 / \mathrm{d}$

$\mathrm{gN} / \mathrm{m} 3 / \mathrm{d}$

$\mathrm{gN} / \mathrm{m} 2 / \mathrm{d}$

$\mathrm{gN} / \mathrm{m} 2 / \mathrm{d}$

$\mathrm{gN} / \mathrm{m} 2 / \mathrm{d}$

$\mathrm{gN} / \mathrm{m} 2 / \mathrm{d}$

$\mathrm{gN} / \mathrm{m} 2 / \mathrm{d}$

$\mathrm{gSi} / \mathrm{m} 3 / \mathrm{d}$

$\mathrm{gSi} / \mathrm{m} 3 / \mathrm{d}$

$\mathrm{gSi} / \mathrm{m} 2 / \mathrm{d}$
_kPMinDetS_P_mineralisation_constant_in_sed

_kNMinDetS_ N_mineralisation_constant_in_sed

_kSiMinDetS_Si_mineralisation_constant_in_sed

_uFunTmMins temp_function

_tDMinDetS_decomposition_of_upper_sediment

_tPMinDetS_: mineralization_of_P_in_upper_sediment

_tNMinDetS_ mineralization_of_N_in_upper_sediment

_tSiMinDetS_mineralization_of_Si_in_upper_sediment

_uFunTmDif_temperature_function_of_diffusion

_akO2DifCor_corrected_O2_diffusion_coefficient

_tSOD_= (_m sediment_oxygen_demand

_aDepthOxyS oxygen_penetration_depth

_afOxySed_=fraction_aerobic_sediment

tDMinOxyDe aerobic_mineralisation

_tO2MinDetS_sediment_oxygen_demand

_tDDenitS_ = mineralisation_flux_by_denitrification

_tNDenitS_ = Denitrification_flux

tNNitrS_ = _c nitrification_flux

tO2NitrS_ = O O2_flux_due_to_nitrification

_tDMinHums_decomposition_of_upper_sediment_humus

_tPMinHumS_mineralization_of_P_in_upper_sediment_humus

_tNMinHumS_mineralization_of_N_in_upper_sediment_humus

_aDepthDif_= average_diffusion_distance

_tPDifPO4_= diffusion_flux_of_dissolved_P_from_sediment_to_water

tNDifNO3_= diffusion_flux_of_NO3_from_sediment_to_water

_tNDifNH4_= diffusion_flux_of_NH4_from_sediment_to_water

_tO2Dif_=_kl O2_diffusion_(water_->_sediment)

_tPDifGroundr diffusion_flux_of_dissolved_P_from_pore_water_to_ground_water

_tNDifGroundl diffusion_flux_of_dissolved_NO3_from_pore_water_to_ground_water

_tNDifGroundl diffusion_flux_of_dissolved_NH4_from_pore_water_to_ground_water

_aPAdsMaxW max_P_adsorption_per_g_inorg_matter_in_water

_aKPAdsW_= P_adsorption_affinity_corrected_for_redox_conditions

_aPIsoAdsW_P_adsorption_isotherm_onto_inorg_matter_in_sediment

_aPEqIMW_ = equilibrium_conc

_wPSorpIMW_sorption_flux_in_water

_aPAdsMaxS_max_P_adsorption_per_g_inorg_matter_in_sediment

_aKPAdsS_ = P_adsorption_affinity_corrected_for_redox_conditions

_aPIsoAdsS_P_adsorption_isotherm_onto_inorg_matter_in_sediment

_aPEqIMS_ = equilibrium_amount

_tPSorpIMS_ sorption

_tPChemPO4_chem_loss_of_dissolved_P_from_pore_water

_wDAbioIMW_total_abiotic/microbial_DW_inorganic_matter_flux_in_water

_wDAbioDeth total_abiotic/microbial_DW_detritus_flux_in_water

_tDAbiolMS_ : total_abiotic/microbial_DW_inorganic_matter_flux_in_sediment

_tDAbioDetS_total_abiotic/microbial_DW_detritus_flux_in_sediment

_tDAbioHumS total_abiotic/microbial_DW_humus_flux_in_sediment

_tDAbioTotT_total_abiotic/microbial_DW_flux_for_mass_balance_check

_wO2AbioW_total_abiotic/microbial_O2_flux_in_water

_wPAbioDetW total_abiotic/microbial_P_detritus_flux_in_water

_wPAbioPO4l total_abiotic/microbial_dissolved_P_flux_in_water

_wPAbioAIMV total_abiotic/microbial_P_absorbed_onto_inorganic_matter_flux_in_water

_tPAbioDetS_total_abiotic/microbial_P_detritus_flux_in_sediment

_tPAbioHumS total_abiotic/microbial_P_humus_flux_in_sediment

_tPAbioPO4S total_abiotic/microbial_dissolved_P_flux_in_sediment

_tPAbioAIMS_total_abiotic/microbial_P_absorbed_onto_inorganic_matter_flux_in_sediment

_tPAbioTotT_total_abiotic/microbial_P_flux_for_mass_balance_check

_wNAbioNH4I total_abiotic/microbial_N_NH4_flux_in_water

_wNAbioNO3I total_abiotic/microbial_N_NO3_flux_in_water

_wNAbioDeth total_abiotic/microbial_N_detritus_flux_in_water

_tNAbioNH4S total_abiotic/microbial_N_NH4_flux_in_sediment

_tNAbioNO3S total_abiotic/microbial_N_NO3_flux_in_sediment

_tNAbioDetS_total_abiotic/microbial_N_detritus_flux_in_sediment

_tNAbioHumS total_abiotic/microbial_N_humus_flux_in_sediment

_tNAbioTotT_total_abiotic/microbial_N_flux_for_mass_balance_check

_wSiAbioSiO2 total_abiotic/microbial_Si_SiO2_flux_in_water

_wSiAbioDetV total_abiotic/microbial_Si_detritus_flux_in_water

_tSiAbioDetS_total_abiotic/microbial_Si_detritus_flux_in_sediment 
_tSiAbioTotT_ _uQEvPhra

_tPEvPO4WM_

- $\mathrm{NEVNNH} 4 \mathrm{WM}$

_tNEvNO3WM_

_tPInfPO4WM_

-tNInfNH4WM_-

_tNInfNO3WM_

_tPInfPO4SM_

_tNInfNH4SM_

_tNInfNO3SM_

tO2AerM

_tDSetIMM

_tPSetAIMM_

tDSetDetM

_tPSetDetM_

_tNSetDetM_

_tSiSetDetM_

_tDSetDiatM_

_PSetDiatM_

_NSetDiatM_

_tSiSetDiatM_

_tDSetGrenM_

_tPSetGrenM_

tNSetGrenM

_tDSetBlueM_

_tPSetBlueM_

tNSetBlueM

_tDSetPhytM_

_tPSetPhytM

-tNSetPhytM_

_tDSetTotM

_wDMinDetWM

wPMinDetWM

_wNMinDetWM_

_wSiMinDetWM_

_aCorO2BODM_

_wO2MinDetWM_

_wDDenitWM

_wNDenitWM_

_aCorO2NitrWM_

_wNNitrWM

_wO2NitrWM

_tDMinDetSM_

_tPMinDetSM_

_tNMinDetSM

tSiMinDetSM_

_akO2DifCorM_-

tSODM_

_aDepthOxySedM_

_afOxySedM_

_tDMinOxyDetSM_

tO2MinDetSM_

_tDDenitSM

_tNDenitSM

_tNNitrSM

_tO2NitrSM

_tDMinHumSM_

tPMinHumSM_

_tNMinHumSM_

_aDepthDifM_

tPDifPO4M

_tNDifNO3M_

tNDifNH4M

tO2DifM

_tPDifGroundPO4M_

_tNDifGroundNO3M_-
$\mathrm{gSi} / \mathrm{m} 2 / \mathrm{d}$

$\mathrm{mm} / \mathrm{d}$

$\mathrm{gP} / \mathrm{m} 2 / \mathrm{d}$

$\mathrm{gN} / \mathrm{m} 2 / \mathrm{d}$

$\mathrm{gN} / \mathrm{m} 2 / \mathrm{d}$

$\mathrm{gP} / \mathrm{m} 2 / \mathrm{d}$

$\mathrm{gN} / \mathrm{m} 2 / \mathrm{d}$

$\mathrm{gN} / \mathrm{m} 2 / \mathrm{d}$

$\mathrm{gP} / \mathrm{m} 2 / \mathrm{d}$

$\mathrm{gN} / \mathrm{m} 2 / \mathrm{d}$

$\mathrm{gN} / \mathrm{m} 2 / \mathrm{d}$

$\mathrm{gO} 2 / \mathrm{m} 2 / \mathrm{d}$

$\mathrm{g} / \mathrm{m} 2 / \mathrm{d}$

$\mathrm{gP} / \mathrm{m} 2 / \mathrm{d}$

$\mathrm{g} / \mathrm{m} 2 / \mathrm{d}$

$\mathrm{gP} / \mathrm{m} 2 / \mathrm{d}$

$\mathrm{gN} / \mathrm{m} 2 / \mathrm{d}$

$\mathrm{gSi} / \mathrm{m} 2 / \mathrm{d}$

$\mathrm{g} / \mathrm{m} 2 / \mathrm{d}$

$\mathrm{gP} / \mathrm{m} 2 / \mathrm{d}$

$\mathrm{gN} / \mathrm{m} 2 / \mathrm{d}$

$\mathrm{gSi} / \mathrm{m} 2 / \mathrm{d}$

$\mathrm{g} / \mathrm{m} 2 / \mathrm{d}$

$\mathrm{gP} / \mathrm{m} 2 / \mathrm{d}$

$\mathrm{gN} / \mathrm{m} 2 / \mathrm{d}$

$\mathrm{gDW} / \mathrm{m} 2 / \mathrm{d}$

$\mathrm{gP} / \mathrm{m} 2 / \mathrm{d}$

$\mathrm{gN} / \mathrm{m} 2 / \mathrm{d}$

$\mathrm{gDW} / \mathrm{m} 2 / \mathrm{d}$

$\mathrm{gP} / \mathrm{m} 2 / \mathrm{d}$

$\mathrm{gN} / \mathrm{m} 2 / \mathrm{d}$

$\mathrm{gDW} / \mathrm{m} 2 / \mathrm{d}$

$\mathrm{gDW} / \mathrm{m} 2 / \mathrm{d}$

$\mathrm{gP} / \mathrm{m} 2 / \mathrm{d}$

$\mathrm{gN} / \mathrm{m} 2 / \mathrm{d}$

$\mathrm{gSi} / \mathrm{m} 3 / \mathrm{d}$

$\mathrm{gO} 2 / \mathrm{m} 3 / \mathrm{d}$

$\mathrm{gDW} / \mathrm{m} 2 / \mathrm{d}$

$\mathrm{gN} / \mathrm{m} 2 / \mathrm{d}$

$\mathrm{gN} / \mathrm{m} 2 / \mathrm{d}$

$\mathrm{mgN} / \mathrm{l} / \mathrm{d}$

$\mathrm{gO} 2 / \mathrm{m} 3 / \mathrm{d}$

$\mathrm{gDW} / \mathrm{m} 2 / \mathrm{d}$

$\mathrm{gP} / \mathrm{m} 2 / \mathrm{d}$

$\mathrm{gN} / \mathrm{m} 2 / \mathrm{d}$

$\mathrm{gN} / \mathrm{m} 2 / \mathrm{d}$

$\mathrm{m} 2 / \mathrm{d}$

$\mathrm{gO} 2 / \mathrm{m} 3 / \mathrm{d}$

$\mathrm{m}$

$\mathrm{gDW} / \mathrm{m} 2 / \mathrm{d}$

$\mathrm{gO} 2 / \mathrm{m} 2 / \mathrm{d}$

$\mathrm{gDW} / \mathrm{m} 2 / \mathrm{d}$

$\mathrm{gN} / \mathrm{m} 2 / \mathrm{d}$

$\mathrm{gN} / \mathrm{m} 2 / \mathrm{d}$

$\mathrm{gO} 2 / \mathrm{m} 2 / \mathrm{d}$

$\mathrm{gDW} / \mathrm{m} 2 / \mathrm{d}$

$\mathrm{gP} / \mathrm{m} 2 / \mathrm{d}$

$\mathrm{gN} / \mathrm{m} 2 / \mathrm{d}$

$\mathrm{m}$

$\mathrm{gP} / \mathrm{m} 2 / \mathrm{d}$

$\mathrm{gP} / \mathrm{m} 2 / \mathrm{d}$

$\mathrm{gP} / \mathrm{m} 2 / \mathrm{d}$

$\mathrm{gO} 2 / \mathrm{m} 2 / \mathrm{d}$

$\mathrm{gP} / \mathrm{m} 2 / \mathrm{d}$

$\mathrm{gN} / \mathrm{m} 2 / \mathrm{d}$
_tSiAbioTotT_total_abiotic/microbial_Si_flux_for_mass_balance_check

_uQEvPhra_=reed_evaporation(set_EQUAL_to_lake_evaporation)

tPEvPO4WN SRP_flux

_tNEvNH4WN ammonium_flux

tNEvNO3WN nitrate_flux

_tPInfPO4WM infiltr_of_SRP

_tNInfNH4WN infiltr_of_ammonium

_tNInfNO3WN infiltr_of_nitrate

tPInfPO4SM_infiltration_of_interst_PO4

_tNInfNH4SM infiltration_of_interst_NH4

_tNInfNO3SM infiltration_of_interst_NO3

_tO2AerM_ = reaeration_flux_of_O2_into_the_water

_tDSetIMM_ = sedimentation_flux_of_inert_matter

_tPSetAIMM_sedimentation_flux_of_P_adsorbed_onto_inert_org_matter

_tDSetDetM_ sedimentation_flux_of_detritus

_tPSetDetM_sedimentation_flux_of_detrital_P

tNSetDetM_sedimentation_flux_of_detrital_N

_tSiSetDetM_sedimentation_flux_of_detrital_Si

_tDSetDiatM_sedimentation_flux_of_detritus

_tPSetDiatM_sedimentation_flux_of_detrital_P

_tNSetDiatM_sedimentation_flux_of_detrital_N

_tSiSetDiatM_sedimentation_flux_of_detrital_Si

_tDSetGrenM_sedimentation_flux_of_detritus

_tPSetGrenM_sedimentation_flux_of_detrital_P

_tNSetGrenM_sedimentation_flux_of_detrital_N

_tDSetBlueM_sedimentation_flux_of_detritus

_tPSetBlueM_sedimentation_flux_of_detrital_P

_tNSetBlueM_sedimentation_flux_of_detrital_N

_tDSetPhytM_sedimentation_flux_of_detritus

_tPSetPhytM_sedimentation_flux_of_detrital_P

_tNSetPhytM_sedimentation_flux_of_detrital_N

_tDSetTotM_: total_sedimentation_in_marsh

_wDMinDetWI decomposition

wPMinDetWI mineralization

_wNMinDetWI mineralization

_wSiMinDetW mineralization

_aCorO2BOD correction_of_O2_demand_in_water_at_low_oxygen_conc

_wO2MinDetV O2_flux_due_to_mineralization_of_detritus

_wDDenitWM_mineralisation_flux_by_denitrification

_wNDenitWM_Denitrification_flux

_aCorO2Nitrh oxygen_use_for_nitrification_in_marsh_water

wNNitrWM : nitrification flux

_wO2NitrWM_O2_flux_due_to_nitrification

_tDMinDetSM decomposition_of_upper_sediment

_tPMinDetSM mineralization_of_P_in_upper_sediment

_tNMinDetSM mineralization_of_N_in_upper_sediment

_tSiMinDetSM mineralization_of_Si_in_upper_sediment

_akO2DifCorl corrected_O2_diffusion_coefficient

_tSODM_ = _Isediment_oxygen_demand

_aDepthOxyS oxygen_penetration_depth

_afOxySedM_fraction_aerobic_sediment

_tDMinOxyDe aerobic_mineralisation

_tO2MinDetSr sediment_oxygen_demand

_tDDenitSM_ mineralisation_flux_by_denitrification

_NDenitSM_Denitrification_flux

_tNNitrSM_ = nitrification_flux

_tO2NitrSM_: O2_flux_due_to_nitrification

_tDMinHumSI decomposition_of_upper_sediment_humus

_tPMinHumS^ mineralization_of_P_in_upper_sediment_humus

_tNMinHumSı mineralization_of_N_in_upper_sediment_humus

_aDepthDifM_average_diffusion_distance

_tPDifPO4M_diffusion_flux_of_dissolved_P_from_sediment_to_water

_tNDifNO3M_diffusion_flux_of_NO3_from_sediment_to_water

_tNDifNH4M_diffusion_flux_of_NH4_from_sediment_to_water

_tO2DifM_ = _O2_diffusion(water_->_sediment)

_tPDifGroundr diffusion_flux_of_dissolved_P_from_pore_water_to_ground_water

_tNDifGroundl diffusion_flux_of_NO3_from_pore_water_to_ground_water 

_aPAdsMaxWM_ aKPAdsWM

_aPIsoAdsWM

_aPEqIMWM_

wPSorpIMWM

_aPAdsMaxSM_

aKPAdsSM

_aPIsoAdsSM_

_aPEqIMSM

tPSorpIMSM

tPChemPO4M

_aDaylnitVeg_

bfRootVeg

bfShootVeg_

_aDRootVeg_

aDShootVeg

_aDEmergVeg_

_aDFloatVeg_

bfSubVeg

_aDSubVeg

aExtVeg

aDepth1Veg

_aDepth2Veg_

_afCovSurfVeg_

_afCovEmergVeg_

_aCovVeg_

aDVeg

_aPVeg_

_aNVeg_

aExtCoef

_aLPARBot

rPDVeg_

rNDVeg

_tDMigrVeg_

tPMigrVeg_

tNMigrVeg

_uFunTmProdVeg_

uFunTmRespVeg_

_afPUptVegS_

_afNUptVegs

aVPUptMaxCrVeg

_aVPUptVegW

_aVPUptVegS_

_tPUptVegW_

_tPUptVegs_

tPUptVeg_

_aVNUptMaxCrVeg_

_ahNUptVeg_

_aVNUptVegW_

afNH4UptVegW

tNUptVegW_

tNUptNH4VegW

_tNUptNO3VegW_

aVNUptVegS_

tNUptVegS

_afNH4UptVegs

tNUptNH4VegS

_tNUptNO3Vegs_

_tNUptVeg_

_aLPAR1Veg_

aLPAR2Veg

_uhLVeg_

aLLimShootVeg

_aMuTmLVeg_

_aPLimVeg_

_aNLimVeg_
$\mathrm{gN} / \mathrm{m} 2 / \mathrm{d}$

$\mathrm{gP} / \mathrm{gD}$

$\mathrm{m} 3 / \mathrm{gP}$

$\mathrm{gP} / \mathrm{gD}$

$\mathrm{gP} / \mathrm{m} 3$

$\mathrm{gP} / \mathrm{m} 3 / \mathrm{d}$

$\mathrm{gP} / \mathrm{gD}$

$\mathrm{m} 3 / \mathrm{gP}$

$\mathrm{gP} / \mathrm{gD}$

$\mathrm{gP} / \mathrm{m} 2$

$\mathrm{gP} / \mathrm{m} 2 / \mathrm{d}$

$\mathrm{gP} / \mathrm{m} 2 / \mathrm{d}$

day

$\mathrm{g} / \mathrm{m} 2$

$\mathrm{g} / \mathrm{m} 2$

$\mathrm{g} / \mathrm{m} 2$

$\mathrm{g} / \mathrm{m} 2$

$\mathrm{g} / \mathrm{m} 2$

$\mathrm{m}-1$

$m$

$\mathrm{m}$

$\mathrm{gDW} / \mathrm{m} 2 / \mathrm{d}$

$\mathrm{gP} / \mathrm{m} 2 / \mathrm{d}$

$\mathrm{gN} / \mathrm{m} 2 / \mathrm{d}$

$\mathrm{m}-1$

W/m2_PAR

$\mathrm{mgP} / \mathrm{mgDW}$

$\mathrm{mgN} / \mathrm{mgDW}$

$\mathrm{gDW} / \mathrm{m} 2 / \mathrm{d}$

$\mathrm{gP} / \mathrm{m} 2 / \mathrm{d}$

$\mathrm{gN} / \mathrm{m} 2 / \mathrm{d}$

$-$

-

$\mathrm{mgP} / \mathrm{mgD} / \mathrm{d}$

$\mathrm{mgP} / \mathrm{mgD} / \mathrm{d}$

$\mathrm{gP} / \mathrm{m} 2 / \mathrm{d}$

$\mathrm{gP} / \mathrm{m} 2 / \mathrm{d}$

$\mathrm{gP} / \mathrm{m} 2 / \mathrm{d}$

$\mathrm{gN} / \mathrm{m} 3$

$\mathrm{mgN} / \mathrm{mgD} / \mathrm{d}$

$\mathrm{gN} / \mathrm{m} 2 / \mathrm{d}$

$\mathrm{gN} / \mathrm{m} 2 / \mathrm{d}$

$\mathrm{gN} / \mathrm{m} 2 / \mathrm{d}$

$\mathrm{mgN} / \mathrm{mgD} / \mathrm{d}$

$\mathrm{gN} / \mathrm{m} 2 / \mathrm{d}$

$\mathrm{gN} / \mathrm{m} 2 / \mathrm{d}$

$\mathrm{gN} / \mathrm{m} 2 / \mathrm{d}$

$\mathrm{gN} / \mathrm{m} 2 / \mathrm{d}$

W/m2_PAR

W/m2_PAR

$\mathrm{W} / \mathrm{m} 2$

g_prod./g_total_bi

-

$-$
_tNDifGroundl diffusion_flux_of_NH4_from_pore_water_to_ground_water

_aPAdsMaxW max_P_adsorption_per_g_inorg_matter_in_water_marsh

_aKPAdsWM_P_adsorption_affinitycorrected_for_redox_conditions

_aPIsoAdsWM P_adsorption_isotherm_onto_inorg_matter_in_sediment

aPEqIMWM_equilibrium_conc

wPSorpIMWI sorption_flux_in_water

_aPAdsMaxSI max_P_adsorption_per_g_inorg_matter_in_sediment_marsh

_aKPAdsSM_P_adsorption_affinitycorrected_for_redox_conditions

_aPIsoAdsSM P_adsorption_isotherm_onto_inorg_matter_in_sediment

_aPEqIMSM_equilibrium_amount

tPSorpIMSM sorption

_tPChemPO4|chem_loss_of_dissolved_P_from_pore_water

_aDayInitVeg_Initial_growth_only_once_a_year

_bfRootVeg_: setting_root_fration

_bfShootVeg_shoot_fraction

_aDRootVeg_root_biomass

aDShootVeg shoot_biomass

_aDEmergVeç emergent_biomass

_aDFloatVeg_floating_biomass

_bfSubVeg_= submerged_fraction_of_shoot

_aDSubVeg_ submerged_biomass

aExtVeg_= _contribution_of_plant_species_to_extinction_(submerged)

_aDepth1Veg_upper_depth_of_vegetation_layer_(minimum_=_0_m_=_surface)

_aDepth2Veg_lower_depth_of_vegetation_layer_(maximum_=_water_depth)

_afCovSurfVe fraction_of_water_SURFACE_covered_by_plant_species

_afCovEmerg' fraction_emergent_coverage

_aCovVeg_ = percent_cover

aDVeg_=_stotal_plant_biomass

_aPVeg_ = _s total_P_in_vegetation

_aNVeg_=_stotal_N_in_vegetation

_aExtCoef_= extinction_coefficient_incl_vegetation

_aLPARBot_: light_at_the_bottom

_rPDVeg_=_P/DW_ratio_of_vegetation

_rNDVeg_ = _N/DW_ratio_of_vegetation

_tDMigrVeg_: migration_flux

_tPMigrVeg_: net_migration_flux

_tNMigrVeg_: net_migration_flux

_uFunTmProd temperature_function_of_vegetation_production

_uFunTmResp temperature_function_of_vegetation_respiration

_afPUptVegS_fraction_of_P_uptake_from_sediment

_afNUptVegS_fraction_of_N_uptake_from_sediment

aVPUptMax (maximum $P$ uptake rate of vegetation corrected for $P / D$ ratio

_aVPUptVegVP_uptake_RATE_by_subm_AND_floating_parts

_aVPUptVegSP_uptake_rate_by_roots

_tPUptVegW_P_uptake_from_water

_tPUptVegS_P_uptake_from_pore_water_(by_root_fraction)

_tPUptVeg_= total_P_uptake_vegetation

aVNUptMax (maximum_N_uptake_rate_of_vegetation_corrected_for_N/D_ratio

_ahNUptVeg_half-sat_constant_for_N_uptake

_aVNUptVegV N_uptake_RATE_by_subm_AND_floating_parts

_afNH4UptVe! fraction_ammonium_uptake_from_water_column_(from_WASP_model_EPA)

_tNUptVegW_N_uptake_from_water_(by_shoots)

_tNUptNH4VeNH4_uptake_of_vegetation_from_water

_tNUptNO3VeNO3_uptake_of_vegetation_from_water

_aVNUptVeg $\leqslant$ N_uptake_RATE_of_roots

_tNUptVegS_N_uptake_from_pore_water_(by_roots)

_afNH4UptVe! fraction_ammonium_uptake_from_pore_water_(from_WASP_model_EPA)

_tNUptNH4VeNH4_uptake_of_vegetation_from_sediment

_tNUptNO3VeNO3_uptake_of_vegetation_from_sediment

_tNUptVeg_= total_N_uptake_vegetation

_aLPAR1Veg_light_at_top_of_vegetation_layer

_aLPAR2Veg_light_at_bottom_of_vegetation_layer

_uhLVeg_= half-sat_light_for_vegetation_production_at_current_temp

_aLLimShootl light_function_of_growth_based_on_shoot_fraction

_aMuTmLVeg max_growth_rate_at_current_temp_AND_light

_aPLimVeg_=Droop_function_(P)_for_vegetation

_aNLimVeg_:Droop_function_(N)_for_vegetation 
_aNutLimVeg_ _aMuVeg

bkMortVeg

_akDIncrVeg_

tDEnvVeg_

_tDEnvProdVeg_

_tDProdVeg_

tDProdSubVeg_

_tDRespVeg_

_tDEnvMortVeg_

tDMortVeg

tDMortVegW

_tDMortVegS

tDGrazVegBird

_bkManVeg_

_tDManVeg_

tPManVeg_

_tNManVeg_

tDBedVeg

_tO2ProdVeg_

_tO2RespVegW_

_tO2RespVegS

tO2ProdVegs

_tO2ProdVegW

_tO2UptNO3VegW

tO2UptNO3Vegs_

_tPExcrVeg_

tPExcrVegs

_tPExcrVegW_

_tPMortVeg

_tPMortVegPO4_

_tPMortVegPO4S

tPMortVegPO4W_

tPMortVegDet_

_tPMortVegDetW_

_tPMortVegDetS_

_tPGrazVegBird_

_tPBedVeg_

tNExcrVeg

_tNExcrVegs_

_tNExcrVegW_

tNMortVeg

_tNMortVegNH4

_tNMortVegNH4S_

-tNMortVegNH4W_

_tNMortVegDet_

_tNMortVegDetW_

_tNMortVegDetS_

_tNGrazVegBird_

_tNBedVeg_

tDAssVegBird

_tDEgesBird_

tPAssVegBird

tPEgesBird

_tPEgesBirdPO4_

tPEgesBirdDet_

_tNAssVegBird_

_tNEgesBird_

_tNEgesBirdN ${ }^{-}{ }_{4}$

_tNEgesBirdDet_

wDBedDetW

-tDBedDetS_

tDBedTotT

wPBedPO4W

_wPBedDetW_

tPBedPO4S

-tPBedDetS_
_aNutLimVeg_nutrient_limitation_function_of_vegetation

g_prod./g_total_bi_aMuVeg_= _actual_growth_rate_of_vegetation

d-1_bkMortVeg_ mortality_constant

d-1 _akDIncrVeg_intrinsic_net_increase_rate_of_vegetation

$\mathrm{gDW} / \mathrm{m} 2 / \mathrm{d} \quad$ _tDEnvVeg_= logistic_correction_of_vegetation

$\mathrm{gDW} / \mathrm{m} 2 / \mathrm{d} \quad$ _tDEnvProdVt logistic_correction_of_production

$\mathrm{gDW} / \mathrm{m} 2 / \mathrm{d} \quad$ tDProdVeg_vegetation_production

$\mathrm{gDW} / \mathrm{m} 2 / \mathrm{d} \quad$ _tDProdSubVisubmerged_production

g.m-2.d-1

$\mathrm{gDW} / \mathrm{m} 2 / \mathrm{d}$

$\mathrm{gDW} / \mathrm{m} 2 / \mathrm{d}$

$\mathrm{gDW} / \mathrm{m} 2 / \mathrm{d}$

$\mathrm{gDW} / \mathrm{m} 2 / \mathrm{d}$

$\mathrm{g} / \mathrm{m} 2 / \mathrm{d}$

d-1

gDW/m2/d

$\mathrm{gP} / \mathrm{m} 2 / \mathrm{d}$

$\mathrm{gN} / \mathrm{m} 2 / \mathrm{d}$

$\mathrm{gDW} / \mathrm{m} 2 / \mathrm{d}$

$\mathrm{gO} 2 / \mathrm{m} 2 / \mathrm{d}$

$\mathrm{gO} 2 / \mathrm{m} 2 / \mathrm{d}$

$\mathrm{gO} 2 / \mathrm{m} 2 / \mathrm{d}$

$\mathrm{gO} 2 / \mathrm{m} 2 / \mathrm{d}$

$\mathrm{gO} 2 / \mathrm{m} 2 / \mathrm{d}$

$\mathrm{gO} 2 / \mathrm{m} 2 / \mathrm{d}$

$\mathrm{gO} 2 / \mathrm{m} 2 / \mathrm{d}$

$\mathrm{gP} / \mathrm{m} 2 / \mathrm{d}$

$\mathrm{gP} / \mathrm{m} 2 / \mathrm{d}$

$\mathrm{gP} / \mathrm{m} 2 / \mathrm{d}$

$\mathrm{gP} / \mathrm{m} 2 / \mathrm{d}$

$\mathrm{gP} / \mathrm{m} 2 / \mathrm{d}$

$\mathrm{gP} / \mathrm{m} 2 / \mathrm{d}$

$\mathrm{gP} / \mathrm{m} 2 / \mathrm{d}$

$\mathrm{gP} / \mathrm{m} 2 / \mathrm{d}$

$\mathrm{gP} / \mathrm{m} 2 / \mathrm{d}$

$\mathrm{gP} / \mathrm{m} 2 / \mathrm{d}$

$\mathrm{gP} / \mathrm{m} 2 / \mathrm{d}$

$\mathrm{gP} / \mathrm{m} 2 / \mathrm{d}$

$\mathrm{gN} / \mathrm{m} 2 / \mathrm{d}$

$\mathrm{gN} / \mathrm{m} 2 / \mathrm{d}$

$\mathrm{gN} / \mathrm{m} 2 / \mathrm{d}$

$\mathrm{gN} / \mathrm{m} 2 / \mathrm{d}$

$\mathrm{gN} / \mathrm{m} 2 / \mathrm{d}$

$\mathrm{gN} / \mathrm{m} 2 / \mathrm{d}$

$\mathrm{gN} / \mathrm{m} 2 / \mathrm{d}$

$\mathrm{gN} / \mathrm{m} 2 / \mathrm{d}$

$\mathrm{gN} / \mathrm{m} 2 / \mathrm{d}$

$\mathrm{gN} / \mathrm{m} 2 / \mathrm{d}$

$\mathrm{gN} / \mathrm{m} 2 / \mathrm{d}$

$\mathrm{gN} / \mathrm{m} 2 / \mathrm{d}$

$\mathrm{gDW} / \mathrm{m} 2 / \mathrm{d}$

$\mathrm{gDW} / \mathrm{m} 2 / \mathrm{d}$

$\mathrm{gP} / \mathrm{m} 2 / \mathrm{d}$

$\mathrm{gP} / \mathrm{m} 2 / \mathrm{d}$

$\mathrm{gP} / \mathrm{m} 2 / \mathrm{d}$

$\mathrm{gP} / \mathrm{m} 2 / \mathrm{d}$

$\mathrm{gN} / \mathrm{m} 2 / \mathrm{d}$

$\mathrm{gN} / \mathrm{m} 2 / \mathrm{d}$

$\mathrm{gN} / \mathrm{m} 2 / \mathrm{d}$

$\mathrm{gN} / \mathrm{m} 2 / \mathrm{d}$

gD.m-3.d-1

$\mathrm{gDW} / \mathrm{m} 2 / \mathrm{d}$

$\mathrm{gDW} / \mathrm{m} 2 / \mathrm{d}$

$\mathrm{gP} / \mathrm{m} 3 / \mathrm{d}$

$\mathrm{gP} / \mathrm{m} 3 / \mathrm{d}$

$\mathrm{gP} / \mathrm{m} 2 / \mathrm{d}$

$\mathrm{gP} / \mathrm{m} 2 / \mathrm{d}$
_tDRespVeg_dark_respiration_of_vegetation

_tDEnvMortV $\epsilon$ logistic_correction_of_mortality

_tDMortVeg_: total_mortality_flux_DW_vegetation

_tDMortVegW mortality_flux_becoming_water_detritus

_tDMortVegS_mortality_flux_becoming_sediment_detritus

tDGrazVegBi biomass_loss_due_to_grazing_of_birds

_bkManVeg_: rate_constant_during_mowing_period

_tDManVeg_: Mowing_of_vegetation_DW

_tPManVeg_: Mowing_of_vegetation_P

_tNManVeg_: Mowing_of_vegetation_N

_tDBedVeg_=derivative_of_vegetation_biomass

_tO2ProdVeg_vegetation_O2_production

_tO2RespVeg submerged_O2_respiration

_tO2RespVeg root_O2_respiration

_tO2ProdVeg! O2_transport_to_roots

_tO2ProdVegl O2_used_for_vegetation_production

_tO2UptNO3V O2_production_to_water_due_to_NO3_uptake_by_macrophytes

_tO2UptNO3V O2_production_due_to_NO3_uptake_from_sed_by_macrophytes

_tPExcrVeg_: P_excretion_by_vegetation

tPExcrVegS_P_excretion_by_vegetation_in_sediment

_tPExcrVegW.P_excretion_by_vegetation_in_water

_tPMortVeg_: $P$ _mortality_flux_of_vegetation

_tPMortVegP( mortality_flux_of_vegetation_becoming_dissolved_P

_tPMortVegP( mortality_flux_of_vegetation_becoming_dissolved_P_in_sediment

tPMortVegP( mortality_flux_of_vegetation_becoming_dissolved_P_in_water

_tPMortVegD $\epsilon$ mortality_flux_of_vegetation_becoming_detritus_P

_tPMortVegD $\epsilon$ mortality_flux_of_vegetation_becoming_detritus_P_in_water

_tPMortVegD $\epsilon$ mortality_flux_of_vegetation_becoming_detritus_P_in_sediment

_tPGrazVegBi P_mortality_flux_of_vegetation_by_bird_grazing

_tPBedVeg_ = total_vegetation_P_flux_in_bed_module

_tNExcrVeg_: N_excretion_by_vegetation

_tNExcrVegS_N_excretion_by_vegetation_to_sediment

_tNExcrVegW N_excretion_by_vegetation_to_water

tNMortVeg_N mortality flux of vegetation

_tNMortVegNi mortality_flux_of_vegetation_becoming_dissolved_N

_tNMortVegNimortality_flux_of_vegetation_becoming_dissolved_N_in_sediment

_tNMortVegNl mortality_flux_of_vegetation_becoming_dissolved_N_in_water

_tNMortVegD $\mathrm{\epsilon}$ mortality_flux_of_vegetation_becoming_detritus_N

_tNMortVegDemortality_flux_of_vegetation_becoming_detritus_N_in_water

_tNMortVegDemortality_flux_of_vegetation_becoming_detritus_N_in_sediment

_tNGrazVegBi N_mortality_flux_of_vegetation_by_bird_grazing

_tNBedVeg_ = total_vegetation_N_flux_in_bed_module

_tDAssVegBir DW_assimilation_by_herbivorous_birds

_tDEgesBird_DW_egestion_by_herbivorous_birds

_tPAssVegBir P_assimilation_by_herbivorous_birds

_tPEgesBird_P_egestion_by_herbivorous_birds

_tPEgesBirdP PO4_egestion_by_herbivorous_birds

_tPEgesBirdD P_detritus_egestion_by_herbivorous_birds

_tNAssVegBir N_assimilation_by_herbivorous_birds

_tNEgesBird_N_egestion_by_herbivorous_birds

_tNEgesBirdN NH4_egestion_by_herbivorous_birds

_tNEgesBirdD N_detritus_egestion_by_herbivorous_birds

_wDBedDetW total_DW_flux_from_Vegetation_module_to_water_detritus

_tDBedDetS_total_DW_flux_from_Vegetation_module_to_sediment_detritus

_tDBedTotT_total_DW_flux_from_Vegetation_module

_wPBedPO4V total_P_flux_from_Vegetation_module_to_PO4_in_water

_wPBedDetW.total_P_flux_from_Vegetation_module_to_water_detritus

_tPBedPO4S_total_P_flux_from_Vegetation_module_to_pore_water_PO4

_tPBedDetS_total_P_flux_from_Vegetation_module_to_sediment_detritus 


\begin{tabular}{|c|c|c|}
\hline _tPBedTotT_ & $\mathrm{gP} / \mathrm{m} 2 / \mathrm{d}$ & _tPBedTotT_: total_P_flux_from_Vegetation_module \\
\hline _wNBedNH4 4 W_ & $\mathrm{gN} / \mathrm{m} 3 / \mathrm{d}$ & _wNBedNH4V total_N_flux_from_Vegetation_module_to_NH4_in_water \\
\hline -wNBedNO3W_ & $\mathrm{gN} / \mathrm{m} 3 / \mathrm{d}$ & _wNBedNO3V total_N_flux_from_Vegetation_module_to_NO3_in_water \\
\hline _wNBedDetW_ & $\mathrm{gN} / \mathrm{m} 3 / \mathrm{d}$ & _wNBedDetW total_N_flux_from_Vegetation_module_to_water_detritus \\
\hline tNBedNH4S_ & $\mathrm{gN} / \mathrm{m} 2 / \mathrm{d}$ & _tNBedNH4S_total_N_flux_from_Vegetation_module_to_NH4_in_pore_water \\
\hline tNBedNO3S_ & $\mathrm{gN} / \mathrm{m} 2 / \mathrm{d}$ & _tNBedNO3S_total_N_flux_from_Vegetation_module_to_NO3_in_pore_water \\
\hline tNBedDetS_ & $\mathrm{gN} / \mathrm{m} 2 / \mathrm{d}$ & _tNBedDetS_total_N_flux_from_Vegetation_module_to_sediment_detritus \\
\hline tNBedTotT_ & $\mathrm{gN} / \mathrm{m} 2 / \mathrm{d}$ & _tNBedTotT_total_N_flux_from_Vegetation_module \\
\hline tO2BedW_- & $\mathrm{gO} 2 / \mathrm{m} 2 / \mathrm{d}$ & _tO2BedW_= total_water_O2_flux_in_vegetation_module \\
\hline _tO2BedS_ & $\mathrm{gO} 2 / \mathrm{m} 2 / \mathrm{d}$ & _tO2BedS_= total_sediment_O2_flux_in_vegetation_module \\
\hline _UseLoss_ & $\mathrm{gO} 2 / \mathrm{m} 2 / \mathrm{d}$ & _UseLoss_= .- \\
\hline uFunTmLoss_ & - & _uFunTmLoss temp_function_of_grazing \\
\hline rPDBlueW_ & - & _rPDBlueW_: P/D_ratio_of_Algae \\
\hline _rNDBlueW_ & - & _rNDBlueW_:N/D_ratio_of_Algae \\
\hline rPDBlues_- & - & _rPDBlueS_=P/D_ratio_of_Algae \\
\hline rNDBlues_ & - & _rNDBlues_=N/D_ratio_of_Algae \\
\hline _uFunTmBlue_ & - & _uFunTmBlue temperature_function_of_Algae \\
\hline _uFunTmProdBlue_ & - & uFunTmProd temperature_function_of_Algae \\
\hline _uFunTmRespBlue_ & - & _uFunTmResp temperature_function_of_Algae \\
\hline _aVPUptMaxCrBlue_ & - & _aVPUptMax(maximum_P_uptake_rate_of_Algaecorrected_for_P/D_ratio \\
\hline _aVPUptBlue_ & $\mathrm{mgP} / \mathrm{mgDW} / \mathrm{d}$ & _aVPUptBlue_P_uptake_rate_of_Algae \\
\hline _wPUptBlue_ & $\mathrm{gP} / \mathrm{m} 2 / \mathrm{d}$ & _wPUptBlue_P_uptake_Algae \\
\hline _aVNUptMaxCrBlue_ & - & _aVNUptMax (maximum_N_uptake_rate_of_Algaecorrected_for_N/D_ratio \\
\hline _ahNUptBlue__ & $\mathrm{mgN} / \mathrm{l}$ & _ahNUptBlue_half-sat_NDissW_for_uptake_by_Algae \\
\hline _aVNUptBlue_ & $\mathrm{mgN} / \mathrm{mgDW} / \mathrm{d}$ & _aVNUptBlue_N_uptake_rate_of_Algae \\
\hline _wNUptBlue_ & $\mathrm{mgN} / \mathrm{l} / \mathrm{d}$ & _wNUptBlue_N_uptake_Algae \\
\hline _afNH4UptBlue_ & - & _afNH4UptBlu fraction_ammonium_uptake_by_Algae \\
\hline _wNUptNH4Blue_ & $\mathrm{mgN} / \mathrm{l} / \mathrm{d}$ & _wNUptNH4B ammonium_uptake_by_Algae \\
\hline _wNUptNO3Blue_ & $\mathrm{mgN} / \mathrm{l} / \mathrm{d}$ & _wNUptNO3B nitrate_uptake_by_Algae \\
\hline _uMuMaxTmBlue_ & $d-1$ & _uMuMaxTmE max_growth_rate_of_Algae_at_ambient_temperature \\
\hline _aPLimBlue_ & - & _aPLimBlue_Droop_function(P)_for_Algae \\
\hline _aNLimBlue_ & - & _aNLimBlue__Droop_function(N)_for_Algae \\
\hline _aSiLimBlue_ & - & _aSiLimBlue_silica_dependence_of_growth_rate \\
\hline _aLLimBlue_ & - & _aLLimBlue_: Light_function \\
\hline _aMuTmLBlue_ & $d-1$ & _aMuTmLBlue growth_rate_at_current_light_AND_temp \\
\hline _aNutLimBlue_ & $d-1$ & _aNutLimBlue nutrient_limitation_function_of_Algae \\
\hline _aMuBlue__ & $d-1$ & _aMuBlue_= growth_rate \\
\hline _wDAssBlue_ & $\mathrm{gD} / \mathrm{m} 3 / \mathrm{d}$ & _wDAssBlue_assimilation_Algae \\
\hline _rChDBlue_ & $\mathrm{mg} / \mathrm{mg}$ & _rChDBlue_= chlorophyll-a/DW_ratio_Algae \\
\hline _oChlaBlue_ & $\mathrm{mg} / \mathrm{m} 3$ & _oChlaBlue_= chlorophyll-a_conc \\
\hline aExtChBlue_ & m2/mg_chl-a & _aExtChBlue_specific_extinction_per_unit_chlorophyll-a \\
\hline _ukDRespTmBlue_ & $d-1$ & _ukDRespTml temp_corrected_respiration_constant_of_Algae \\
\hline _wDRespBlueW_ & $\mathrm{g} / \mathrm{m} 2 / \mathrm{d}$ & _wDRespBlue respiration_of_Algae_in_water \\
\hline _ukLossTmBlue_ & $d-1$ & _ukLossTmBlı daily_grazing_on_Algae \\
\hline _wDLossBlue_ & $\mathrm{mgDW} / \mathrm{l} / \mathrm{d}$ & _wDLossBlue_Algae_grazing_loss \\
\hline _wDMortBlueW_ & $\mathrm{g} / \mathrm{m} 3 / \mathrm{d}$ & _wDMortBluel mortality_in_water \\
\hline _uCorVSetBlue_ & $\mathrm{m} / \mathrm{d}$ & _uCorVSetBlu corrected_sedimentation_velocity_of_Algae \\
\hline tDSetBlue_ & $\mathrm{g} / \mathrm{m} 2 / \mathrm{d}$ & _tDSetBlue_= sedimentation_flux_of_Algae \\
\hline _tDResusBlue_ & $\mathrm{g} / \mathrm{m} 2 / \mathrm{d}$ & _tDResusBlue resuspension_DW_blue-greens \\
\hline _tDRespBlueS_ & $\mathrm{gD} / \mathrm{m} 2 / \mathrm{d}$ & _tDRespBlue $\{$ respiration_of_sediment_Algae \\
\hline _tDMortBlues_ & $\mathrm{g} / \mathrm{m} 2 / \mathrm{d}$ & _tDMortBlueS mortality_in_sed \\
\hline _ukDDecBlue_ & $d-1$ & _ukDDecBlue_total_loss_rate_of_algae_in_water(excl_dilution) \\
\hline _wPExcrBlueW_ & $\mathrm{gP} / \mathrm{m} 3 / \mathrm{d}$ & _wPExcrBluelP_excretion_Algae_in_water \\
\hline _wPLossBlue_ & $\mathrm{mgP} / \mathrm{l} / \mathrm{d}$ & _wPLossBlue_Algae_grazing_loss \\
\hline _wPMortBlue $\bar{W}_{-}$ & $\mathrm{gP} / \mathrm{m} 3 / \mathrm{d}$ & _wPMortBluel mortality_Algae_in_water \\
\hline _tPSetBlue_ & $\mathrm{gP} / \mathrm{m} 2 / \mathrm{d}$ & _tPSetBlue_ = sedimentation \\
\hline _tPResusBlue_ & $\mathrm{gD} / \mathrm{m} 2 / \mathrm{d}$ & _tPResusBlue Resuspension_of_algae \\
\hline _tPExcrBlues_ & $\mathrm{gP} / \mathrm{m} 2 / \mathrm{d}$ & _tPExcrBlueS_P_excretion_of_algae_in_sediment \\
\hline _tPMortBlues_ & $\mathrm{gP} / \mathrm{m} 2 / \mathrm{d}$ & _tPMortBlueS_P_mortality_of_algae_in_sediment \\
\hline _wNExcrBlueW_ & $\mathrm{gN} / \mathrm{m} 3 / \mathrm{d}$ & _wNExcrBluel N_excretion_Algae_in_water \\
\hline _wNLossBlue_ & $\mathrm{mgN} / \mathrm{l} / \mathrm{d}$ & _wNLossBlue_Algae_grazing_loss \\
\hline _wNMortBlueW_ & $\mathrm{gN} / \mathrm{m} 3 / \mathrm{d}$ & _wNMortBluel mortality_Algae_in_water \\
\hline _tNSetBlue_ & $\mathrm{gN} / \mathrm{m} 2 / \mathrm{d}$ & _tNSetBlue_= sedimentation \\
\hline _tNResusBlue_ & $\mathrm{gD} / \mathrm{m} 2 / \mathrm{d}$ & _tNResusBlue Resuspension_of_algae \\
\hline tNExcrBlues_ & $\mathrm{gN} / \mathrm{m} 2 / \mathrm{d}$ & _tNExcrBlueS N_excretion_of_algae_in_sediment \\
\hline _tNMortBlueS_ & $\mathrm{gN} / \mathrm{m} 2 / \mathrm{d}$ & _tNMortBlueS N_mortality_of_algae_in_sediment \\
\hline wDPrimBlueW_ & $\mathrm{mgD} / / / \mathrm{d}$ & _wDPrimBluel total_PRIM_flux_to_algae_in_water \\
\hline
\end{tabular}




\begin{tabular}{|c|c|c|}
\hline _wPPrimBlueW_ & $\mathrm{mgP} / / / \mathrm{d}$ & _wPPrimBluel Total_PRIM_flux_to_Algae \\
\hline _wNPrimBlueW & $\mathrm{mgN} / \mathrm{l} / \mathrm{d}$ & _wNPrimBluel Total_PRIM_flux_to_Algae \\
\hline _tDPrimBlues_ & $\mathrm{gD} / \mathrm{m} 2 / \mathrm{d}$ & _tDPrimBlueS total_flux_from_PRIM_module_to_sediment_Algae \\
\hline tPPrimBlues_- & $\mathrm{gP} / \mathrm{m} 2 / \mathrm{d}$ & _tPPrimBlueS total_flux_from_PRIM_module_to_sediment_Algae \\
\hline _tNPrimBlueS_ & $\mathrm{gN} / \mathrm{m} 2 / \mathrm{d}$ & _tNPrimBlueS total_flux_from_PRIM_module_to_sediment_Algae \\
\hline rPDGrenW_ & - & _rPDGrenW_P/D_ratio_of_Algae \\
\hline rNDGrenW & - & rNDGrenW_N/D_ratio_of_Algae \\
\hline rPDGrens_ & - & _rPDGrens_=P/D_ratio_of_Algae \\
\hline rNDGrens__ & - & _rNDGrenS_:N/D_ratio_of_Algae \\
\hline _uFunTmGren_ & - & _uFunTmGrer temperature_function_of_Algae \\
\hline _uFunTmProdGren_ & - & _uFunTmProd temperature_function_of_Algae \\
\hline _uFunTmRespGren_ & - & _uFunTmResp temperature_function_of_Algae \\
\hline _aVPUptMaxCrGren_- & - & _aVPUptMax (maximum_P_uptake_rate_of_Algaecorrected_for_P/D_ratio \\
\hline _aVPUptGren_ & $\mathrm{mgP} / \mathrm{mgDW} / \mathrm{d}$ & _aVPUptGren P_uptake_rate_of_Algae \\
\hline _wPUptGren_- & $\mathrm{gP} / \mathrm{m} 2 / \mathrm{d}$ & _wPUptGren_P_uptake_Algae \\
\hline _aVNUptMaxCrGren_ & - & _aVNUptMax (maximum_N_uptake_rate_of_Algaecorrected_for_N/D_ratio \\
\hline _ahNUptGren__ & $\mathrm{mgN} / \mathrm{l}$ & _ahNUptGren . half-sat_NDissW_for_uptake_by_Algae \\
\hline _aVNUptGren_ & $\mathrm{mgN} / \mathrm{mgDW} / \mathrm{d}$ & _aVNUptGren N_uptake_rate_of_Algae \\
\hline _wNUptGren_ & $\mathrm{mgN} / \mathrm{l} / \mathrm{d}$ & _wNUptGren_N_uptake_Algae \\
\hline _afNH4UptGren_ & - & _afNH4UptGrefraction_ammonium_uptake_by_Algae \\
\hline _wNUptNH4Gren_ & $\mathrm{mgN} / \mathrm{l} / \mathrm{d}$ & _wNUptNH4Gammonium_uptake_by_Algae \\
\hline _wNUptNO3Gren_ & $\mathrm{mgN} / / \mathrm{d}$ & _wNUptNO3G nitrate_uptake_by_Algae \\
\hline _uMuMaxTmGren_ & d-1 & _uMuMaxTmCmax_growth_rate_of_Algae_at_ambient_temperature \\
\hline _aPLimGren_ & - & _aPLimGren_Droop_function(P)_for_Algae \\
\hline _aNLimGren_- & - & _aNLimGren_Droop_function(N)_for_Algae \\
\hline _aSiLimGren_- & - & _aSiLimGren_silica_dependence_of_growth_rate \\
\hline _aLLimGren_- & - & _aLLimGren__Light_function \\
\hline _aMuTmLGren_ & $d-1$ & _aMuTmLGreı growth_rate_at_current_light_AND_temp \\
\hline _aNutLimGren_ & $d-1$ & _aNutLimGrenutrient_limitation_function_of_Algae \\
\hline _aMuGren_ & $d-1$ & _aMuGren_= growth_rate \\
\hline _wDAssGren_ & $\mathrm{gD} / \mathrm{m} 3 / \mathrm{d}$ & _wDAssGren_assimilation_Algae \\
\hline _rChDGren_ & $\mathrm{mg} / \mathrm{mg}$ & _rChDGren_= chlorophyll-a/DW_ratio_Algae \\
\hline _oChlaGren_- & $\mathrm{mg} / \mathrm{m} 3$ & _oChlaGren_chlorophyll-a_conc \\
\hline _aExtChGren__ & m2/mg_chl-a & _aExtChGren_specific_extinction_per_unit_chlorophyll-a \\
\hline _ukDRespTmGren_ & $\mathrm{d}-1$ & _ukDRespTmitemp_corrected_respiration_constant_of_Algae \\
\hline wDRespGrenW & $\mathrm{g} / \mathrm{m} 2 / \mathrm{d}$ & wDRespGrer respiration of Algae in water \\
\hline _ukLossTmGren_- & $d-1$ & _ukLossTmGr daily_grazing_on_Algae \\
\hline wDLossGren_ & $\mathrm{mgDW} / \mathrm{l} / \mathrm{d}$ & _wDLossGren Algae_grazing_loss \\
\hline _wDMortGrenW_ & $\mathrm{g} / \mathrm{m} 3 / \mathrm{d}$ & _wDMortGren mortality_in_water \\
\hline _uCorVSetGren_ & $\mathrm{m} / \mathrm{d}$ & _uCorVSetGrecorrected_sedimentation_velocity_of_Algae \\
\hline tDSetGren_ & $\mathrm{g} / \mathrm{m} 2 / \mathrm{d}$ & _tDSetGren_: sedimentation_flux_of_Algae \\
\hline tDResusGren_ & $\mathrm{gD} / \mathrm{m} 2 / \mathrm{d}$ & _tDResusGrer resuspension_of_Algae \\
\hline tDRespGrens_- & $\mathrm{gD} / \mathrm{m} 2 / \mathrm{d}$ & _tDRespGren! respiration_of_sediment_Algae \\
\hline tDMortGrens_ & $\mathrm{g} / \mathrm{m} 2 / \mathrm{d}$ & _tDMortGrens mortality_in_sed \\
\hline ukDDecGren_- & d-1 & _ukDDecGren total_loss_rate_of_algae_in_water(excl_dilution) \\
\hline _wPExcrGrenW_ & $\mathrm{gP} / \mathrm{m} 3 / \mathrm{d}$ & _wPExcrGren'P_excretion_Algae_in_water \\
\hline _wPLossGren_- & $\mathrm{mgP} / \mathrm{l} / \mathrm{d}$ & _wPLossGren Algae_grazing_loss \\
\hline _wPMortGrenW_ & $\mathrm{gP} / \mathrm{m} 3 / \mathrm{d}$ & _wPMortGren'mortality_Algae_in_water \\
\hline tPSetGren_ & $\mathrm{gP} / \mathrm{m} 2 / \mathrm{d}$ & _tPSetGren_: sedimentation \\
\hline tPResusGren_ & $\mathrm{gD} / \mathrm{m} 2 / \mathrm{d}$ & _tPResusGrer Resuspension_of_algae \\
\hline _tPExcrGrens_ & $\mathrm{gP} / \mathrm{m} 2 / \mathrm{d}$ & _tPExcrGrenSP_excretion_of_algae_in_sediment \\
\hline tPMortGrens_ & $\mathrm{gP} / \mathrm{m} 2 / \mathrm{d}$ & _tPMortGrenSP_mortality_of_algae_in_sediment \\
\hline wNExcrGrenW & $\mathrm{gN} / \mathrm{m} 3 / \mathrm{d}$ & _wNExcrGren' N_excretion_Algae_in_water \\
\hline wNLossGren_ & $\mathrm{mgN} / \mathrm{l} / \mathrm{d}$ & _wNLossGren Algae_grazing_loss \\
\hline wNMortGrenW_ & $\mathrm{gN} / \mathrm{m} 3 / \mathrm{d}$ & _wNMortGren mortality_Algae_in_water \\
\hline tNSetGren_ & $\mathrm{gN} / \mathrm{m} 2 / \mathrm{d}$ & _tNSetGren_: sedimentation \\
\hline _tNResusGren_ & $\mathrm{gD} / \mathrm{m} 2 / \mathrm{d}$ & _tNResusGrer Resuspension_of_algae \\
\hline tNExcrGrens_ & $\mathrm{gN} / \mathrm{m} 2 / \mathrm{d}$ & _tNExcrGrens N_excretion_of_algae_in_sediment \\
\hline tNMortGrens_- & $\mathrm{gN} / \mathrm{m} 2 / \mathrm{d}$ & _tNMortGrensN_mortality_of_algae_in_sediment \\
\hline wDPrimGrenW & $\mathrm{mgD} / \mathrm{l} / \mathrm{d}$ & _wDPrimGren total_PRIM_flux_to_algae_in_water \\
\hline _wPPrimGrenW_ & $\mathrm{mgP} / \mathrm{l} / \mathrm{d}$ & _wPPrimGren Total_PRIM_flux_to_Algae \\
\hline wNPrimGrenW_- & $\mathrm{mgN} / \mathrm{l} / \mathrm{d}$ & _wNPrimGren Total_PRIM_flux_to_Algae \\
\hline tDPrimGrens_ & $\mathrm{gD} / \mathrm{m} 2 / \mathrm{d}$ & _tDPrimGrens total_flux_from_PRIM_module_to_sediment_Algae \\
\hline tPPrimGrens_ & $\mathrm{gP} / \mathrm{m} 2 / \mathrm{d}$ & _tPPrimGrens total_flux_from_PRIM_module_to_sediment_Algae \\
\hline tNPrimGrens_- & $\mathrm{gN} / \mathrm{m} 2 / \mathrm{d}$ & _tNPrimGrenstotal_flux_from_PRIM_module_to_sediment_Algae \\
\hline rPDDiatW_ & - & _rPDDiatW_=P/D_ratio_of_Algae \\
\hline rNDDiatW_ & - & rNDDiatW_=N/D_ratio_of_Algae \\
\hline
\end{tabular}


_rPDDiats

rNDDiats

_uFunTmDiat

_uFunTmProdDiat_

_uFunTmRespDiat

_aVPUptMaxCrDiat_

_aVPUptDiat_

_wPUptDiat

_aVNUptMaxCrDiat_

_ahNUptDiat_

aVNUptDiat

_wNUptDiat_

_afNH4UptDiat

_wNUptNH4Diat

_wNUptNO3Diat_

_uMuMaxTmDiat_

_aPLimDiat

aNLimDiat_

_aSiLimDiat

_aLLimDiat_

_aMuTmLDiat_

aNutLimDiat_

_aMuDiat

_wDAssDiat

rChDDiat

_oChlaDiat_

_aExtChDiat_

ukDRespTmDiat

_wDRespDiatW_

_ukLossTmDiat_

_wDLossDiat_

_wDMortDiatW_

_uCorVSetDiat_

_tDSetDiat_

_tDResusDiat_

tDRespDiatS_

_tDMortDiatS_

_ukDDecDiat_

_wPExcrDiatW_

_wPLossDiat_

_wPMortDiatW_

_tPSetDiat_

tPResusDiat

_tPExcrDiatS_

_tPMortDiats_

_WNExcrDiatW_

_wNLossDiat

_wNMortDiatW

_tNSetDiat_

tNResusDiat

_tNExcrDiats_

_tNMortDiatS_

_wDPrimDiatW

_wPPrimDiatW

_wNPrimDiatW_

tDPrimDiats

_tPPrimDiats_

tNPrimDiatS

_oChla_

_wDAssPhyt_

_wDRespPhytw_

_wDMortPhytw_

_tDSetPhyt

_wDLossPhyt

_wDPrimPhytW_

_wPUptPhyt

_wPExcrPhytw_
-

$\mathrm{mgP} / \mathrm{mgDW} / \mathrm{d}$

$\mathrm{gP} / \mathrm{m} 2 / \mathrm{d}$

$\mathrm{mgN} / \mathrm{l}$

$\mathrm{mgN} / \mathrm{mgDW} / \mathrm{d}$

$\mathrm{mgN} / / \mathrm{d}$

$\mathrm{mgN} / / \mathrm{d}$

$\mathrm{mgN} / / \mathrm{d}$

d-1

d-1

d-1

d-1

$\mathrm{gD} / \mathrm{m} 3 / \mathrm{d}$

$\mathrm{mg} / \mathrm{mg}$

$\mathrm{mg} / \mathrm{m} 3$

m2/mg_chl-a

d-1

$\mathrm{g} / \mathrm{m} 2 / \mathrm{d}$

d-1

$\mathrm{mgDW} / \mathrm{l} / \mathrm{d}$

$\mathrm{g} / \mathrm{m} 3 / \mathrm{d}$

$\mathrm{m} / \mathrm{d}$

$\mathrm{g} / \mathrm{m} 2 / \mathrm{d}$

$\mathrm{gD} / \mathrm{m} 2 / \mathrm{d}$

$\mathrm{gD} / \mathrm{m} 2 / \mathrm{d}$

$\mathrm{g} / \mathrm{m} 2 / \mathrm{d}$

d-1

$\mathrm{gP} / \mathrm{m} 3 / \mathrm{d}$

$\mathrm{mgP} / \mathrm{ld}$

$\mathrm{gP} / \mathrm{m} 3 / \mathrm{d}$

$\mathrm{gP} / \mathrm{m} 2 / \mathrm{d}$

$\mathrm{gD} / \mathrm{m} 2 / \mathrm{d}$

$\mathrm{gP} / \mathrm{m} 2 / \mathrm{d}$

$\mathrm{gP} / \mathrm{m} 2 / \mathrm{d}$

$\mathrm{gN} / \mathrm{m} 3 / \mathrm{d}$

$\mathrm{mgN} / / \mathrm{d}$

$\mathrm{gN} / \mathrm{m} 3 / \mathrm{d}$

$\mathrm{gN} / \mathrm{m} 2 / \mathrm{d}$

$\mathrm{gD} / \mathrm{m} 2 / \mathrm{d}$

$\mathrm{gN} / \mathrm{m} 2 / \mathrm{d}$

$\mathrm{gN} / \mathrm{m} 2 / \mathrm{d}$

$\mathrm{mgD} / / \mathrm{d}$

$\mathrm{mgP} / / \mathrm{d}$

$\mathrm{mgN} / / \mathrm{d}$

$\mathrm{gD} / \mathrm{m} 2 / \mathrm{d}$

$\mathrm{gP} / \mathrm{m} 2 / \mathrm{d}$

$\mathrm{gN} / \mathrm{m} 2 / \mathrm{d}$

$\mathrm{mg} / \mathrm{m} 3$

$\mathrm{gDW} / \mathrm{m} 3 / \mathrm{d}$

$\mathrm{gD} / \mathrm{m} 3 / \mathrm{d}$

$\mathrm{gD} / \mathrm{m} 3 / \mathrm{d}$

$\mathrm{gDW} / \mathrm{m} 2 / \mathrm{d}$

$\mathrm{gDW} / \mathrm{m} 3 / \mathrm{d}$

$\mathrm{gD} / \mathrm{m} 3 / \mathrm{d}$

$\mathrm{gP} / \mathrm{m} 3 / \mathrm{d}$

$\mathrm{gP} / \mathrm{m} 3 / \mathrm{d}$
_rPDDiatS_= P/D_ratio_of_Algae

_rNDDiatS_ = N/D_ratio_of_Algae

uFunTmDiat_temperature_function_of_Algae

_uFunTmProd temperature_function_production_of_Algae

_uFunTmResp temperature_function_respiration_of_Algae

aVPUptMax (maximum_P_uptake_rate_of_Algaecorrected_for_P/D_ratio

_aVPUptDiat_P_uptake_rate_of_Algae

_wPUptDiat_: P_uptake_Algae

_aVNUptMax (maximum_N_uptake_rate_of_Algaecorrected_for_N/D_ratio

_ahNUptDiat_half-sat_NDissW_for_uptake_by_Algae

_aVNUptDiat_N_uptake_rate_of_Algae

_wNUptDiat_: N_uptake_Algae

_afNH4UptDic fraction_ammonium_uptake_by_Algae

_wNUptNH4D ammonium_uptake_by_Algae

_wNUptNO3D nitrate_uptake_by_Algae

_uMuMaxTm[ max_growth_rate_of_Algae_at_ambient_temperature

_aPLimDiat_=Droop_function $(P) \_$for_Algae

_aNLimDiat_: Droop_function(N)_for_Algae

_aSiLimDiat_silica_dependence_of_growth_rate

_aLLimDiat_= Light_function

_aMuTmLDiat growth_rate_at_current_light_AND_temp

_aNutLimDicnutrient_limitation_function_of_Algae

_aMuDiat_= growth_rate

_wDAssDiat_assimilation_Algae

_rChDDiat_= chlorophyll-a/DW_ratio_Algae

_oChlaDiat_ = chlorophyll-a_conc

_aExtChDiat_specific_extinction_per_unit_chlorophyll-a

_ukDRespTml temp_corrected_respiration_constant_of_Algae

_wDRespDiat' respiration_of_Algae_in_water

_ukLossTmDii daily_grazing_on_Algae

_wDLossDiat_Algae_grazing_loss

_wDMortDiatV mortality_in_water

_uCorVSetDia corrected_sedimentation_velocity_of_Algae

_tDSetDiat_= sedimentation_flux_of_Algae

_tDResusDiat resuspension_of_Algae

_tDRespDiatS respiration_of_sediment_Algae

_tDMortDiatS_mortality_in_sed

_ukDDecDiat_total_loss_rate_of_algae_in_water(excl_dilution)

_wPExcrDiatV $P$ _excretion_Algae_in_water

_wPLossDiat_Algae_grazing_loss

_wPMortDiatV mortality_Algae_in_water

tPSetDiat_ = sedimentation

_tPResusDiat_Resuspension_of_algae

_tPExcrDiatS_P_excretion_of_algae_in_sediment

_tPMortDiatS_P_mortality_of_algae_in_sediment

_wNExcrDiatV N_excretion_Algae_in_water

_wNLossDiat_Algae_grazing_loss

_wNMortDiatV mortality_Algae_in_water

_tNSetDiat_= sedimentation

_tNResusDiat Resuspension_of_algae

_tNExcrDiatS_N_excretion_of_algae_in_sediment

_tNMortDiatS_N_mortality_of_algae_in_sediment

_wDPrimDiatV total_PRIM_flux_to_algae_in_water

_wPPrimDiatV Total_PRIM_flux_to_Algae

_wNPrimDiatV Total_PRIM_flux_to_Algae

_tDPrimDiatS_total_flux_from_PRIM_module_to_sediment_Algae

_tPPrimDiatS_total_flux_from_PRIM_module_to_sediment_Algae

_tNPrimDiatS_total_flux_from_PRIM_module_to_sediment_Algae

_oChla_=_octotal_chlorophyll-a

_wDAssPhyt_total_algal_growth

_wDRespPhyt total_algal_respiration_in_water

_wDMortPhytl total_algal_mortality_in_water

_tDSetPhyt_= total_phytoplankton_sedimentation

_wDLossPhyt_total_phytoplankton_grazing_loss

_wDPrimPhyti total_of_PRIM_processes_of_algae_in_water

_wPUptPhyt_total_P_uptake_phytoplankton

_wPExcrPhytt total_P_excretion_phytoplankton_in_water 


\begin{tabular}{|c|c|c|}
\hline _wPMortPhytW_ & $\mathrm{gP} / \mathrm{m} 3 / \mathrm{d}$ & _wPMortPhytl total_P_mortality_phytoplankton_in_water \\
\hline _tPSetPhyt_ & $\mathrm{gP} / \mathrm{m} 2 / \mathrm{d}$ & _tPSetPhyt_=total_sedimentation_of_algae \\
\hline _tPResusPhyt_ & $\mathrm{gP} / \mathrm{m} 2 / \mathrm{d}$ & tPResusPhyt - \\
\hline _wPLossPhyt_ & $\mathrm{mgP} / \mathrm{l} / \mathrm{d}$ & _wPLossPhyt_total_grazing_loss \\
\hline _wPPrimPhytW_ & $\mathrm{gP} / \mathrm{m} 3 / \mathrm{d}$ & _wPPrimPhytl total_of_PRIM_processes_of_algae_in_water \\
\hline _wNUptPhyt_ & $\mathrm{mgN} / \mathrm{l} / \mathrm{d}$ & _wNUptPhyt_total_N_uptake_phytoplankton \\
\hline _wNUptNH4Phyt_ & $\mathrm{mgN} / \mathrm{l} / \mathrm{d}$ & _wNUptNH4P total_ammonium-N_uptake_phytoplankton \\
\hline _wNUptNO3Phyt_ & $\mathrm{mgN} / \mathrm{l} / \mathrm{d}$ & _wNUptNO3P total_nitrate-N_uptake_phytoplankton \\
\hline _wNExcrPhytw_ & $\mathrm{gN} / \mathrm{m} 3 / \mathrm{d}$ & _wNExcrPhytl total_N_excretion_phytoplankton_in_water \\
\hline _wNMortPhytW_ & $\mathrm{gN} / \mathrm{m} 3 / \mathrm{d}$ & _wNMortPhytl total_N_mortality_phytoplankton_in_water \\
\hline _tNSetPhyt_ & $\mathrm{gN} / \mathrm{m} 2 / \mathrm{d}$ & _tNSetPhyt_= total_sedimentation_of_algae \\
\hline _tNResusPhyt_ & $\mathrm{gN} / \mathrm{m} 2 / \mathrm{d}$ & _tNResusPhyl- \\
\hline _wNLossPhyt_ & $\mathrm{mgN} / \mathrm{l} / \mathrm{d}$ & _wNLossPhyt_total_grazing_loss \\
\hline _wNPrimPhytW_ & $\mathrm{gN} / \mathrm{m} 3 / \mathrm{d}$ & _wNPrimPhytl total_of_PRIM_processes_of_algae_in_water \\
\hline _tDRespPhytS_ & $\mathrm{g} / \mathrm{m} 2 / \mathrm{d}$ & _tDRespPhyt $\_$respiration_of_algae_on_bottom \\
\hline _tDMortPhytS_ & $\mathrm{g} / \mathrm{m} 2 / \mathrm{d}$ & _tDMortPhytS mortality_of_algae_on_bottom \\
\hline _tDPrimPhytS_ & $\mathrm{g} / \mathrm{m} 2 / \mathrm{d}$ & _tDPrimPhytS total_flux_of_algae_on_bottom \\
\hline _tPExcrPhytS_ & $\mathrm{gP} / \mathrm{m} 2 / \mathrm{d}$ & _tPExcrPhytS total_P_excretion_sediment_phytoplankton \\
\hline _tPMortPhytS_ & $\mathrm{gP} / \mathrm{m} 2 / \mathrm{d}$ & _tPMortPhytS total_phytoplankton_mortality \\
\hline _tPPrimPhytS_ & $\mathrm{gP} / \mathrm{m} 2 / \mathrm{d}$ & _tPPrimPhytS total_flux_of_algae_on_bottom \\
\hline _tNExcrPhytS_ & $\mathrm{gN} / \mathrm{m} 2 / \mathrm{d}$ & _tNExcrPhytS total_N_excretion_sediment_phytoplankton \\
\hline _tNMortPhytS_ & $\mathrm{gN} / \mathrm{m} 2 / \mathrm{d}$ & _tNMortPhytS total_phytoplankton_mortality \\
\hline _tNPrimPhyts_ & $\mathrm{gN} / \mathrm{m} 2 / \mathrm{d}$ & _tNPrimPhytS total_flux_of_algae_on_bottom \\
\hline _wSiUptDiat_ & $\mathrm{mgSi} / \mathrm{l} / \mathrm{d}$ & _wSiUptDiat_Diatoms_silica_uptake \\
\hline _wSiExcrDiatW_ & $\mathrm{mgSi} / / / \mathrm{d}$ & _wSiExcrDiatl Si_excretion \\
\hline _wSiLossDiat_ & $\mathrm{mgSi} / \mathrm{l} / \mathrm{d}$ & _wSiLossDiat_diatom_grazing_loss \\
\hline _wSiMortDiatW_ & $\mathrm{gSi} / \mathrm{m} 3 / \mathrm{d}$ & _wSiMortDiatl Diatoms_mortality_in_water \\
\hline _tSiSetDiat_ & $\mathrm{gSi} / \mathrm{m} 2 / \mathrm{d}$ & _tSiSetDiat_= Diatoms_sedimentation \\
\hline _tSiResusDiat_ & $\mathrm{gSi} / \mathrm{m} 3 / \mathrm{d}$ & _tSiResusDiat Diatoms_sedimentation \\
\hline _wSiPrimDiatW_ & $\mathrm{gSi} / \mathrm{m} 2 / \mathrm{d}$ & _wSiPrimDiatl total_Si_flux_to_sed_diatoms_in_PRIM_module \\
\hline _rCyDBlue_ & $\mathrm{mg} / \mathrm{mg}$ & _rCyDBlue_= C-phycocyanin/DW-ratio_blue-greens \\
\hline _oCyan_- & $\mathrm{mg} / \mathrm{m} 3$ & _oCyan_=_r(C-phycocyanin \\
\hline _fDDiat__ & - & _fDDiat_=_sl DW_fraction_of_algal_group_of_total_algae \\
\hline _wDPrimDetW_ & $\mathrm{mg} / \mathrm{l} / \mathrm{d}$ & _wDPrimDeth Flux_to_water_detritus \\
\hline tDPrimDetS_ & $\mathrm{mg} / \mathrm{l} / \mathrm{d}$ & _tDPrimDetS_Flux_to_sediment_detritus \\
\hline _tDPrimTotT_- & $\mathrm{gD} / \mathrm{m} 2 / \mathrm{d}$ & _tDPrimTotT_total_DW_flux \\
\hline _wO2ProdPhyt_ & $\mathrm{gO} 2 / \mathrm{m} 3 / \mathrm{d}$ & _wO2ProdPhy O2_production_by_phytoplankton \\
\hline _wO2RespPhytW_ & $\mathrm{gO} 2 / \mathrm{m} 3 / \mathrm{d}$ & _wO2RespPh: O2_production_by_phytoplankton \\
\hline _wO2UptNO3Phyt_ & $\mathrm{gO} 2 / \mathrm{m} 3 / \mathrm{d}$ & _wO2UptNO3 O2_production_due_to_NO3_uptake_by_phytopl \\
\hline _wO2PrimW_ & $\mathrm{gO} 2 / \mathrm{m} 3 / \mathrm{d}$ & _wO2PrimW_O2_flux_by_water_algae \\
\hline _tO2RespPhytS_ & $\mathrm{gO} 2 / \mathrm{m} 2 / \mathrm{d}$ & _tO2RespPhy O2_respiration_by_sediment_algae \\
\hline tO2Prims_ & $\mathrm{gO} 2 / \mathrm{m} 2 / \mathrm{d}$ & _tO2Prims_= O2_flux_by_sediment_algae \\
\hline _wPMortPhytPO4W_ & $\mathrm{mgP} / \mathrm{l} / \mathrm{d}$ & _wPMortPhytF soluble_P_flux_from_died_Algae \\
\hline _wPMortPhytDetW_ & $\mathrm{mgP} / \mathrm{l} / \mathrm{d}$ & _wPMortPhyt[ detrital_P_flux_from_died_Algae \\
\hline _wPLossPhytPO4_ & $\mathrm{mgP} / / \mathrm{d}$ & _wPLossPhyti soluble_P_grazing_loss \\
\hline _wPLossPhytDet_ & $\mathrm{mgP} / / / \mathrm{d}$ & _wPLossPhytl detrital_P_grazing_loss \\
\hline _wPPrimPO4W_ & $\mathrm{mgP} / / \mathrm{d}$ & _wPPrimPO4ISRP_in_water \\
\hline _wPPrimDetW_ & $\mathrm{mgP} / \mathrm{l} / \mathrm{d}$ & _wPPrimDeth Detritus_in_water \\
\hline _tPMortPhytPO4S_ & $\mathrm{gP} / \mathrm{m} 2 / \mathrm{d}$ & _tPMortPhytPisoluble_P_flux_from_died_Algae \\
\hline _tPMortPhytDetS_ & $\mathrm{gP} / \mathrm{m} 2 / \mathrm{d}$ & _tPMortPhytD detrital_P_flux_from_died_Algae \\
\hline _tPPrimDetS_ & $\mathrm{gP} / \mathrm{m} 2 / \mathrm{d}$ & _tPPrimDetS_Sediment_detritus \\
\hline _tPPrimPO4S_ & $\mathrm{gP} / \mathrm{m} 2 / \mathrm{d}$ & _tPPrimPO4S Pore_water_P \\
\hline -tPPrimTotT_ & $\mathrm{gP} / \mathrm{m} 2 / \mathrm{d}$ & _tPPrimTotT_total_P_flux \\
\hline _wNMortPhytNH4W_ & $\mathrm{mgN} / \mathrm{l} / \mathrm{d}$ & _wNMortPhytr ammonium_flux_from_died_Algae \\
\hline _wNMortPhytDetW_- & $\mathrm{mgN} / \mathrm{l} / \mathrm{d}$ & _wNMortPhyt[ detrital_N_flux_from_died_Ailgae \\
\hline _wNLossPhytNH4_ & $\mathrm{mgN} / \mathrm{l} / \mathrm{d}$ & _wNLossPhytl NH4-N_grazing_loss \\
\hline _wNLossPhytDet_ & $\mathrm{mgN} / \mathrm{l} / \mathrm{d}$ & _wNLossPhytl detrital_N_grazing_loss \\
\hline _wNPrimNH4W_ & $\mathrm{mgN} / \mathrm{l} / \mathrm{d}$ & _wNPrimNH4l ammonium_in_water \\
\hline -wNPrimNO3W_ & $\mathrm{mgN} / \mathrm{l} / \mathrm{d}$ & _wNPrimNO3! nitrate_in_water \\
\hline _wNPrimDetW_- & $\mathrm{mgN} / \mathrm{l} / \mathrm{d}$ & _wNPrimDeth Detritus_in_water \\
\hline _tNMortPhytNH4S_ & $\mathrm{gN} / \mathrm{m} 2 / \mathrm{d}$ & _tNMortPhytN ammonium_flux_from_died_Algae \\
\hline _tNMortPhytDetS_ & $\mathrm{gN} / \mathrm{m} 2 / \mathrm{d}$ & _tNMortPhytD detrital_N_flux_from_died_Algae \\
\hline _tNPrimNH4S_ & $\mathrm{gN} / \mathrm{m} 2 / \mathrm{d}$ & _tNPrimNH4S Pore_water_ammonium \\
\hline _tNPrimNO3S_ & $\mathrm{gN} / \mathrm{m} 2 / \mathrm{d}$ & _tNPrimNO3S Pore_water_nitrate \\
\hline _tNPrimDetS_ & $\mathrm{gN} / \mathrm{m} 2 / \mathrm{d}$ & _tNPrimDetS_Sediment_detritus \\
\hline _tNPrimTotT_- & $\mathrm{gN} / \mathrm{m} 2 / \mathrm{d}$ & _tNPrimTotT_total_N_flux \\
\hline _tSiExcrDiatS_ & $\mathrm{gSi} / \mathrm{m} 2 / \mathrm{d}$ & _tSiExcrDiatS_Si_excretion_of_bottom_Algae \\
\hline
\end{tabular}




\begin{tabular}{|c|c|c|}
\hline _tSiMortDiatS_ & $\mathrm{gSi} / \mathrm{m} 2 / \mathrm{d}$ & _tSiMortDiatS_mortality_of_bottom_Algae \\
\hline wSiPrimSiO2 $\mathrm{W}_{-}$ & $\mathrm{mgSi} / \mathrm{l} / \mathrm{d}$ & _wSiPrimSiO2 total_Si_flux_to_SiO2_in_PRIM_module \\
\hline wSiPrimDetW & $\mathrm{mgSi} / / \mathrm{d}$ & wSiPrimDetV total $\mathrm{Si}$ flux to sed detritus in PRIM module \\
\hline tSiPrimDiatS_ & $\mathrm{gSi} / \mathrm{m} 2 / \mathrm{d}$ & _tSiPrimDiatS total_Si_flux_to_sed_diatoms_in_PRIM_module \\
\hline tSiPrimDetS_ & $\mathrm{gSi} / \mathrm{m} 2 / \mathrm{d}$ & _tSiPrimDetS_Sediment_detritus \\
\hline tSiPrimTotT_ & $\mathrm{gSi} / \mathrm{m} 2 / \mathrm{d}$ & _tSiPrimTotT_total_Si_flux \\
\hline aPACoef_ & - & _aPACoef_= Poole-Atkins_coefficient \\
\hline bSecchiMax & $\mathrm{m}$ & _bSecchiMax_max_Secchi_depth \\
\hline _aSecchi_ & $\mathrm{m}$ & _aSecchi_=_Secchi_depth \\
\hline _aTransparency_ & $\mathrm{m}$ & _aTransparen Secchi_depth \\
\hline _aDepthEuph_ & $\mathrm{m}$ & _aDepthEuph_euphotic_depth \\
\hline _aRelDepthEuph_ & $\mathrm{m}$ & _aRelDepthEı relative_euphotic_depth \\
\hline _aChlaH__ & mg_chlorophyll-a/l & _aChlaH_=_Chla_per_m2 \\
\hline aCovPhytW_ & $\%$ & _aCovPhytW_\%_cover_with_algae \\
\hline _rExtChPhyt__ & m2/g_chl-a & _rExtChPhyt_average_spec_extinction_of_algae_per_unit_chl-a \\
\hline _uFunTmZoo_ & - & _uFunTmZoo_temp_function_of_zooplankton \\
\hline _PDZoo_ & $\mathrm{mgP} / \mathrm{mgDW}$ & _rPDZoo_=_P/D_ratio_herbzooplankton \\
\hline _rNDZoo_ & $\mathrm{mgN} / \mathrm{mgDW}$ & _rNDZoo_=_N/C_ratio_herbzooplankton \\
\hline _oDFoodZoo_ & $\mathrm{mgD} / \mathrm{l}$ & _oDFoodZoo_food_for_zooplankton \\
\hline aFilt & Itr/mgDW/d & aFilt $=$ cFil filtering rate \\
\hline _ukDĀssTmZoo_ & $d-1$ & _ukDĀssTmZı max_assimilation_rate_of_zooplanktontemp_corrected \\
\hline _aDSatZoo_ & - & _aDSatZoo_=food_saturation_function_of_zooplankton \\
\hline _ukDRespTmZoo_ & $d-1$ & _ukDRespTmirespiration_constant_of_zooplankton \\
\hline _ukDIncrZoo_ & $d-1$ & _ukDIncrZoo_intrinsic_rate_of_increase_of_zooplankton \\
\hline wDEnvZoo_ & $\mathrm{mg} / / \mathrm{d}$ & _wDEnvZoo_environmental_correction_of_zooplankton \\
\hline _wDAssZoo_ & $\mathrm{mg} / \mathrm{l} / \mathrm{d}$ & _wDAssZoo_assimilation_of_zooplankton \\
\hline _wDConsZoo_ & $\mathrm{mg} / \mathrm{l} / \mathrm{d}$ & _wDConsZoo_consumption_of_zooplankton \\
\hline _wDConsDetZoo_ & $\mathrm{mg} / / \mathrm{d}$ & _wDConsDetz̄DW_detritus_consumption_by_zooplankton \\
\hline _wDConsDiatZoo_ & $\mathrm{mg} / \mathrm{l} / \mathrm{d}$ & _wDConsDiat:DW_diatoms_consumption_by_zooplankton \\
\hline _wDConsGrenZoo_ & $\mathrm{mg} / \mathrm{l} / \mathrm{d}$ & _wDConsGrer DW_greens_consumption_by_zooplankton \\
\hline _wDConsBlueZoo_ & $\mathrm{mg} / / \mathrm{d}$ & _wDConsBlue DW_blue-greens_consumption_by_zooplankton \\
\hline _wDConsPhytZoo_ & $\mathrm{mg} / \mathrm{l} / \mathrm{d}$ & _wDConsPhyt phytoplankton_consumption_by_zooplankton \\
\hline _wDEgesZoo_ & $\mathrm{mg} / \mathrm{l} / \mathrm{d}$ & _wDEgesZoo_egestion_of_zooplankton \\
\hline _aCorDRespZoo_ & - & _aCorDRespZ corr_factor_of_zoopl_respiration_for_P_and_N_content \\
\hline _wDRespZoo_ & $\mathrm{mg} / \mathrm{l} / \mathrm{d}$ & _wDRespZoo_zoopl_respiration \\
\hline _wDMortZoo_ & $\mathrm{mg} / / \mathrm{d}$ & _wDMortZoo_zoopl_mortalityincl_environmental_correction \\
\hline oPFoodZoo_ & $\mathrm{mgP} / \mathrm{l}$ & oPFoodZoo_Zooplankton_food \\
\hline _rPDFoodZoo_ & $\mathrm{mgP} / \mathrm{mgDW}$ & _rPDFoodZoo P/D_ratio_of_zooplankton_food \\
\hline _wPConsDiatZoo_ & $\mathrm{mgP} / \mathrm{l} / \mathrm{d}$ & _wPConsDiat،P_diatom_consumption_by_zoopl \\
\hline _wPConsGrenZoo_ & $\mathrm{mgP} / \mathrm{l} / \mathrm{d}$ & _wPConsGrer P_green_consumption_by_zoopl \\
\hline _wPConsBlueZoo_ & $\mathrm{mgP} / \mathrm{l} / \mathrm{d}$ & _wPConsBlue P_bluegreen_consumption_by_zoopl \\
\hline _wPConsPhytZoo_ & $\mathrm{mgP} / \mathrm{l} / \mathrm{d}$ & _wPConsPhyt total_P_phytoplankton_consumption_by_zoopl \\
\hline _wPConsDetZoo_ & $\mathrm{mgP} / \mathrm{d} / \mathrm{d}$ & _wPConsDetŽ consumption_of_detrital_P \\
\hline _wPConsZoo_ & $\mathrm{mgP} / \mathrm{l} / \mathrm{d}$ & _wPConsZoo_total_P_consumption \\
\hline _afPAssZoo_ & - & _afPAssZoo_P_assimilation_efficiency_of_herbivores \\
\hline _wPAssZoo_ & $\mathrm{mgP} / \mathrm{l} / \mathrm{d}$ & _wPAssZoo_: assimilation_by_herbivores \\
\hline _wPEgesZoo_ & $\mathrm{mgP} / / \mathrm{d}$ & _wPEgesZoo_P_egestion \\
\hline _wPEgesZooPO4_ & $\mathrm{mgP} / \mathrm{l} / \mathrm{d}$ & _wPEgesZooF soluble_P_egestion \\
\hline _wPEgesZooDet_ & $\mathrm{mgP} / \mathrm{l} / \mathrm{d}$ & _wPEgesZoo[ detrital_P_egestion \\
\hline _akPExcrZoo_ & $d-1$ & _akPExcrZoo_P_excretion_rate_of_herbivores \\
\hline _wPExcrZoo_ & $\mathrm{mgP} / \mathrm{l} / \mathrm{d}$ & _WPExcrZoo_P_excretion \\
\hline _wPMortZoo_ & $\mathrm{mgP} / \mathrm{l} / \mathrm{d}$ & _wPMortZoo_mortality \\
\hline _wPMortZooPO4_ & $\mathrm{mgP} / \mathrm{l} / \mathrm{d}$ & _wPMortZooPsoluble_P_mortality \\
\hline wPMortZooDet & $\mathrm{mgP} / / \mathrm{d}$ & _wPMortZooD detrital_P_mortality \\
\hline _oNFoodZoo_ & $\mathrm{mgN} / \mathrm{l}$ & _oNFoodZoo_Zooplankton_food \\
\hline rNDFoodZoo_ & $\mathrm{mgN} / \mathrm{mgDW}$ & _rNDFoodZoo N/C_ratio_of_zooplankton_food \\
\hline _wNConsDiatZoo_ & $\mathrm{mgN} / \mathrm{l} / \mathrm{d}$ & _wNConsDiati_N_diatom_consumption_by_zoopl \\
\hline _wNConsGrenZoo_ & $\mathrm{mgN} / / \mathrm{d}$ & _wNConsGrer N_green_consumption_by_zoopl \\
\hline _wNConsBlueZoo_ & $\mathrm{mgN} / / \mathrm{d}$ & _wNConsBlue N_bluegreen_consumption_by_zoopl \\
\hline _wNConsPhytZoo_ & $\mathrm{mgN} / \mathrm{l} / \mathrm{d}$ & _wNConsPhyt total_N_phytoplankton_consumption_by_zoopl \\
\hline _wNConsDetZoo_ & $\mathrm{mgN} / \mathrm{l} / \mathrm{d}$ & _wNConsDetz̄ consumption_of_detrital_N \\
\hline _wNConsZoo_ & $\mathrm{mgN} / \mathrm{l} / \mathrm{d}$ & _wNConsZoo_total_N_consumption \\
\hline _afNAssZoo_ & - & _afNAssZoo_N_assimilation_efficiency_of_herbivores \\
\hline _wNAssZoo_ & $\mathrm{mgN} / / \mathrm{d}$ & _wNAssZoo_assimilation_by_herbivores \\
\hline _wNEgesZoo_ & $\mathrm{mgN} / / \mathrm{d}$ & _wNEgesZoo_N_egestion \\
\hline _wNEgesZooNH4_ & $\mathrm{mgN} / \mathrm{l} / \mathrm{d}$ & _wNEgesZool soluble_N_egestion \\
\hline _wNEgesZooDet_ & $\mathrm{mgN} / / \mathrm{d}$ & wNEgesZoo[ detrital_N_egestion \\
\hline
\end{tabular}


_kNExcrZoo_

_wNExcrZoo_

_wNMortZoo_

_wNMortZooNH4

_wNMortZooDet_

_wSiConsDiatZoo_

_uFunTmBent_

_aDFoodBent_

r.PDBent_

_rNDBent

tDMigrBent

_aDSatBent

_ukDIncrBent_

_tDEnvBent_

_tDAssBent

_aDAssBentSp_

tDConsBent

_tDConsDetBent

_tDConsDiatBent_

_tDConsGrenBent

_tDConsBlueBent_

tDConsPhytBent_

_tDEgesBent_

_tDRespBent

tDMortBent

_aPFoodBent

_rPDFoodBent_

tPConsDetBent

_tPConsDiatBent

_tPConsGrenBent_

_tPConsBlueBent_

_tPConsPhytBent_

_tPConsBent

afPAssBent

tPAssBent

_tPEgesBent

_tPEgesBentPO4

_tPEgesBentDet_

tPExcrBent_

tPMortBent

_tPMortBentPO4

_tPMortBentDet_

_tPMigrBent_

_aNFoodBent

rNDFoodBent

_tNMigrBent

_tNConsDetBent_

tNConsDiatBent

- $\mathrm{N}$ ConsGrenBent

tNConsBlueBent_

_tNConsPhytBent_

_tNConsBent

_afNAssBent_

tNAssBent

_tNEgesBent_

_tNEgesBentNH4

_tNEgesBentDet_

_NExcrBent_

-tNMortBent_-

_tNMortBentNH4

_tNMortBentDet_

_tSiConsDiatBent

_aDFish_

aPFish

_aNFish_

_rPDFiJv_

rPDFiAd d-1

$\mathrm{mgN} / \mathrm{l} / \mathrm{d}$

$\mathrm{mgN} / \mathrm{l} / \mathrm{d}$

$\mathrm{mgN} / / \mathrm{d}$

$\mathrm{mgN} / \mathrm{l} / \mathrm{d}$

$\mathrm{mgSi} / / / \mathrm{d}$

$\mathrm{gD} / \mathrm{m} 2$

$\mathrm{gP} / \mathrm{gD}$

$\mathrm{gN} / \mathrm{g}$

$\mathrm{gD} / \mathrm{m} 2 / \mathrm{d}$

-

d-1

$\mathrm{gD} / \mathrm{m} 2 / \mathrm{d}$

$\mathrm{gD} / \mathrm{m} 2 / \mathrm{d}$

d-1

$\mathrm{gD} / \mathrm{m} 2 / \mathrm{d}$

$\mathrm{gD} / \mathrm{m} 2 / \mathrm{d}$

$\mathrm{gD} / \mathrm{m} 2 / \mathrm{d}$

$\mathrm{gD} / \mathrm{m} 2 / \mathrm{d}$

$\mathrm{gD} / \mathrm{m} 2 / \mathrm{d}$

$\mathrm{gD} / \mathrm{m} 2 / \mathrm{d}$

$\mathrm{gD} / \mathrm{m} 2 / \mathrm{d}$

$\mathrm{gD} / \mathrm{m} 2 / \mathrm{d}$

$\mathrm{gD} / \mathrm{m} 2 / \mathrm{d}$

$\mathrm{gP} / \mathrm{m} 2$

$\mathrm{gP} / \mathrm{gD}$

$\mathrm{gP} / \mathrm{m} 2 / \mathrm{d}$

$\mathrm{gP} / \mathrm{m} 2 / \mathrm{d}$

$\mathrm{gP} / \mathrm{m} 2 / \mathrm{d}$

$\mathrm{gP} / \mathrm{m} 2 / \mathrm{d}$

$\mathrm{gP} / \mathrm{m} 2 / \mathrm{d}$

$\mathrm{gP} / \mathrm{m} 2 / \mathrm{d}$

$\mathrm{gP} / \mathrm{m} 2 / \mathrm{d}$

$\mathrm{gP} / \mathrm{m} 2 / \mathrm{d}$

$\mathrm{gP} / \mathrm{m} 2 / \mathrm{d}$

$\mathrm{gP} / \mathrm{m} 2 / \mathrm{d}$

d-1

$\mathrm{gP} / \mathrm{m} 2 / \mathrm{d}$

$\mathrm{gP} / \mathrm{m} 2 / \mathrm{d}$

$\mathrm{gP} / \mathrm{m} 2 / \mathrm{d}$

$\mathrm{gP} / \mathrm{m} 2 / \mathrm{d}$

$\mathrm{gN} / \mathrm{m} 2$

$\mathrm{gN} / \mathrm{gD}$

$\mathrm{gN} / \mathrm{m} 2 / \mathrm{d}$

$\mathrm{gN} / \mathrm{m} 2 / \mathrm{d}$

$\mathrm{gN} / \mathrm{m} 2 / \mathrm{d}$

$\mathrm{gN} / \mathrm{m} 2 / \mathrm{d}$

$\mathrm{gN} / \mathrm{m} 2 / \mathrm{d}$

$\mathrm{gN} / \mathrm{m} 2 / \mathrm{d}$

$\mathrm{gN} / \mathrm{m} 2 / \mathrm{d}$

$\mathrm{gN} / \mathrm{m} 2 / \mathrm{d}$

$\mathrm{gN} / \mathrm{m} 2 / \mathrm{d}$

$\mathrm{gN} / \mathrm{m} 2 / \mathrm{d}$

$\mathrm{gN} / \mathrm{m} 2 / \mathrm{d}$

d-1

$\mathrm{gN} / \mathrm{m} 2 / \mathrm{d}$

$\mathrm{gN} / \mathrm{m} 2 / \mathrm{d}$

$\mathrm{gN} / \mathrm{m} 2 / \mathrm{d}$

$\mathrm{gSi} / \mathrm{m} 2 / \mathrm{d}$

gD_m-2

gP_m-2

gN_m-2

$\mathrm{gP} / \mathrm{gD}$

$\mathrm{gP} / \mathrm{gD}$
_kNExcrZoo_N_excretion_rate_of_herbivores

_wNExcrZoo_N_excretion

_wNMortZoo_mortality

_wNMortZoo^ soluble_N_mortality

_wNMortZoo[ detrital_N_mortality

_wSiConsDiat consumption_of_diatoms

_uFunTmBent temp_function_of_zoobenthos

_aDFoodBent food_for_zoobenthos

_rPDBent_=_P/D_ratio_of_zoobenthos

_rNDBent_ = N N/D_ratio_of_zoobenthos

_tDMigrBent_migration_flux

_aDSatBent_food_limitation_function_of_zoobenthos

_ukDIncrBent_intrinsic_net_increase_rate_of_zoobenthos

tDEnvBent_: environmental_correction_of_zoobenthos

_tDAssBent_: assimilation_of_zoobenthos

_aDAssBentS specific_assimilation_rate_of_zoobenthos

_tDConsBent_consumption_of_zoobenthos

_tDConsDetBı detritus_consumption_by_zoobenthos

_tDConsDiatB diatoms_consumption_by_zoobenthos

_tDConsGrenl greens_consumption_by_zoobenthos

_tDConsBlueE blue-greens_consumption_by_zoobenthos

_tDConsPhytE phutoplankton_consumption_by_zoobenthos

_tDEgesBent_egestion_of_zoobenthos

_tDRespBent_respiration_of_zoobenthos

_tDMortBent_zoobenthos_mortality_incl_environmental_correction

_aPFoodBent food_for_zoobenthos

_rPDFoodBen average_P/D_ratio_of_zoobenthos_food

_tPConsDetB $\Leftrightarrow$ detrital_P_consumption_by_zoobenthos

_tPConsDiatB diatom_P_consumption_by_zoobenthos

_tPConsGrenl greens_P_consumption_by_zoobenthos

_tPConsBlueE blue-greens_P_consumption_by_zoobenthos

_tPConsPhytE phytoplankton_P_consumption_by_zoobenthos

_tPConsBent_total_P_consumption_of_zoobenthos

_afPAssBent_P_assim_efficiency_of_zoobenthos

_tPAssBent_: P_assimilation_of_zoobenthos

_tPEgesBent_egestion_of_zoobenthos

_tPEgesBentF SRP_egestion_of_zoobenthos

_tPEgesBent[ detrital_P_egestion_of_zoobenthos

-tPExcrBent_P_excretion_of_zoobenthos

_tPMortBent_mortality_of_zoobenthos

_tPMortBentP part_of_died_zoobenthos_P_becoming_dissolved_P

_tPMortBentD part_of_died_zoobenthos_P_becoming_detrital_P

_tPMigrBent_net_migration_flux

_aNFoodBent food_for_zoobenthos

_rNDFoodBen average_N/D_ratio_of_zoobenthos_food

_tNMigrBent_Net_migration_flux

_tNConsDetBı detrital_N_consumption_by_zoobenthos

_tNConsDiatB diatom_N_consumption_by_zoobenthos

_tNConsGrenl greens_N_consumption_by_zoobenthos

_tNConsBlueE blue-greens_N_consumption_by_zoobenthos

_tNConsPhytE phytoplankton_N_consumption_by_zoobenthos

_tNConsBent_total_N_consumption_of_zoobenthos

_afNAssBent_N_assim_efficiency_of_zoobenthos

_tNAssBent_: N_assimilation_of_zoobenthos

_tNEgesBent_egestion_of_zoobenthos

_tNEgesBentr NH4_egestion_of_zoobenthos

_tNEgesBent[ detrital_N_egestion_of_zoobenthos

_tNExcrBent_N_excretion_of_zoobenthos

_tNMortBent_mortality_of_zoobenthos

_tNMortBentN part_of_died_zoobenthos_N_becoming_ammonium-N

_tNMortBentD part_of_died_zoobenthos_N_becoming_detrital_N

_tSiConsDiatE diatom_consumption_by_zoobenthos

_aDFish_=_stotal_fish_biomass

_aPFish_= _stotal_fish_biomass

_aNFish_=_stotal_fish_biomass

_rPDFiJv_ = _P/D_ratio_of_young_fish

${ }_{-}$rPDFiAd_ = _P/D_ratio_of_adult_fish 


\begin{tabular}{|c|c|c|}
\hline _NDFiJv_ & $\mathrm{gN} / \mathrm{gD}$ & _rNDFiJv_=_N/D_ratio_of_young_fish \\
\hline rNDFiAd_ & $\mathrm{gN} / \mathrm{gD}$ & _rNDFiAd_ = N/D_ratio_of_adult_fish \\
\hline tDReprFish_ & gD_m-2_d-1 & _tDReprFish_Reproduction_flux \\
\hline tDAgeFish_ & $g D \_m-2 \_d-1$ & _tDAgeFish_= Ageing \\
\hline _aFunVegFish_ & - & _aFunVegFist vegetation_dependence_of_fish_feeding \\
\hline aDSatFiJv__ & - & _aDSatFiJv_= food_limitation_function_of_young_fish \\
\hline _ukDIncrFiJv__ & $d-1$ & _ukDIncrFiJv_intrinsic_net_increase_rate_of_fish \\
\hline tDEnvFiJv_- & $\mathrm{gD} / \mathrm{m} 2 / \mathrm{d}$ & _tDEnvFiJv_= environmental_correction_of_fish \\
\hline tDAssFiJv_ & $\mathrm{gD} / \mathrm{m} 2 / \mathrm{d}$ & _tDAssFiJv_ $=$ assimilation_of_fish \\
\hline tDConsFiJv_ & $\mathrm{gD} / \mathrm{m} 2 / \mathrm{d}$ & _tDConsFiJv_zooplankton_consumption_of_fish \\
\hline _tDEgesFiJv_ & $\mathrm{gD} / \mathrm{m} 2 / \mathrm{d}$ & _tDEgesFiJv_egestion_of_fish \\
\hline tDRespFiJv_ & $\mathrm{gD} / \mathrm{m} 2 / \mathrm{d}$ & _tDRespFiJv_respiration_of_fish \\
\hline tDMortFiJv_ & $\mathrm{gD} / \mathrm{m} 2 / \mathrm{d}$ & _tDMortFiJv_fish_mortality_incl_environmental_correction \\
\hline _tDMigrFiJv_- & $\mathrm{gD} / \mathrm{m} 2 / \mathrm{d}$ & _tDMigrFiJv_: migration_flux \\
\hline _aDSatFiAd_- & - & _aDSatFiAd_food_limitation_function_of_adult_fish \\
\hline ukDIncrFiAd__ & $d-1$ & _ukDIncrFiAd_ intrinsic_net_increase_rate_of_fish \\
\hline tDEnvFiAd_ & $\mathrm{gD} / \mathrm{m} 2 / \mathrm{d}$ & _tDEnvFiAd_: environmental_correction_of_fish \\
\hline tDAssFiAd_ & $\mathrm{gD} / \mathrm{m} 2 / \mathrm{d}$ & _tDAssFiAd_: assimilation_of_fish \\
\hline tDConsFiAd_ & $\mathrm{gD} / \mathrm{m} 2 / \mathrm{d}$ & _tDConsFiAd_zoobenthos_consumption_of_fish \\
\hline tDEgesFiAd_- & $\mathrm{gD} / \mathrm{m} 2 / \mathrm{d}$ & _tDEgesFiAd_egestion_of_fish \\
\hline tDRespFiAd_- & $\mathrm{gD} / \mathrm{m} 2 / \mathrm{d}$ & _tDRespFiAd_respiration_of_fish \\
\hline _tDMortFiAd_ & $\mathrm{gD} / \mathrm{m} 2 / \mathrm{d}$ & _tDMortFiAd_fish_mortality_incl_environmental_correction \\
\hline _ukHarvFish_ & $d-1$ & _ukHarvFish_fish_harvesting_constant \\
\hline _tDHarvFish_ & $\mathrm{gD} / \mathrm{m} 2 / \mathrm{d}$ & _tDHarvFish_harvesting_of_fish \\
\hline tDMigrFiAd_- & $\mathrm{gD} / \mathrm{m} 2 / \mathrm{d}$ & _tDMigrFiAd_migration_flux \\
\hline tDMortFish_ & $\mathrm{gD} / \mathrm{m} 2 / \mathrm{d}$ & _tDMortFish_bent_fish_mortality \\
\hline _tDMortFishBot_ & $\mathrm{g} / \mathrm{m} 2 / \mathrm{d}$ & _tDMortFishB̈ part_of_died_fish_DW_fixed_in_bones_and_scales \\
\hline _tDMortFishDet_ & $\mathrm{gD} / \mathrm{m} 2 / \mathrm{d}$ & _tDMortFishDı part_of_died_fish_DW_becoming_detritus \\
\hline tPReprFish_ & gP_m-2_d-1 & _tPReprFish_Reproduction_flux \\
\hline _tPAgeFish_ & gD_m-2_d-1 & _tPAgeFish_= Ageing \\
\hline _tPMigrFiJv_ & $\mathrm{gP} / \mathrm{m} 2 / \mathrm{d}^{-}$ & _tPMigrFiJv_enet_migration_flux \\
\hline tPConsFiJv_ & $\mathrm{gP} / \mathrm{m} 2 / \mathrm{d}$ & _tPConsFiJv_(zooplankton)_P_consumption_by_FiJv \\
\hline afPAssFiJv_ & - & _afPAssFiJv_P_assim_efficiency_of_FiJv \\
\hline tPAssFiJv_ & $\mathrm{gP} / \mathrm{m} 2 / \mathrm{d}$ & _tPAssFiJv_= P_assimilation_of_FiJv \\
\hline tPEgesFiJv_ & $\mathrm{gP} / \mathrm{m} 2 / \mathrm{d}$ & _tPEgesFiJv_egestion_of_FiJv \\
\hline tPExcrFiJv_ & $d-1$ & _tPExcrFiJv_: P_excretion_of_FiJv \\
\hline _tPMortFiJv_- & $\mathrm{gP} / \mathrm{m} 2 / \mathrm{d}$ & _tPMortFiJv_: mortality_of_FiJv \\
\hline tPMigrFiAd_- & $\mathrm{gP} / \mathrm{m} 2 / \mathrm{d}$ & _tPMigrFiAd_net_migration_flux \\
\hline _tPConsFiAd_ & $\mathrm{gP} / \mathrm{m} 2 / \mathrm{d}$ & _tPConsFiAd_(zoobenthos)_P_consumption_by_FiAd \\
\hline _afPAssFiAd_ & - & _afPAssFiAd_P_assim_efficiency_of_FiAd \\
\hline _tPAssFiAd_- & $\mathrm{gP} / \mathrm{m} 2 / \mathrm{d}$ & _tPAssFiAd_: P_assimilation_of_FiAd \\
\hline _tPEgesFiAd_ & $\mathrm{gP} / \mathrm{m} 2 / \mathrm{d}$ & _tPEgesFiAd_egestion_of_FiAd \\
\hline - tPExcrFiAd_- & d-1 & -tPExcrFiAd_P_excretion_of_FiAd \\
\hline _tPMortFiAd_ & $\mathrm{gP} / \mathrm{m} 2 / \mathrm{d}$ & _tPMortFiAd_mortality_of_FiĀd \\
\hline _tPHarvFish_ & $\mathrm{gP} / \mathrm{m} 2 / \mathrm{d}$ & _tPHarvFish_harvesting_of_FiAd \\
\hline _tPMortFish_ & $\mathrm{gP} / \mathrm{m} 2 / \mathrm{d}$ & _tPMortFish_ - \\
\hline _tPMortFishBot_ & $\mathrm{gP} / \mathrm{m} 2 / \mathrm{d}$ & _tPMortFishB̈ part_of_died_fish_P_fixed_in_bones_AND_scales \\
\hline _tPMortFishPO4_ & $\mathrm{gP} / \mathrm{m} 2 / \mathrm{d}$ & _tPMortFishP( part_of_died_fish_P_becoming_dissolved_P \\
\hline _tPMortFishDet_- & $\mathrm{gP} / \mathrm{m} 2 / \mathrm{d}$ & _tPMortFishDıpart_of_died_fish_PW_becoming_detritus \\
\hline _tPEgesFish_ & gP_m-2_d-1 & _tPEgesFish_total_fish_egestion \\
\hline _tPEgesFishPO4_ & $\mathrm{gP} / \mathrm{m} 2 / \mathrm{d}$ & _tPEgesFishP SRP_egestion_of_fish \\
\hline _tPEgesFishDet_ & $\mathrm{gP} / \mathrm{m} 2 / \mathrm{d}$ & _tPEgesFishD detrital_P_egestion_of_fish \\
\hline tNReprFish_ & $g N \_m-2 \_d-1$ & _tNReprFish_Reproduction_flux \\
\hline _tNAgeFish_ & gD_m-2_d-1 & _tNAgeFish_= Ageing \\
\hline tNMigrFiJv_- & $\mathrm{gN} / \mathrm{m} 2 / \mathrm{d}^{-}$ & _tNMigrFiJv_: net_migration_flux \\
\hline _tNConsFiJv_ & $\mathrm{gN} / \mathrm{m} 2 / \mathrm{d}$ & _tNConsFiJv_(zooplankton)_N_consumption_by_FiJv \\
\hline _afNAssFiJv_ & - & _afNAssFiJv_N_assim_efficiency_of_FiJv \\
\hline tNAssFiJv_ & $\mathrm{gN} / \mathrm{m} 2 / \mathrm{d}$ & _tNAssFiJv_ $=\mathrm{N}$ _assimilation_of_FiJv \\
\hline tNEgesFiJv_ & $\mathrm{gN} / \mathrm{m} 2 / \mathrm{d}$ & _tNEgesFiJv_egestion_of_FiJv \\
\hline - tNExcrFiJv_ & d-1 & _tNExcrFiJv_ N_excretion_of_FiJv \\
\hline tNMortFiJv_- & $\mathrm{gN} / \mathrm{m} 2 / \mathrm{d}$ & _tNMortFiJv_ mortality_of_FiJv \\
\hline _tNMigrFiAd_ & $\mathrm{gN} / \mathrm{m} 2 / \mathrm{d}$ & _tNMigrFiAd_net_migration_flux \\
\hline _tNConsFiAd_ & $\mathrm{gN} / \mathrm{m} 2 / \mathrm{d}$ & _tNConsFiAd_(zoobenthos)_N_consumption_by_FiAd \\
\hline _afNAssFiAd_ & - & _afNAssFiAd_N_assim_efficiency_of_FiAd \\
\hline tNAssFiAd_ & $\mathrm{gN} / \mathrm{m} 2 / \mathrm{d}$ & _tNAssFiAd_: N_assimilation_of_FiAd \\
\hline _tNEgesFiAd & $\mathrm{gN} / \mathrm{m} 2 / \mathrm{d}$ & _tNEgesFiAd__egestion_of_FiAd \\
\hline _tNExcrFiAd_- & $d-1$ & _tNExcrFiAd_N_excretion_of_FiAd \\
\hline
\end{tabular}




\begin{tabular}{|c|c|c|}
\hline _tNMortFiAd_ & $\mathrm{gN} / \mathrm{m} 2 / \mathrm{d}$ & _tNMortFiAd_mortality_of_FiAd \\
\hline _tNHarvFish_ & $\mathrm{gN} / \mathrm{m} 2 / \mathrm{d}$ & _tNHarvFish_harvesting_of_FiAd \\
\hline tNMortFish_ & $\mathrm{gN} / \mathrm{m} 2 / \mathrm{d}$ & _tNMortFish_- \\
\hline _tNMortFishBot_ & $\mathrm{gN} / \mathrm{m} 2 / \mathrm{d}$ & _tNMortFishBıpart_of_died_fish_N_fixed_in_bones_AND_scales \\
\hline _NMortFishNH4_ & $\mathrm{gN} / \mathrm{m} 2 / \mathrm{d}$ & _tNMortFishN| part_of_died_fish_N_becoming_dissolved_N \\
\hline _NMortFishDet_ & $\mathrm{gN} / \mathrm{m} 2 / \mathrm{d}$ & _tNMortFishDipart_of_died_fish_NW_becoming_detritus \\
\hline _NEgesFish_ & gN_m-2_d-1 & _tNEgesFish_total_fish_egestion \\
\hline _tNEgesFishNH4_ & $\mathrm{gN} / \mathrm{m} 2 / \mathrm{d}$ & _tNEgesFishN NH4_egestion_of_fish \\
\hline _tNEgesFishDet_ & $\mathrm{gxN} / \mathrm{m} 2 / \mathrm{d}$ & _tNEgesFish[ detrital_xN_egestion_of_fish \\
\hline _uFunTmPisc_ & - $\quad$ & _uFunTmPisc.temp_function_of_Pisc \\
\hline _tDMigrPisc_ & $\mathrm{gD} / \mathrm{m} 2 / \mathrm{d}$ & _tDMigrPisc_ migration_flux \\
\hline _aDCarrPisc_ & gD.m-2 & _aDCarrPisc_Carrying_capacity_of_Pisc_for_lake_without_OR_with_marsh_zone_resp \\
\hline _aFunVegPisc_ & - & _aFunVegPisc vegetation_dependence_of_Pisc_growth_rate \\
\hline _aDSatPisc_ & - & _aDSatPisc_: food_limitation_function_of_Pisc \\
\hline _akDIncrPisc_ & $d-1$ & _akDIncrPisc_intrinsic_net_increase_rate_of_Pisc \\
\hline tDEnvPisc_ & $\mathrm{gD} / \mathrm{m} 2 / \mathrm{d}$ & _tDEnvPisc_ = environmental_correction_of_Pisc \\
\hline tDAssPisc_ & $\mathrm{gD} / \mathrm{m} 2 / \mathrm{d}$ & _tDAssPisc_ = assimilation_of_Pisc \\
\hline _tDConsPisc_ & $\mathrm{gD} / \mathrm{m} 2 / \mathrm{d}$ & _tDConsPisc_consumption_of_Pisc \\
\hline _tDEgesPisc_ & $\mathrm{gD} / \mathrm{m} 2 / \mathrm{d}$ & _tDEgesPisc_egestion_of_Pisc \\
\hline _tDConsFiJvPisc_ & $\mathrm{gD} / \mathrm{m} 2 / \mathrm{d}$ & _tDConsFiJvP young_fish_consumption_by_Pisc \\
\hline tDConsFiAdPisc_ & $\mathrm{gD} / \mathrm{m} 2 / \mathrm{d}$ & _tDConsFiAdF adult_fish_consumption_by_Pisc \\
\hline tDRespPisc_ & $\mathrm{gD} / \mathrm{m} 2 / \mathrm{d}$ & _tDRespPisc_respiration_of_Pisc \\
\hline _tDMortPisc_ & $\mathrm{gD} / \mathrm{m} 2 / \mathrm{d}$ & _tDMortPisc_mortality_of_Pisc(incl_environmental_correction) \\
\hline _tDMortPiscBot_ & $\mathrm{g} / \mathrm{m} 2 / \mathrm{d}$ & _tDMortPiscBı part_of_died_fish_DW_fixed_in_bones_AND_scales \\
\hline _tDMortPiscDet_ & $\mathrm{gD} / \mathrm{m} 2 / \mathrm{d}$ & _tDMortPiscDı part_of_died_Pisc_DW_becoming_detritus \\
\hline _ukHarvPisc_ & d-1 & _ukHarvPisc_fish_harvesting_constant \\
\hline _tDHarvPisc_ & $\mathrm{gD} / \mathrm{m} 2 / \mathrm{d}$ & _tDHarvPisc_harvesting_of_Pisc \\
\hline aPPisc_ & $\mathrm{gP} / \mathrm{m} 2$ & _aPPisc_=_c_Piscivorous_fish \\
\hline _tPConsFiJvPisc_ & $\mathrm{gP} / \mathrm{m} 2 / \mathrm{d}$ & _tPConsFiJvPyoung_fish_consumption_by_Pisc \\
\hline _tPConsFiAdPisc_ & $\mathrm{gP} / \mathrm{m} 2 / \mathrm{d}$ & _tPConsFiAdF adult_fish_consumption_by_Pisc \\
\hline _tPConsPisc_ & gP_m-2_d-1 & _tPConsPisc_total_P_consumption_by_Pisc \\
\hline _PDFoodPisc_ & $\mathrm{gP} / \mathrm{gD}$ & _rPDFoodPisc average_P/D_ratio_of_Pisc_food \\
\hline _afPAssPisc_ & - & _afPAssPisc_P_assim_efficiency_of_Pisc \\
\hline _tPAssPisc_ & $\mathrm{gP} / \mathrm{m} 2 / \mathrm{d}$ & _tPAssPisc_=P_assimilation_of_Pisc \\
\hline _PEgesPisc_ & $\mathrm{gP} / \mathrm{m} 2 / \mathrm{d}$ & _tPEgesPisc_egestion_of_Pisc \\
\hline _tPEgesPiscPO4_ & $\mathrm{gP} / \mathrm{m} 2 / \mathrm{d}$ & _tPEgesPiscP SRP_egestion_of_Pisc \\
\hline _tPEgesPiscDet_ & $\mathrm{gP} / \mathrm{m} 2 / \mathrm{d}$ & _tPEgesPiscD detrital_P_egestion_of_Pisc \\
\hline _tPExcrPisc_ & $\mathrm{gP} / \mathrm{m} 2 / \mathrm{d}$ & _tPExcrPisc_respiration_of_Pisc \\
\hline _tPMortPisc_ & $\mathrm{gP} / \mathrm{m} 2 / \mathrm{d}$ & _tPMortPisc_mortality_of_Pisc \\
\hline _tPMortPiscBot_ & $\mathrm{gP} / \mathrm{m} 2 / \mathrm{d}$ & _tPMortPiscBc part_of_died_Pisc_P_fixed_in_bones_AND_scales \\
\hline _tPMortPiscPO4_ & $\mathrm{gP} / \mathrm{m} 2 / \mathrm{d}$ & _tPMortPiscP( part_of_died_fish_P_becoming_dissolved_P \\
\hline _tPMortPiscDet_ & $\mathrm{gP} / \mathrm{m} 2 / \mathrm{d}$ & _tPMortPiscDıpart_of_died_Pisc_P_becoming_detrital_P \\
\hline _tPMigrPisc_ & $\mathrm{gP} / \mathrm{m} 2 / \mathrm{d}$ & _tPMigrPisc_: net_migration_flux \\
\hline _tPHarvPisc_ & $\mathrm{gP} / \mathrm{m} 2 / \mathrm{d}$ & _tPHarvPisc_harvesting_of_Pisc \\
\hline _aNPisc_ & gN_m-2 & _aNPisc__=_cPiscivorous_fish \\
\hline _tNConsFiJvPisc_ & $\mathrm{gN} / \mathrm{m} 2 / \mathrm{d}$ & _tNConsFiJvP young_fish_consumption_by_Pisc \\
\hline _tNConsFiAdPisc_ & $\mathrm{gN} / \mathrm{m} 2 / \mathrm{d}$ & _tNConsFiAdF adult_fish_consumption_by_Pisc \\
\hline _tNConsPisc_ & gN_m-2_d-1 & _tNConsPisc_total_N_consumption_by_Pisc \\
\hline _rNDFoodPisc_ & $\mathrm{gN} / \mathrm{gD}$ & _rNDFoodPisc average_N/D_ratio_of_Pisc_food \\
\hline _afNAssPisc_ & - & _afNAssPisc_N_assim_efficiency_of_Pisc \\
\hline tNAssPisc_ & $\mathrm{gN} / \mathrm{m} 2 / \mathrm{d}$ & _tNAssPisc_ = N_assimilation_of_Pisc \\
\hline _NEgesPisc__ & $\mathrm{gN} / \mathrm{m} 2 / \mathrm{d}$ & _tNEgesPisc_egestion_of_Pisc \\
\hline _tNEgesPiscNH4_ & $\mathrm{gN} / \mathrm{m} 2 / \mathrm{d}$ & _tNEgesPisc^ SRN_egestion_of_Pisc \\
\hline _tNEgesPiscDet_ & $\mathrm{gN} / \mathrm{m} 2 / \mathrm{d}$ & _tNEgesPisc[ detrital_N_egestion_of_Pisc \\
\hline _tNExcrPisc_ & $\mathrm{gN} / \mathrm{m} 2 / \mathrm{d}$ & _tNExcrPisc_respiration_of_Pisc \\
\hline _tNMortPisc_ & $\mathrm{gN} / \mathrm{m} 2 / \mathrm{d}$ & _tNMortPisc_mortality_of_Pisc \\
\hline _NMortPiscBot_ & $\mathrm{gN} / \mathrm{m} 2 / \mathrm{d}$ & _tNMortPiscBı part_of_died_Pisc_N_fixed_in_bones_AND_scales \\
\hline _tNMortPiscNH4_ & $\mathrm{gN} / \mathrm{m} 2 / \mathrm{d}$ & _tNMortPiscN| part_of_died_fish_N_becoming_dissolved_N \\
\hline _tNMortPiscDet_ & $\mathrm{gN} / \mathrm{m} 2 / \mathrm{d}$ & _tNMortPiscDipart_of_died_Pisc_N_becoming_detrital_N \\
\hline _NMigrPisc_ & $\mathrm{gN} / \mathrm{m} 2 / \mathrm{d}$ & _tNMigrPisc_net_migration_flux \\
\hline _tNHarvPisc_ & $\mathrm{gN} / \mathrm{m} 2 / \mathrm{d}$ & _tNHarvPisc_harvesting_of_Pisc \\
\hline _wDWebZoo_ & $\mathrm{mgDW} / \mathrm{l} / \mathrm{d}$ & _wDWebZoo_total_foodweb_flux_of_DW_in_Herbivorous_zooplankton \\
\hline _wPWebZoo_ & $\mathrm{mgP} / \mathrm{l} / \mathrm{d}$ & _wPWebZoo_total_foodweb_flux_of_P_in_Herbivorous_zooplankton \\
\hline _wNWebZoo_ & $\mathrm{mgN} / \mathrm{l} / \mathrm{d}$ & _wNWebZoo_total_foodweb_flux_of_N_in_Herbivorous_zooplankton \\
\hline _tDWebBent_ & $\mathrm{gDW} / \mathrm{m} 2 / \mathrm{d}$ & _tDWebBent_total_foodweb_flux_of_DW_in_Zoobenthos \\
\hline _tPWebBent_ & $\mathrm{gP} / \mathrm{m} 2 / \mathrm{d}$ & _tPWebBent_total_foodweb_flux_of_P_in_Zoobenthos \\
\hline _tNWebBent_ & $\mathrm{gN} / \mathrm{m} 2 / \mathrm{d}$ & _tNWebBent_total_foodweb_flux_of_N_in_Zoobenthos \\
\hline
\end{tabular}




\begin{tabular}{|c|c|c|}
\hline tDWebFiJv_ & $\mathrm{gDW} / \mathrm{m} 2 / \mathrm{d}$ & _tDWebFiJv_total_foodweb_flux_of_DW_in_Young_fish \\
\hline tPWebFiJv_ & $\mathrm{gP} / \mathrm{m} 2 / \mathrm{d}$ & _tPWebFiJv_total_foodweb_flux_of_P_in_Young_fish \\
\hline tNWebFiJv_ & $\mathrm{gN} / \mathrm{m} 2 / \mathrm{d}$ & _tNWebFiJv_total_foodweb_flux_of_N_in_Young_fish \\
\hline _tDWebFiAd_- & $\mathrm{gDW} / \mathrm{m} 2 / \mathrm{d}$ & _tDWebFiAd_total_foodweb_flux_of_DW_in_Adult_fish \\
\hline tPWebFiAd_ & $\mathrm{gP} / \mathrm{m} 2 / \mathrm{d}$ & _tPWebFiAd_total_foodweb_flux_of_P_in_Adult_fish \\
\hline tNWebFiAd_ & $\mathrm{gN} / \mathrm{m} 2 / \mathrm{d}$ & _tNWebFiAd_total_foodweb_flux_of_N_in_Adult_fish \\
\hline tDWebPisc_ & $\mathrm{g} / \mathrm{m} 2 / \mathrm{d}$ & _tDWebPisc_total_foodweb_flux_of_DW_in_predatory_fish \\
\hline wDWebDetW_ & $\mathrm{mg} / / / \mathrm{d}$ & _wDWebDeth total_foodweb_flux_of_DW_in_Detritus_in_lake_water \\
\hline _wDWebDiatW_ & $\mathrm{mg} / \mathrm{l} / \mathrm{d}$ & _wDWebDiatV total_foodweb_flux_of_DW_in_Diatoms_in_lake_water \\
\hline wDWebGrenW & $\mathrm{mg} / \mathrm{l} / \mathrm{d}$ & _wDWebGren total_foodweb_flux_of_DW_in_Greens_in_lake_water \\
\hline _wDWebBlueW_ & $\mathrm{mg} / \mathrm{l} / \mathrm{d}$ & _wDWebBluel total_foodweb_flux_of_DW_in_Blue-greens_in_lake_water \\
\hline tDWebDetS_ & $\mathrm{gDW} / \mathrm{m} 2 / \mathrm{d}$ & _tDWebDetS_total_foodweb_flux_of_DW_in_Sediment_detritus_in_lake \\
\hline _tDWebDiatS_ & $\mathrm{g} / \mathrm{m} 2 / \mathrm{d}$ & _tDWebDiatS_total_foodweb_flux_of_DW_in_sediment_diatoms_in_lake \\
\hline tDWebGrens_ & $\mathrm{g} / \mathrm{m} 2 / \mathrm{d}$ & _tDWebGrenstotal_foodweb_flux_of_DW_in_sediment_greens_in_lake \\
\hline tDWebBlues_ & $\mathrm{g} / \mathrm{m} 2 / \mathrm{d}$ & _tDWebBlueS total_foodweb_flux_of_DW_in_sediment_blue-greens_in_lake \\
\hline _tDWebPhyts_- & $\mathrm{gDW} / \mathrm{m} 2 / \mathrm{d}$ & _tDWebPhytS total_food_web_flux_of_sediment_algae $\overline{-}$ \\
\hline tDWebTotT_ & $\mathrm{gDW} / \mathrm{m} 2 / \mathrm{d}$ & _tDWebTotT_total_DW_in_system \\
\hline _wPWebPO4W_ & $\mathrm{mgP} / / \mathrm{d}$ & _wPWebPO4I total_foodweb_flux_of_P_in_SRP_in_water_in_lake_water \\
\hline _wPWebDetW_ & $\mathrm{mgP} / \mathrm{l} / \mathrm{d}$ & _wPWebDeth total_foodweb_flux_of_P_in_Detritus_in_lake_water \\
\hline _wPWebDiatW_ & $\mathrm{mgP} / \mathrm{l} / \mathrm{d}$ & _wPWebDiatV total_foodweb_flux_of_P_in_Diatoms_in_lake_water \\
\hline -wPWebGrenW_ & $\mathrm{mgP} / \mathrm{l} / \mathrm{d}$ & _wPWebGren total_foodweb_flux_of_P_in_Greens_in_lake_water \\
\hline _wPWebBlueW_ & $\mathrm{mgP} / \mathrm{l} / \mathrm{d}$ & _wPWebBluel total_foodweb_flux_of_P_in_Blue-greens_in_lake_water \\
\hline tPWebPO4S_ & $\mathrm{gP} / \mathrm{m} 2 / \mathrm{d}$ & _tPWebPO4S total_foodweb_flux_of_P_in_Pore_water_P_in_lake_sediment \\
\hline _tPWebDetS_ & $\mathrm{gP} / \mathrm{m} 2 / \mathrm{d}$ & _tPWebDetS_total_foodweb_flux_of_P_in_Sediment_P_in_lake \\
\hline tPWebDiats_ & $\mathrm{gP} / \mathrm{m} 2 / \mathrm{d}$ & _tPWebDiatS_total_foodweb_flux_of_P_in_sediment_diatoms_in_lake \\
\hline tPWebGrens & $\mathrm{gP} / \mathrm{m} 2 / \mathrm{d}$ & _tPWebGrenS total_foodweb_flux_of_P_in_sediment_greens_in_lake \\
\hline tPWebBlues_- & $\mathrm{gP} / \mathrm{m} 2 / \mathrm{d}$ & _tPWebBlueS total_foodweb_flux_of_P_in_sediment_blue-greens_in_lake \\
\hline tPWebPhyts_- & $\mathrm{gP} / \mathrm{m} 2 / \mathrm{d}$ & _tPWebPhytS total_food_web_flux_of_sediment_algae \\
\hline tPWebTotT_- & $\mathrm{gP} / \mathrm{m} 2 / \mathrm{d}$ & _tPWebTotT_total_P_in_system \\
\hline -wNWebNH4W_ & $\mathrm{mgN} / \mathrm{l} / \mathrm{d}$ & _wNWebNH4l total_foodweb_flux_of_N_in_ammonium_in_water_in_lake_water \\
\hline -wNWebNO3W_ & $\mathrm{mgN} / \mathrm{l} / \mathrm{d}$ & _wNWebNO3! total_foodweb_flux_of_N_in_nitrate_in_water_in_lake_water \\
\hline _wNWebDetW_ & $\mathrm{mgN} / \mathrm{l} / \mathrm{d}$ & _wNWebDeth total_foodweb_flux_of_N_in_Detritus_in_lake_water \\
\hline _wNWebDiatW_- & $\mathrm{mgN} / \mathrm{l} / \mathrm{d}$ & _wNWebDiatV total_foodweb_flux_of_N_in_Diatoms_in_lake_water \\
\hline wNWebGrenW_ & $\mathrm{mgN} / \mathrm{l} / \mathrm{d}$ & _wNWebGren total_foodweb_flux_of_N_in_Greens_in_lake_water \\
\hline _wNWebBlueW_ & $\mathrm{mgN} / \mathrm{l} / \mathrm{d}$ & _wNWebBluel total_foodweb_flux_of_N_in_Blue-greens_in_lake_water \\
\hline tNWebNH4S_ & $\mathrm{gN} / \mathrm{m} 2 / \mathrm{d}$ & _tNWebNH4S total_foodweb_flux_of_N_in_Pore_water_ammonium_in_lake_sediment \\
\hline tNWebNO3S_- & $\mathrm{gN} / \mathrm{m} 2 / \mathrm{d}$ & _tNWebNO3S total_foodweb_flux_of_N_in_Pore_water_nitrate_in_lake_sediment \\
\hline tNWebDetS_ & $\mathrm{gN} / \mathrm{m} 2 / \mathrm{d}$ & _tNWebDetS_total_foodweb_flux_of_N_in_Sediment_N_in_lake_sediment \\
\hline _tNWebDiatS_- & $\mathrm{gN} / \mathrm{m} 2 / \mathrm{d}$ & _tNWebDiatS_total_foodweb_flux_of_N_in_sediment_diatoms_in_lake \\
\hline tNWebGrens_ & $\mathrm{gN} / \mathrm{m} 2 / \mathrm{d}$ & _tNWebGrens total_foodweb_flux_of_N_in_sediment_greens_in_lake \\
\hline _tNWebBlues_- & $\mathrm{gN} / \mathrm{m} 2 / \mathrm{d}$ & _tNWebBlueS total_foodweb_flux_of_N_in_sediment_blue-greens_in_lake \\
\hline tNWebPhytS_ & $\mathrm{gN} / \mathrm{m} 2 / \mathrm{d}$ & _tNWebPhytS total_food_web_flux_of_sediment_algae \\
\hline tNWebTotT_ & $\mathrm{gN} / \mathrm{m} 2 / \mathrm{d}$ & _tNWebTotT_total_N_in_system \\
\hline wSiWebSiO2W_ & $\mathrm{gSi} / \mathrm{m} 3 / \mathrm{d}$ & _wSiWebSiOz total_foodweb_flux_of_silica_in_SiO2_lake_water \\
\hline _wSiWebDetW_ & $\mathrm{gSi} / \mathrm{m} 3 / \mathrm{d}$ & _wSiWebDetV total_foodweb_flux_of_silica_in_lake_water_detritus \\
\hline tSiWebDets_ & $\mathrm{gSi} / \mathrm{m} 2 / \mathrm{d}$ & _tSiWebDetS_total_foodweb_flux_of_silica_in_sediment_detritus \\
\hline tSiWebTotT_- & $\mathrm{gSi} / \mathrm{m} 2 / \mathrm{d}$ & _tSiWebTotT_total_foodweb_flux_of_silica \\
\hline aPrefAve_ & - & aPrefAve_= average_selection_factor \\
\hline _wDConsZoo2_ & $\mathrm{mg} / \mathrm{l} / \mathrm{d}$ & _wDConsZoo: total_zoopl_consumption(check) \\
\hline aDConsZooSp_ & $d-1$ & _aDConsZoosspecific_consumption_rate_of_zoopl(daily_ration) \\
\hline aDAssZooSp_ & $d-1$ & _aDAssZooSp specific_C_assimilation_of_zooplankton \\
\hline aDGrazSp_ & $d-1$ & _aDGrazSp_=specific_DW_grazing(daily_grazing) \\
\hline aPConsZooSp_ & $d-1$ & _aPConsZooミspecific_P_consumption_OR_daily_ration \\
\hline aPGrazSp_ & $d-1$ & _aPGrazSp_=specific_P_grazing_OR_daily_grazing \\
\hline aNConsZoosp_ & $d-1$ & aNConsZoosspecific_N_consumption_OR_daily_ration \\
\hline aNGrazSp_ & $d-1$ & _aNGrazSp_: specific_N_grazing_OR_daily_grazing \\
\hline _afDShootPhra_ & - & _afDShootPhr Shoot/total_-ratio \\
\hline rDSRPhra_ & - & _rDSRPhra_=Shoot/Root_-ratio \\
\hline rPDShootPhra_ & - & _rPDShootPhı Shoot_P/D_-ratio \\
\hline rNDShootPhra_ & - & _rNDShootPhıShoot_N/D_-ratio \\
\hline _PDRootPhra_ & - & rPDRootPhre Root_P/D_ratio \\
\hline rNDRootPhra_- & - & _rNDRootPhrc Root_N/D_-ratio \\
\hline aLengShootPhra & - & aLengShootF - \\
\hline bDaylnitPhra_ & - & _bDaylnitPhra marks_start_of_root_allocation_to_shoot_of_phragmities \\
\hline _aDAllPhra_ & $\mathrm{gD} / \mathrm{m} 2$ & _aDAllPhra_=root_biomass_available_for_allocation_to_shoot \\
\hline tDAllPhra_ & $\mathrm{gD} / \mathrm{m} 2 / \mathrm{d}$ & _tDAllPhra_ = allocation_flux \\
\hline tNTransPhra & $\mathrm{gN} / \mathrm{m} 2 / \mathrm{d}$ & tNTransPhra translocation of $\mathrm{N}$ initial growth \\
\hline
\end{tabular}


_tPTransPhra _aVNUptPhraMaxCr_ _ahNUptPhras_

_aVNUptPhras_

_tNUptPhras

tNUptNH4Phras

_tNUptNO3PhraS

tNUptShootPhra

tNUptRootPhra_

_aVPUptPhraMaxCr_

_ahPUptPhras_

_aVPUptPhras_

_tPUptPhras

_tPUptShootPhra

_tPUptRootPhra_

_uFunTmProdPhra

_ukDRespTmPhra

_aMuPhotPhra_

aNLimProdPhra

_aPLimProdPhra_

_aNutLimPhra

aMuPhra

_akDIncrPhra_

_tDDensPhra

_tDDensProdPhra_

tDProdPhra

_tDProdShootPhra

tDProdRootPhra

_tDRespShootPhra

_tDRespRootPhra_

tO2RespRootPhra

_tO2FlowPhra

_bDayRealPhra_

_aDRealPhra_

_tDRealPhra_

tNRetrPhra_

-tPRetrPhra_

_tDMortShootPhra

tNMortShootPhra

_tPMortShootPhra

_tDMortRootPhra_

tNMortRootPhra

_tPMortRootPhra

_tDManShootPhra_

_tNManShootPhra_

_tPManShootPhra

tDIMSM

-tDHumSM

_tDDetSM_

vDeltaSM

_tDBurIMM

_tDBurOMM_

tDBurDetM

_tDBurHumM

tDBurTotM

tPBurHumM

tPBurDetM

tPBurAIMM

tPBurPO4M

_tPBurTotM

tNBurHumM

tNBurDetM

_tNBurNH4M_

tNBurNO3M

_tNBurTotM_

tSiBurDetM_

_tSiBurTotM_
$\mathrm{gP} / \mathrm{m} 2 / \mathrm{d}$

$\mathrm{mgN} / \mathrm{mgD} / \mathrm{d}$

$\mathrm{mgP} / \mathrm{l}$

$\mathrm{mgN} / \mathrm{mgD} / \mathrm{d}$

$\mathrm{gN} / \mathrm{m} 2 / \mathrm{d}$

$\mathrm{gN} / \mathrm{m} 2 / \mathrm{d}$

$\mathrm{gN} / \mathrm{m} 2 / \mathrm{d}$

$\mathrm{gN} / \mathrm{m} 2 / \mathrm{d}$

$\mathrm{gN} / \mathrm{m} 2 / \mathrm{d}$

$\mathrm{mgP} / \mathrm{mgD} / \mathrm{d}$

$\mathrm{gP} / \mathrm{m} 3$

$\mathrm{mgP} / \mathrm{mgD} / \mathrm{d}$

$\mathrm{gP} / \mathrm{m} 2 / \mathrm{d}$

$\mathrm{gP} / \mathrm{m} 2 / \mathrm{d}$

$\mathrm{gP} / \mathrm{m} 2 / \mathrm{d}$

$1 / d$

$1 / d$

$1 / d$

$1 / d$

$\mathrm{gDW} / \mathrm{m} 2 / \mathrm{d}$

$\mathrm{gDW} / \mathrm{m} 2 / \mathrm{d}$

$\mathrm{gDW} / \mathrm{m} 2 / \mathrm{d}$

$\mathrm{gDW} / \mathrm{m} 2 / \mathrm{d}$

$\mathrm{gDW} / \mathrm{m} 2 / \mathrm{d}$

$\mathrm{gDW} / \mathrm{m} 2 / \mathrm{d}$

$\mathrm{gDW} / \mathrm{m} 2 / \mathrm{d}$

gO2.m-2.d-1

$\mathrm{gO} 2 / \mathrm{m} 2 / \mathrm{d}$

gDW/m2

$\mathrm{gDW} / \mathrm{m} 2 / \mathrm{d}$

$\mathrm{gN} / \mathrm{m} 2 / \mathrm{d}$

$\mathrm{gP} / \mathrm{m} 2 / \mathrm{d}$

$\mathrm{gDW} / \mathrm{m} 2 / \mathrm{d}$

$\mathrm{gN} / \mathrm{m} 2 / \mathrm{d}$

$\mathrm{gP} / \mathrm{m} 2 / \mathrm{d}$

$\mathrm{gDW} / \mathrm{m} 2 / \mathrm{d}$

$\mathrm{gN} / \mathrm{m} 2 / \mathrm{d}$

$\mathrm{gP} / \mathrm{m} 2 / \mathrm{d}$

$\mathrm{gDW} / \mathrm{m} 2 / \mathrm{d}$

$\mathrm{gDW} / \mathrm{m} 2 / \mathrm{d}$

$\mathrm{gDW} / \mathrm{m} 2 / \mathrm{d}$

$\mathrm{gDW} / \mathrm{m} 2 / \mathrm{d}$

$\mathrm{gDW} / \mathrm{m} 2 / \mathrm{d}$

$\mathrm{gDW} / \mathrm{m} 2 / \mathrm{d}$

$\mathrm{m} / \mathrm{d}$

$\mathrm{gDW} / \mathrm{m} 2 / \mathrm{d}$

$\mathrm{gDW} / \mathrm{m} 2 / \mathrm{d}$

$\mathrm{gDW} / \mathrm{m} 2 / \mathrm{d}$

$\mathrm{gDW} / \mathrm{m} 2 / \mathrm{d}$

$\mathrm{gDW} / \mathrm{m} 2 / \mathrm{d}$

$\mathrm{gP} / \mathrm{m} 2 / \mathrm{d}$

$\mathrm{gP} / \mathrm{m} 2 / \mathrm{d}$

$\mathrm{gP} / \mathrm{m} 2 / \mathrm{d}$

$\mathrm{gP} / \mathrm{m} 2 / \mathrm{d}$

$\mathrm{gP} / \mathrm{m} 2 / \mathrm{d}$

$\mathrm{gN} / \mathrm{m} 2 / \mathrm{d}$

$\mathrm{gN} / \mathrm{m} 2 / \mathrm{d}$

$\mathrm{gN} / \mathrm{m} 2 / \mathrm{d}$

$\mathrm{gN} / \mathrm{m} 2 / \mathrm{d}$

$\mathrm{gN} / \mathrm{m} 2 / \mathrm{d}$

$\mathrm{gSi} / \mathrm{m} 2 / \mathrm{d}$

$\mathrm{gSi} / \mathrm{m} 2 / \mathrm{d}$
_tPTransPhra translocation_of_P_initial_growth

_aVNUptPhral max_uptake_rate_at_current_N/D_ratio_AND_temp

_ahNUptPhra: half-saturating_N_concentration

_aVNUptPhra: N_uptake_rate(by_roots)

_tNUptPhraS_Total_N_uptake_of_reed

_tNUptNH4Ph NH4_uptake_of_reed

_tNUptNO3Ph NO3_uptake_of_reed

_tNUptShootP N_uptake_shoot

_tNUptRootPr N_uptake_root

_aVPUptPhral max_uptake_rate_at_current_P/D_ratio_AND_temp

_ahPUptPhras half-saturating_P_concentration

_aVPUptPhra! $P$ _uptake_rate(by_roots)

_tPUptPhraS_Total_P_uptake_of_reed

tPUptShootP $P$ uptake shoot

_tPUptRootPhP_uptake_root

_uFunTmProd tempfunction_production_vegetation

_ukDRespTml maintenance_respiration_rate_at_current_temperature

_aMuPhotPhr: max_photosynthetic_rate_at_current_light_AND_temp

aNLimProdP Droop_function_N-limitation

_aPLimProdPI Droop_function_P-limitation

_aNutLimPhra nutrient_reduction_function

_aMuPhra_= growth_rate

_akDIncrPhra_intrinsic_net_increase_rate_of_reed

_tDDensPhra_density_correction_of_reed

tDDensProdf density_correction_of_production

_tDProdPhra_production_of_reed

_tDProdShoot production_shoot_of_reed

tDProdRootF production root of reed

_tDRespShoo maintenance_respiration_shoot_of_reed

_tDRespRootf maintenance_respiration_root_of_reed

_tO2RespRoo root_O2_respiration

_tO2FlowPhra O2_flux_to_sediment

bDayRealPhl -

_aDRealPhra_shoot_biomass_available_for_reallocation to root

_tDRealPhra_reallocation_of_D_per_day_at_end_of_growing_season

_tNRetrPhra_retranslocation_of_N_end_growing_season

tPRetrPhra_retranslocation_of_P_end_growing_season

_tDMortShootl mortality_of_shoots

_tNMortShoot|mortality_of_shoots

_tPMortShootl mortality_of_shoots

_tDMortRootP mortality_of_roots

_tNMortRootP mortality_of_roots

_tPMortRootP mortality_of_roots

_tDManShootl loss_flux_of_biomass_by_management

_tNManShootl loss_flux_of_N_through_management

_tPManShootr loss_flux_of_P_through_management

_tDIMSM_ = _increase_in_inorganic_matter_in_sediment

_tDHumSM_=increase_in_sediment_humus_in_marsh

_tDDetSM_ = increase_in_sediment_detritus_in_marsh

_vDeltaSM_ = turnover_depth_in_marsh

_tDBurIMM_- burial_flux_of_DW_in_inorganic_matter_in_marsh

_tDBurOMM_burial_flux_of_DW_in_organic_matter_in_marsh

_tDBurDetM_burial_flux_of_DW_in_detritus_in_marsh

_tDBurHumM_burial_flux_of_DW_in_humus_in_marsh

_tDBurTotM_total_DW_burial_flux_in_marsh

_tPBurHumM_burial_flux_of_P_in_humus_in_marsh

_tPBurDetM_burial_flux_of_P_in_detritus_in_marsh

_tPBurAIMM_burial_flux_of_P_absorbed_onto_inorganic_matter_in_marsh

_tPBurPO4M_burial_flux_of_dissolved_P_in_marsh

_tPBurTotM_: total_P_burial_flux_in_marsh

_tNBurHumM_burial_flux_of_N_in_humus_in_marsh

_tNBurDetM_burial_flux_of_N_in_detritus_in_marsh

_tNBurNH4M_burial_flux_of_dissolved_NH4_in_marsh

_tNBurNO3M_burial_flux_of_dissolved_NO3_in_marsh

_tNBurTotM_ total_N_burial_flux_in_marsh

_tSiBurDetM_burial_flux_of_Si_in_detritus_in_marsh

_tSiBurTotM_total_Si_burial_flux_in_marsh 
$\begin{array}{ll}\text { _vDeltaWM__ } & \mathrm{m} / \mathrm{d} \\ \text { _aRelDeltaWM_ } & \mathrm{d}-1 \\ \text { tDSetTot } & \mathrm{gD} / \mathrm{m}\end{array}$

tPSetTot

tNSetTot

tDResusTot

tPResusTot_

tNResusTot_

bTimeDred_

_aDepthStart

_akDredDepth_

_akDred

_akDredBent_

vDredDepthW_

tDDredDetS_

_tPDredDetS_

tNDredDets

_tSiDredDetS

tPDredAIMS

bRhoSolidSoil

_tDDredNetSoil_

tDDredNetIMS

-tDDredNetHums

_tPDredNetHumS

_tNDredNetHums_

_tDDredDiatS_

_tPDredDiatS_

tNDredDiatS

_tDDredGrens

_tPDredGrens_

-tNDredGrens

_tDDredBlues_

tPDredBlues_

tNDredBlues

tDDredPhyts_

tPDredPhyts_

_tNDredPhyts_

_tDDredBent_

tPDredBent

-tNDredBent

_tDDredVeg_

tPDredVeg

tNDredVeg_

tDDredNetTot

_tPDredNetTot_

_tNDredNetTot_

tSiDredTot

tDIMS

_tDHums

tDDetS

_vDeltas

_tDBurlM

tDBurOM

tDBurDet

tDBurHum

tDBurTot

_tPBurHum

tPBurDet

tPBurAIM

_tPBurPO4

tPBurTot

_tNBurHum

tNBurDet

tNBurNH4

tNBurNO3

_tNBurTot_

_tSiBurDet_ $\mathrm{m} / \mathrm{d}$

d-1

$\mathrm{gD} / \mathrm{m} 2 / \mathrm{d}$

$\mathrm{gP} / \mathrm{m} 2 / \mathrm{d}$

$\mathrm{gN} / \mathrm{m} 2 / \mathrm{d}$

$\mathrm{gD} / \mathrm{m} 2 / \mathrm{d}$

$\mathrm{gP} / \mathrm{m} 2 / \mathrm{d}$

$\mathrm{gN} / \mathrm{m} 2 / \mathrm{d}$

d

d

d-1

d-1

d-1

$\mathrm{m} / \mathrm{d}$

$\mathrm{gDW} / \mathrm{m} 2 / \mathrm{d}$

$\mathrm{gP} / \mathrm{m} 2 / \mathrm{d}$

$\mathrm{gN} / \mathrm{m} 2 / \mathrm{d}$

$\mathrm{gSi} / \mathrm{m} 2 / \mathrm{d}$

$\mathrm{gP} / \mathrm{m} 2 / \mathrm{d}$

$\mathrm{g} / \mathrm{m} 3$

$\mathrm{gDW} / \mathrm{m} 2 / \mathrm{d}$

$\mathrm{gDW} / \mathrm{m} 2 / \mathrm{d}$

$\mathrm{gDW} / \mathrm{m} 2 / \mathrm{d}$

$\mathrm{gP} / \mathrm{m} 2 / \mathrm{d}$

$\mathrm{gN} / \mathrm{m} 2 / \mathrm{d}$

$\mathrm{gDW} / \mathrm{m} 2 / \mathrm{d}$

$\mathrm{gP} / \mathrm{m} 2 / \mathrm{d}$

$\mathrm{gN} / \mathrm{m} 2 / \mathrm{d}$

$\mathrm{gDW} / \mathrm{m} 2 / \mathrm{d}$

$\mathrm{gP} / \mathrm{m} 2 / \mathrm{d}$

$\mathrm{gN} / \mathrm{m} 2 / \mathrm{d}$

$\mathrm{gDW} / \mathrm{m} 2 / \mathrm{d}$

$\mathrm{gP} / \mathrm{m} 2 / \mathrm{d}$

$\mathrm{gN} / \mathrm{m} 2 / \mathrm{d}$

$\mathrm{gDW} / \mathrm{m} 2 / \mathrm{d}$

$\mathrm{gP} / \mathrm{m} 2 / \mathrm{d}$

$\mathrm{gN} / \mathrm{m} 2 / \mathrm{d}$

$\mathrm{gDW} / \mathrm{m} 2 / \mathrm{d}$

$\mathrm{gP} / \mathrm{m} 2 / \mathrm{d}$

$\mathrm{gN} / \mathrm{m} 2 / \mathrm{d}$

$\mathrm{gDW} / \mathrm{m} 2 / \mathrm{d}$

$\mathrm{gP} / \mathrm{m} 2 / \mathrm{d}$

$\mathrm{gN} / \mathrm{m} 2 / \mathrm{d}$

$\mathrm{gDW} / \mathrm{m} 2 / \mathrm{d}$

$\mathrm{gP} / \mathrm{m} 2 / \mathrm{d}$

$\mathrm{gN} / \mathrm{m} 2 / \mathrm{d}$

$\mathrm{gSi} / \mathrm{m} 2 / \mathrm{d}$

$\mathrm{gDW} / \mathrm{m} 2 / \mathrm{d}$

$\mathrm{gDW} / \mathrm{m} 2 / \mathrm{d}$

$\mathrm{gDW} / \mathrm{m} 2 / \mathrm{d}$

$\mathrm{m} / \mathrm{d}$

$\mathrm{gDW} / \mathrm{m} 2 / \mathrm{d}$

$\mathrm{gDW} / \mathrm{m} 2 / \mathrm{d}$

$\mathrm{gDW} / \mathrm{m} 2 / \mathrm{d}$

$\mathrm{gDW} / \mathrm{m} 2 / \mathrm{d}$

$\mathrm{gDW} / \mathrm{m} 2 / \mathrm{d}$

$\mathrm{gP} / \mathrm{m} 2 / \mathrm{d}$

$\mathrm{gP} / \mathrm{m} 2 / \mathrm{d}$

$\mathrm{gP} / \mathrm{m} 2 / \mathrm{d}$

$\mathrm{gP} / \mathrm{m} 2 / \mathrm{d}$

$\mathrm{gP} / \mathrm{m} 2 / \mathrm{d}$

$\mathrm{gN} / \mathrm{m} 2 / \mathrm{d}$

$\mathrm{gN} / \mathrm{m} 2 / \mathrm{d}$

$\mathrm{gN} / \mathrm{m} 2 / \mathrm{d}$

$\mathrm{gN} / \mathrm{m} 2 / \mathrm{d}$

$\mathrm{gN} / \mathrm{m} 2 / \mathrm{d}$

$\mathrm{gSi} / \mathrm{m} 2 / \mathrm{d}$
_vDeltaWM_=marsh_water_depth_change

_aRelDeltaWn relative_marsh_water_depth_change

tDSetTot_ = total_settling

_tPSetTot_ $=$. total_settling

_tNSetTot_=.total_settling

-tDResusTot_total_resuspension

_tPResusTot_total_P_resuspension_flux

_tNResusTot_total_N_resuspension_flux

_bTimeDred_dredging_time(every_nth_year)

_aDepthStart_update_dredget_layer

_akDredDeptr rate_constant_of_deepening

_akDred_=_I rate_constant_of_dredging(exponential_function)

_akDredBent_rate_constant_of_dredging_for_zoobenthos

_vDredDepthv change_in_water_depth_due_to_dredging

_tDDredDetS_dredging_flux_of_DW_Detritus_in_lake_sediment

_tPDredDetS_dredging_flux_of_P_Detritus_in_lake_sediment

_tNDredDetS_dredging_flux_of_N_Detritus_in_lake_sediment

_tSiDredDetS_dredging_flux_of_Si_Det_in_lake_sediment

_tPDredAIMS_dredging_flux_of_P_absorbed_onto_inorganic_matter_in_lake_sediment

_bRhoSolidSo average_solid_density_of_soil_material

_tDDredNetSc dredging_flux_of_DW_NetSoil_in_lake_sediment

_tDDredNetIM dredging_flux_of_DW_NetIMS_in_lake_sediment

_tDDredNetHı dredging_flux_of_DW_NetHum_in_lake_sediment

_tPDredNetHı dredging_flux_of_P_NetHum_in_lake_sediment

tNDredNetHı dredging_flux_of_N_NetHum_in_lake_sediment

_tDDredDiatS dredging_flux_of_DW_Diat_on_lake_sediment

_tPDredDiatS_dredging_flux_of_P_Diat_on_lake_sediment

tNDredDiatS dredging_flux_of_N_Diat_on_lake_sediment

_tDDredGrensdredging_flux_of_DW_Gren_on_lake_sediment

_tPDredGren dredging_flux_of_P_Gren_on_lake_sediment

tNDredGren`dredging_flux_of_N_Gren_on_lake_sediment

_tDDredBlueS dredging_flux_of_DW_Blue_on_lake_sediment

_tPDredBlueS dredging_flux_of_P_Blue_on_lake_sediment

_tNDredBlueS dredging_flux_of_N_Blue_on_lake_sediment

_tDDredPhytS dredging_flux_of_DW_Phyt_on_lake_sediment

_tPDredPhytS dredging_flux_of_P_Phyt_on_lake_sediment

_tNDredPhytS dredging_flux_of_N_Phyt_on_lake_sediment

_tDDredBent_dredging_flux_of_DW_Bent_on_lake_sediment

_tPDredBent_dredging_flux_of_P_Bent_on_lake_sediment

_tNDredBent_dredging_flux_of_N_Bent_on_lake_sediment

_tDDredVeg_dredging_flux_of_DW_Veg_on_lake_sediment

_tPDredVeg_dredging_flux_of_P_Veg_on_lake_sediment

_tNDredVeg_dredging_flux_of_N_Veg_on_lake_sediment

_tDDredNetTc total_DW_dredging_flux

_tPDredNetTototal_P_dredging_flux

_tNDredNetTc total_N_dredging_flux

_tSiDredTot_: total_Si_dredging_flux

tDIMS_ = _t $\mathrm{t}$ increase_in_inorganic_matter_in_sediment

_tDHumS_= _increase_in_sediment_humus_in_lake

_tDDetS_=_t increase_in_sediment_detritus_in_lake

${ }_{-} \mathrm{vDeltaS}=$ - (turnover_depth_in_lake

_tDBurlM__ = burial_flux_of_DW_in_inorganic_matter_in_lake

_tDBurOM_ = burial_flux_of_DW_in_organic_matter_in_lake

_tDBurDet_= burial_flux_of_DW_in_detritus_in_lake

_tDBurHum_ = burial_flux_of_DW_in_humus_in_lake

_tDBurTot_= total_DW_burial_flux_in_lake

_tPBurHum_=burial_flux_of_P_in_humus_in_lake

_tPBurDet_= burial_flux_of_P_in_detritus_in_lake

_tPBurAIM_- burial_flux_of_P_absorbed_onto_inorganic_matter_in_lake

_tPBurPO4_=burial_flux_of_dissolved_P_in_lake

_tPBurTot_= total_P_burial_flux_in_lake

_tNBurHum_: burial_flux_of_N_in_humus_in_lake

_tNBurDet_= burial_flux_of_N_in_detritus_in_lake

_tNBurNH4_=burial_flux_of_dissolved_NH4_in_lake

_tNBurNO3_=burial_flux_of_dissolved_NO3_in_lake

_tNBurTot_= total_N_burial_flux_in_lake

_tSiBurDet_=burial_flux_of_Si_in_detritus_in_lake 


\begin{tabular}{|c|c|c|}
\hline _tSiBurTot_ & $\mathrm{gSi} / \mathrm{m} 2 / \mathrm{d}$ & _tSiBurTot_= total_Si_burial_flux_in_lake \\
\hline _vDeltaW_ & $\mathrm{m} / \mathrm{d}$ & _vDeltaW_ = _lake_water_depth_change \\
\hline _aRelDeltaW_ & $d-1$ & _aRelDeltaW_relative_water_depth_change_due_to_sediment_turnover_AND_dredging \\
\hline tDMarsTotT_ & $\mathrm{g} / \mathrm{m} 2$ lake/d & _tDMarsTotT_Mass_balance_totals_of_DW_marsh_water_and_vegetation_module \\
\hline _tPMarsTotT_ & $\mathrm{g} / \mathrm{m} 2$ lake/d & _tPMarsTotT_Mass_balance_totals_of_P_marsh_water_and_vegetation_module \\
\hline tNMarsTotT_ & $\mathrm{g} / \mathrm{m} 2 \mathrm{lake} / \mathrm{d}$ & _tNMarsTotT_Mass_balance_totals_of_N_marsh_water_and_vegetation_module \\
\hline _tSiMarsTotT_ & $\mathrm{g} / \mathrm{m} 2 \mathrm{lake} / \mathrm{d}$ & _tSiMarsTotT_Mass_balance_totals_of_SI_marsh_water_and_vegetation_module \\
\hline _aDTotT_ & $\mathrm{gD} / \mathrm{m} 2$ & _aDTotT_ $=($ _total_DW_in_system \\
\hline _aNTotT_ & $\mathrm{gN} / \mathrm{m} 2$ & _aNTotT_= (_total_N_in_system \\
\hline _aPTotT_ & $\mathrm{gP} / \mathrm{m} 2$ & _aPTotT_= (_total_P_in_system \\
\hline _aSiTotT_ & $\mathrm{gSi} / \mathrm{m} 2$ & _aSiTotT_= ( total_Si_in_system \\
\hline _aDError_- & $\mathrm{gD} / \mathrm{m} 2$ & _aDError_=_DW_mass_balance_error \\
\hline _aNError_ & $\mathrm{gN} / \mathrm{m} 2$ & _aNError_=_N_mass_balance_error \\
\hline _aPError_ & $\mathrm{gP} / \mathrm{m} 2$ & _aPError_=_P_mass_balance_error \\
\hline _aSiError_ & $\mathrm{gSi} / \mathrm{m} 2$ & _aSiError_ $=$ _Si_mass_balance_error \\
\hline dDepthW_ & $\mathrm{m} / \mathrm{d}$ & _dDepthW_= derivative_for_water_depth_change_in_lake_water \\
\hline dNH4W_ & $\mathrm{mgN} / \mathrm{l} / \mathrm{d}$ & _dNH4W_=_derivative_for_N_ammonium_in_water_in_lake_water \\
\hline _dNO3W_ & $\mathrm{mgN} / / \mathrm{d}$ & _dNO3W_=_derivative_for_N_nitrate_in_water_in_lake_water \\
\hline _dPO4W_ & $\mathrm{mgP} / / / \mathrm{d}$ & _dPO4W_=_derivative_for_P_SRP_in_water_in_lake_water \\
\hline dPAIMW & $\mathrm{mgP} / / \mathrm{d}$ & _dPAIMW_ = derivative_for_P_P-adsorbed_onto_IM_in_water_in_lake_water \\
\hline _dSiO2W_- & $\mathrm{mgSi} / \mathrm{l} / \mathrm{d}$ & _dSiO2W_ = derivative_for_Si_dissolved_silica_in_water_in_lake_water \\
\hline dO2W_ & $\mathrm{gO} 2 / \mathrm{m} 3 / \mathrm{d}$ & _dO2W__ = w derivative_for_O2_oxygen_in_water_in_lake_water \\
\hline dDDetW_ & $\mathrm{mg} / \mathrm{l} / \mathrm{d}$ & _dDDetW_= derivative_for_DW_Detritus_in_lake_water \\
\hline _dNDetW_ & $\mathrm{mgN} / \mathrm{l} / \mathrm{d}$ & _dNDetW_=_derivative_for_N_Detritus_in_lake_water \\
\hline _dPDetW_ & $\mathrm{mgP} / \mathrm{l} / \mathrm{d}$ & _dPDetW_ $=$ _derivative_for_P_Detritus_in_lake_water \\
\hline dSiDetW & $\mathrm{mgSi} / \mathrm{l} / \mathrm{d}$ & _dSiDetW_ $=$. derivative_for_Si_Detritus_in_lake_water \\
\hline dDIMW_ & $\mathrm{mg} / \mathrm{l} / \mathrm{d}$ & _dDIMW_ = _'derivative_for_DW_inorg_matter_in_water_in_lake_water \\
\hline dDDiatW_ & $\mathrm{mg} / / / \mathrm{d}$ & _dDDiatW_= derivative_for_DW_Diatoms_in_lake_water \\
\hline dNDiatW_ & $\mathrm{mgN} / / \mathrm{d}$ & _dNDiatW_= derivative_for_N_Diatoms_in_lake_water \\
\hline _dPDiatW_ & $\mathrm{mgP} / / / \mathrm{d}$ & _dPDiatW_= derivative_for_P_Diatoms_in_lake_water \\
\hline dDGrenW & $\mathrm{mg} / / / \mathrm{d}$ & _dDGrenW_= derivative_for_DW_Greens_in_lake_water \\
\hline dNGrenW_ & $\mathrm{mgN} / \mathrm{l} / \mathrm{d}$ & _dNGrenW_= derivative_for_N_Greens_in_lake_water \\
\hline _dPGrenW_ & $\mathrm{mgP} / / \mathrm{d}$ & _dPGrenW_= derivative_for_P_Greens_in_lake_water \\
\hline _dDBlueW_ & $\mathrm{mg} / / \mathrm{d}$ & _dDBlueW_= derivative_for_DW_Bluegreens_in_lake_water \\
\hline _dNBlueW_ & $\mathrm{mgN} / \mathrm{l} / \mathrm{d}$ & _dNBlueW_ = derivative_for_N_Bluegreens_in_lake_water \\
\hline _dPBlueW_ & $\mathrm{mgP} / / \mathrm{d}$ & _dPBlueW_= derivative_for_P_Bluegreens_in_lake_water \\
\hline _dDZoo_ & $\mathrm{mg} / / \mathrm{d}$ & _dDZoo_=_uderivative_for_DW_Zooplankton_in_lake_water \\
\hline _dNZoo_ & $\mathrm{mgN} / \mathrm{l} / \mathrm{d}$ & _dNZoo_=_uderivative_for_N_Zooplankton_in_lake_water \\
\hline _dPZoo_ & $\mathrm{mgP} / \mathrm{l} / \mathrm{d}$ & _dPZoo_=_u derivative_for_P_Zooplankton_in_lake_water \\
\hline _dDFiAd_ & $\mathrm{gD} / \mathrm{m} 2 / \mathrm{d}$ & _dDFiAd_= 1 derivative_for_DW_Adult_whitefish_in_lake_water \\
\hline _dDFiJv_ & $\mathrm{gD} / \mathrm{m} 2 / \mathrm{d}$ & _dDFiJv_= $t$ derivative_for_DW_Juvenile_whitefish_in_lake_water \\
\hline _dNFiAd_ & $\mathrm{gN} / \mathrm{m} 2 / \mathrm{d}$ & _dNFiAd_=_lderivative_for_N_Adult_whitefish_in_lake_water \\
\hline _dNFiJv_ & $\mathrm{gN} / \mathrm{m} 2 / \mathrm{d}$ & _dNFiJv_=_t derivative_for_N_Juvenile_whitefish_in_lake_water \\
\hline _dPFiAd_ & $\mathrm{gP} / \mathrm{m} 2 / \mathrm{d}$ & _dPFiAd_= _t derivative_for_P_Adult_whitefish_in_lake_water \\
\hline _dPFiJv_ & $\mathrm{gP} / \mathrm{m} 2 / \mathrm{d}$ & _dPFiJv_= tt derivative_for_P_Juvenile_whitefish_in_lake_water \\
\hline _dDPisc_ & $\mathrm{g} / \mathrm{m} 2 / \mathrm{d}$ & _dDPisc_=_t derivative_for_DW_predatory_fish_in_lake_water \\
\hline _dNH4S_ & $\mathrm{gN} / \mathrm{m} 2 / \mathrm{d}$ & _dNH4S_= $\mathrm{t}$ derivative_for_N_Pore_water_ammonium_in_lake_water \\
\hline _dNO3S_ & $\mathrm{gN} / \mathrm{m} 2 / \mathrm{d}$ & _dNO3S_= $\_$derivative_for_N_Pore_water_nitrate_in_lake_water \\
\hline _dPO4S_ & $\mathrm{gP} / \mathrm{m} 2 / \mathrm{d}$ & _dPO4S_ $=$ _t derivative_for_P_Pore_water_SRP_in_lake_water \\
\hline dPAIMS_ & $\mathrm{gP} / \mathrm{m} 2 / \mathrm{d}$ & _dPAIMS_=_derivative_for_P_P-adsorbed_onto_IM_in_sediment_in_lake_sediment \\
\hline dDDetS_ & $\mathrm{g} / \mathrm{m} 2 / \mathrm{d}$ & _dDDetS_=_derivative_for_DW_Sediment_detritus_in_lake_sediment \\
\hline _dNDetS_ & $\mathrm{gN} / \mathrm{m} 2 / \mathrm{d}$ & _dNDetS_ $=$ _derivative_for_N_Sediment_detritus_N_in_lake_sediment \\
\hline _dPDetS_ & $\mathrm{gP} / \mathrm{m} 2 / \mathrm{d}$ & _dPDetS_= derivative_for_P_Sediment_detritus_P_in_lake_sediment \\
\hline _dSiDetS_ & $\mathrm{gSi} / \mathrm{m} 2 / \mathrm{d}$ & _dSiDetS_=_derivative_for_Si_Sediment_detritus_Si_in_lake_sediment \\
\hline _dDHums_ & $\mathrm{gD} / \mathrm{m} 2 / \mathrm{d}$ & _dDHumS_ $=$ - derivative_for_DW_humus_in_lake_sediment \\
\hline _dNHumS_ & $\mathrm{gN} / \mathrm{m} 2 / \mathrm{d}$ & _dNHumS_= derivative_for_N_humus_in_lake_sediment \\
\hline _dPHumS_ & $\mathrm{gP} / \mathrm{m} 2 / \mathrm{d}$ & _dPHumS_= derivative_for_P_humus_in_lake_sediment \\
\hline _dDIMS_ & $\mathrm{gD} / \mathrm{m} 2 / \mathrm{d}$ & _dDIMS_= _tl derivative_for_DW_inorg_matter_in_sediment_in_lake_sediment \\
\hline _dDDiatS_ & $\mathrm{g} / \mathrm{m} 2 / \mathrm{d}$ & _dDDiatS_= derivative_for_DW_Sed_Diatoms_in_lake_sediment \\
\hline _dNDiatS_ & $\mathrm{gN} / \mathrm{m} 2 / \mathrm{d}$ & _dNDiatS_= _derivative_for_N_Sediment_diatoms_in_lake_sediment \\
\hline _dPDiatS_ & $\mathrm{gP} / \mathrm{m} 2 / \mathrm{d}$ & _dPDiatS_= _derivative_for_P_Sediment_diatoms_in_lake_sediment \\
\hline _dDGrens_ & $\mathrm{g} / \mathrm{m} 2 / \mathrm{d}$ & _dDGrenS_= derivative_for_DW_Sed_Greens_in_lake_sediment \\
\hline _dNGrens_ & $\mathrm{gN} / \mathrm{m} 2 / \mathrm{d}$ & _dNGrenS_= derivative_for_N_Sediment_green_algae_in_lake_sediment \\
\hline _dPGrens_ & $\mathrm{gP} / \mathrm{m} 2 / \mathrm{d}$ & _dPGrenS_= derivative_for_P_Sediment_green_algae_in_lake_sediment \\
\hline _dDBlues_ & $\mathrm{g} / \mathrm{m} 2 / \mathrm{d}$ & _dDBlueS_= derivative_for_DW_Sed_Blue-greens_in_lake_sediment \\
\hline _dNBlues_ & $\mathrm{gN} / \mathrm{m} 2 / \mathrm{d}$ & _dNBlueS_= derivative_for_N_Sediment_blue-greens_in_lake_sediment \\
\hline _dPBlues_ & $\mathrm{gP} / \mathrm{m} 2 / \mathrm{d}$ & _dPBlueS_ $=$. derivative_for_P_Sediment_blue-greens_in_lake_sediment \\
\hline
\end{tabular}




\begin{tabular}{|c|c|}
\hline _dDVeg_ & $\mathrm{gD} / \mathrm{m} 2 / \mathrm{d}$ \\
\hline _dNVeg_ & $\mathrm{gN} / \mathrm{m} 2 / \mathrm{d}$ \\
\hline dPVeg_ & $\mathrm{gP} / \mathrm{m} 2 / \mathrm{d}$ \\
\hline dDBent_ & $\mathrm{gD} / \mathrm{m} 2 / \mathrm{d}$ \\
\hline dNBent_ & $\mathrm{gN} / \mathrm{m} 2 / \mathrm{d}$ \\
\hline _dPBent_ & $\mathrm{gP} / \mathrm{m} 2 / \mathrm{d}$ \\
\hline dDepthWM_ & $\mathrm{m} / \mathrm{d}$ \\
\hline _dNH4WM_ & $\mathrm{gN} / \mathrm{m} 3 / \mathrm{d}$ \\
\hline _dNO3WM_ & $\mathrm{gN} / \mathrm{m} 3 / \mathrm{d}$ \\
\hline _dPO4WM_ & $\mathrm{gP} / \mathrm{m} 3 / \mathrm{d}$ \\
\hline _dPAIMWM_ & $\mathrm{gP} / \mathrm{m} 3 / \mathrm{d}$ \\
\hline _dSiO2WM_ & $\mathrm{gP} / \mathrm{m} 3 / \mathrm{d}$ \\
\hline _dO2WM_ & $\mathrm{gO} 2 / \mathrm{m} 3 / \mathrm{d}$ \\
\hline _dDDetWM_ & $\mathrm{gD} / \mathrm{m} 3 / \mathrm{d}$ \\
\hline _dNDetWM_ & $\mathrm{gN} / \mathrm{m} 3 / \mathrm{d}$ \\
\hline _dPDetWM_ & $\mathrm{gP} / \mathrm{m} 3 / \mathrm{d}$ \\
\hline _dSiDetWM_ & $\mathrm{gSi} / \mathrm{m} 3 / \mathrm{d}$ \\
\hline _dDIMWM_ & $\mathrm{gD} / \mathrm{m} 3 / \mathrm{d}$ \\
\hline _dDDiatWM_ & gD_m-3_d-1 \\
\hline _dNDiatWM_ & gN_m-3_d-1 \\
\hline _dPDiatWM_ & gP_m-3_d-1 \\
\hline _dDGrenWM_ & gD_m-3_d-1 \\
\hline dNGrenWM_ & gN_m-3_d-1 \\
\hline _dPGrenWM_ & gP_m-3_d-1 \\
\hline _dDBlueWM_ & gD_m-3_d-1 \\
\hline _dNBlueWM_ & gN_m-3_d-1 \\
\hline _dPBlueWM_ & gP_m-3_d-1 \\
\hline _dDZooM_ & gD_m-3_d-1 \\
\hline _dNZooM_ & gN_m-3_d-1 \\
\hline _dPZooM_ & gP_m-3_d-1 \\
\hline _dNH4SM_ & $\mathrm{gN} / \mathrm{m} 2 / \mathrm{d}$ \\
\hline _dNO3SM_ & $\mathrm{gN} / \mathrm{m} 2 / \mathrm{d}$ \\
\hline _dPO4SM_ & $\mathrm{gN} / \mathrm{m} 2 / \mathrm{d}$ \\
\hline _dPAIMSM_ & $\mathrm{gP} / \mathrm{m} 2 / \mathrm{d}$ \\
\hline _dDDetSM_ & $\mathrm{gD} / \mathrm{m} 2 / \mathrm{d}$ \\
\hline _dNDetSM_ & $\mathrm{gN} / \mathrm{m} 2 / \mathrm{d}$ \\
\hline _dPDetSM_ & $\mathrm{gP} / \mathrm{m} 2 / \mathrm{d}$ \\
\hline _dSiDetSM_ & $\mathrm{gP} / \mathrm{m} 2 / \mathrm{d}$ \\
\hline _dDHumSM_ & $\mathrm{gD} / \mathrm{m} 2 / \mathrm{d}$ \\
\hline _dNHumSM_ & $\mathrm{gN} / \mathrm{m} 2 / \mathrm{d}$ \\
\hline _dPHumSM_ & $\mathrm{gP} / \mathrm{m} 2 / \mathrm{d}$ \\
\hline _dDIMSM_ & $\mathrm{gD} / \mathrm{m} 2 / \mathrm{d}$ \\
\hline _dDRootPhra_ & $\mathrm{gD} / \mathrm{m} 2 / \mathrm{d}$ \\
\hline _dDShootPhra_ & $\mathrm{gD} / \mathrm{m} 2 / \mathrm{d}$ \\
\hline _dNRootPhra_ & $\mathrm{gN} / \mathrm{m} 2 / \mathrm{d}$ \\
\hline _dNShootPhra_ & $\mathrm{gN} / \mathrm{m} 2 / \mathrm{d}$ \\
\hline _dPRootPhra_ & $\mathrm{gP} / \mathrm{m} 2 / \mathrm{d}$ \\
\hline _dPShootPhra_ & $\mathrm{gP} / \mathrm{m} 2 / \mathrm{d}$ \\
\hline _dDExtTotT_ & $\mathrm{gD} / \mathrm{m} 2 / \mathrm{d}$ \\
\hline _dNExtTotT_ & $\mathrm{gN} / \mathrm{m} 2 / \mathrm{d}$ \\
\hline _dPExtTotT_ & $\mathrm{gP} / \mathrm{m} 2 / \mathrm{d}$ \\
\hline _dSiExtTotT_ & $\mathrm{gSi} / \mathrm{m} 2 / \mathrm{d}$ \\
\hline
\end{tabular}

_dDVeg_=_t derivative_for_DW_Vegetation_in_lake_sediment _dNVeg_= _t derivative_for_N_Vegetation_in_lake_sediment _dPVeg_= tt derivative_for_P_Vegetation_in_lake_sediment _dDBent_=_lderivative_for_DW_Zoobenthos_in_lake_sediment _dNBent_ = _lderivative_for_N_Zoobenthos_in_lake_sediment _dPBent_=_tderivative_for_P_Zoobenthos_in_lake_sediment _dDepthWM_derivative_for_water_depth_change_in_marsh_water _dNH4WM_= derivative_for_N_NH4_in_water_in_marsh_water _dNO3WM_ = derivative_for_N_NO3_in_water_in_marsh_water _dPO4WM_= derivative_for_P_PO4_in_water_in_marsh_water _dPAIMWM_: derivative_for_P_P_adsorbed_onto_IM_in_water_in_marsh_water _dSiO2WM_ = derivative_for_Si_SiO2_in_marsh_water _dO2WM_ = derivative_for_O2_O2_in_water_in_marsh_water _dDDetWM_= derivative_for_DW_Detritus_in_marsh_water _dNDetWM_ = derivative_for_N_detritus_in_marsh_water _dPDetWM_ = derivative_for_P_detritus_in_marsh_water _dSiDetWM_ derivative_for_Si_detritus_in_marsh_water _dDIMWM_= derivative_for_DW_Inorg_matter_in_marsh_water _dDDiatWM_derivative_for_DW_diatoms_in_marsh_water _dNDiatWM_derivative_for_N_diatoms_in_marsh_water _dPDiatWM_: derivative_for_P_diatoms_in_marsh_water _dDGrenWM_derivative_for_DW_greens_in_marsh_water _dNGrenWM_derivative_for_N_greens_in_marsh_water _dPGrenWM_derivative_for_P_greens_in_marsh_water _dDBlueWM_derivative_for_DW_blue-greens_in_marsh_water _dNBlueWM_derivative_for_N_blue-greens_in_marsh_water _dPBlueWM_derivative_for_P_blue-greens_in_marsh_water _dDZooM_ = derivative_for_DW_zooplankton_in_marsh_water _dNZooM_ = _derivative_for_N_zooplankton_in_marsh_water _dPZooM_ = _derivative_for_P_zooplankton_in_marsh_water _dNH4SM_ = derivative_for_N_NH4_in_water_in_marsh_sediment _dNO3SM_ = derivative_for_N_NO3_in_marsh_sediment _dPO4SM_ = derivative_for_P_PO4_in_marsh_sediment _dPAIMSM_ = derivative_for_P_P_adsorbed_onto_IM_in_marsh_sediment _dDDetSM_ = derivative_for_DW_Detritus_in_marsh_sediment

_dNDetSM_= derivative_for_N_detritus_in_marsh_sediment _dPDetSM_- derivative_for_P_detritus_in_marsh_sediment _dSiDetSM_ = derivative_for_P_detritus_in_marsh_sediment _dDHumSM_derivative_for_DW_sediment_humus_in_marsh_sediment _dNHumSM_derivative_for_N_sediment_humus_in_marsh_sediment _dPHumSM_derivative_for_P_sediment_humus_in_marsh_sediment _dDIMSM_ = derivative_for_DW_Inorg_matter_in_sediment_in_marsh_sediment _dDRootPhra_derivative_for_DW_biomass_root_reed_in_marsh_sediment _dDShootPhrc derivative_for_DW_biomass_shoot_reed_in_marsh_sediment _dNRootPhra_derivative_for_N_N_in_root_in_marsh_sediment _dNShootPhre derivative_for_N_N_in_shoot_in_marsh_sediment _dPRootPhra_derivative_for_P_P_in_root_in_marsh_sediment _dPShootPhre derivative_for_P_P_in_shoot_in_marsh_sediment _dDExtTotT_: derivative_for_total_external_DW_flux_

_dNExtTotT_: derivative_for_total_external_N_flux_

_dPExtTotT_ : derivative_for_total_external_P_flux_ _dSiExtTotT_derivative_for_total_external_Si_flux_ 